\title{
Building the Paper Economy:
}

Finding spatial and cultural agency through recycled paper

by

\begin{abstract}
Jesse John Bird
A thesis submitted to the Faculty of Graduate and Postdoctoral Affairs in partial fulfillment of the requirements for the degree of
\end{abstract}

\section{Master of Architecture}

Azrieli School of Architecture \& Urbanism

Carleton University

Ottawa, Ontario, Canada

\author{
(c) 2020 \\ Jesse Bird
}



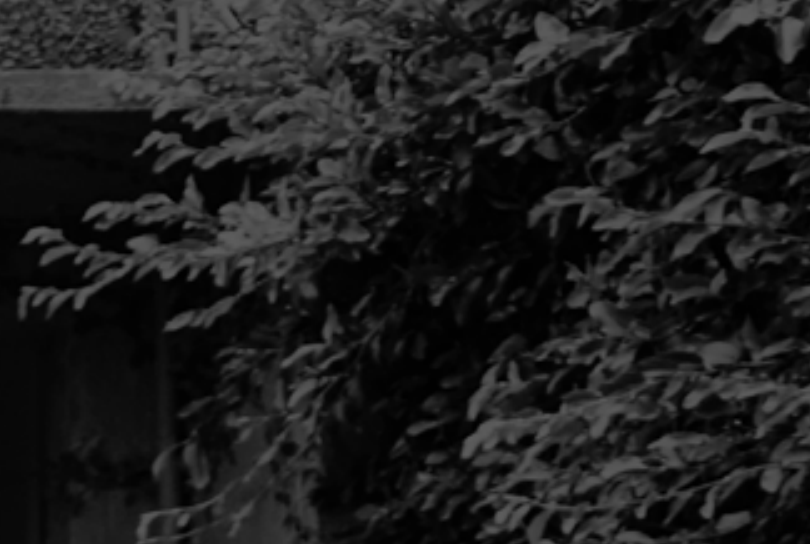

\section{BUILDING THE PAPER ECONOMY.}




\section{A B S T R ACT}

Throughout the world, demographic, economic, and technological trends have accelerated our ability to knowingly and unknowingly change the environment in which we live. These changes are now forcing us to reconsider our relationship with natural resources and consider alternative frameworks that support resource recovery, inclusive policy frameworks, and sustainable economic models. Following a global waste trade recycling ban in early 2018 , this thesis sets out to understand how current paper recovery methods could be better utilized for the design and fabrication of sustainably sourced building components.

This project identifies conventional solid waste management strategies and adopts an integrated systematic approach to help not only the processes that generate paper waste, but understand how second-generation materials could be reused, repurposed, and redistributed back into the social networks and economies of Sao Paulo, Brazil. Through a series of investigations and multiple field studies, this thesis explores new-found solutions for nano and micro-fibrillated paper fibre products that could be utilized and deployed in a variety of contexts in the developing world. While acknowledging the many complexities of this topic, this project embraces a thinking that will generate new conversations on alternative material solutions, thereby provoking consumers and industries alike to rethink what happens when we simply throw something away! 


\section{ACKNOWLEDGEMENTS}

I would like to sincerely thank my thesis advisor, Professor Sheryl Boyle for her continuous support and constant sharing of extensive knowledge in the field of architecture and material research. I am grateful to have been given the opportunity to explore this topic and for the many valuable contacts she has made available along the way. Over the past year I have learned more than I could have wished for and she has shown me how much, and how little, can be achieved and addressed within hands on research and design. This exercise in learning would not have been possible without the guidance and encouragement of Sheryl Boyle.

Secondly, I would like to express my deepest appreciation for the many local experts and foreign researchers that helped and supported me along this journey. Special gratitude to Alf Wheeler, Matt Champion, Martin Ernegg and Tony Humble for their on going support from the beginning of this investigation and for the extensive time and resources they have each provided. I am grateful for the professional relationships and friendships that have developed during my time in Australia and Toronto and look forward to our future collaborations.

This thesis is the culmination of over a year of international research, comprising of fieldwork, review of literature, and extensive design work supported through the Mitacs Accelerate Award Program (IT13466) in partnership with Zeo IP Pty. I would like to thank them both for their incredible support. Although acting alone in the development of this thesis, I had the privilege of working alongside a range of professional advisors, professors and mentors. I would sincerely like to thank Owen Rowland (bi- 
ology), Jeffery Erochko (civil engineering), Cynthia Cruickshank (mechanical engineering), and Wayne Wang (chemistry) for sharing their expertise in various fields to assist in my thesis work. Understanding different points of view on various aspects of the project has afforded a broader view of issues at play and has contributed to the development of an interdisciplinary concept of design in many ways. 


\section{TABLE OF CONTENTS}

\author{
3 Abstract \\ 4 Acknowledgements \\ 6 Table of Contents \\ 7 List of Figures \\ 11 Introduction
14 PART ONE // SHIFTING SEAS
15 1.1-Global PaperTrade
17 1.2-Challenges + Opportunities
18 1.3-Future of Second Generation Waste
201.4 - Reimagining the Geographies of Waste
221.5 - Moving from a linear to a circular economy
26 PART TWO // MATERIAL ARCHIVING
27 2.1-Field Documentation / Australia
$47 \quad 2.2$-Material Archiving
$51 \quad 2.3$ - New Material Futures
54 2.4-Material Properties
572.5 - Structurally Insulated Panels (SIPs)
592.6 -SIPs in context

63 PART THREE // RETHINKING THE WASTE CHAIN

64 3.1-The Maintenance Economy

68 3.2-The Informal Waste Chain Today

763.3 - Rethinking the Informal Waste Chain
$78 \quad 3.4$-Challenges + Opportunities

793.5 - Inclusion as a Solution

83 3.6-Selective Collection

853.7 -Building from Second-generation Materials

91 FIELD RESEARCH // SAO PAULO Photo Documentation Journal

147 PART FOUR // MATERIAL DEVELOPMENT 148 3.1-Material Explorations

$150 \quad 3.2$-Artisan scale making

152 3.3-Paper making

157 PART FIVE // MATERIAL DEPLOYMENT

158 5.1-Contextualizing the material

1605.2 -Engaging through Conversation

164 5.3-Engaging between the Economies

168 5.4-Exploring the Physical

172 5.5-Unconventional Drawings

182 PART SIX // CONCLUSIONS

183 6.1-Methods, Testing, and Prototypes

184 6.2-Post Script

186 Appendix

188 Glossary of Terms

190 Sources 


\section{LIST OF FIGURES}

Fig. 01 Shipping Container heading to Chinese Port

Fig. 02 Import and Export of Global Waste from G7 countries

Fig. 03 Wired Magazine Headline

Fig. 04 CBC News Headline

Fig. 05 CBC News Headline

Fig. o6 Problem, Result, Opportunity

Fig. 07 Second Generation Hemp material

Fig. o8 Local Worker Using recovered materials to construct

Fig. og Shipping Container in Open Sea.

Fig. 10 Pile of recycled material in shipping port.

Fig. 11 Linear Economy Diagram

Fig. 12 Resources in a Linear Economy

Fig. 13 Consumption and Production

Fig. 14 Zeoform Refining Facility

Fig. 15 Zeoform Refining Facility - Martin Erneg

Fig. 16 Detail photos of NMFC samples, 2019-2020

Fig. 17 Field Research and Sketches, 2019

Fig. 18 Zeoform Fibrillation Process Diagram

Fig. 19 Close up of NMFC surface texture 1

Fig. 20 Close up of NMFC surface texture 2

Fig. 21 Sketch of Material Processes

Fig. 22 SIP in context - IKEA factory built home

Fig. 23 SIP in context - IKEA built home 2

Fig. 24 Sketch of Material Processes, 2019

Fig. 25 SIP in construction.

Fig. 26 Exploded Axonometric of Structurally Insulated Panel Construction

Fig. 27 SIP in context. Construction of full dwelling

Fig. 28 Diagram representing how new building component 
Fig. 29 Waste Picker in landfill outside city. 2016.

Fig. 30 Image of Informal waste cart in Sao Paulo

Fig. 31 Methane Escapes from a Sao Paulo Landfill. 2020

Fig. 32 Manila, Philippieans

Fig. 33 Bogota, Columbia

Fig. 34 Mumbai, India

Fig. 35 Material Life-cycle and the Informal Recycling Chain

Fig. 36 Informal Waste Chain

Fig. 37 Coopermar Cooperative, Sao Paulo, Brazil. 2020.

Fig. 38 Sketches of Waste Chain understanding, 2020

Fig. 39 'Rejeito' The bi-product of informal recycling.

Fig. 40 Image from Inside Coopermar Cooperative, Sao Paulo.

Fig. 41 Image from Inside Coopermar Cooperative, Sao Paulo.

Fig. 42 Formal Recycling Collection vehicle dumping wood Scraps

Fig. 43 Illustrates the selective waste collection

Fig. 44 Formal Waste Chain

Fig. 45 Plastic Lumber 1

Fig. 46 Plastic Lumber 2

Fig. 47 Newspaperwood 1

Fig. 48 Newspaperwood 2

Fig. 49 Modroof 1

Fig. 50 Modroof 2

Fig. 51 Prototype NMFC building block

Fig. 52 Process photo of artisan scale making, Carleton University.

Fig. 53 Process photo of artisan scale making, Carleton University

Fig. 54 Photo of paper pulp casted block 1, Carleton University, 2019

Fig. 55 Photo of paper pulp casted block 2,Carleton University, 2019

Fig. $5618^{\prime \prime} \times 24^{\prime \prime}$ Ash frame for paper making, 2019

Fig. 57 Photo of paper pulp casted process.

Fig. 58 Photo of Mould and Deckle for casting paper. 1

Fig. 59 Photo of Mould and Deckle for casting paper.

Fig. 60 Photo of Paper press, borrowed from Mark MacGuigan and Robert Wood.

Fig. 61 Photo Montage of Informal Waste Pickers of the Global South.

Fig. 62 Hand-made Paper 1, Carleton University, 2019

Fig. 63 Hand-made Paper 2, Carleton University, 2019

Fig. 64 Worker using wood products in construction. Brazil, 2016. 
Fig. 65 Digital sketch of waste Picker and their environment.

Fig. 66 Pamphlet Architectures 1

Fig. 67 Building the Paper Economy: Material Deployment Pamphlet

Fig. 68 Pamphlet Architectures 2

Fig. 69 Building the Paper Economy: Waste Picker Inclusion Pamphlet

Fig.70 Image depicting the upgrading of selective zones in Sao Paulo favela.

Fig. 71 Sketch depicting projects deployment within the context of Brazil.

Fig.72 Images of SIP deployment

Fig. 73 The Dwelling Scale Operation and Collaboration:

Fig. 74 The Community Scale Operation and Collaboration:

Fig. 75 Factory Scale Operation and Collaboration

Fig. 76 Concepts of Deplyment: Education

Fig. 77 Concepts of Deplyment: Recycling

Fig. 78 Concepts of Deplyment: Engaging

Fig.79 Concepts of Deplyment: Innovation

Fig. 80 Concepts of Deplyment: Inclusion 


\section{AUTHORS NOTE}

This thesis is the culmination of over a year of international research comprising of physical explorations, review of literature, and extensive design work conducted in Australia, Brazil, and at Carleton University. 


\section{INTRODUCTION}

In the face of rising global population and exponential resource consumption, current economic thinking demands urgent alternative models that embrace a circular ideology. ${ }^{1}$ Throughout the world, demographic, economic, and technological trends have accelerated our ability to knowingly and unknowingly change the environment in which we live. In early 2018, global waste trade underwent a radical transformation after the Chinese government proposed new precautions for how they handled and processed the world's waste. Named the National Sword Policy (NSP), its goal was to dramatically reduce the importation of soiled and contaminated materials (including metals, plastic, paper, and glass) from much of the developed world, resulting in a major reshuffling of the international waste trade. The NSP left many waste exporters, such as North America, Europe, and Australia, scrambling to find alternative solutions and destinations for their unwanted paper and plastic exports. ${ }^{2}$ As other countries followed suit, large volumes of material are now accumulating in landfills, headed for incinerators, or sitting dormant in shipping ports around the globe. Yet the NSP has already proven to be double-edged. These new pressures have forced governments and industries to find alternative solutions for their surplus of second-generation materials. ${ }^{3}$ In response to the effects of the NSP and through a series of investigations, extensive review of literature, and multiple field studies conducted in Australia and Brazil, this project imagines an alternative paper waste chain that emphasizes intelligent product design, prefabrication, and circular economic design to reuse and recycle fiber-based materials as a sustainable alternative to virgin-based building components.
"The Concept of Circular Economy: Its Origins and Its Evolution." Research Gate, January 2018 . 
With the help of an interdisciplinary team of engineers and material scientists in Australia and Canada, research is underway to develop, design, and fabricate methodologies for structurally insulated panels (SIP) components that are comprised of only recovered paper and cardboard. Blended and formed in a matrix of only fibre and water, the material's exhibitions of thermal, structural, and water-resistant qualities show promising potential for prefabrication and rapid construction in the developing world. 5

With new solutions for cellulose utilization at hand, this project proposes working within the global south contextto recycle, reimagine and redistribute sustainable building components throughout both the informal and formal economies of developing regions. The project contributes to local goals of economic and environmental improvement through the integration and exchange of paper recycling techniques and material innovations within the city of Sao Paulo, Brazil. Using local knowledge and existing frameworks, this project compliments the sophisticated social and recycling structures that employ millions of people globally. Providing new opportunities for Brazilian waste pickers to enhance their socio-economic and environmental situations by providing access to material recovery solutions and alternative occupational support. Using proposed concepts of engagement, inclusion, recycling, education, and innovation, this project identifies conventional solid waste management strategies and adopts an integrated systematic approach to help not only the processes that generate waste, but understand how material could be handled, repaired, reused and redistributed back into the local social networks and economy. While learning from varying steams of field work and academic research, this thesis addresses our relationship with the world's natural resources and considers alternative frameworks that support resource recovery, inclusive policy frameworks, and sustainable economic design.
This innovative processing method has been patented by Zeo Ip Pty in Australia.

Wheeler, Alf. "Zeoform - Characteristics". Zeoform - Making Form Sustainable, 2011

Informal Recycling Sector A subset to the formal recycling sector. Operating in most developing countries as viable means of income for waste pickers or cart-men 
PAR T 1
A 
SHIFTING SEAS

"In a time of global
concern for the
environment, global
conversations of
trade and climate
action initiatives has
never been higher" 


\subsection{GLOBAL PAPER TRADE}

Environmental concerns over the paper and paperboard industry practices are growing at exponential rates around the world, from increased deforestation to higher than normal droughts that has led to some of the most catastrophic wildfires of our generation. However, in a time of global concern for the environment, global conversations of trade and climate action initiatives have never been higher. We are in the middle of an environmental revolution and one where industry leaders and consumers play a significantly larger role than the past. ${ }^{6}$ The need for increased production has not only put pressure on local economies to find alternative material
5Zeoform - Making Form Sustainable, 2011

\section{$6-$}

Wazeka, Robert. "Paper and Paperboard in Developing Countries: The Potential Is There." Unasylva - No. 144 - Pulp \& Paper in Developing Countries - Paper and Paperboard in Developing Countries The Potential Is There, Forest Industry Division, 1984 .

Fig. 001: Shipping Container heading to Chinese Port - Contaminated garbage being sent from developed countries to Chinese ports. Prior to Jan 2018.

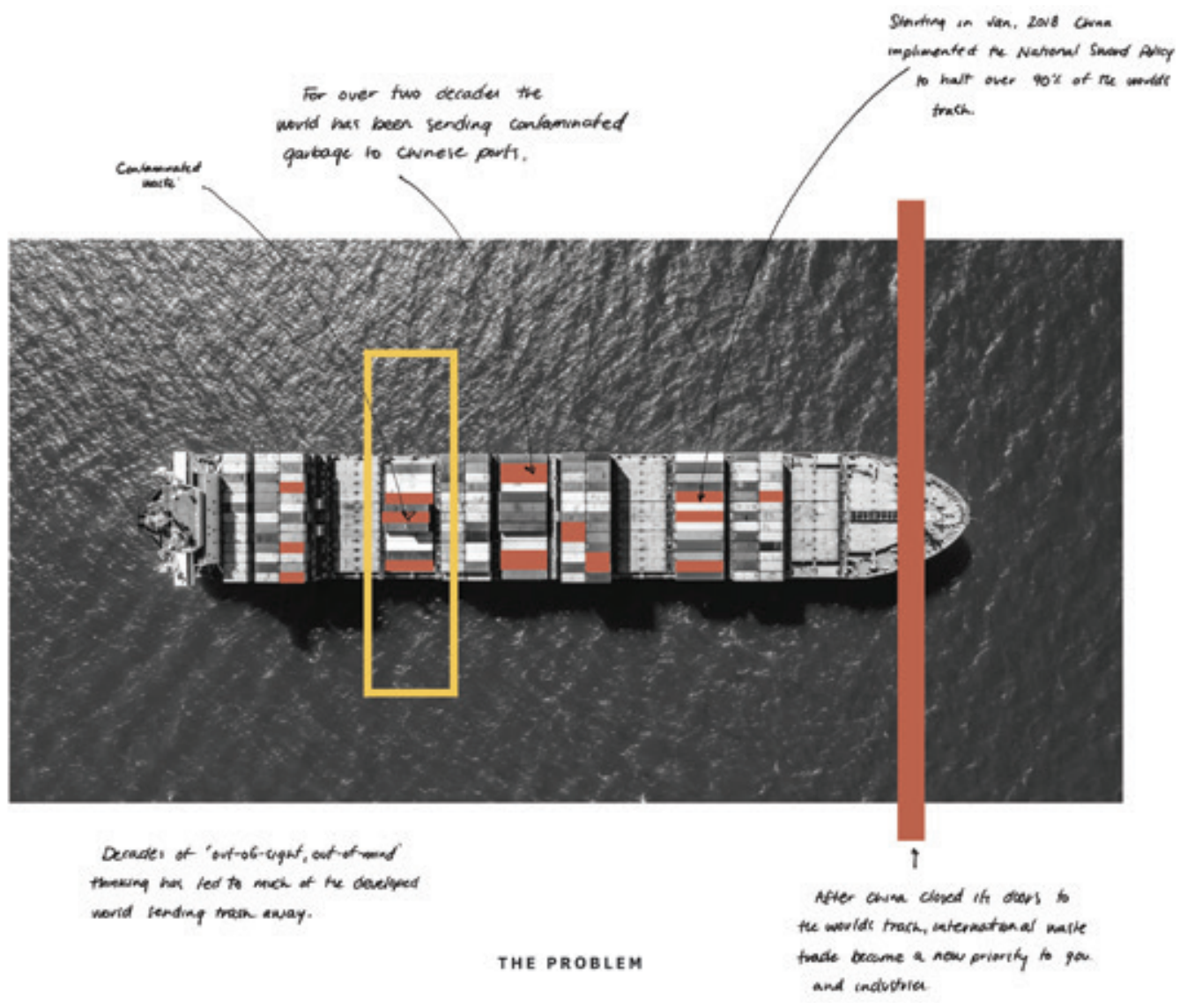


sources but figure out new ways for material recovery that take part in a more circular ideology. Most economies have adopted simple forms of paper product recycling to create further down-cycled products while balancing the cost of machine reorganization and operations that utilize alternative feedstocks. ${ }^{6}$ In addition, current recycled fibre is by no means uniform, with many newsprint and packaging grades having more than 50\% recycled content and printing and writing paper containing an average of $8 \%$ recycled content. ${ }^{7}$ Due to the ubiquitous nature of wood and wood based products, paper industries are operating from an antiquated linear production model, and therefore are often sidelined when discussing nonvirgin alternative feedstocks. Second-generation materials have been recently recognized as a viable alternative to virgin harvesting, yet many countries have neglected the opportunity to capitalize on its full potential.
THE REST OF ASIA HAS OVERTAKEN CHINA AS THE BIGGEST IMPORTER OF G 7 PAPER WASTE

EXPORTS OF PAPER AND PAPERBOARD WASTE FROM G C COUNTRIES ('00O TONNES)

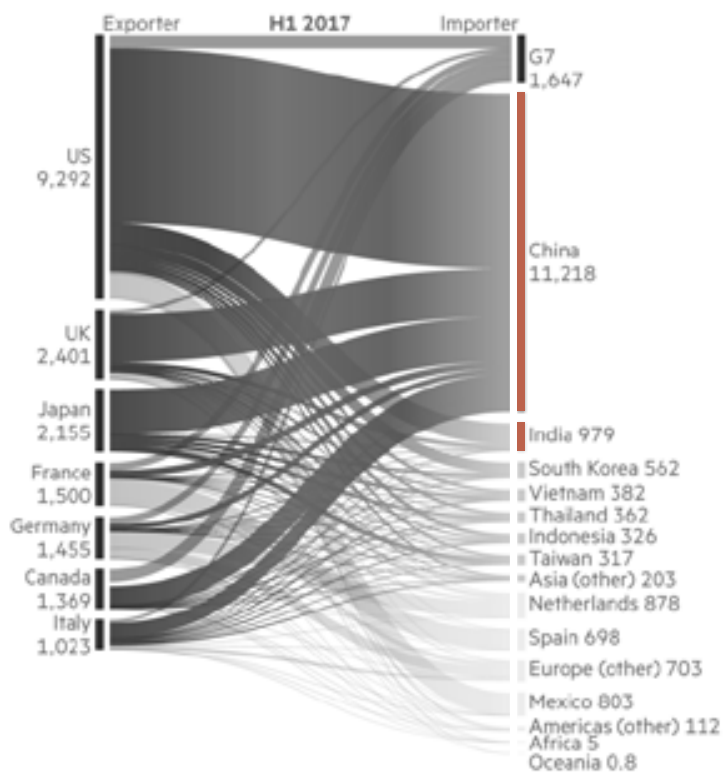




\subsection{CHALLENGES + OPPORTUNITIES OF BUILDING THE PAPER ECONOMY}

Responding to the challenging effects of the National Sword policy, this thesis joins the conversation of sustainable waste management by providing alternative systematic approaches that promotes the recovery of resources, innovative product design, and inclusive waste management. The NSP is initiating new levels of economic pressure and drawing overdue attention to the way the world deals with its waste. ${ }^{8}$ As the backlog of waste material mounts, new opportunities are emerging for recycling businesses to gain a competitive advantage of their sorting practices and to reimagine how we can utilize this now surplus material. 9

This thesis is a key investigation into the newfound opportunities of paper recovery and aims to understand the complex intertwining of the nature of social integration, industry disruption and recycling methods of a global South context.

ШI田ะ回

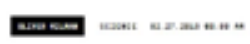

Since China's Ban, Recycling in the US Has Gone Up in Flames

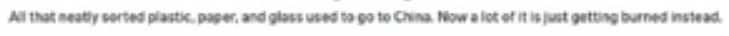

4CBC

Technology \& science

\section{Canadian garbage on its way from Philippines to} Vancouver

Fights over mislabelied Canadian trash have been going on for 6 years

The Cenacian Press - Posted. May 30, 2019 4.40 PM ET I Last Updated: May 30

蛅CBC

works

China is no longer world's dumping ground, but cleaning up its own backyard is proving to be a challenge
8 -

Reed, John, et al. "Why the World's Recycling System Stopped Working." Financial Times, FT Magazine Environment, 25 Oct. 2018

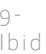

Fig. 003: Wired Magazine Headline

Fig. 004: CBC News Headline

Fig. 005: CBC News Headline 


\subsection{THE FUTURE OF SECOND GENERATION FEEDSTOCKS}

Second-generation feedstocks embody a wide a range of possibilities that offer many advantages over virgin or firstgeneration feedstocks. Mainly desired for their competitive costs in manufacturing, second-generation materials require a fraction of the energy and labour costs that virgin resources demand. ${ }^{10}$ Within the forest industry specifically, virgin resource extraction accounts for almost $60 \%$ of the total energy demands for the finished product. This staggering number is often given additional support from governmental leaders to improve energy efficiency while harvesting. However, as industries continue to address the surrounding consequences of material extraction, limited attention is focused on how to step away from our current economic model of consumption and production.

Second-generation feedstocks are abundant, cheap, and sustainable and can range from anything from recovered paper

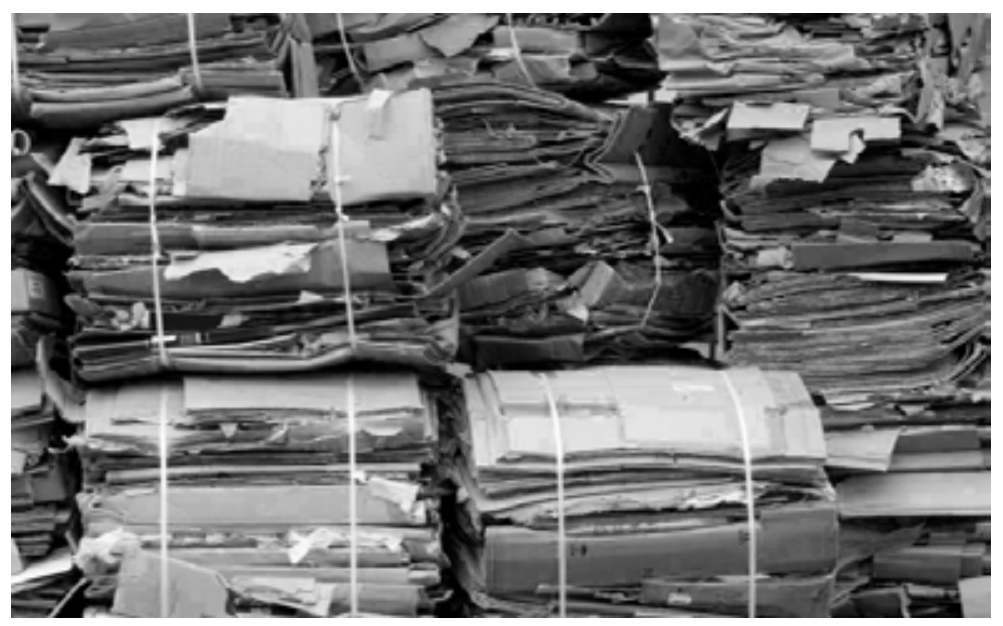

World Agriculture: Towards 2015 2030. Towards Sustainability Forestry. 1st ed., FAO, 2002

libid
Fig. 006: Pile of compacted cardboard Canadian Recycling Centre, 2018 ISword Policy enacted in 2018. 
and cardboard, to cellulosic trimmings from crop harvests. Significant studies have been conducted in the EU, US, and Canadian markets to explore these solutions in detail. ${ }^{12}$ While the opportunity is recognised, there are two important risks to consider; firstly, that there is sufficient feedstock security and secondly, that alternative technologies can rely on continued investment. ${ }^{13}$ Due to the fallout of the NSP, an abundance of second-generation material is now accumulating in regions around the world and patiently awaiting for alternative utilization methods. ${ }^{14}$

Academic research is currently exploring the potential of cellulose based feedstocks. Cellulose is the world's largest and most abundant natural resource and often utilized for its potential as a biofuel or additive agent. Research conducted in this thesis addresses micro-and nano-fibrillated cellulose (NMFC), derived from recovered paper and cardboard, as a potential secondgeneration feedstock for the construction of sustainable alternative building components. ${ }^{15}$
Marquis, Caitlin. "This is Advanced Energy": Second and Third Genera tion Biofuels." THIS IS ADVANCED ENERGY: Second and Third Generation Biofuels, Advanced Energy Perspectives, 11 Dec. 2019

\section{lbid}

"What a Waste: An Updated Look into the Future of Solid Waste Management." World Bank, The World Bank, 20 Sept. 2018

Siró, István and David Plackett Microfibrillated cellulose and new nanocomposite materials: a review, Cellulose, Volume 17, Issue 3 , June 2010.

Fig. 007: The Result of the National Sword Policy.

This image depicts the resultng accumulation of material ending up in shipping ports around the word.

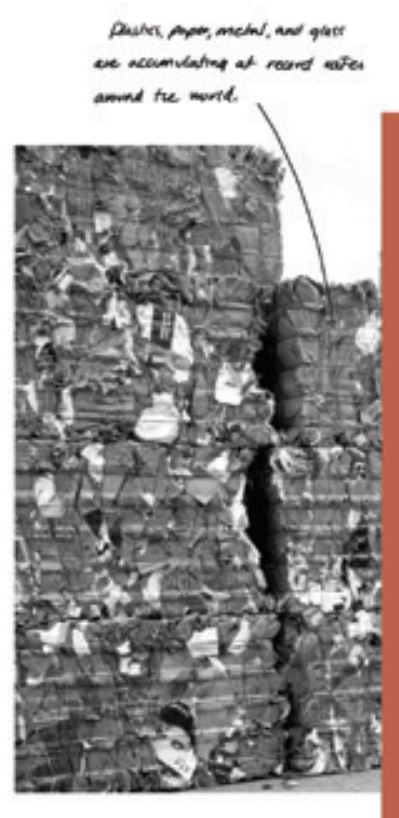

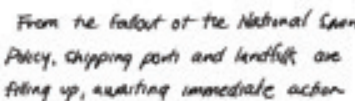

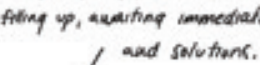

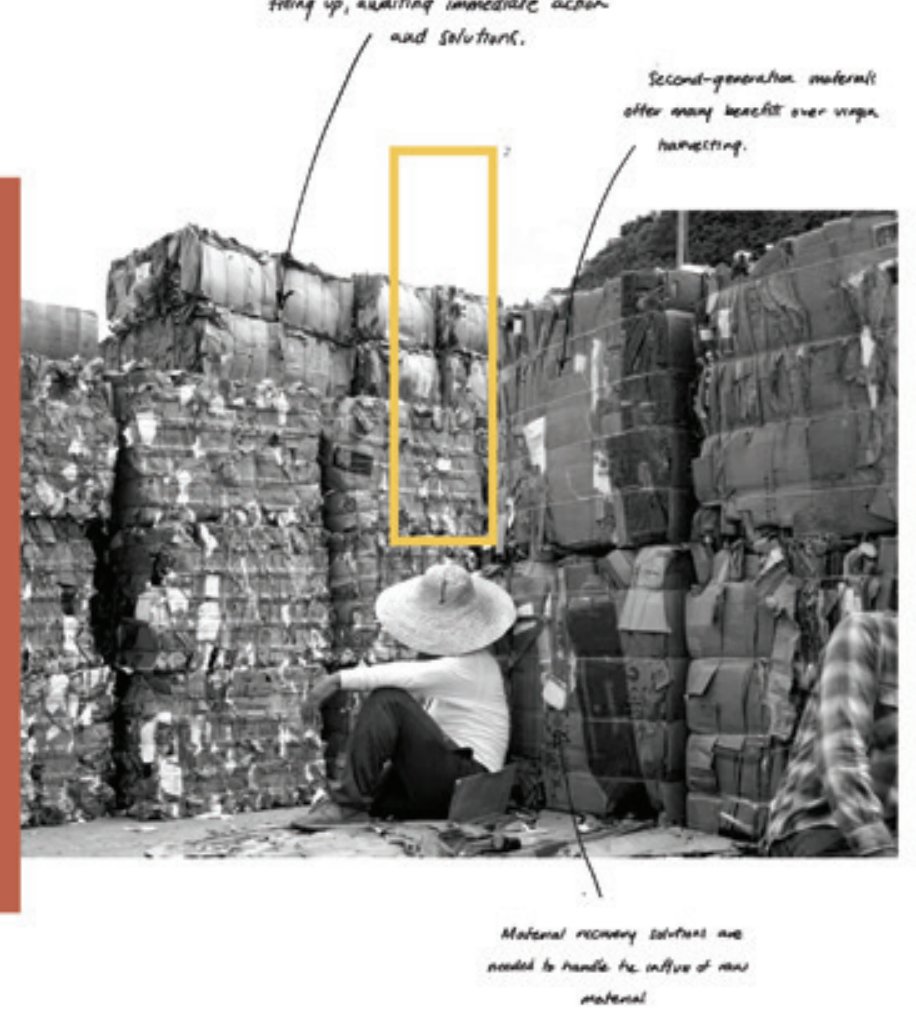

THE RESULT 


\subsection{REIMAGINING THE GEOGRAPHIES OF WASTE}

Our global system of production is predominantly based on by a linear model of production where we 'take, make, and dispose' of our products. ${ }^{16}$ Enabled by a century of declining commodity prices, waste is generated as companies plan obsolescence in their products, generating long term sales volume by reducing time between repeat purchases. ${ }^{17}$ This leads to problems of two major kinds, one where our finite resources are depleted, while the other is the catastrophic environmental damage from hazardous runoff and leachate that flows from our landfills into our rivers and oceans. ${ }^{18}$

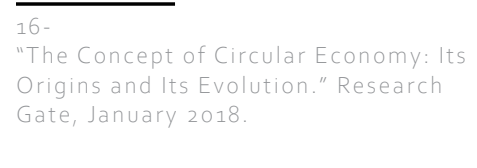

Ellen MacArthur Foundation. 2015 Building Blocks of a Circular Econ omy. Ellen MacArthur Foundation. Referenced 7 December 2019

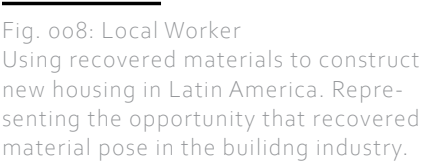

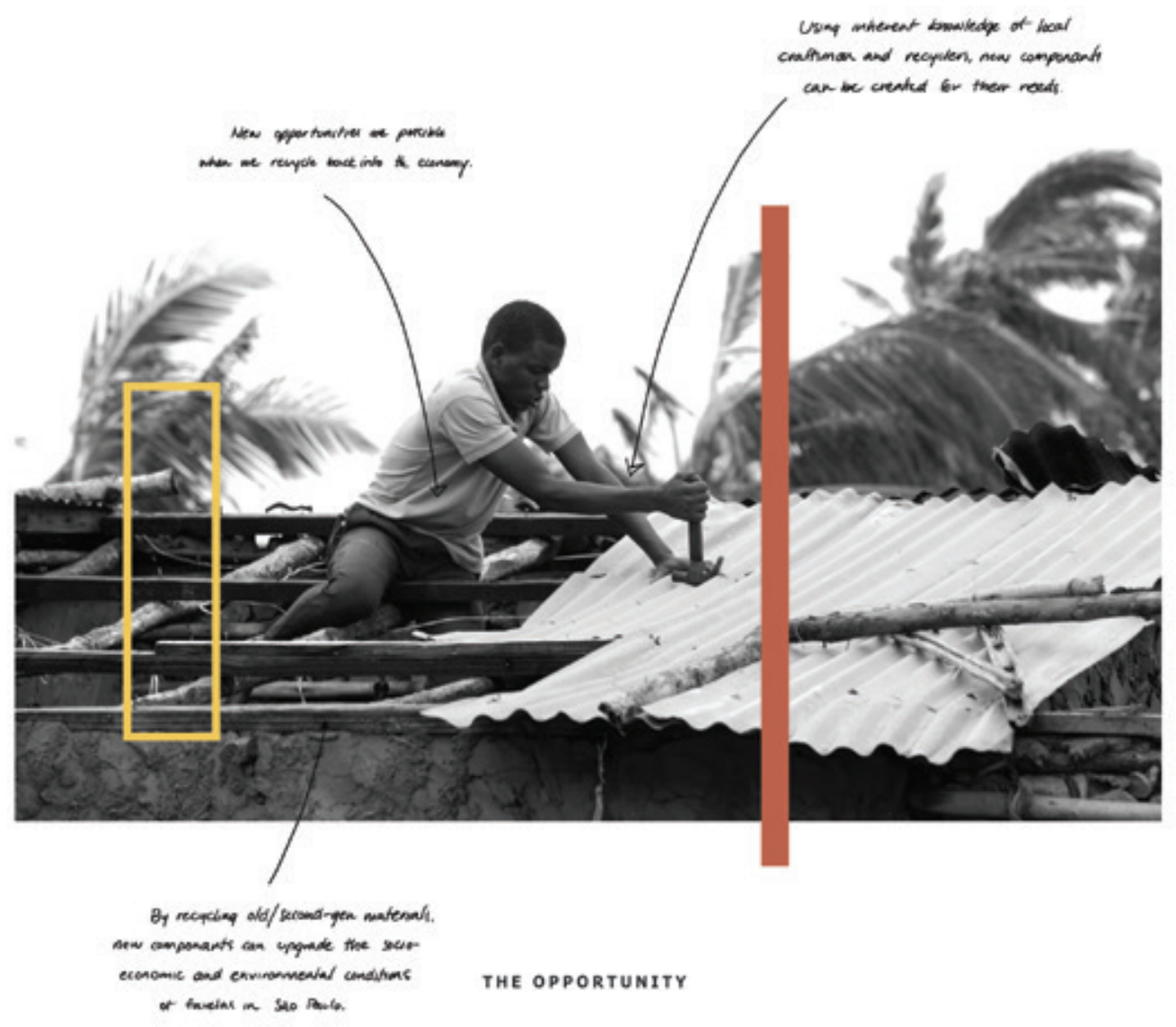


To address these issues, many countries have begun investing in highly sophisticated incinerators, which is neither sustainable or responsible, by effecictly removing any potential of second generation value and provoking industry leaders to maintain models of extraction to keep up with the new demand of their products. ${ }^{19}$ By proposing alternatives to the current global waste flows, this thesis brings together second-generation material solutions in order to advance waste management practices around the globe. ${ }^{20}$ Designed to recycle, reimagine and redistribute sustainable building components into the developing economy, the material recovery techniques illustrated in this thesis can be adapted and applied as solutions fit for the global North.
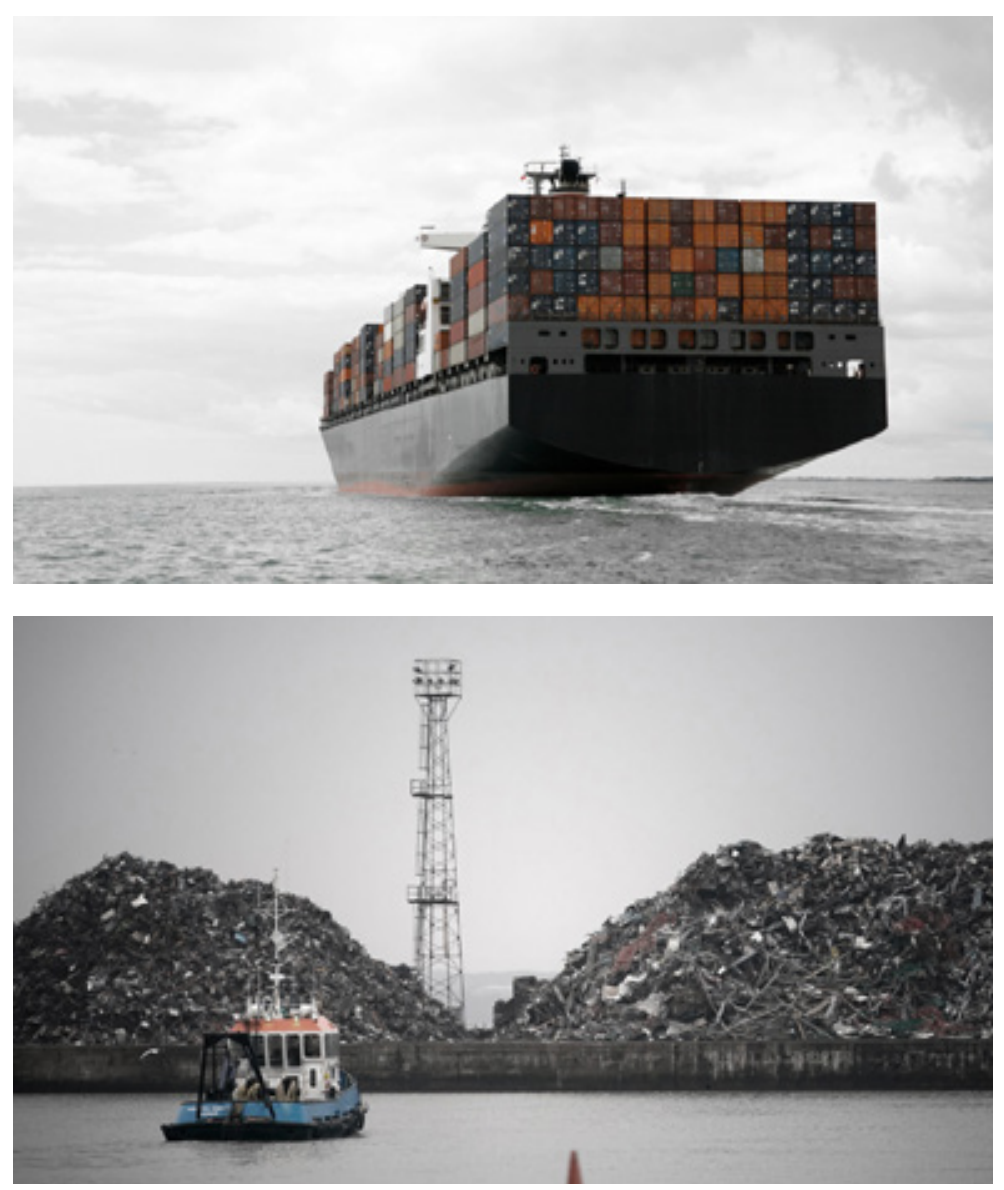

Nathanson, Jerry. "Hazardous-Waste Management". Encyclopedia Britannica, and ed., 2020 .

Reed, John, et al. "Why the World's Recycling System Stopped Working." Financial Times, FT Magazine Environment, 25 Oct. 2018

The Circular Economy and the Built Environment." Global Foresight Research Innovation, Sept. 2016, pp. 5-12

Fig. oog: Shipping Container in Open Sea. shipping port. 


\subsection{MOVING FROM A LINEAR TO CIRCULAR ECONOMY}

Over the last 150 years, our industrial economy has been dominated by an established model of production and consumption in which goods have been manufactured from raw materials, sold, used, and discarded as waste. ${ }^{21}$ In the face of a rising global population and exponential resource consumption, our current economic model now requires a dramatic refocusing to recognize alternative economic models of material recovery and reuse. ${ }^{22}$ In pursuit of this change, reverse logistics, performance economies, and sharing economies must all be understood to facilitate a regenerative and restorative model known as a Circular Economy (CE). Through techniques that enable the reuse, recycling and remanufacturing of resources, a CE can become the catalyst that embodies 'smart sustainable solutions'. ${ }^{23}$ Both businesses and industries are required to take action, not only from a cooperate perspective but also encourage the consumer. ${ }^{24}$ This collective transition must embrace change and draw on analogies from natural ecological cycles, where end products as well as bi-products of a system are rescued in other processes in a perpetual chain.
$21-$
ibid

Heshmati, Almas. "A Review of the Circular Economy and Its Imple. mentation." International Journal of Green Economics, vol. 11, no. 3/4, Dec. 2015

"The Paradigm Shift Needed in Tech. nology: Sustainable Digital Design." Apply Digital Sustainability, 1 Oct. 2019, applydigital.co/blog/the-paradigm-shift-needed-in-technology-sustainable-digital-design/.

Upadhayay, Sugam, and Omaima Alqassimi. Ellenmacarthurfoundation. Org, 2020

Fig. 011: Linear Economic Model -Representing both the biological and technological cycles that take part in a Linear Economy

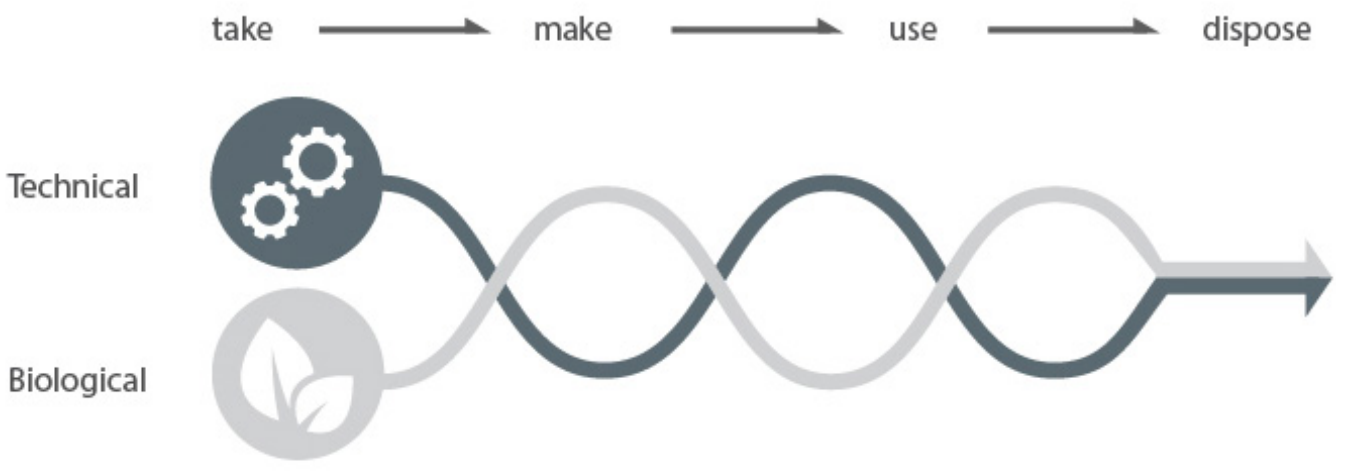


Commonly known as a 'Cradle to Cradle' model, it is on the notion that material flows can be divided into two interacting loops: a technical and a biological resource cycle, where fabricated products are designed so that at the end of their service life - their components are extracted and reused, or remanufactured into new products. ${ }^{25}$ Therefore, it is considerably more sustainable, or dematerialized, than our present economy which is focused on production and consumption as its principal means to create high material flows and wealth. ${ }^{26}$

The Ellen MacArthur Foundation is a international charity-run organization dedicated to promoting the global transition toward a circular economy. ${ }^{27}$ The foundation embraces the 'Performance Economy' (PE) introduced earlier - a model first sketched by architect and industrial analyst Walter R. Stahel in the late $70^{\prime}$ s. ${ }^{28}$
25

Helen Kopnina. Circular Economy and Cradle to Cradle in educational practice, Journal of Integrative Environmental Sciences, 15:1, 123-138, 2018.

Ellen MacArthur Foundation. 2015. Building Blocks of a Circular Economy. Ellen MacArthur Foundation. Referenced 7 Decemeber 2019.

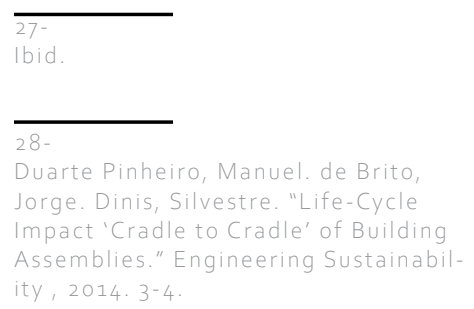

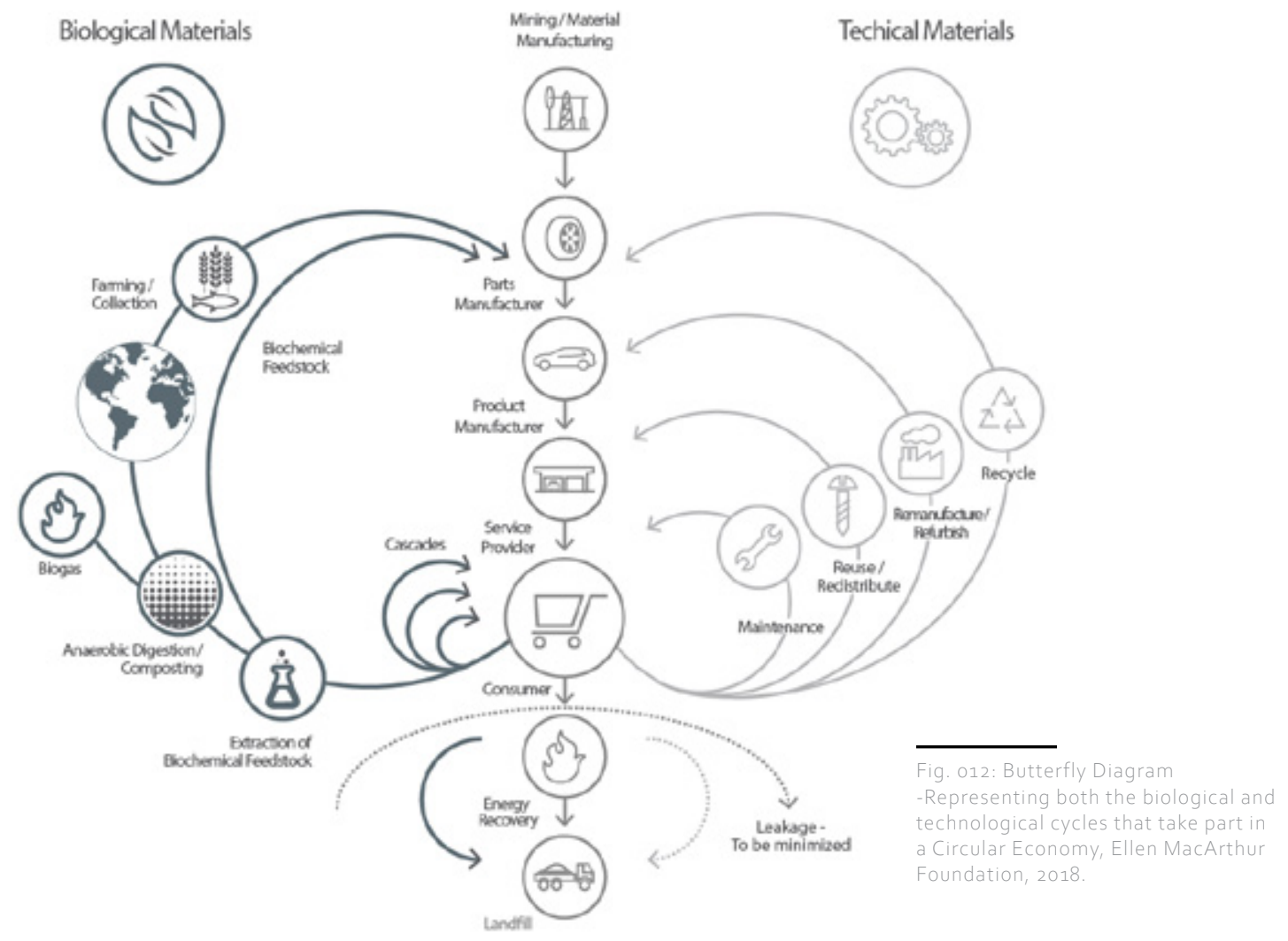


With a vision of an economy of loops it stimulates job creation, economic competitiveness, and waste prevention. Similar to the 'Cradle to Cradle' approach, the Performance Economy draws on several specific approaches that participate in the the circular economy. With power in numbers the PE is a labour force that is found throughout the recycling industry. ${ }^{29}$ In order to take place in a $C E$, this thesis incorporates the Performance Economy and Cradle to Cradle model as its foundation by integrating material flows of second-generation material back into its perpetual chain.
Stahel, Walter R. "The Functional Economy: Cultural and Organizational Change." National Academy Press. 1997, PP. 14-39
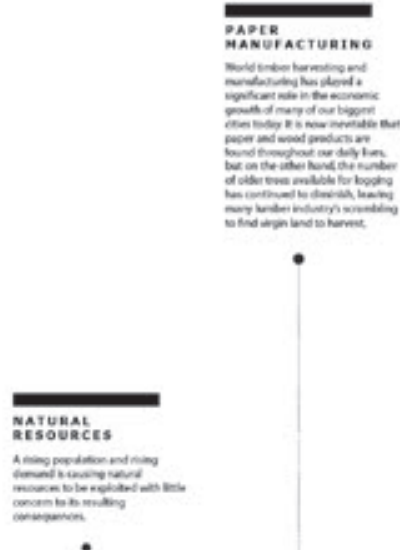

$\bullet$

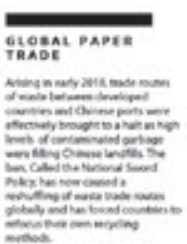

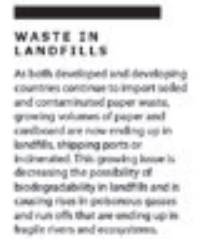

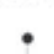

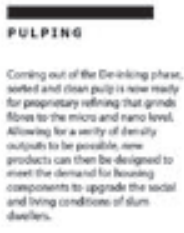

$\bullet$
DOTDINO THS

mereanidede

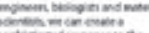
-

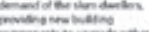

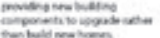
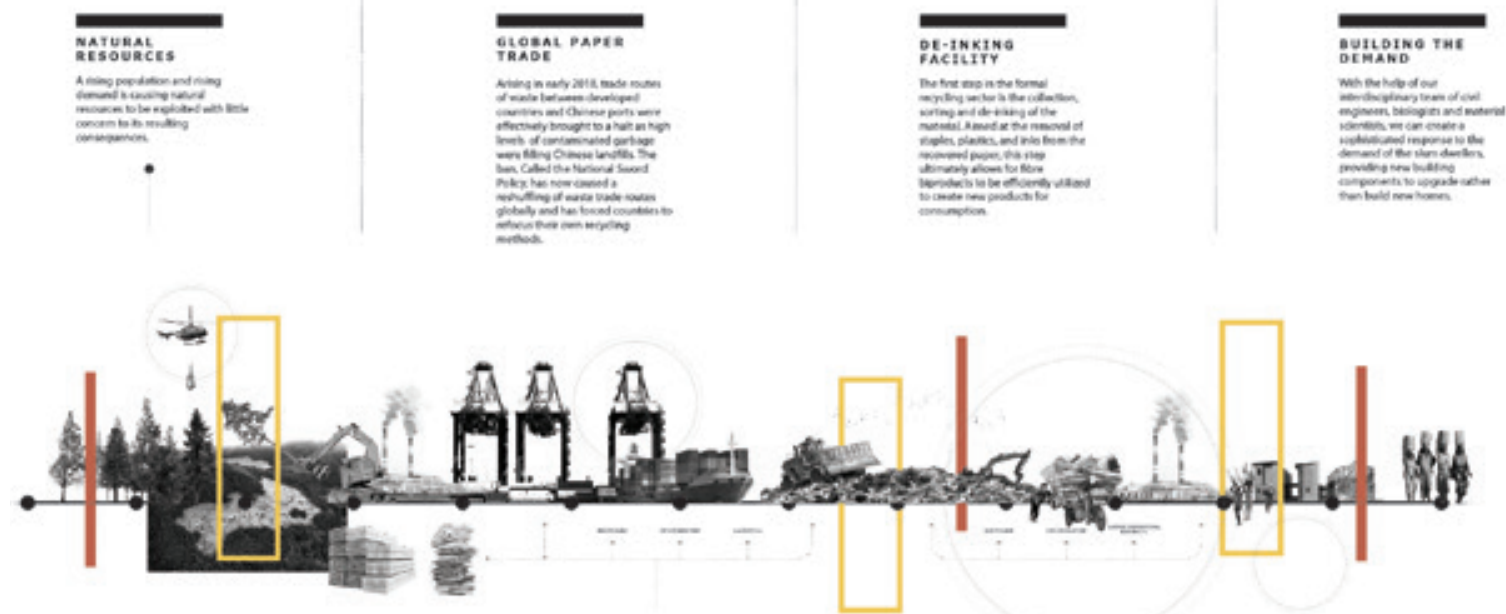

Fig. 013: Consumption and Production This image depicts the linear model thinking our economies currently take part in. From Extraction of natural resources to the end of life cycle in the Informal Recycling Chain. 
PART I I MATERIAL ARCHIVING / 0001 
2.0 MATERIAL ARCHIVING

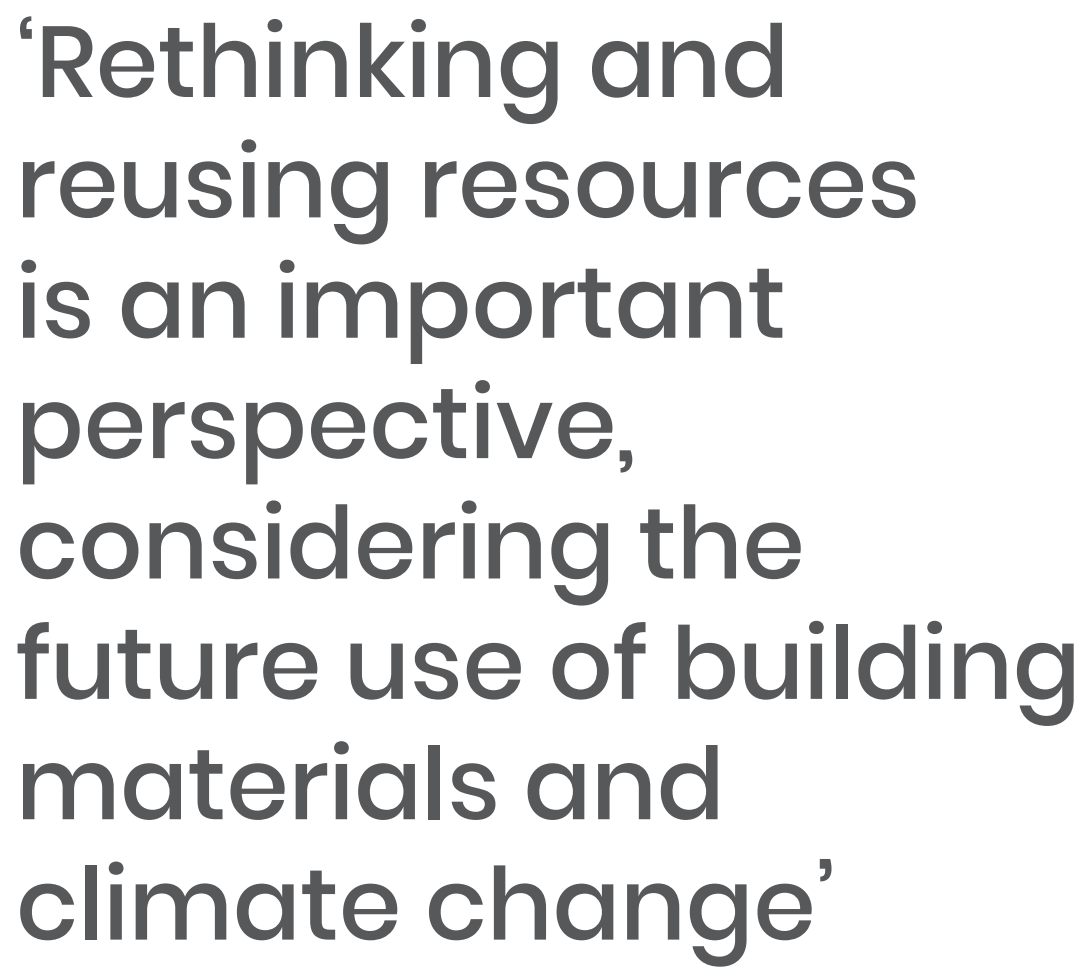




\subsection{MATERIAL ARCHIVING}

Over the course of three months in the summer 2019, I had the privilege to work with an inspiring research team in New South Whales, Australia to understand the technical properties and commercialization of micro-and nona-fibrillated paper and cardboard. With over 30 years of prior technical knowledge in cellulose refining technology, Zeoform ${ }^{\mathrm{TM}}$ uses natural properties of mechanically extracted nano-cellulose in a water-only matrix to achieve a range of structurally mouldable density outputs.

The following images are part of a documentation series that spanned three months in 2019 between Byron Bay, Nimbin, and Mullumbimby, Australia. Conversations of resource recovery, the circular economy, and innovative design methodologies played a fundamental role in my understanding of nano/micro fibrillated cellulose and its potential applications within the built environment. $3^{\circ}$

My sincerest appreciation goes out to everyone who made this trip possible and to the many friendships and relationships that developed over the course of this internship.
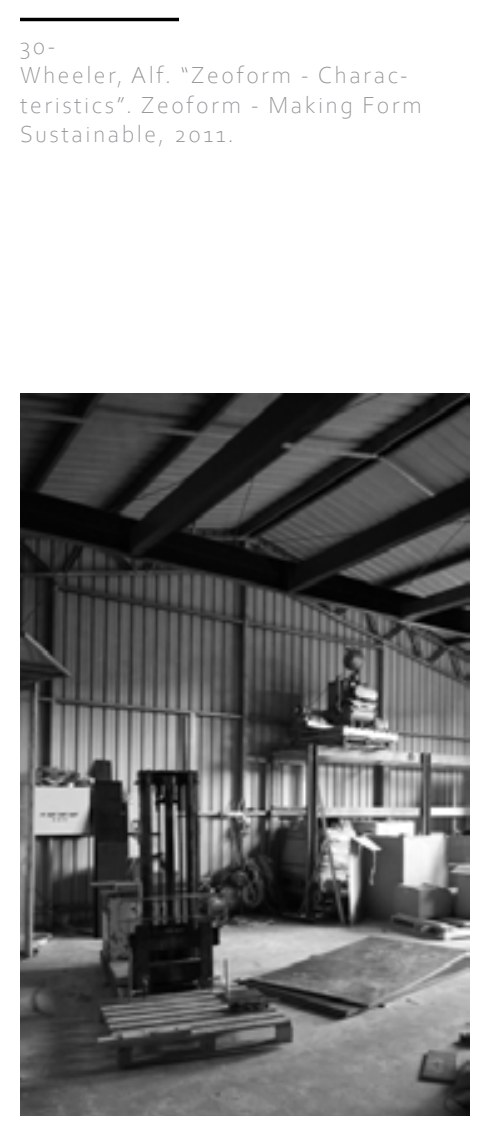

Fig. 014: Zeoform Factory in construction Australia, 2019 



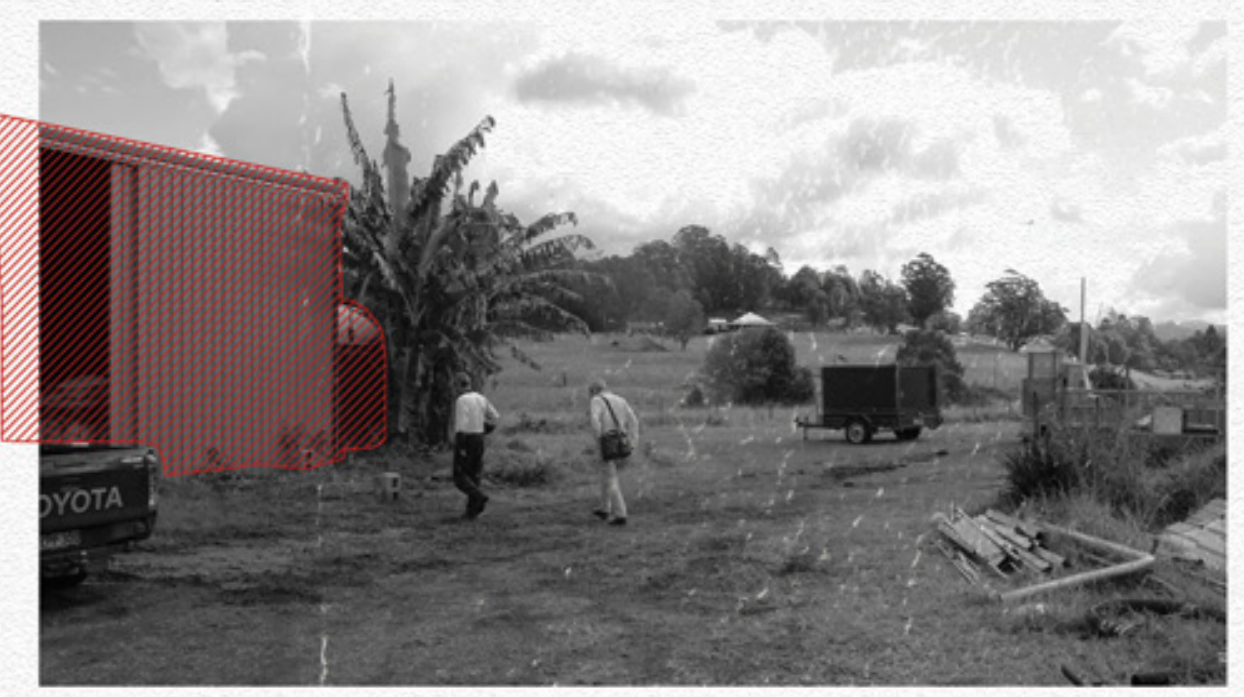

Zooforn Rofialng Facility, Nimbin

Positifoned inside Australia's Bastern rainfor

est, the Zeotorn refining facility becane a pri-

nary point of departure for nuch of this thesis.

Working collaboratively with the Zeoforn tean, I

had the opportunity to understand the technical

and nechanical properties of nano/nicrofibrillat-

ed cellulose. 

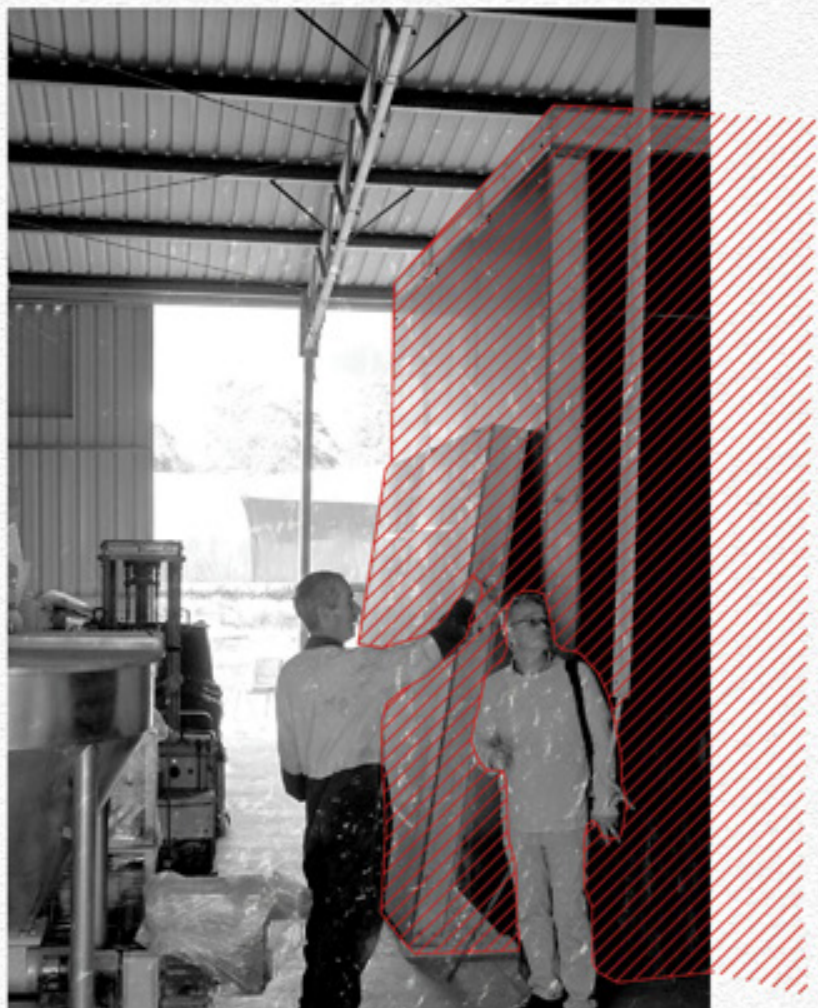

Alf and Martin Frnegg are shown discussing fibre

refining machinery and equipment. During my time

in Australia I worked collaboratively with A.1E

and Nartin to understand kusiness logistica and

raterial-developtent arplications for nano/mies

fibrillated fibres. 


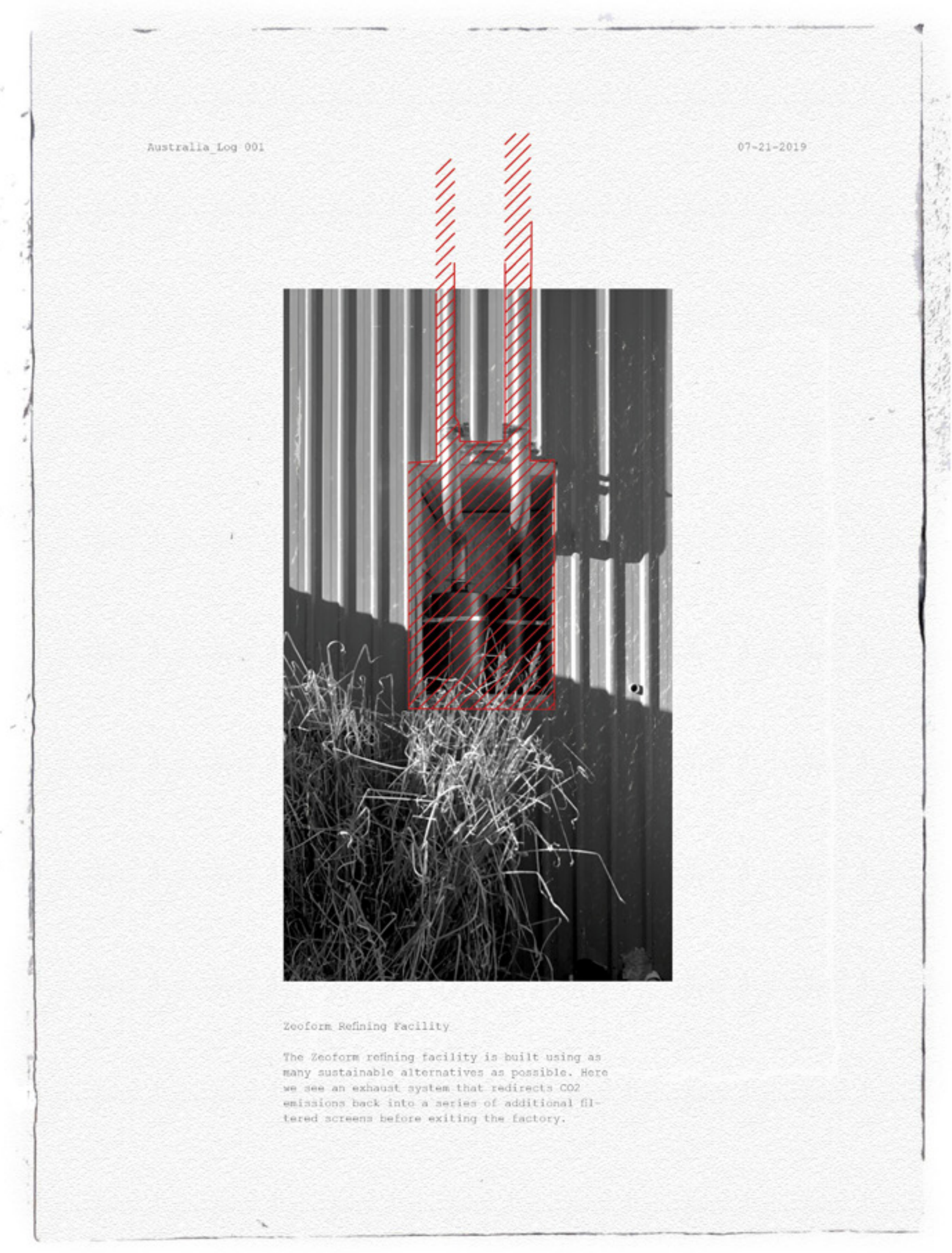




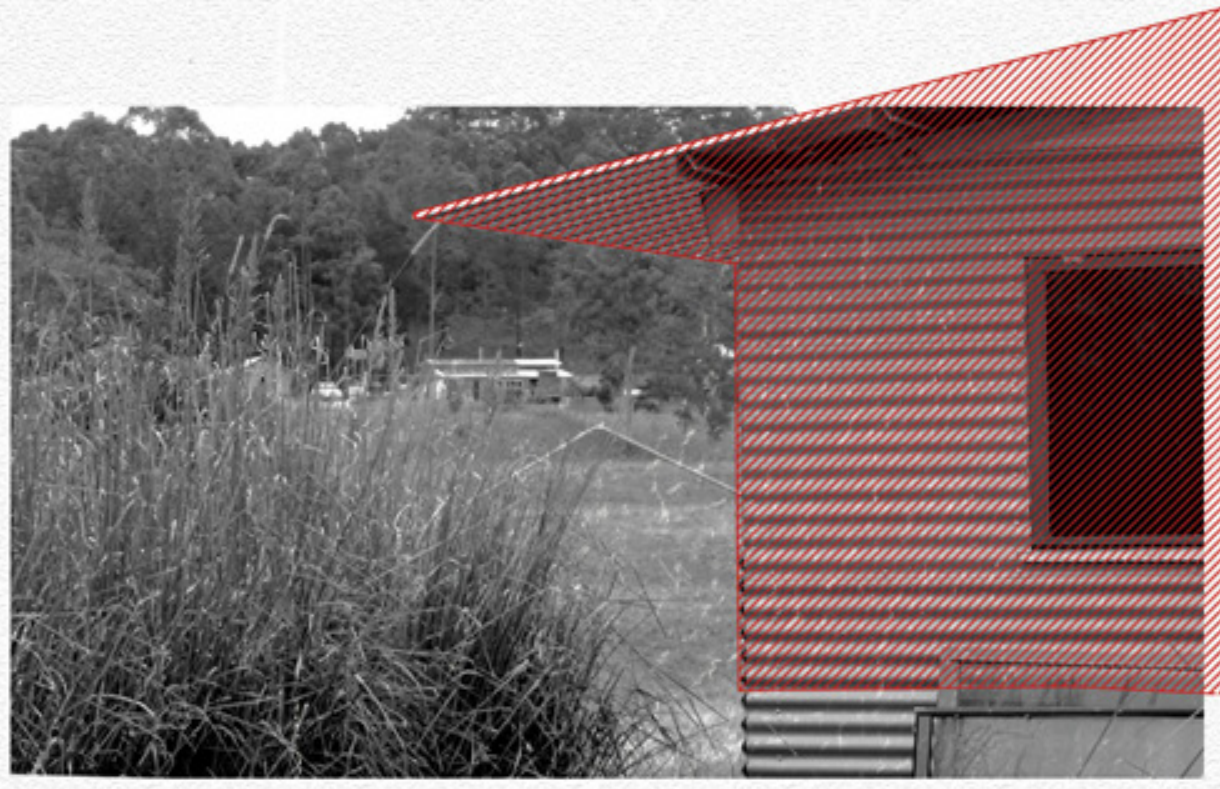

Zooforn Rofialing Facility

Standard construction techniques vere used in

fabrication of the zooforn refining facility.

Consideration of material sourcing, diatribu-

tion, labour, and price vere all carefully con

sidered before installnent. 


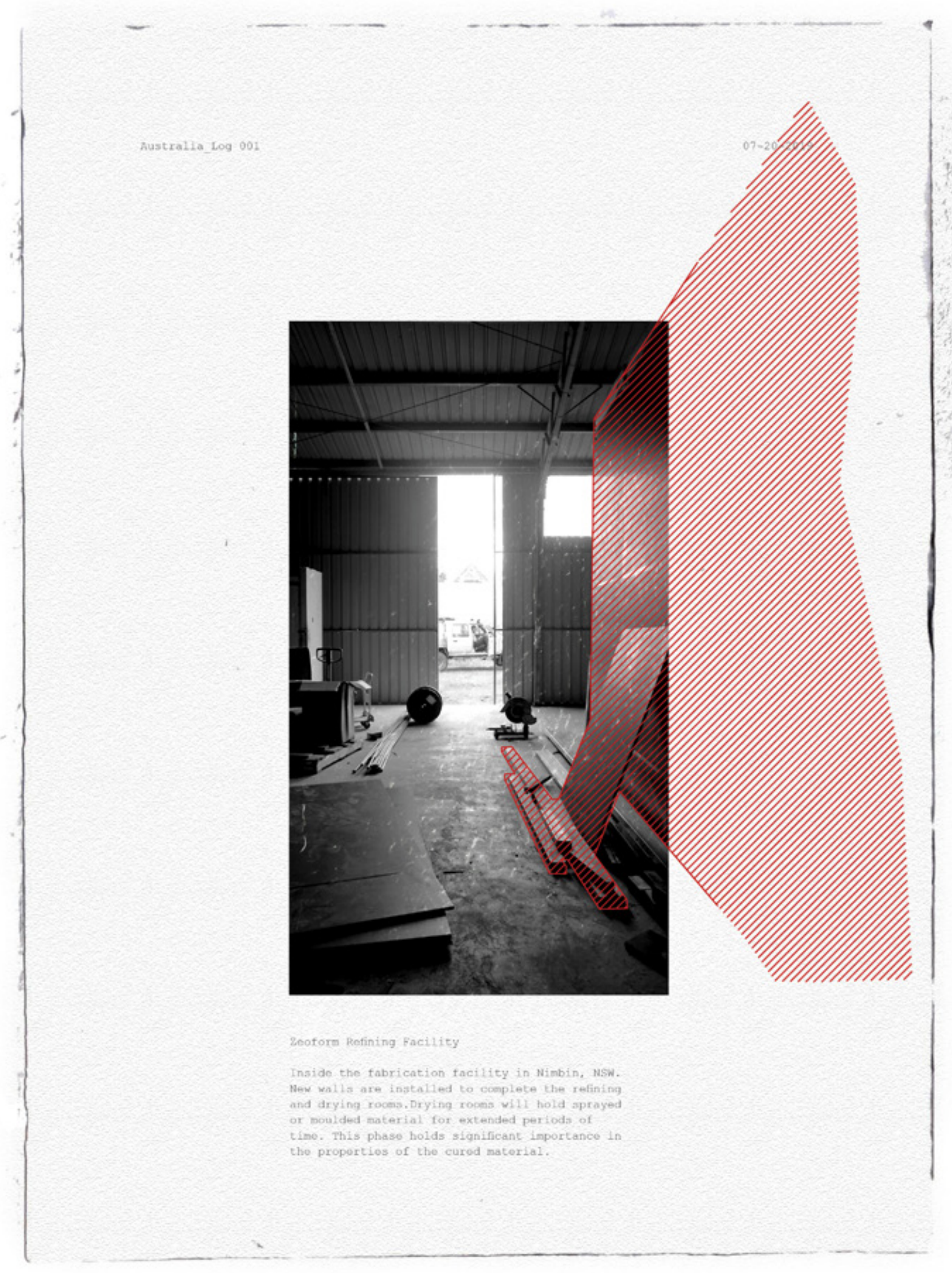




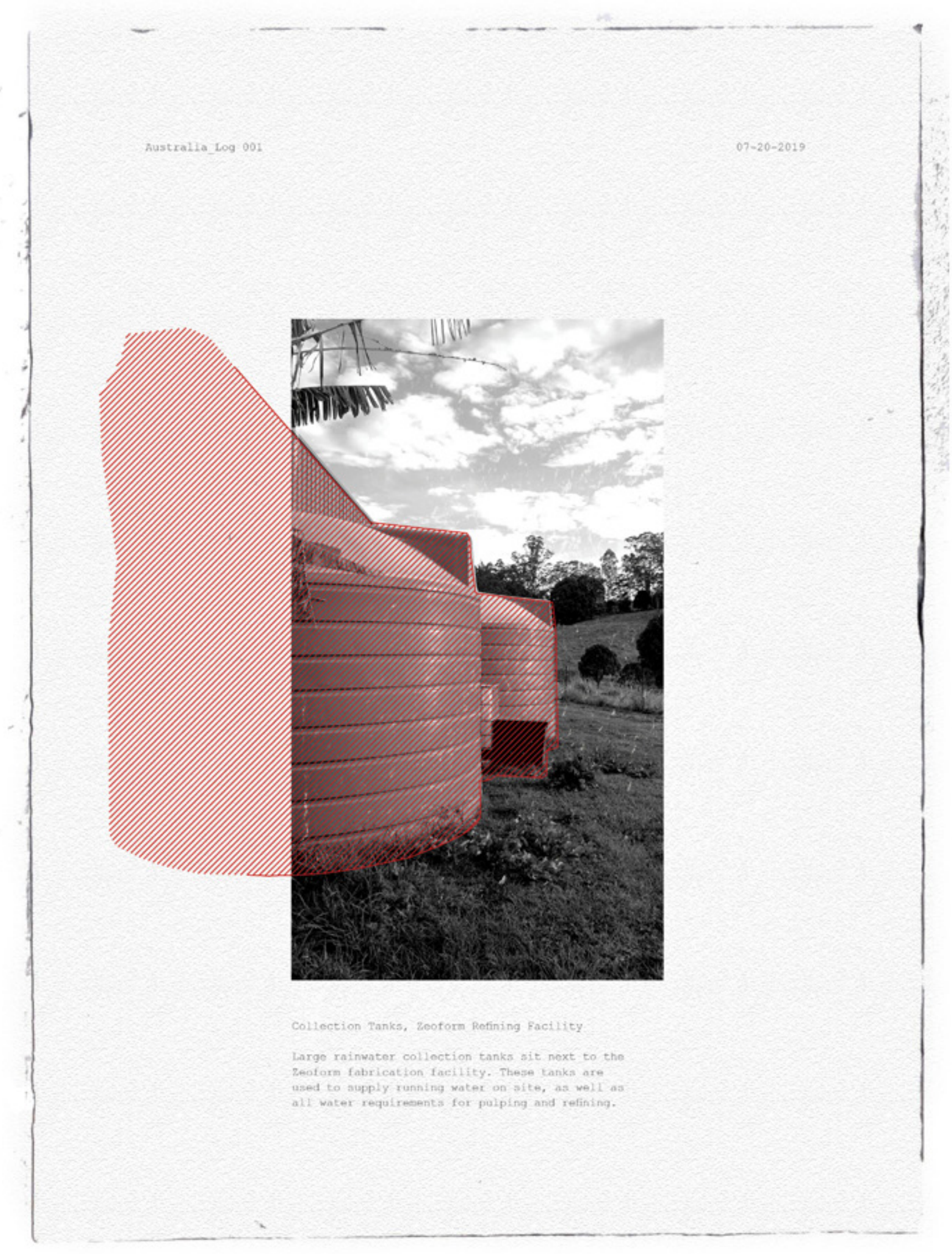



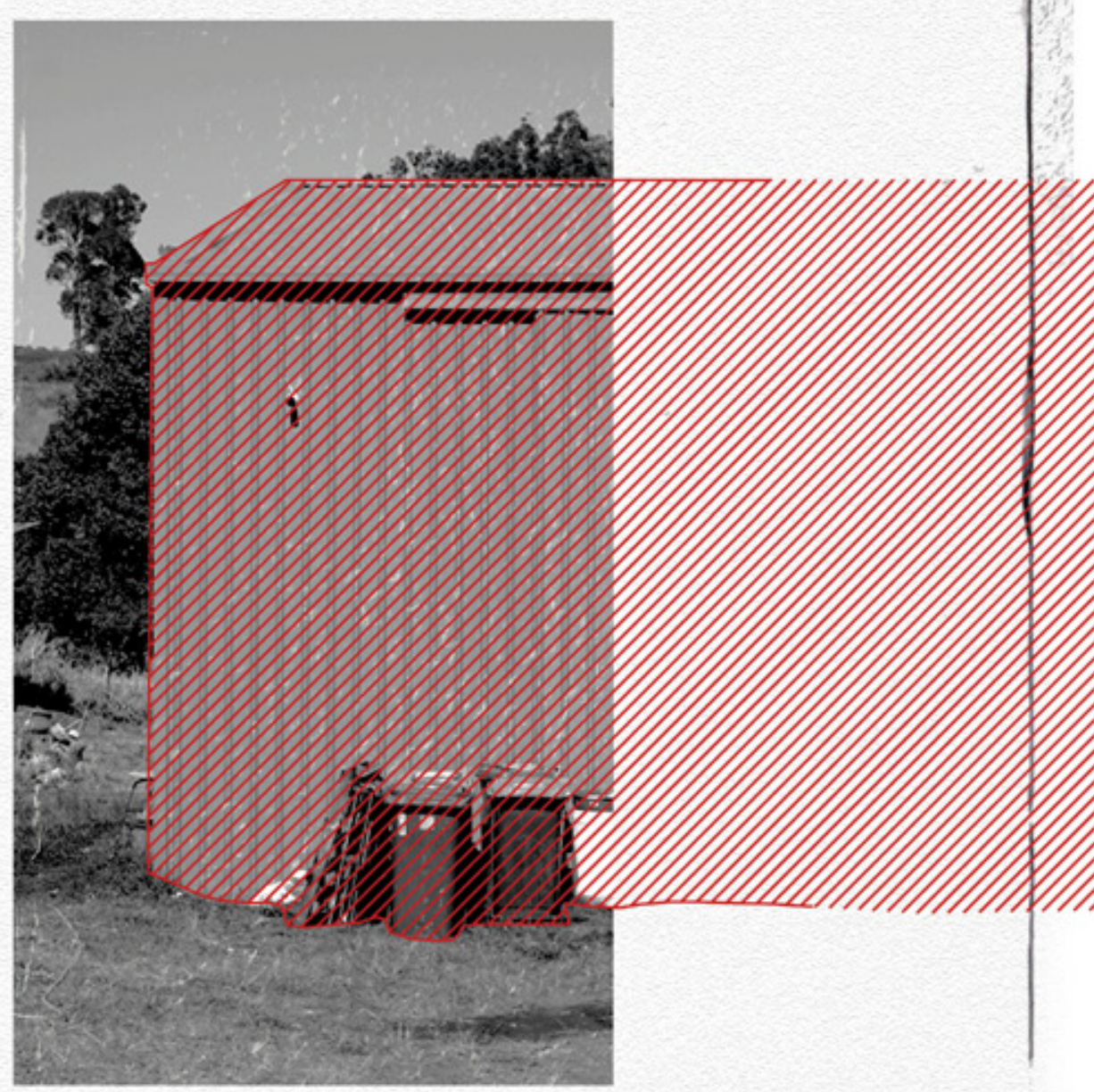

$08-10-2019$

Exterior of zeoform Refining Facility

Working a Longsido 2ooform proved fundamental in

ey underatanding of fibre bi-prodict ut ilizatiph

and material recovery aolations. Sftuated rokm

froe the coast on zeoform's private property,

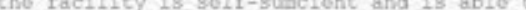

produce close to 5 tonnes of pulp/woek. 


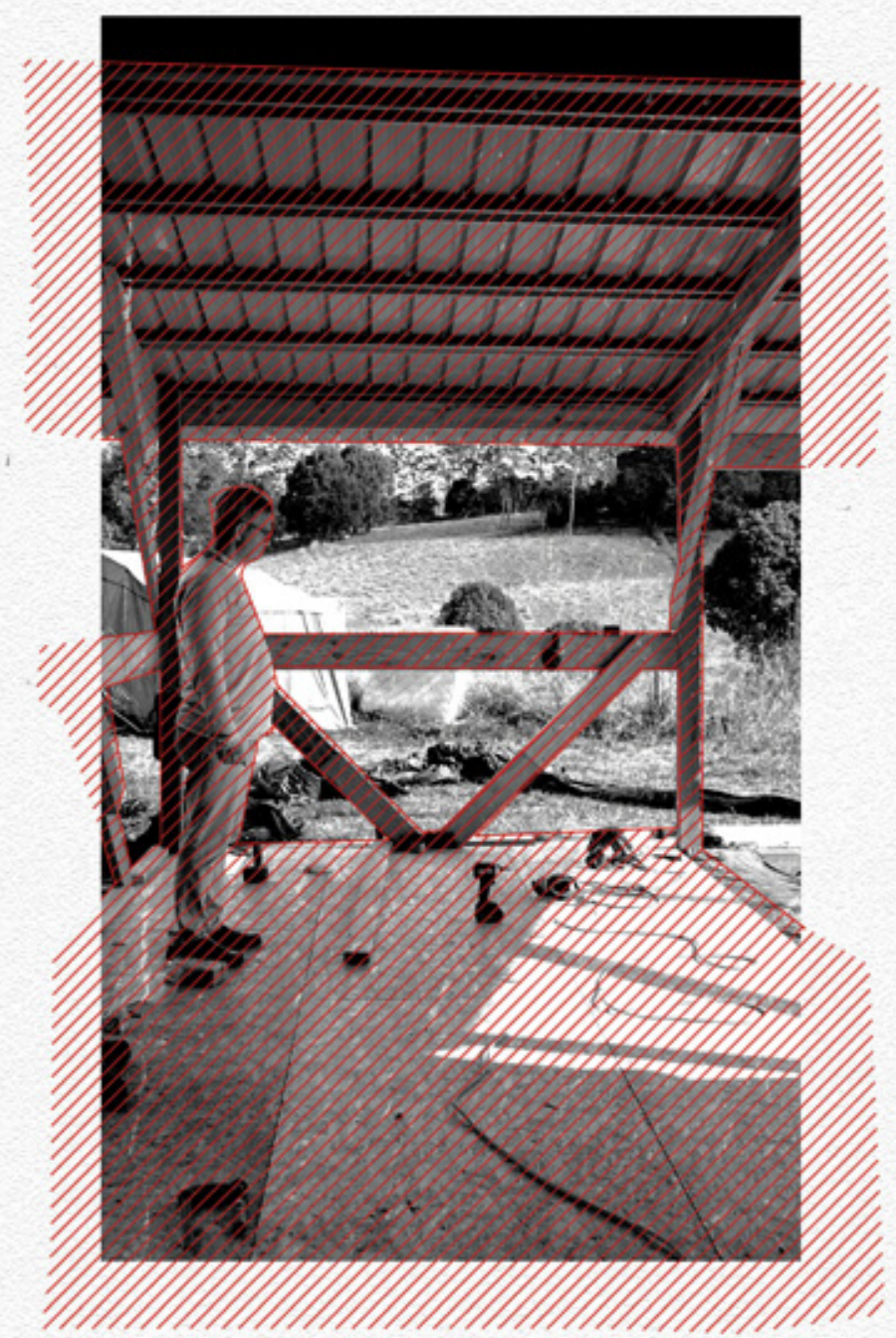

Finishing Roon, Zeoform Refining Facility

Alfred wheeler stands on the nearly complote fin

Ishing room where Zeoform pulp will undergo 'it'

final stages betore distribution. 

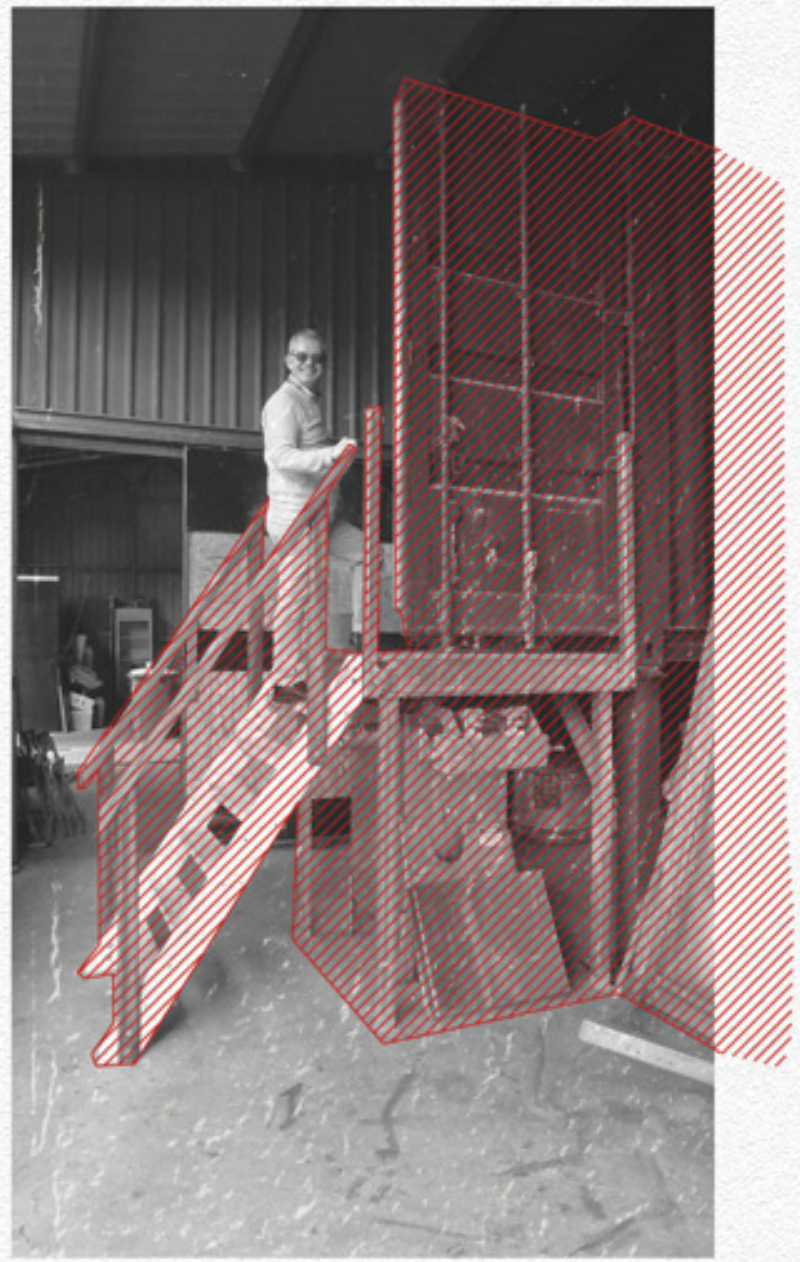

$06-05-2019$

Refining stage, zeoform Fabrication Facilit:

Alfrod Whoeler atands on the ontrance plat

torm to the zeoform pulp retiner. Thin is the

pritlary stage of production whete decorticated

Bast fibres ester the high-speed pressurized disk

reliner that zearas fibres down to the micro and

nano scales. This is the fundamental procoss

to extract collulose fibres from recovered ribre

products. 


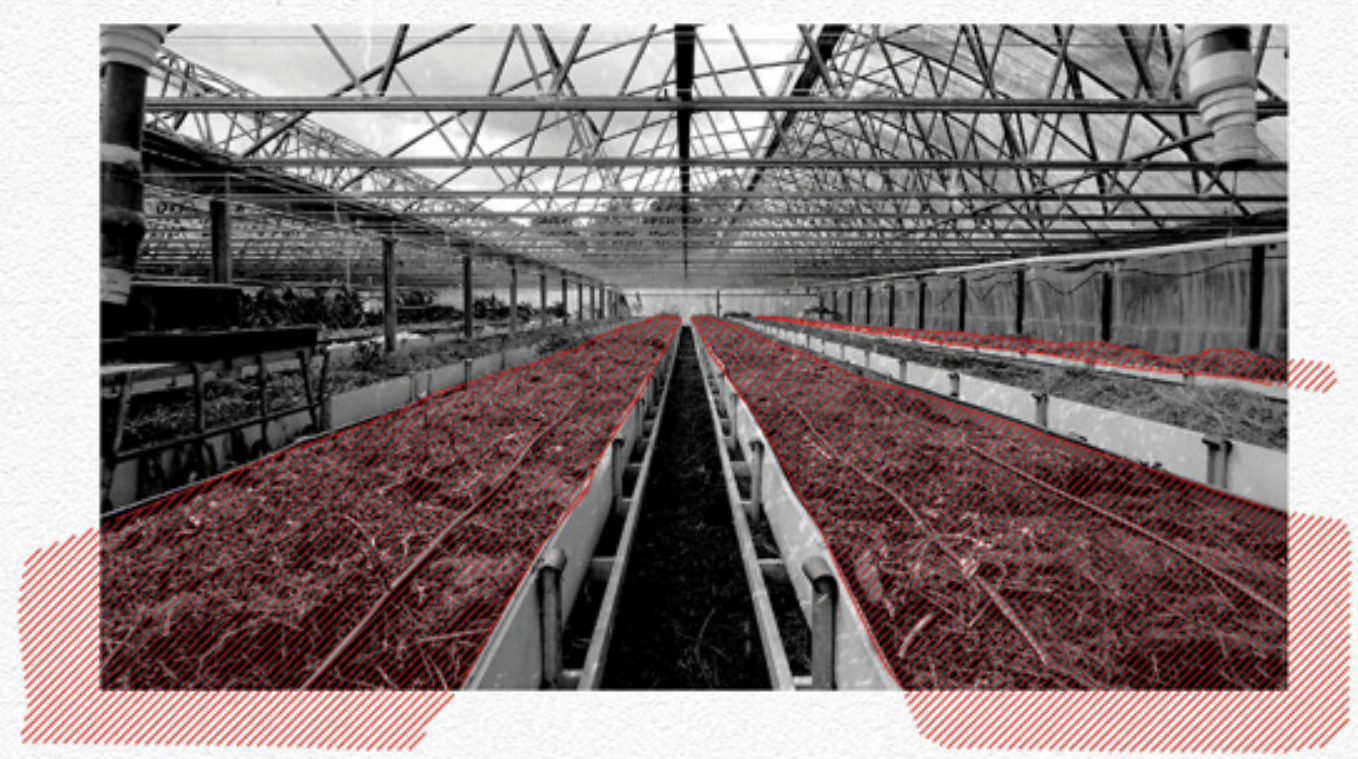

Zooforn Greenhouse

Jong rous of sofy boxes are seng inside - zeo

form's independent greenhouse. Here, a variety

of Bast and plant fibres are qrown to harvest,

nill, and supply renewable feedstocks for NRFC

components. 


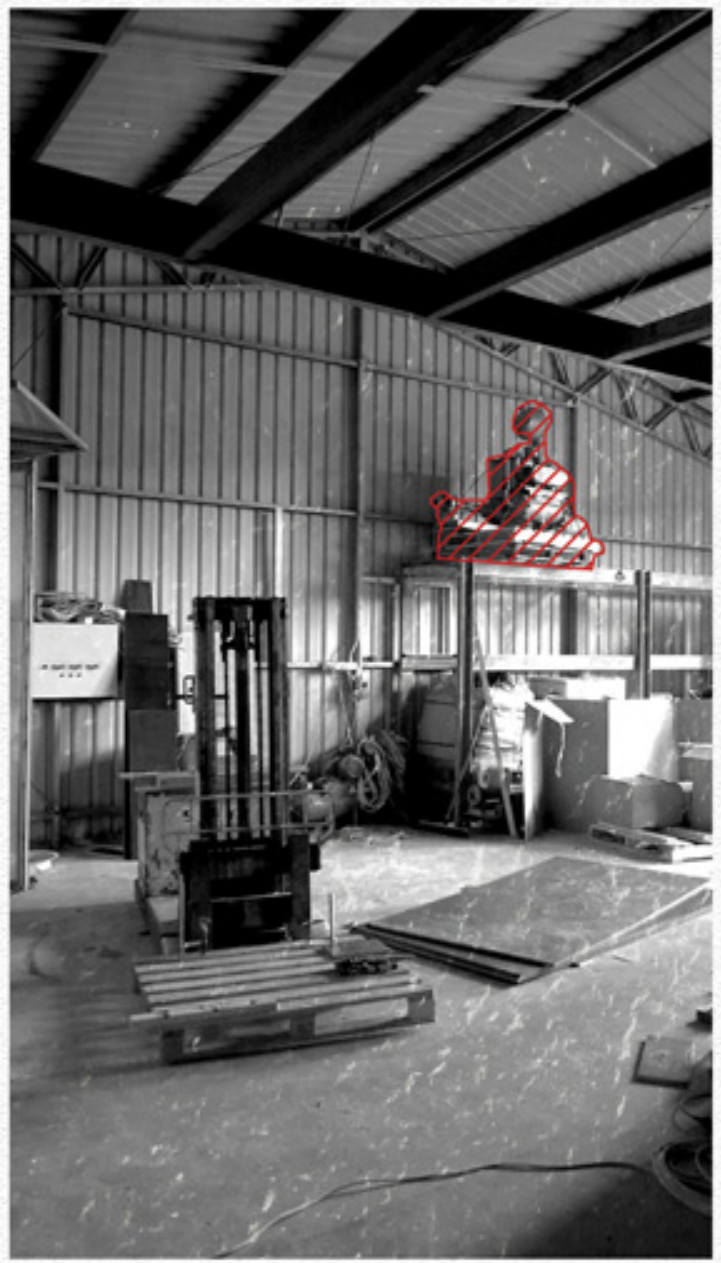

$06-05-2019$

zeofork Refining racility, NSW

Old and new manufacturing oquipment is seen

inside the zeotorm refining facility in Nimbin.

Australia. The state of the facility was in con

stant censtruction during my time in Austealia,

atrowing the tear to also focus on nethods of

commercialization. 


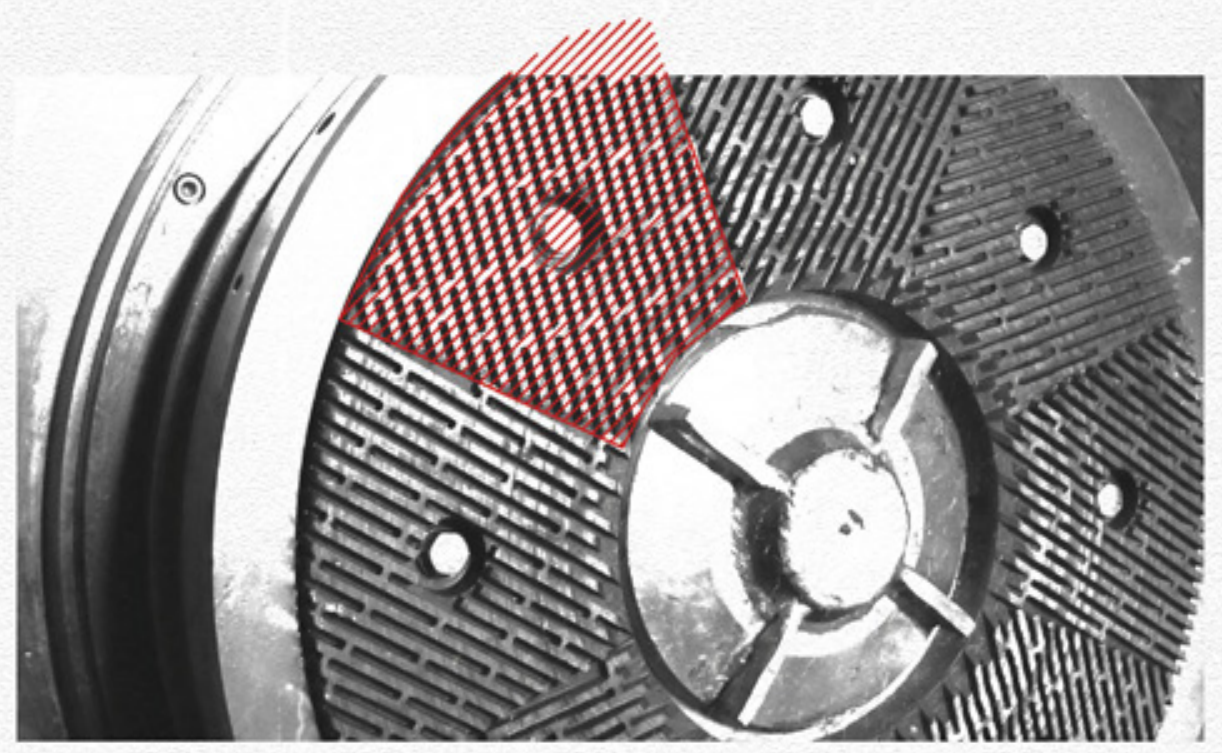

High-Speed Disk Rofirex

A close-up zieu of the pressurized high-speed

refining disk. This is the prinary pioce of

equipment in the Zeoforn process and is respon

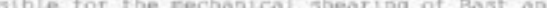

plant fibres. 


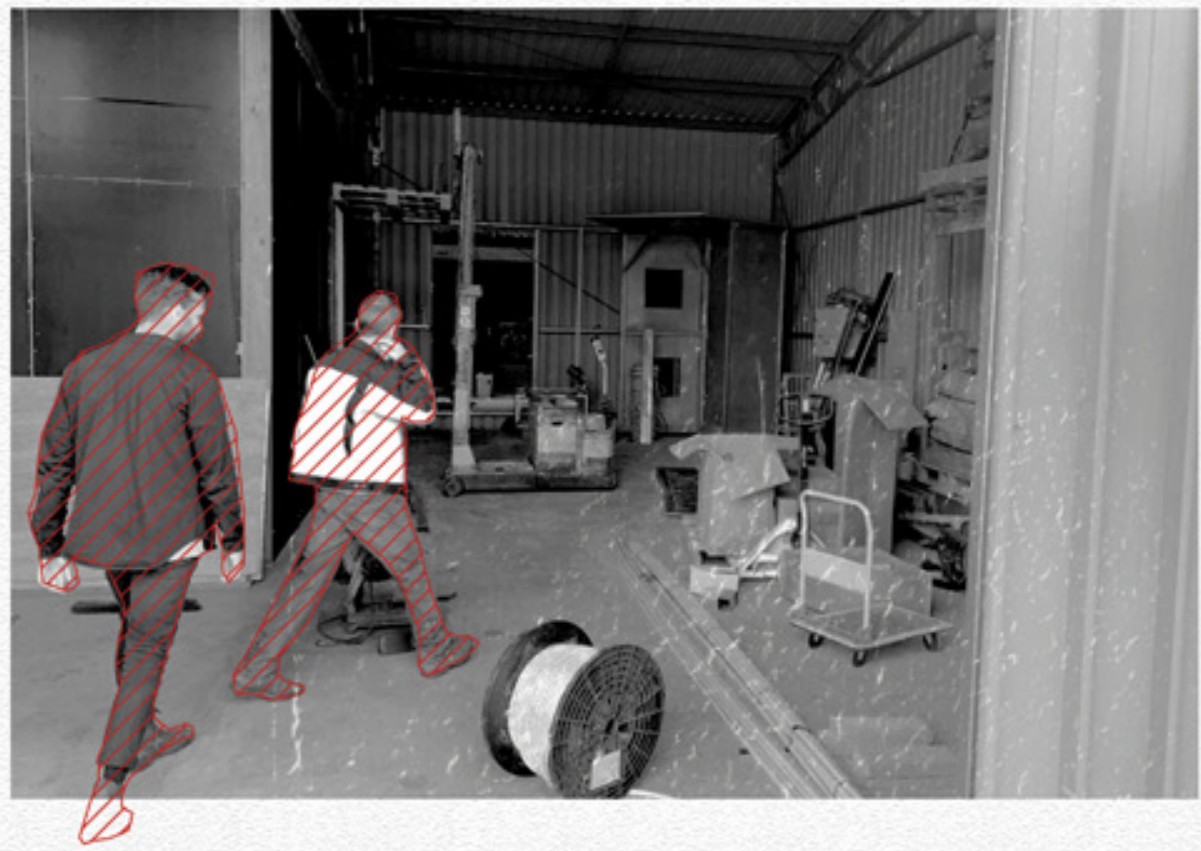

Zooforn Rofialing Facility

Martin Brnegg, Zeoforn's nateriar technologist.

and nyself working together to assemble new

equipnent for zeoforn'a refining facility. 


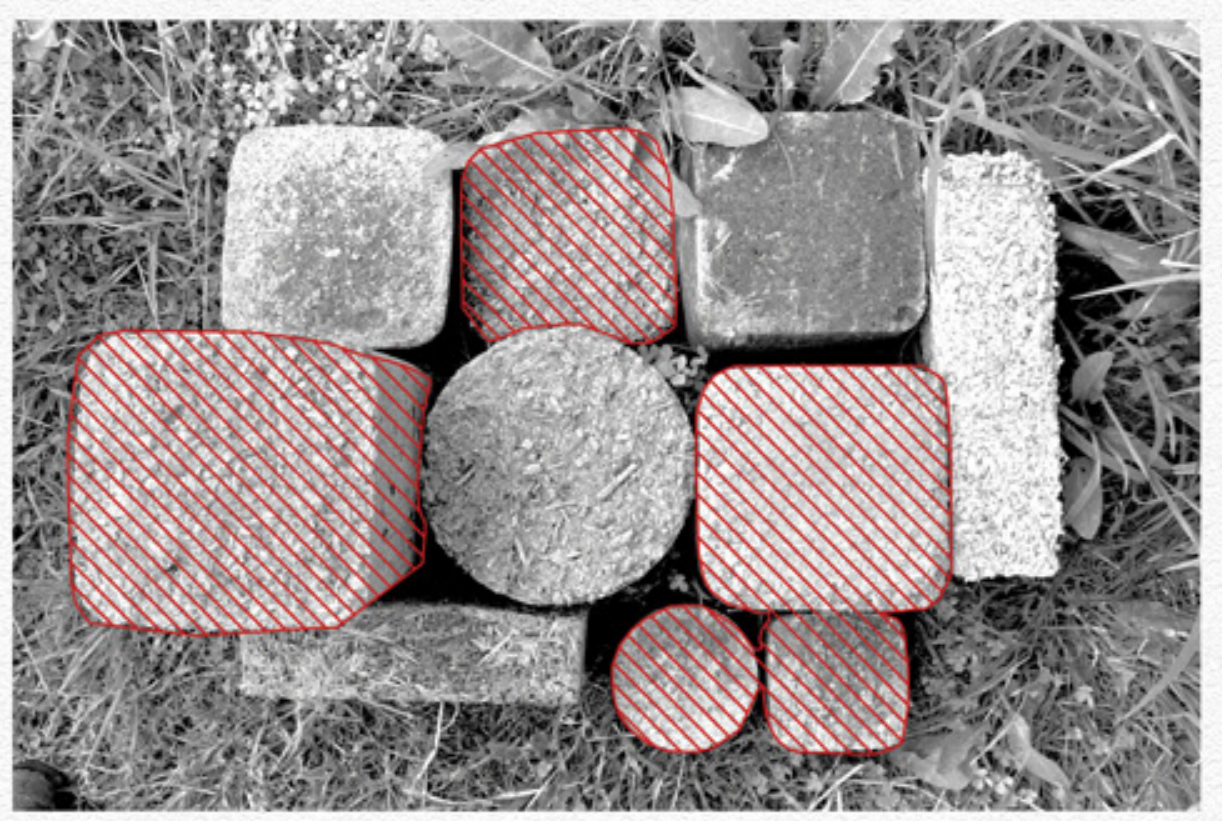

Prototype Henpcrete Blcoks

Prototype herperete buflding corponents, These

sarples are part of a series where wo investi-

gated ratios of building 1 ine and herp fibres.

fose explorations yill becone prinary polpts of

departure as I continue research back in Canada. 


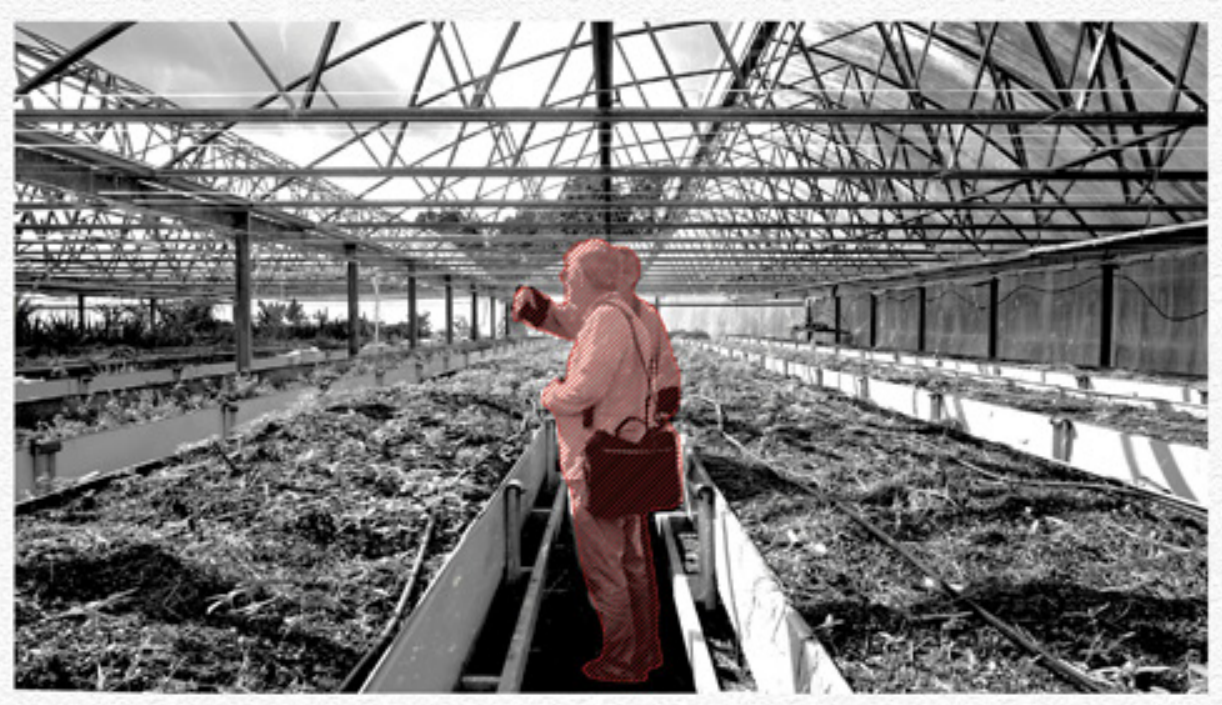

Zeoforn Greenhouse

Alfred wheeler and Martin Frnegg are seen diz

cussing growing and harvesting conditions in

Zeoform's independentiy ouned greenhouse. A va

ciety of east and plant fibres are being grown to

understand the nany possibilities of renewable

feedstocks for cellulose prodoctlon. 


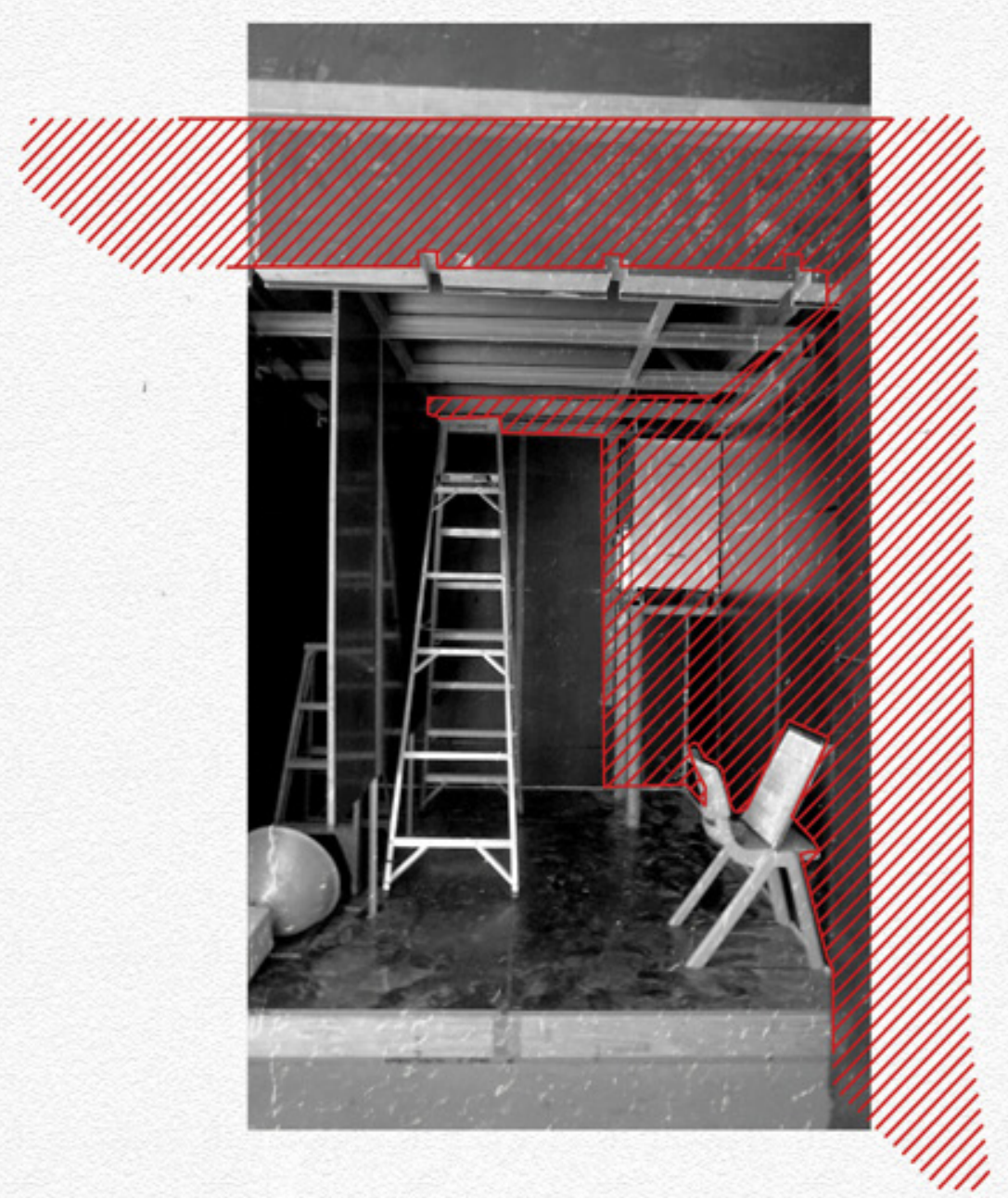

Eooform Refining facility

Inside the seotorm drying roon whore pressed

$t$-sprayed pulp witl undergo vaxying drying

teoperatores and tises. After this stoge.

coeponents - will enter the de-burring and

finishing phase before being distributed to local

consumers. 
Australla Log 00:

$07-20-2019$
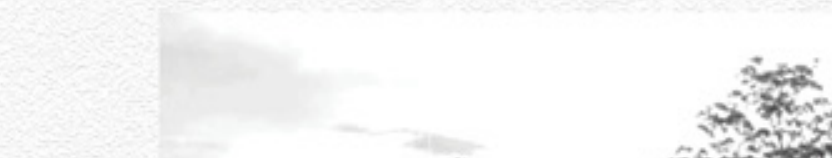

Phanger.

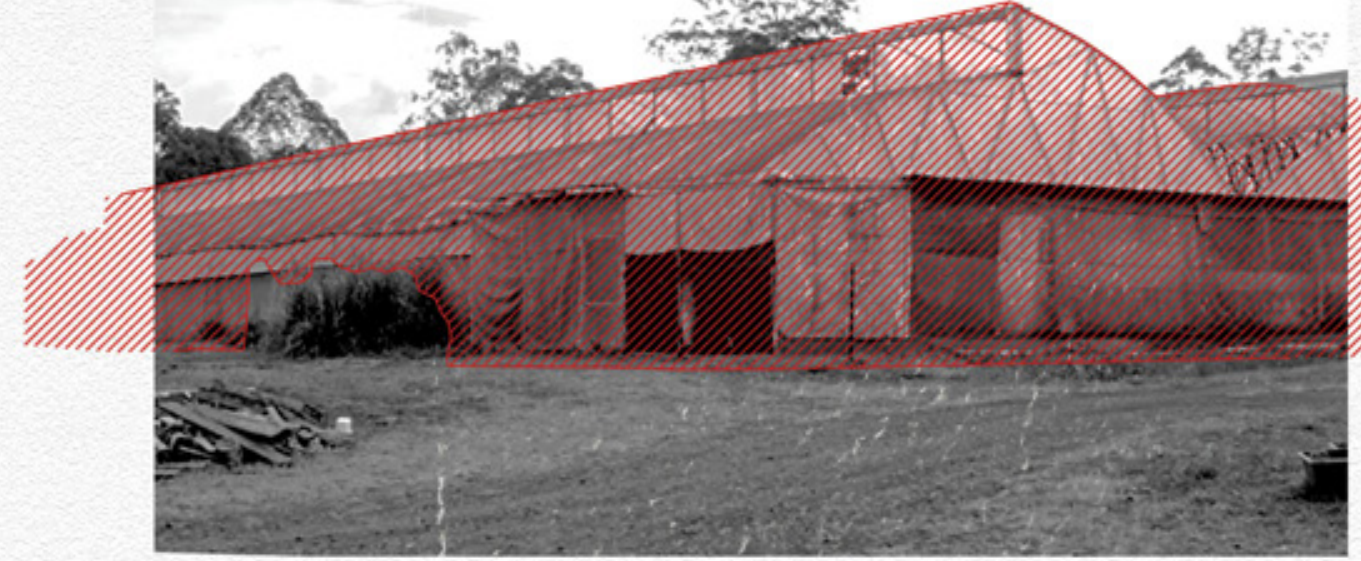

Zooforn Greoahouse Facility

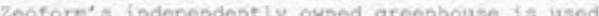

for growing and harvesting a variety of plast

and Bast fibres. While the recipe of zeoforn'

pulp is vell established, future experinen-

tal plants are continuingly being explored to

inprove and expand the potential applications

of Narsc. 


\subsection{MATERIAL ARCHIVING}

Material investigations are at the core of this thesis. Over the course of three months in 2019, my experience working with research partner Zeoform proved to be fundamental in understanding of cellulose recovery and second-generation material feedstocks. Working with the visionary team at Zeoform, days were spent equally with Alf Wheeler, Zeoform CEO, and Mathew Champion COO, and Martin Ernegg Zeoform's material scientist, to understand business frameworks and commercialization strategies for NMFC. For three months, I was part of a process that seemed infinity circular, from the biological and climactic cycles of the southern hemisphere to the technological cycles of what we were working on.

Zeoform holds close to thirty years of technical investigations with NMFC while having a primary focus on industrial design components and consumer goods. Using my background in architectural design and thinking, my involvement with Zeoform generated new opportunities for Zeoform by shedding light on the significance that sustainable sourced building materials could play in dramatically reducing the carbon emissions of the industry. ${ }^{31}$

Working first hand with Martin allowed me to understand, document, and catalogue his work into visual forms of representation that have helped deploy the projects voice within the business landscape. Using varying forms of graphic illustration, I spent equal days between the office and factory, categorizing

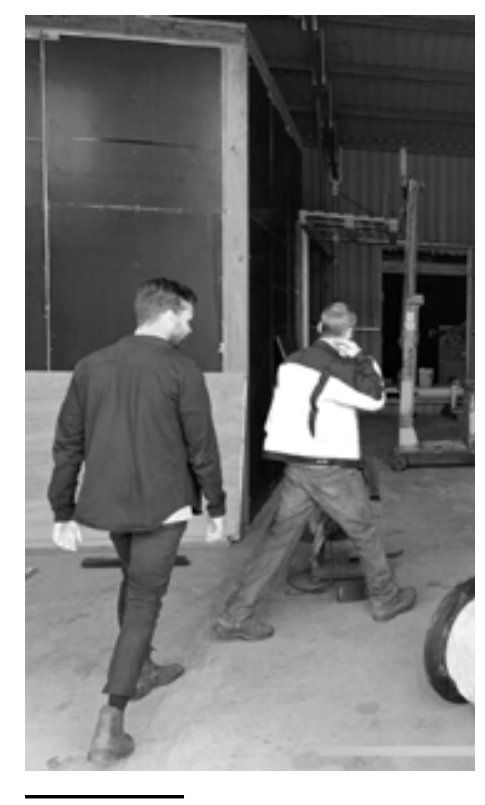

Fig. 015: Martin Ernegg and myself working on factory layouts and operations in NSW, Australia

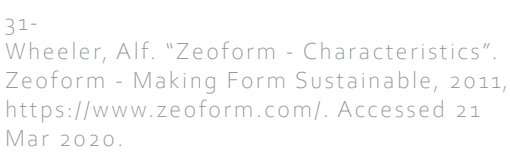
Mar 2020. 
information into visually compelling brochures for the Zeoform team. These exercises helped not only my understanding of the materials properties but of the limits of publicly acceptable knowledge regarding Zeoform's patented technology. In addition to helping construct their new manufacturing and refining facility, we enjoyed discussions of the materials placement within a global context and the revolutionary qualities and possibilities the material can offer. ${ }^{32}$ Understanding techniques of refining, forming, and drying allowed supplementary research which will develop from this thesis to better position itself between artisan making and industry scale operations. Relationships built in Australia have given this thesis new direction while remaining connected to both business, industry, and academia.

The following images are a series of fabricated prototypes from Australia using the NMFC blend.
Ernegg, Martin. "Field Research Australia Log 17". New South Whales, Australia, 2019 

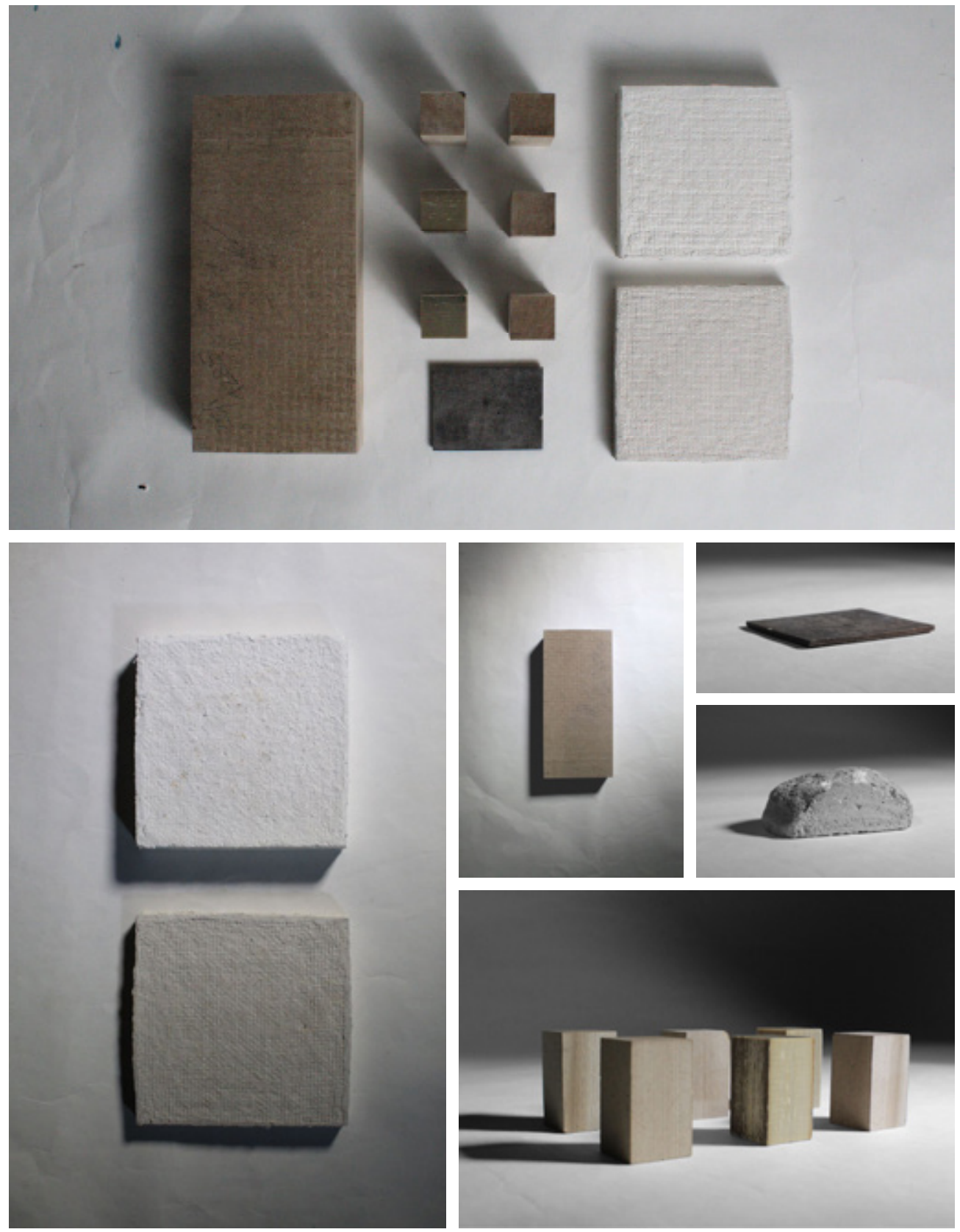

Fig. 016: Detail photos of NMFC

samples, 2019-2020 
JaN is/20

Demong as mection

What foren was $x$ ideal.

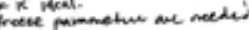

inen to renoose nater.

what to pros.| haw th

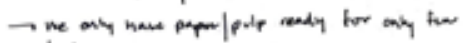
tuth

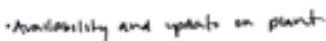

$\rightarrow$ Troform as weriany now strectures

to sell lievent.

$\square \longrightarrow ;$

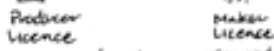

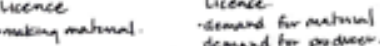

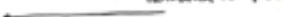

ximen sanding nomal dercith mativial

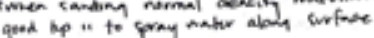

S. that klower diap aom.

sealen of spouthon.

rom man.

3 in at peratien dougromen. at. a- if.

$\longrightarrow 100$ kiloc $/$ wet

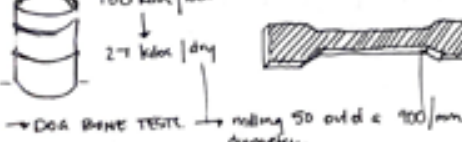
demein.
Mevina Foawaro

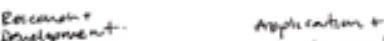

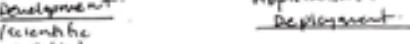

resuin)

Frane tre motavial hod dees material

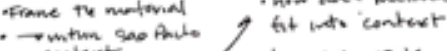

context hav are peaple

- how doer paper vimg the makned

prodich qef und Cpapd.

in the eny. What cave etrdien

"Borritaction do you mave.

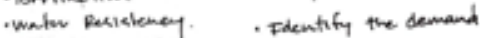

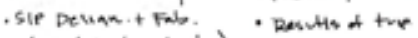

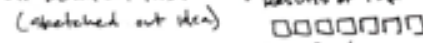

Facelitine.

7D Docuencentation

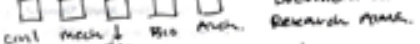

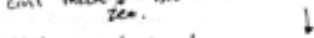

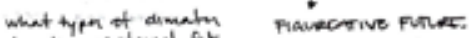
does the meterial At

m.

Diagramatice spotare.

deima velemention

and idea.

Repreunlation:

Hend dowem

Hand paper?

wiont do yer print on?

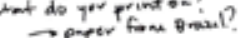

What style.

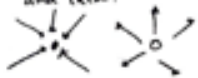

Felory $=$ catt syetrm.

$t$ mear (antiot. cien).

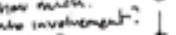

neathe? each out

hesc a rile

acherite.

man on

a demand be new facilther b treat peake watt. Revelusing centron of peper can dien greater effeciencied. I Theation and experation paper bis tones that que throvic Gormal pocese.

\begin{tabular}{|c|c|}
\hline 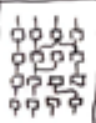 & 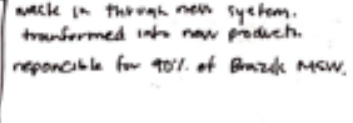 \\
\hline
\end{tabular}

Map ot ceatres.

Mare of reving

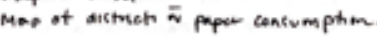

Colow trented collectur. In socin inducion

$\square \square \square \square$

ond reoner op. meiale.

\#. Auk quikom for what you leviking forl.

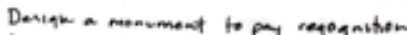

to the invieible work dese by plitem.

ethen refered to an cant mom,

selective cellectuan oriested proqram

tadyale of whath cesusing the ciaciumption

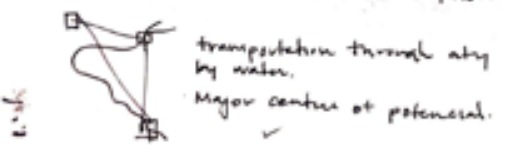

BUAZIL BEEAKDOWN

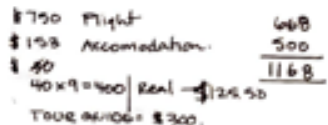

\$1353 cono. I Food:-

capaenia. | pintence.

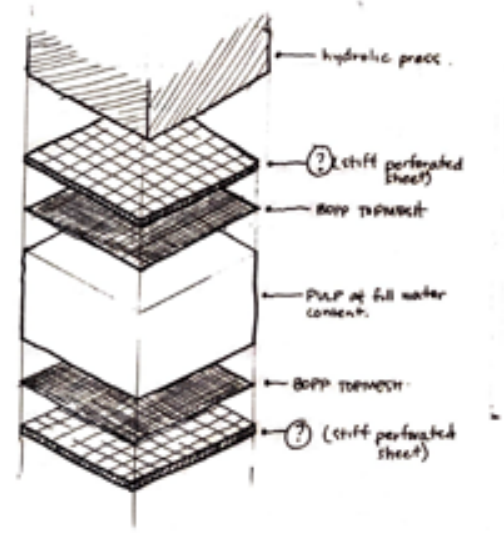




\subsection{MATERIAL FUTURES}

The search for sustainable materials has begun to embrace not only materials sourced from within a technological cycle of reuse but also the importance of "clean" materials which can decompose and partake in a biological cycle of composting and regeneration. ${ }^{33}$ Cellulose is the most abundant organic compound on the planet. In recent years cellulose research has moved from laboratory curiosity to an explosion of interest in materials research, design development and business opportunities and is set to play a major role in moving advanced materials away from petroleum-based products that are not biodegradable. ${ }^{34}$ With cellulistic materials in abundance due to the fallout of China's National Sword Policy, Zeoform's revolutionary fibre recovery technology proves to become a great catalyst in material recovery solutions the world over.

Working first hand with Zeoform over the course of the summer gave me a unique opportunity to understand the many processes and complexities involved with creating NMFC at the industrial and artisan scale.

\section{Material Inputs}

Unlike typical fibre recycling, Zeoform can use a range of fibre inputs from recovered fibre materials to plant and pulp fibres.

Pulp fibres are typically high in cellulose and lignocellulose, which derive from softwood fibres and aid to the strength of the final output. Plant fibres can derive from virgin or second generation materials and are generally composed of both cellulose and lignin. Recovered fibres derive from a variety of sources and use

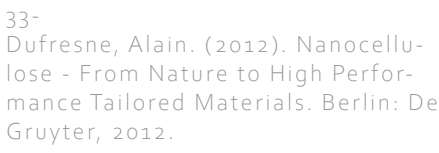


an average of 20-70\% less energy than virgin harvested materials. Using these three main fibre types as a point of departure within this project explores multiple applications within the building industry in both Canadian and Brazilian climates. Shown in Figure 15, we can see the range of recovered fibres that were explored and analyzed through the research in this thesis.

\section{Material Processes}

Using a wide range of second generation fibre feedstocks, Zeoform uses a simple refining process similar to that of 18 th century paper making and blended in water-only matrix for a variety of products and outputs. Zeoform's patented technology offers new potentials in fibre refining while using natural hydroxyl bonding to create a structural mouldable material.

Equally dependent on its refining time, drying time, and pressing methods, the products exhibitions can range from the lightness of styrofoam to the strength of ultra-dense composites, allowing the material to be utilized in a variety of contexts by industries and designers alike.

\section{o3 Material Outputs}

In consultation with civil and mechanical engineers at Carleton University in Ottawa, design and fabrication methodologies are being explored that use the materials ranging densities to generate prototype blocks and sheets fit for the prefabrication of new sustainable building components in developing regions. The material's early exhibitions of thermal, structural, and waterresistant qualities show promising potential for component replacement in these regions and help illustrate the potential of second-generation feedstocks as a viable alternative to many petroleum based composites. ${ }^{35}$

35

Wheeler, Alf. "Zeoform - Characteristics". Zeoform - Making Form Sus. tainable, 2011, https://www.zeoform $\mathrm{com} /$. Accessed 21 Mar 2020. 


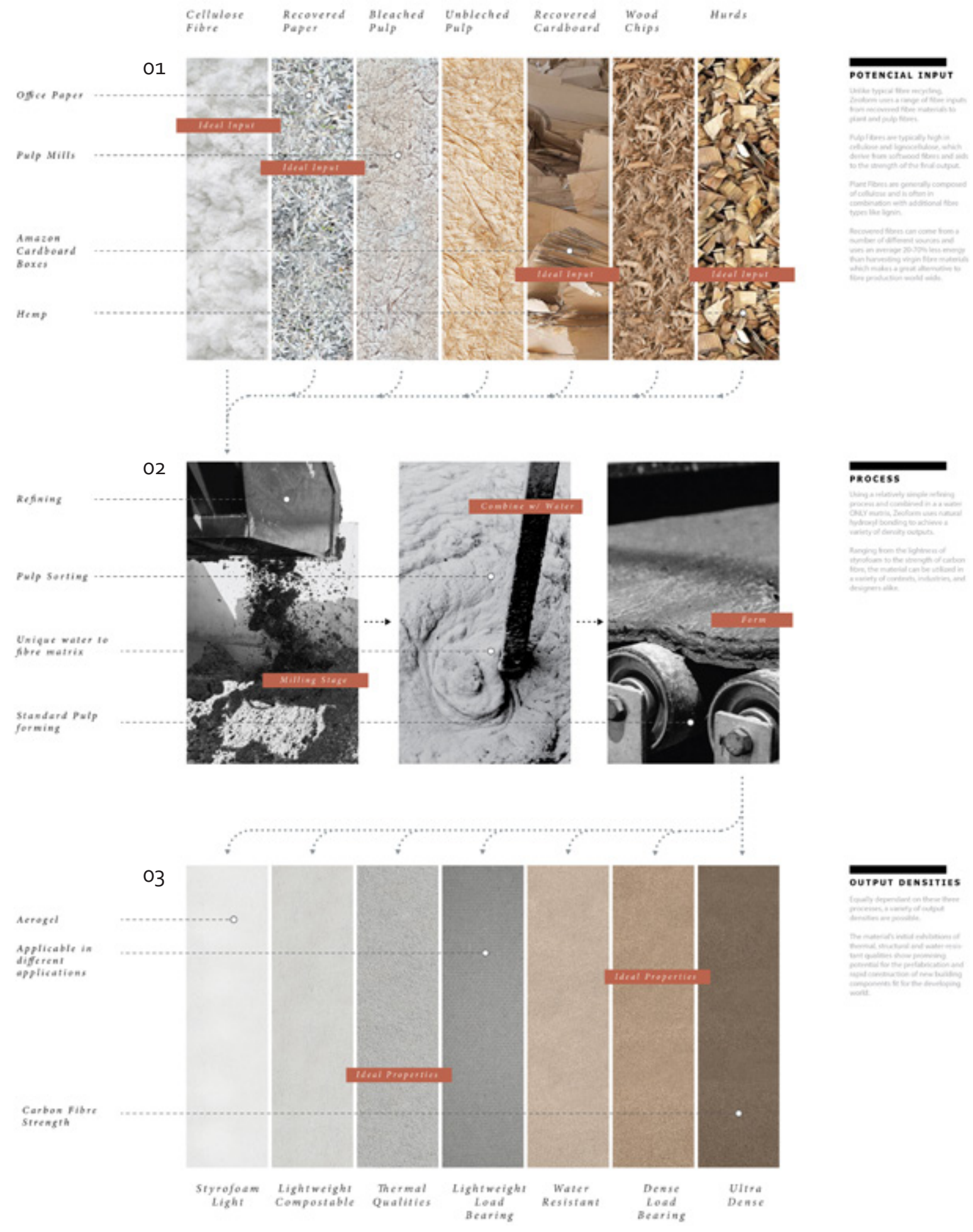

$\overline{\text { Fig. 018: Zeoform Fibrillation Process }}$

DiagramFactory in construction,

Australia, 2019 


\subsection{MATERIAL PROPERTIES}

Building on over thirty years of technical work with microfibrillated cellulose, the simple but proprietary refining technology developed by Zeoform is able to produce a variety of density outputs that are equally dependant on their refining time, drying time, and methods of moulding. This project uses NMFC and its ranging densities to create prototype exterior sheets and insulating boards fit for the prefabrication of new sustainable SIP prototypes
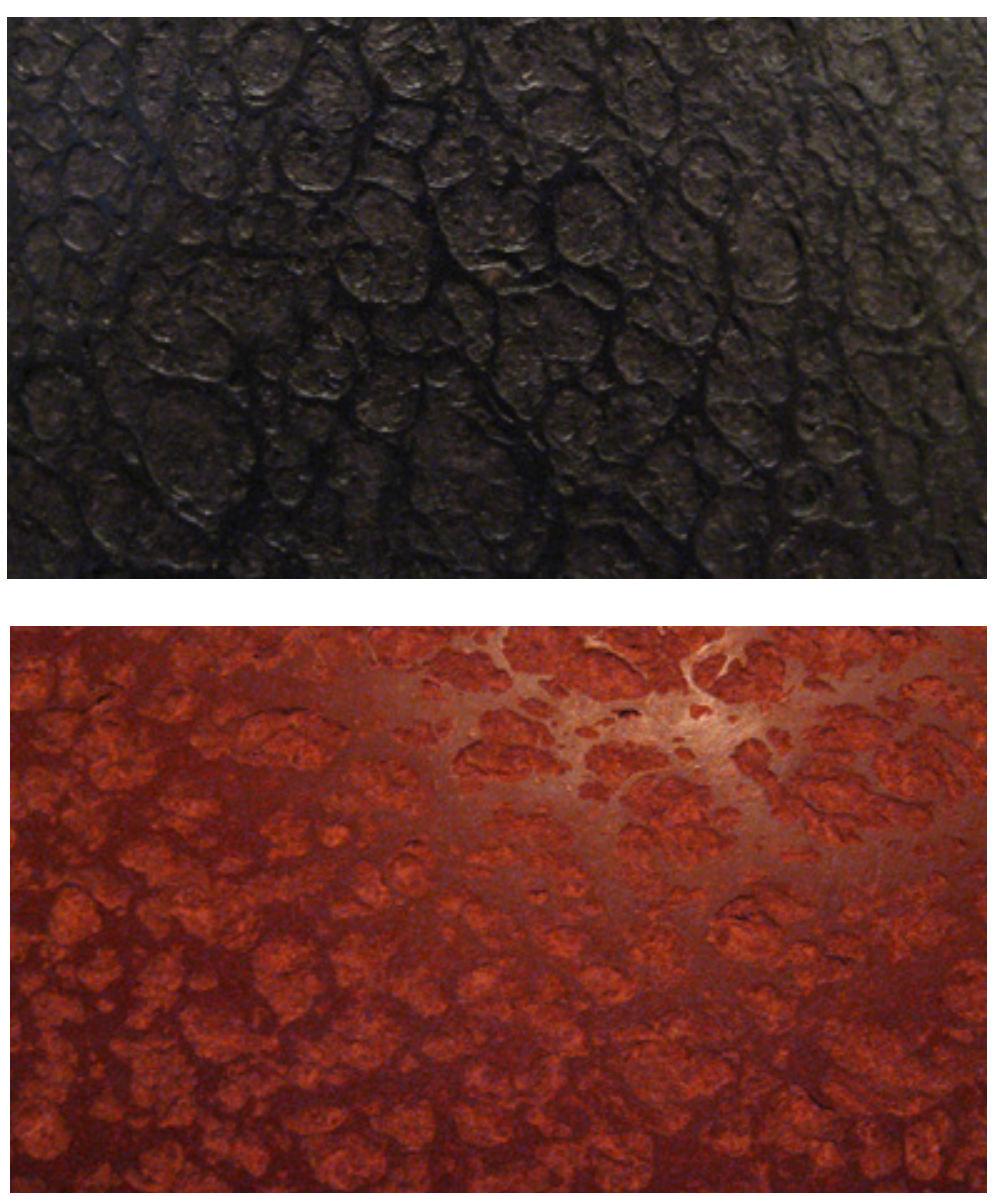

Fig. 019: Close up of NMFC surface texture 1

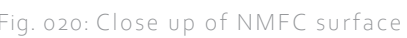
texture 1 
Efficient insulation is the most practical and cost-effective method for increasing energy efficiency in buildings. In the southern hemisphere insulation is used as an acoustical damper, and also helps with the reduction of solar gain by preventing cooled air from warming back up..$^{36}$ Insulation efficiency was most recently ranked as thirty-fifth most important actions we can take to reduce emissions. ${ }^{37}$ Preliminary tests have been conducted using NMFC aerogels at the Zeoform facility in Australia, ${ }^{8}$ as a proven method for creating insulative properties when fully dried. Sustainable techniques using ambient pressure drying (APD), vacuum filtration and freeze casting have also been studied and show promise in the production of cellulose based aerogel insulations. 39

The material does however present specific challenges in terms of water resistancey as it is by nature, hydrophobic. Our research hasidentified the potential of using thermal modification, a heat treatment process used in the Canadian wood industry to enhance the hydrophobic capabilities of fibre based components. 40 NMFC material will be tested in a low oxygen environments and "cooked" for an extended period of time to naturually and chemically alter the properties of the NMFC blend. This process, called thermal modification (torrefaction) results in the removal of the organic material (lignin) found in typical fibre products, and reduces the resultant material's ability to rot and moisture penetration. Wood products and their adhesives constitute more than $65 \%$ by volume of all the adhesives used in the world. ${ }^{41}$ Important wood industry research in green chemistry 42 calls for the elimination of toxic aldehydes as wood panel adhesives and the adoption of various bio-sourced adhesives and composites used with cellulose. ${ }^{43}$ In producing a bio-based SIP, this project aims to embrace the emerging field of green adhesives and organic laminates compatible with NMFC.

While mechanical properties of fibrillated cellulose mixes are complex, they are best evaluated with methodologies

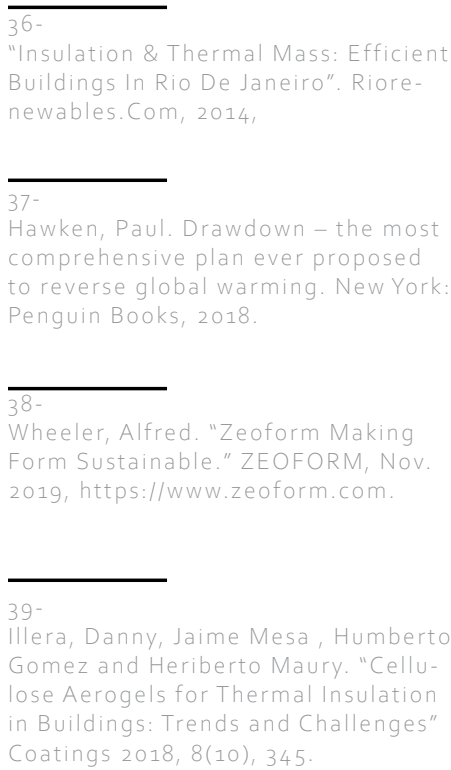

Wheeler, Alfred. "Zeoform Making Form Sustainable." ZEOFORM, Nov. 2019, https://www.zeoform.com.

39

Illera, Danny, Jaime Mesa, Humberto Gomez and Heriberto Maury. "Cellulose Aerogels for Thermal Insulation in Buildings: Trends and Challenges" Coatings 2018, 8(10), 345 .

Pizzi, Antonio. Wood products and green chemistry. Annals of Forest Science, Springer Verlag/EDP Sciences, 2016, 73 (1), pp.185-203.

lbid.

Illera, Danny, Jaime Mesa, Humberto Gomez and Heriberto Maury. "Cellulose Aerogels for Thermal Insulation in Buildings: Trends and Challenges" Coatings 2018, 8(10), 345 . 
relevant to their application. ${ }^{44}$ As the project moves forward, the interdisciplinary research conducted with Carleton University's team of civil and mechanical engineers will generate data sets

Dufresne, Alain. (2012). Nanocellulose From Nature to High Performance Tailored Materials. Berlin: De Gruyter, 2012

of the material's properties. Using standard ASTM tests for SIP panels and fibre-based boards, we will aim to show the products relevancy in the Canadian climate while also exploring additional modification techniques that can suit the more humid environments of the developing world. These material properties will serve as design development parameters for overall design, material connections, and its in-situ deployment.
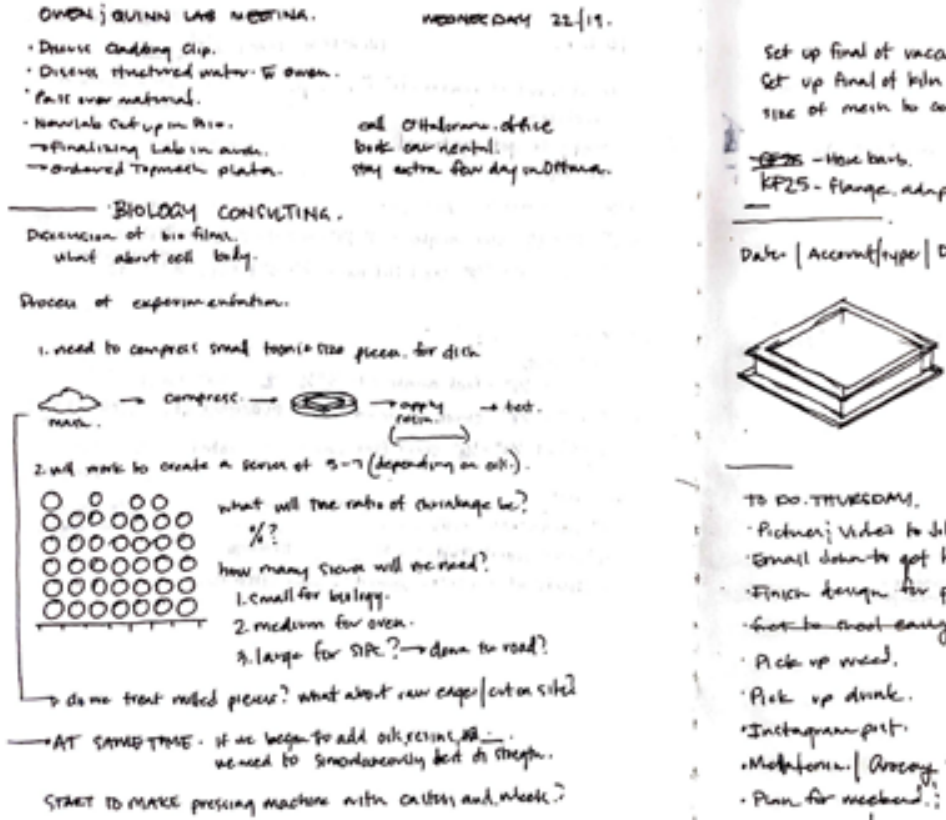

to Do. Truxcom

- Picturerividea bo Jill. (com to use).

- Email doknto sef boperesh.

Finica deregr fir prese.

that bo mod eany (Brad)

Act ue weel.

Pitk ve dirik.

Inctagrament.

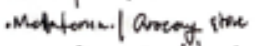

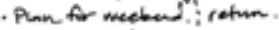

rade for Aual 


\subsection{STRUCTUALLY INSULATED PANELS}

While prefabrication can take on many forms, Structurally InsulatedPanels(SIPs) have becomea key playerwithin the building industry for its lightweight, structurally sound, and dimensionally accurate qualities. Using these elements as a point of departure, this project pairs current academic and professional research that confirms the success of nano-fibrillated cellulose as a durable and sustainable material for use in a variety of products due to its abundance, high strength, low weight and biodegradability. 45

Originating after the first World War, prefabrication took a notable stance in the industry with higher efficiencies and innovative materials like polyurethane foam or (PUR), (XPS), and (EPS). The prototype design of SIPS, which is remarkably similar to today's technology, fills two roles in a building simultaneously: firstly, acting as the structural walls that support vertical and horizontal loads and secondly for creating an airtight building envelope. ${ }^{46}$ Today, SIPs are manufactured to suit a variety of uses from commercial and industrial settings, to residential and small temporary structures. ${ }^{47}$ Their range of sheathing materials include sheet metal, plywood, fiber-cement siding, magnesiumoxide board, fiberglass mat, gypsum sheathing, composite structural siding panels, and can often be referred to as structural foam panels, foam-core panels, stress-skin panels, and sandwich panels. ${ }^{48}$ With the added benefit of R-Value customization, structural rigidity, and acoustical performances, SIPs have the ability to become a modern alternative to traditional timberframed construction, while simultaneously providing additional environmental benefits by reducing on-site construction time and waste. ${ }^{49}$ Congruent with the implementation of new
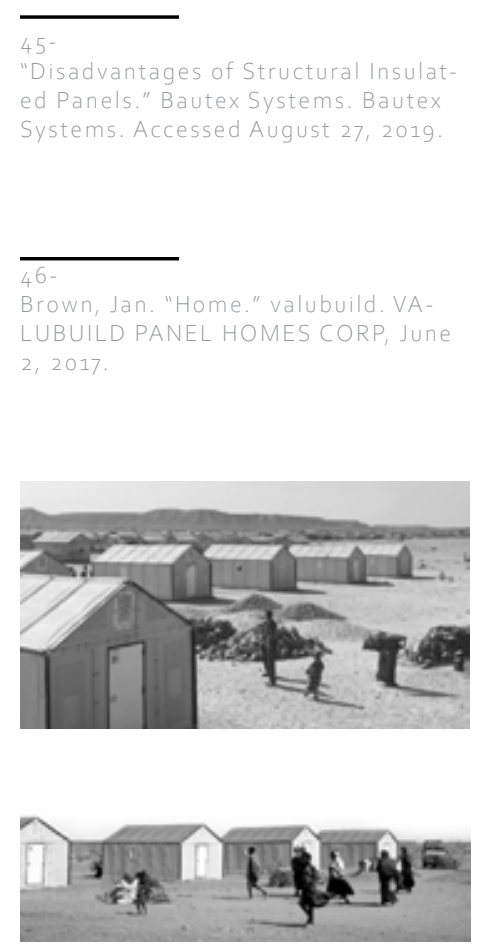

Fig. 022: SIP in context - IKEA factory built home

Fig. 023: SIP in context - IKEA built home 2

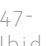

lbid

48

laddic Shelters. "Global Mobile Factory: Construction: SIP Panels," 2005

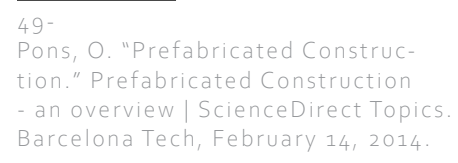


environmental standards within the building industry, SIPs offer significant advantages not only in the residential housing market but also toward disaster relief, emergency shelters and largescale regional housing shortages. ${ }^{50}$

However, academic, and professional research has identified SIP manufacturing as an environmental concern as its subsequent processes use heavy adhesives with sometimes toxic emission 50 Pacheco-Torgal, Fernando, and Luisa F. Cabeza. "Eco-Efficient Construction and Building Materials." Science Direct. Woodhead Publishing Limited 2014

outputs. This thesis directly addresses SIP construction by demonstrating new found solutions for recovered material feedstocks. ${ }^{51}$

Teedranon | Neboser

Manounk: Pup requed to create bulding bock.

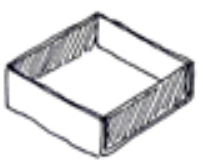

two piece nowle.

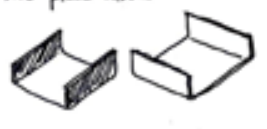

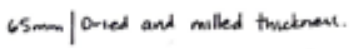

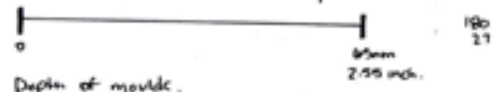

Depten of monke.

wet colliok in ottana, $8 \mathrm{~L}$

Band of PAP I 180K net

$\rightarrow\left(\left(y^{2}-y^{\prime}\right) / y^{\prime}\right) \times 100$
$=((27-190) / 27) \times 100$

$=-85 \%$

$10 L-85 \%=1.5 L$ of dy

Addetienal pup is reagrred to make blocke.

- Mnet be flat

- minimim of $250 \mathrm{mmix} 250 \mathrm{~mm} 400 \times 400$

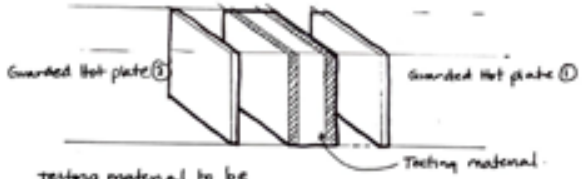

Terting material to be

$250 / 300 \times 200 / 300$.

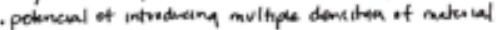

(1) Derke byen of zedirm pulp. (

(2) Nenget layer of zedorm p-p C

(3) Dense layer of retorm plp. (

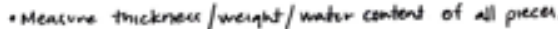

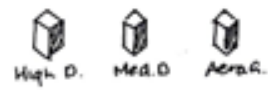

mearue] blend prece. [mosid.

(1) measure torrifuetion wen.

make bitt ot motal ard proce.

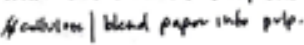

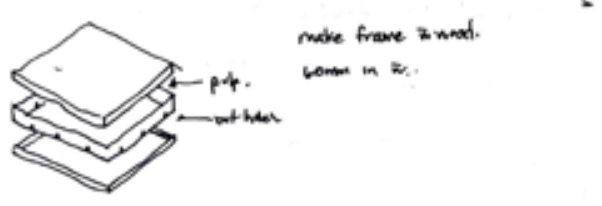




\subsection{SIPS IN CONTEXT}

In the face of growing public awareness an concern for the environment and new information regarding the impact of building materials in this landscape, there has been a resurgence of interest in sustainable alternatives and environmentally conscious design. The United States Energy Information Association estimates that the building and construction industry alone contributes to almost $40 \%$ of the total energy use in the United States. ${ }^{52}$ Buildings offer significant opportunity to increase performance while aiming to lower operating costs and its carbon footprint. 53 Designers and organizations have the opportunity to become leaders in this changing landscape by making critical and informed decisions on how they source and integrate materials in their design proposals. While advances in material innovation are taking place rapidly across the world, the industry still faces challenges in its ability to integrate new materials into a workforce comprised of conventional labourers. This gap has been further exaggerated by developers who seek low up-front costs with little consideration for a materials' lifetime operation performance. Furthermore, the building industry is multi-layered, with many different professions (manufacturers, architects, contractors, plumbers, electricians, laborers, and clients) who must all take leaps simultaneously to be truly innovative.

In recent years, interest in SIP design has grown due to the introduction of streamlined assembly processes and technology, reduction of construction time, and subsequent reduction of onsite labour. ${ }^{54}$ SIP deployment has maintained traction within the US in recent years while other countries like Canada, Europe, and Central America it is gaining momentum due to the rise in 52-
US Energy Information Association.
Accessed: October 215t 2014

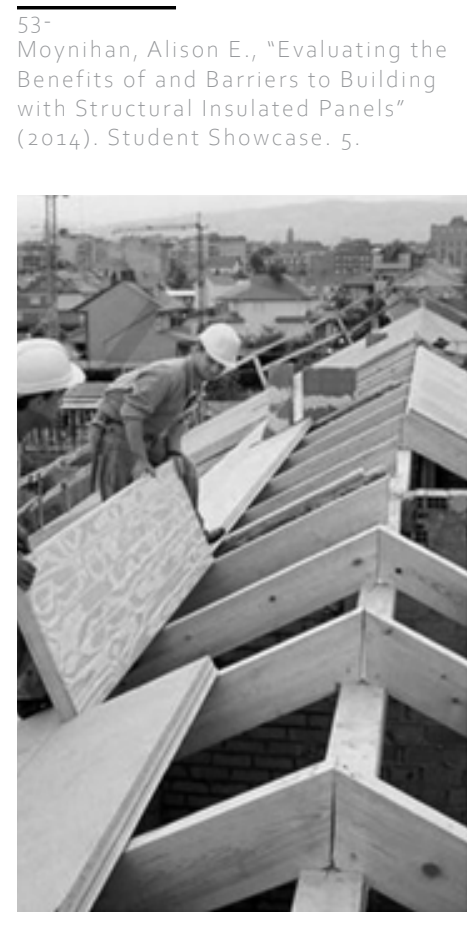

Fig. 025: SIP in construction. Sips can be handled by 1 or 2 working men or crane lifted into place.

Maynard, N. 2010. Structural insulated panels have many fans, so why don't more builders use them? Build. er. August 3oth, 2010. 
televised networks of tiny homes and off-grid living.

In the context of Brazil, building materials generally comprise of stone-based materials like brick and concrete, but new developments in fibre based compoents are beginning to take shape in these regions as innovative technologies continue to integrate themselves around the globe. ${ }^{55}$ Upcoming and ongoing investigations of cellulose-based materials will prove vital to cement as it is not only a wood-based replacement, but also as a cheap additive to manufactered stone based composites. Organizations like MateriaLabDesign, based out of Sao Paulo, have already joined the conversation of material sustainability by using new social platforms and design as an iterative tool for greater social impact. ${ }^{5}$

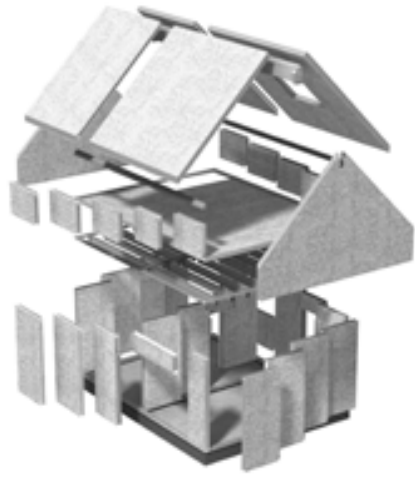

Fig. 026: Exploded Axonometric of Struc turally Insulated Panel Construction

55 Cairns Regional Council, "Sustainable Tropical Building Design: Guidelines for Commercial Buildings," 2011.

Kulb, Tania, and Carol Piccin. "Materialab Design". Materialab.Com.Br. 2017, http://materialab.com.br/.

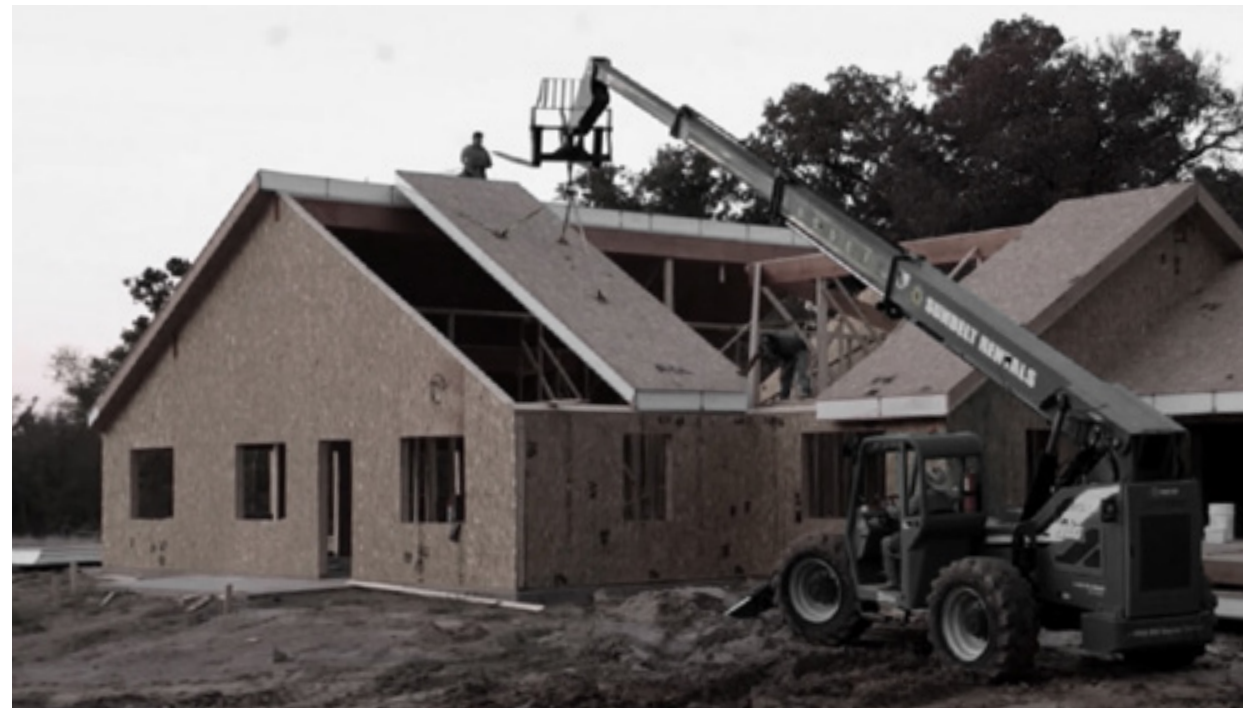

Fig. 027: SIP in context. Construction of full dwelling 


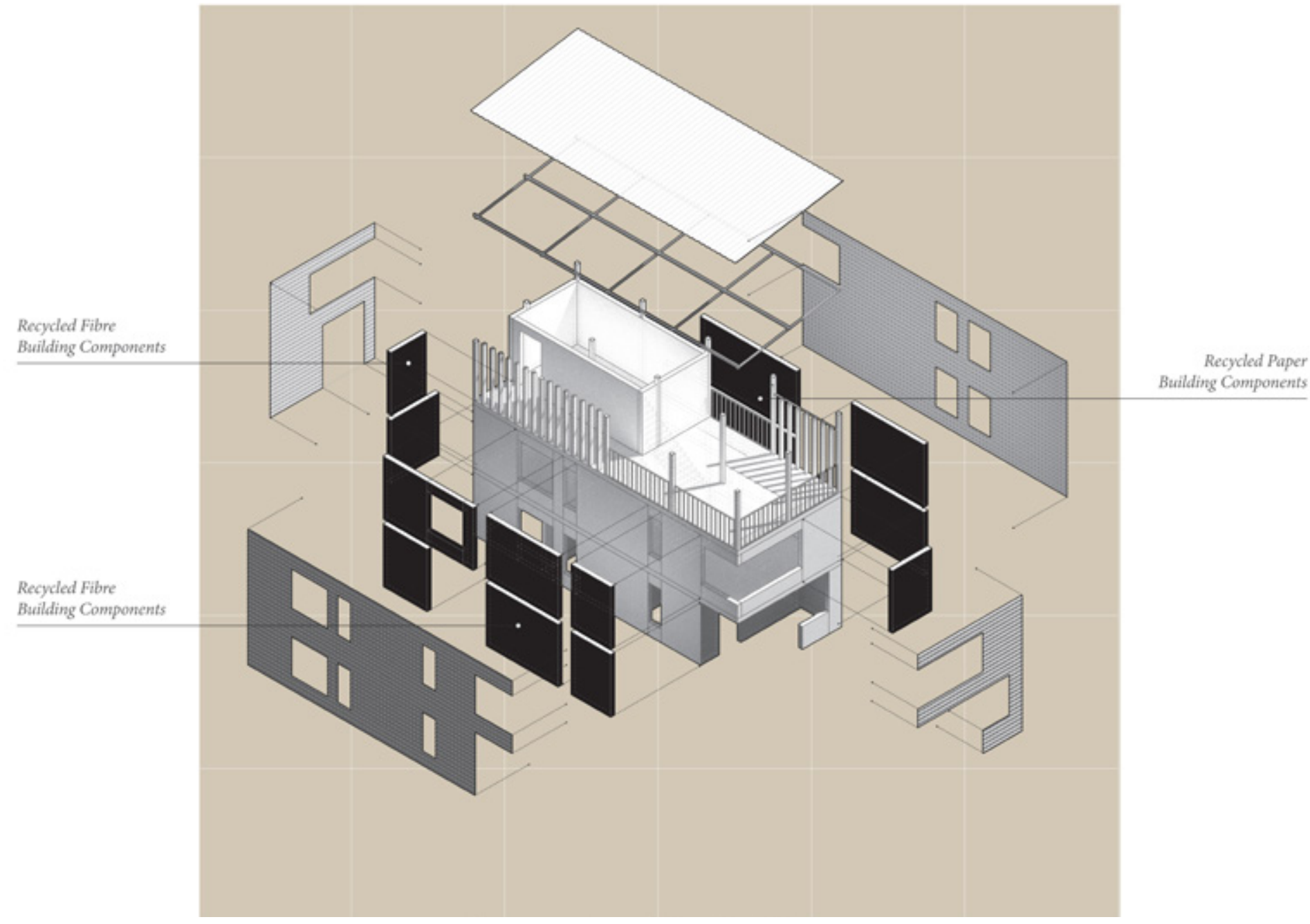


PART I I I 
3.0 RETHINKING THE WASTE CHAIN

Looking beyond our current take-usedispose industrial model, the circular economy gains

traction as it redefines growth and prosperity by focusing on positive society-wide benefits. 


\subsection{THE MAINTENANCE ECONOMY}

Values like innovation and newness hold mass appeal in governmental and industry leadership. ${ }^{57}$ This chapter explores broken and neglected urban infrastructures and their theoretical frameworks that have been deployed over time. Cities are built to sustain economies while collectivly supporting all its inhabitants and industries.

By focusing on the global South context for its sophisticated means of informal and formal recycling, this project identified regions of substandard, informal urban settlements often referred to as slums or favelas in Brazil, that were built on squatted land that lack adequate infrastructure, formal city involvement and support high population densities. These regions and the people who inhabit them often turn to filling voids in the formal economy such as recycling and maintenance through the picking, sorting, recycling of discarded objects or material..$^{8}$

Covering vast areas of Brazil, these favelas show significant potential in their eligibility for slum transformation and upgrading. If governments and industries were to address these regions, perhaps we can imagine a world where physical infrastructures support alternative ecologies to provide necessary physical settings for industries like the recycling sector. In order to fully understand this idea, we must first understand current waste management practices and social inclusive strategies. Perhaps this concept can be built through interventions at the juncture between formal recycling workers and the informal economy of recycling and maintenance.

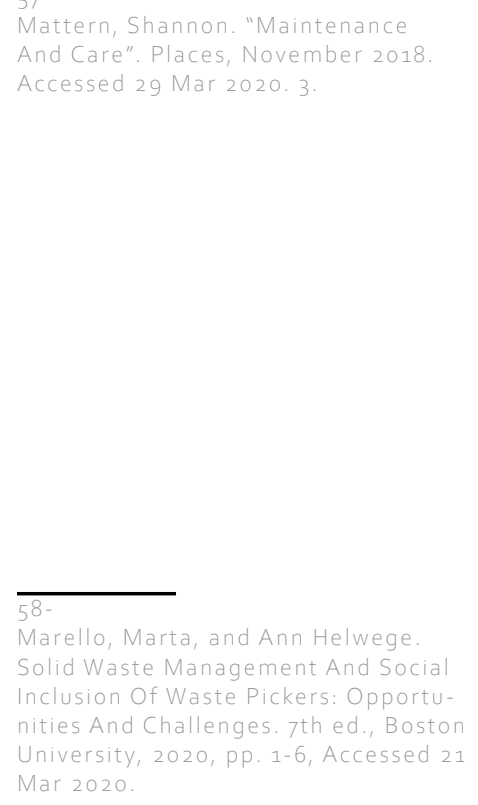

Mattern, Shannon. "Maintenance And Care". Places, November 2018 Accessed 29 Mar 2020. 3.

Marello, Marta, and Ann Helwege Solid Waste Management And Social Inclusion Of Waste Pickers: Opportunities And Challenges. 7 th ed., Boston University, 2020, pp. 1-6, Accessed 21 Mar 2020 
By providing frameworks and interventions that blur these boundaries in everyday engagement, we can then understand the value that social infrastructures play within this landscape.

This project aims to specifically address these economies by introducing new frameworks that not only support waste picker inclusion within Brazil, but allow new forms of social transformation to take place. Through education, innovation, recycling, engagement and inclusion, this project uses specific collaboration techniques to deploy its intervention at a variety of scales that will be addressed in subsequent chapters of this project.

Over time, society has pushed the labour of recycling and maintenance out of sight. These foundational concepts which are integral in our lives can be quite hard to see, let alone rearrange or modify. ${ }^{59}$ In the early development of European housing models, maids, cooks and cleaners were given back access to the house's formal circulation, allowing services workers alternative routes where families could not see the jobs and maintenance being performed. ${ }^{60}$ The recycling industry is no exception, our world's cities have developed sophisticated urban plans that keep waste out of the way. By understanding how these systems participate in our everyday life, this project can better contribute to the conversation that aims to blur these boundaries and introduce new concepts that embrace recycling, maintenance and repair as a designing tool, not only for objects and places but for greater socital inclusion and stronger economies.

Scholars in various fields have recently turned their focus to 'discard studies' which include material waste streams and their lifespans. ${ }^{61}$ Sociologist Jenna Burrel describes this shadow industry as a network of entrepreneurial refurbishment and secondhand trade. ${ }^{62}$ Burrell argues that the focus is not in designing new machines, but instead in "finding opportunities for agency and innovation" in their provisioning, repair, and distribution. ${ }^{36}$
60

Mattern, Shannon. "Maintenance And Care". Places, November 2018 Accessed 29 Mar 2020. 5-6

Ibid.

Jenna Burrell, Invisible Users: Youth in the Internet Cafes of Urban Ghana (Cambridge MIT Press, 2012), 14, 161, 180. 
Present in almost all developing regions around the world, these processes of transformation take place in the marginalized zones of cities and have been witnessed through countless professional photo-essay style assignments. ${ }^{63}$ But these shadow industries aren't always positioned in the background, these types of transformations take place largely in underdeveloped regions of the world ${ }^{64}$ Referred to as a social performance, Burrel illustrates how this industry is part of a public pedagogy, an 'operating theatre' where repair, innovation, and education can take place and encourage onlookers to engage by interest rather than as an ideology forced upon them, extending not only the value of the products they handle but also a mechanism of social interaction and transfer of knowledge. ${ }^{65}$ People gather, crowd, they watch and they learn.

In January 2020, I had the privilege to travel to Sao Paulo to study ideas of waste management, the circular economy, and cellulose recovery within the city. By engaging with varying local agencies and industries, this project is able to participate in social inclusiveness by proposing alternative systematic approaches to resource recovery within the informal and formal recycling economies of the city. By following the fundamental and biological cycles that our earth lives by, only then can we participate in a social metamorphosis that uses waste as a valuable resource rather than ignoring its potential while searching for more finite resources. ${ }^{66}$

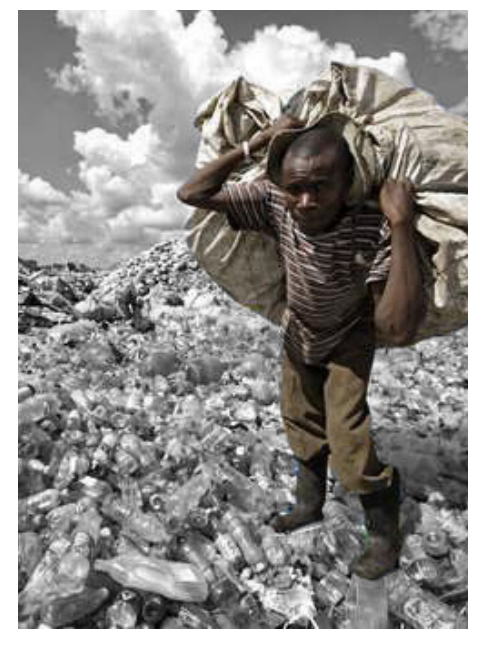

Fig. 029: Waste Picker in landfill outside city. 2016.

$63^{-}$

bid

Lisa Parks, "Media Fixes: Thoughts on Repair Cultures," Flow, December 16,2013

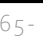

Mattern, Shannon. "Maintenance And Care". Places, November 2018 Accessed 29 Mar 2020.3

Moghaddamnik, Reza. "Blurring Boundaries: Waste As A Vehicle For A Social Metamorphosis". Dalhousie Univerity, 2013. 


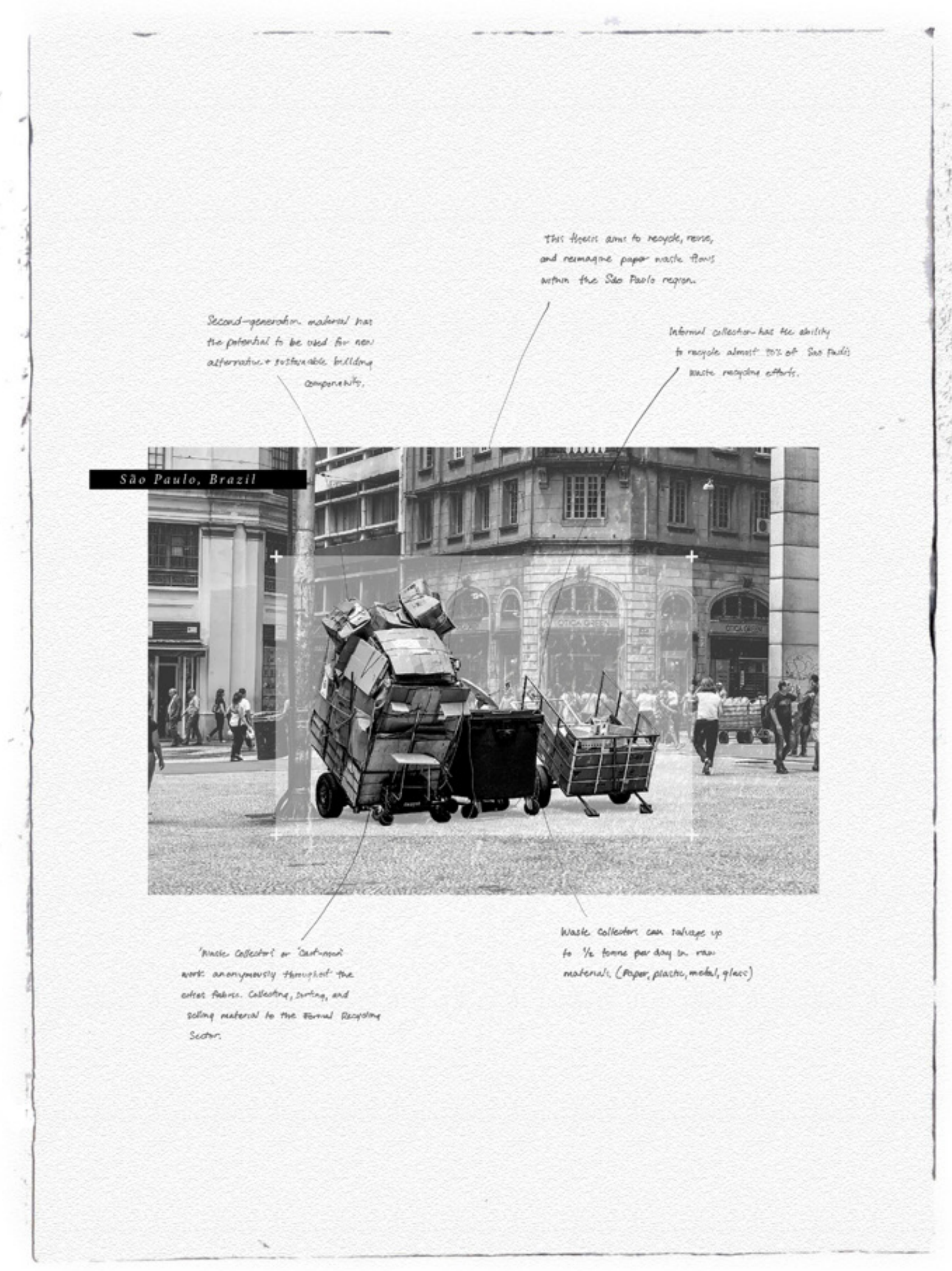




\subsection{THE INFORMAL WASTE CHAIN TODAY}

Throughout the developing world, waste management has been largely dominated by the Informal Waste Sector. ${ }^{67}$ Various examples around the world demonstrate that informal waste management can be both effective and challenging, reaching high levels of collection, material recovery rates, and sophisticated social structures. ${ }^{68}$ However, the adverse affects on the health of individuals involved in this system have gained international attention. This section sets out to understand these conditions by uncovering the many complexities of the recycling industry in various regions of the global South.

In the current scenario, municipalities, multinational organizations and waste management companies have struggled to work with the informal stakeholders - despite evidence of the commercial, environmental and social benefits of forming partnerships. ${ }^{69}$ The informal community, which is often seen as a subset to the formal economy, has been able to generate sophisticated systems throughout many cities around the world, including in India, South East Asia, and Latin America.70 (Fig: 69,70,71)

Through preliminary research conducted in this thesis, varying cities of the global South were chosen as case studies to identify how and where waste was consumed, treated, recycled, and processed. The following images depict zones, highlighted in red, of three separate cities where informal collection and sorting takes place.

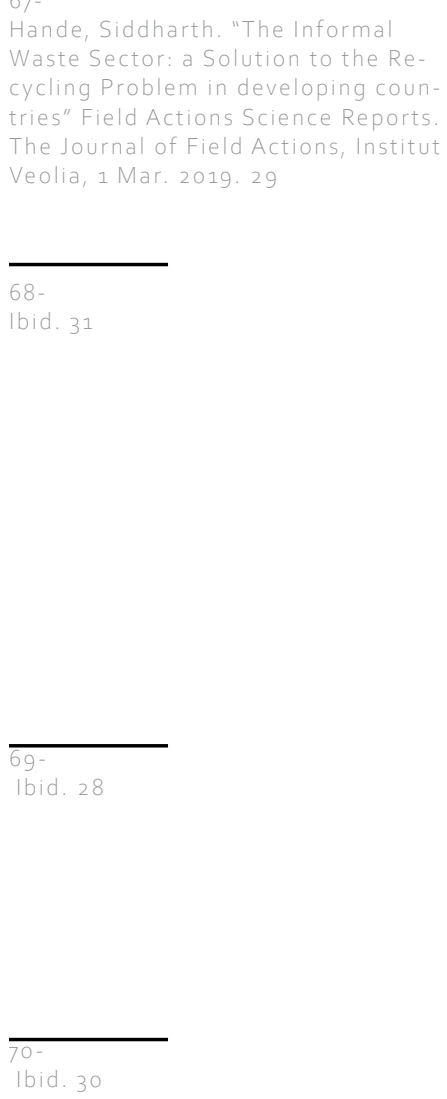



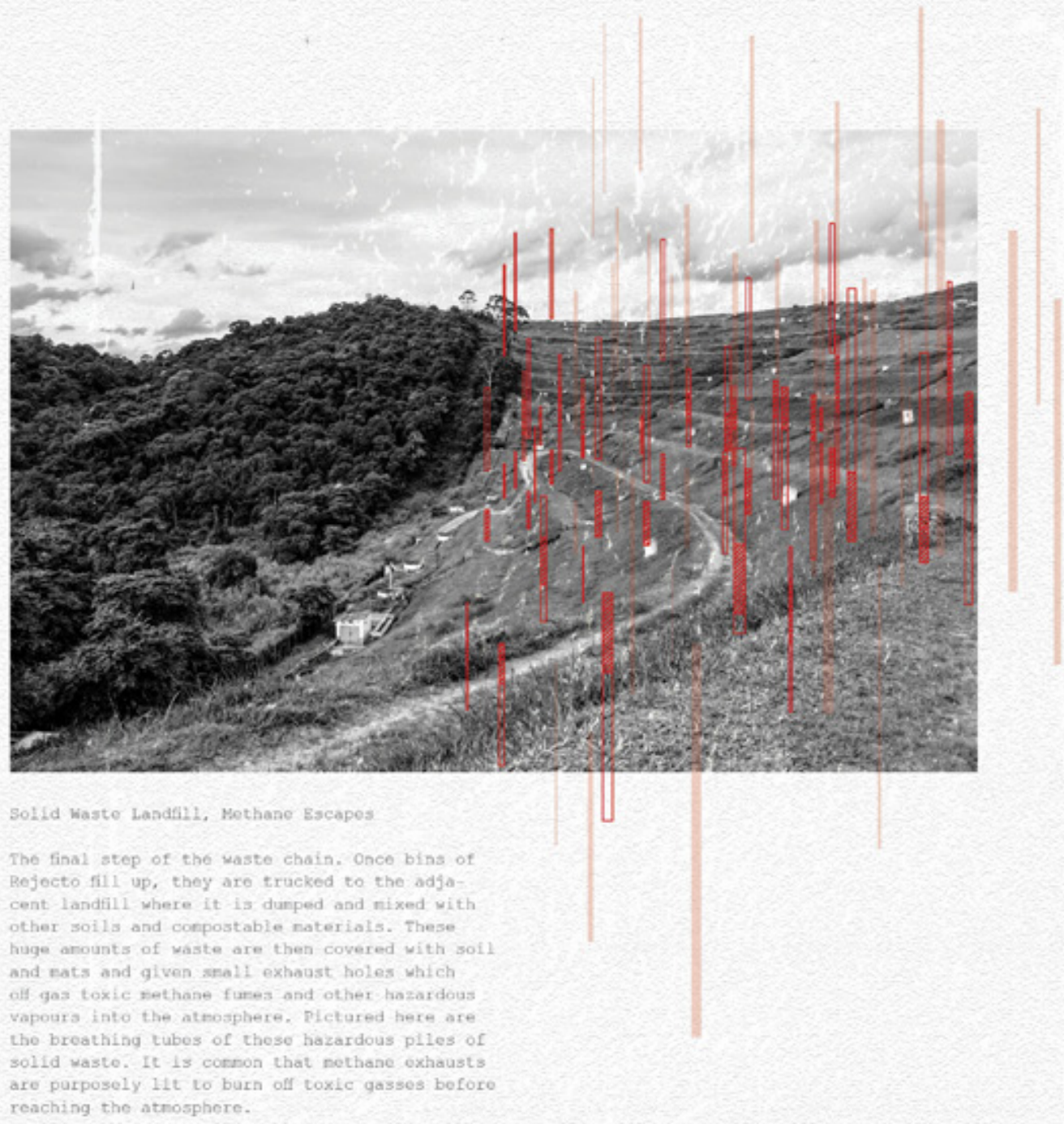


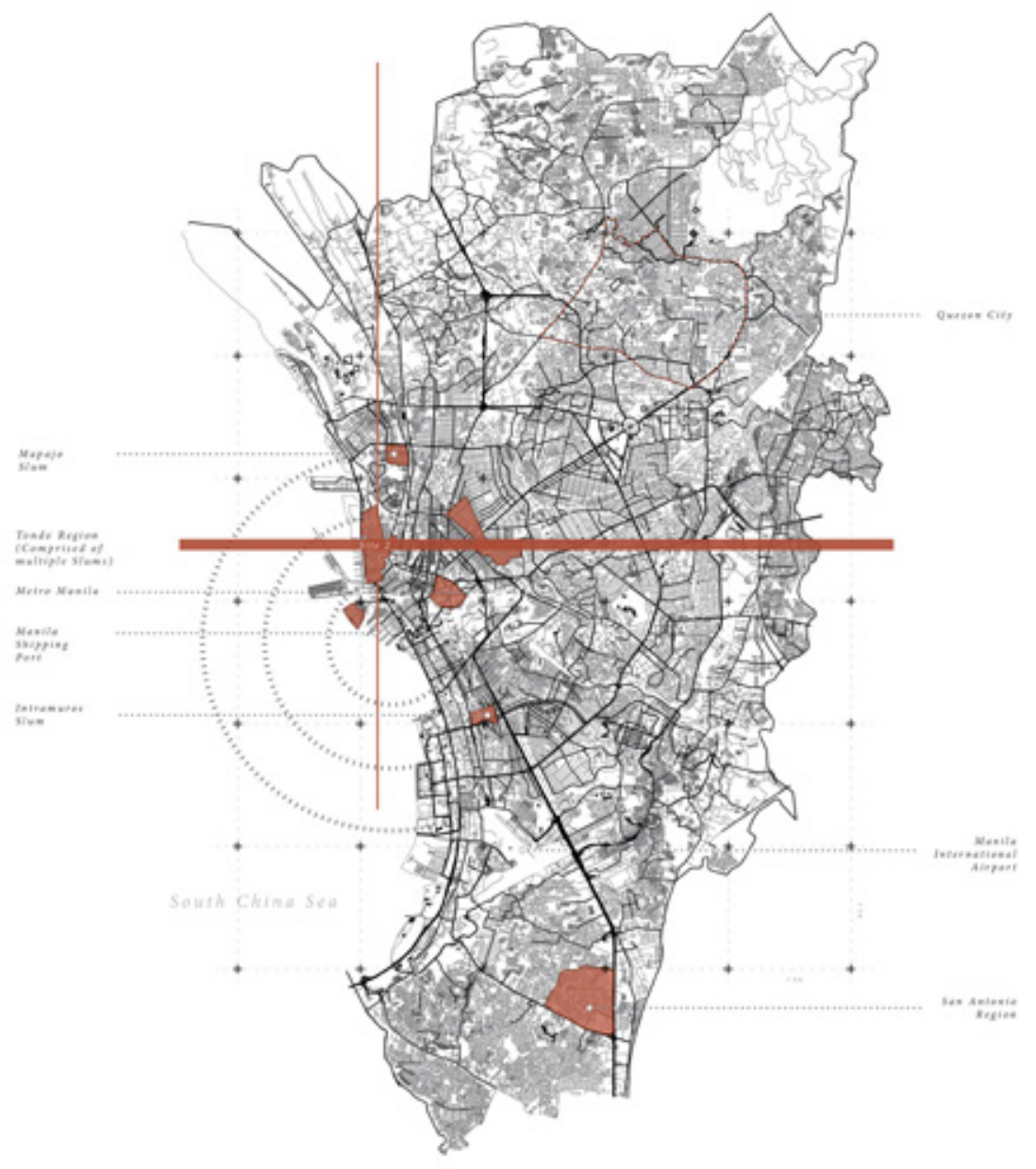

Fig. 032: Informal Settlements of Manila, Philippines.

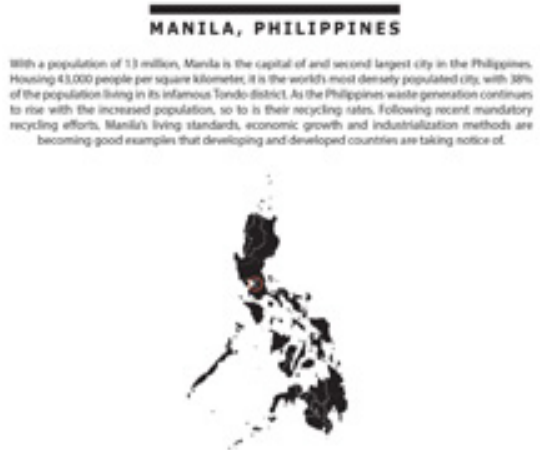




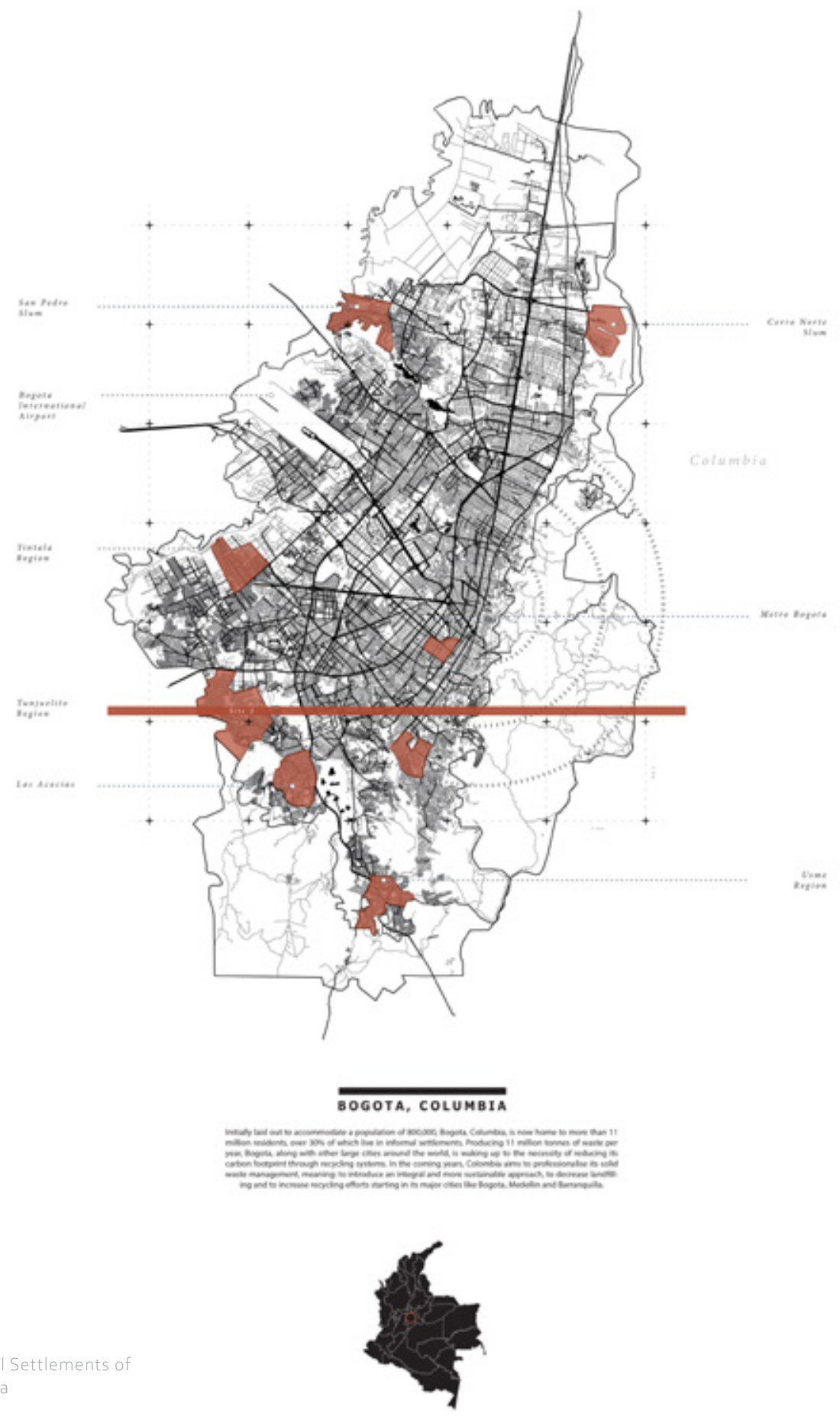




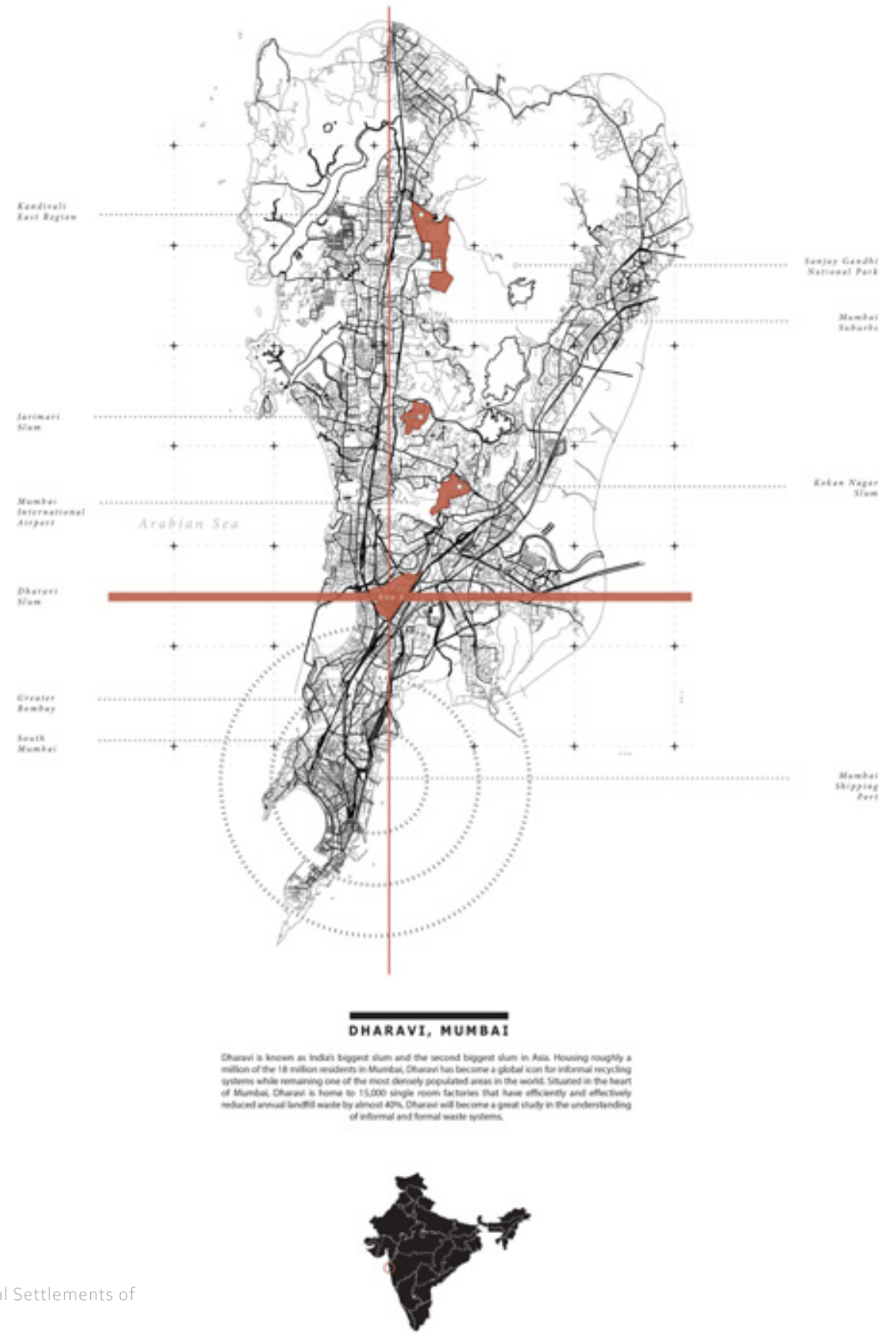


Globally, the informal community has consistently struggled with deploying systems that bridge the gap between the informal and formal markets. While they remain part of a centralized economy, the informal networks associated with waste collection often work in sub-par conditions, rummaging through landfills, collecting from streets and buying/trading between themselves. ${ }^{71}$

In the networks observed in varying regions of the global South (Latin America, India, Southeast Asia), the informal recycling chain is generally organized in ranks and defined by a series of Aggregators and Processors. ${ }^{72}$

Level 1 Aggregator: Waste pickers often operate solo with minimal to no input costs, collecting material from households, community businesses, or landfills where a constant material supply is found. ${ }^{44}$ Operating with no more than a cart or trolly, LIA can collect up to half a tonne per day in raw unsorted material. 73

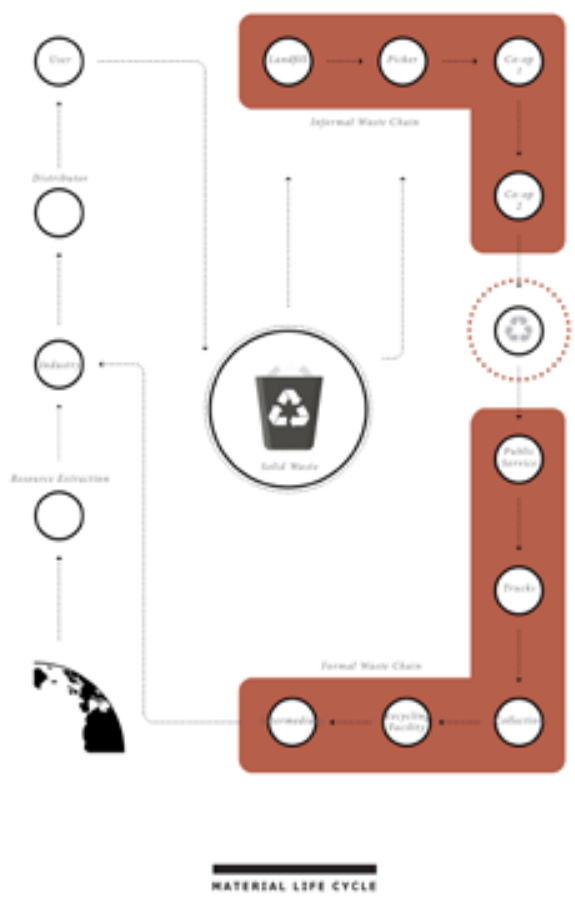




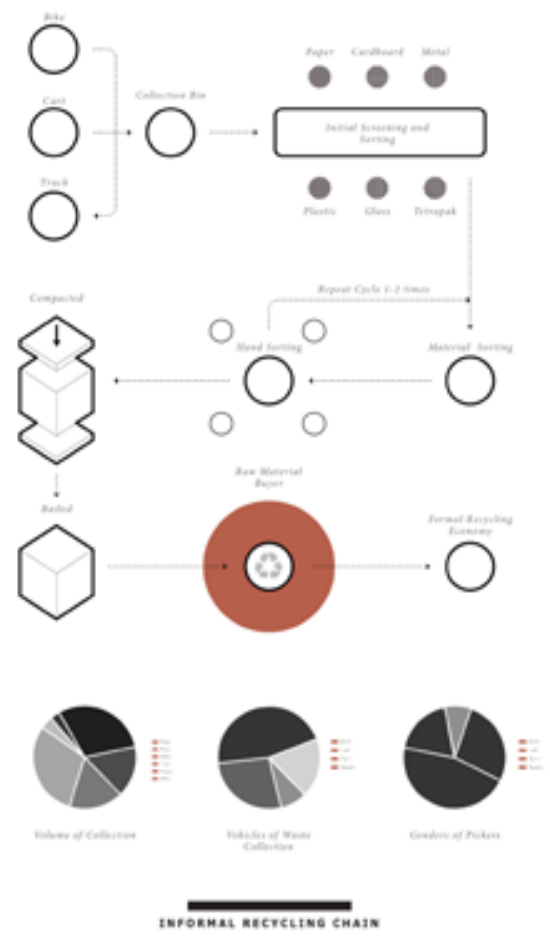

Level 2 Aggregator: Primarily buying from multiple L1 aggregators, L2 aggregators will often own their own private facility, often on their own property or in partnership with a local cooperative to handle greater volumes of waste. Working in sophisticated patterns throughout the city fabric, $\mathrm{L} 2 \mathrm{~A}$ begin to control the price fluxes of recovered material. ${ }^{74}$

Fig. 036 - Informal Waste Chain These images depicts the Materia Life-cycle and the Informal Recycling Chain in Sao Paulo, Brazil.

Level 2 Processor: At this stage in the InformalWaste Chain (IWC), sophisticated patterns of efficiency and sorting begin emerging in where and how aggregators sort and sell their material. L2 processors often maintain a steady flows of waste and by selling directly to before it is sold to the Formal Recycling Sector. Paper waste is sold in bails to later be shredded and processed in the phase called De-Inking. ${ }^{75}$

De-Inking: Due to the high costs of a de-inking facility, it is usually operated inside the formal recycling sector as it deals with massive quantities of recovered fibre material that needs to be cleaned, sorted, and separated from any unwanted contaminates like stables, inks and plastics. Due to the nature of the de-inking 
process, and much like the plastic recycling industry, fibre products take part in a down-cycling system where fibre strength is lost through chemical bleaching processes that occur in this phase. This leads to problems of two major kinds; material degradation creating a product of lesser strength each time it is recycled, and the loss of material value, provoking industries to maintain virgin extraction methods. ${ }^{76}$

Intermediary: Following the de-inking process, fibres which have been sorted and cleaned are then sold in large quantities to a series of intermediary businesses who then sell to distributors as a feedstock for new products. 7

Understanding the Informal Waste Chain is critical to this project's development as it strategically integrates itself into this system to provide new value to fibre products before being sold to intermediaries, distributors, and consumers. By providing new opportunities for paper recovery and demonstrating options to up-cycle fibre products back into society, this radical approach is able to take part in a social metamorphosis that reintroduces material back into the economy in the form of sustainable and biodegradable building components.

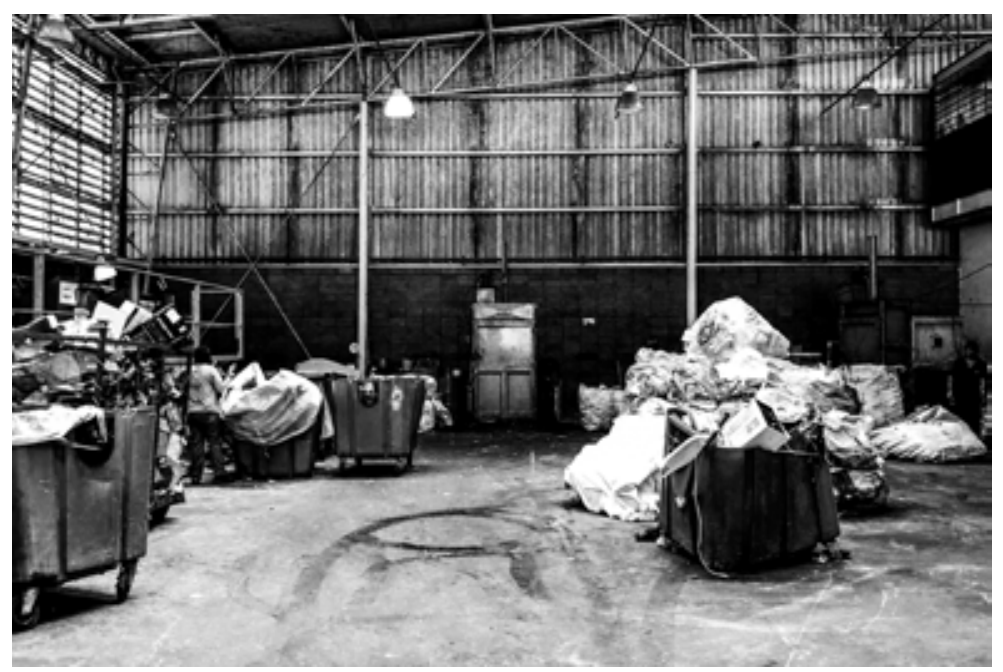

Bid. 32

Gutberlet, Jutta. "Sao Paulo Research Follow-Up". Skype, 2020 Fig. 037: Coopermar Cooperative, Sao
Paulo, Brazil. 2020 .
-The Coopermar warehouse where waste
pickers, drop off, clean, and sort material
in its appropriate waste stream. 
Waste picking around the world is currently a predominant or exclusive way for material to find its way back into the waste stream before incineration or landfill disposal. In nations like Brazil, informal waste inclusion is taking new steps towards sustainable waste management by providing additional supportive infrastructures and governmental support.

With the aid of technology and further transparency of global industries, waste picking is becoming commonly recognized as a driving force in the world of recycling. ${ }^{78}$ Despite the numerous environmental and social benefits of waste picker inclusion, the

78

M. de Azevedo, Adalberto, Sebastián Carenzo, Charles Goodluck, and Jutta Gutberlet,. 2016. Inclusive Waste Governance And Grassroots Innovations For Scoial, Envrionmental And Economic Change.. Canada: Recycling Networks and Waste Governance. community remains widely excluded from segments of society and in some regions is even illegal. These challanges give rise to persistent poverty and substandard living conditions within these nations, leading to the further discrimination and stigmatization.

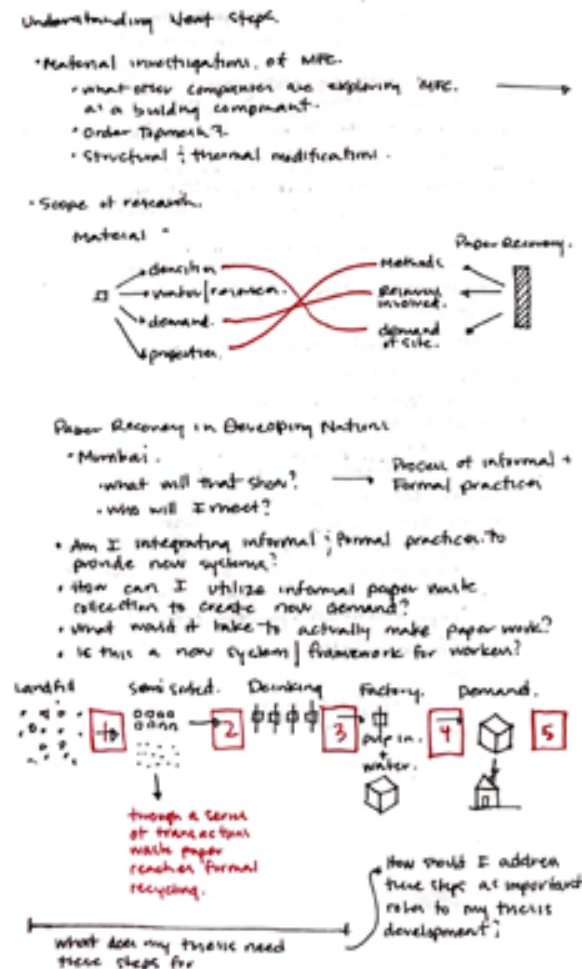

Nordic Marcke skap investhouting mec revened bo explese altermativer to product and plactios.

* Replacement on eninecred moed protuch and as hazandor material memifacturing and pudiction sperations.

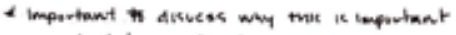
-bepletion natural resowert

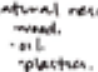
- Hamersing pewer ot recaverd fine pedich " Anding replacementi $n$ nen-withicast merufacturma techaiges.

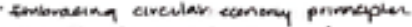

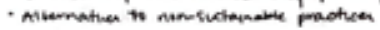

- what are the methods for cillechion

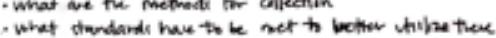
nimal pach hes.

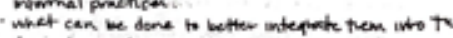
formal prestice.

- How wellox are informal recyelen to hey thu novk?

- Ane these sape betweesa treve metwods?

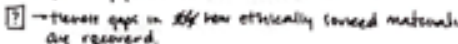

2 - wat is the proces from semisonted matomals to the formal deanking poeter.

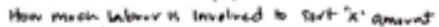
ot recovend matrial

ther mow energy, resarmes ave reapured in inim ins? 


\subsection{RETHINKING THE INFORMAL WASTE CHAIN}

Like most countries in the global north, the economic state of developing countries including Brazil has seen exponential growth and urbanization with growing concerns regarding the disposal of its waste. Until now, most urban local governments have adopted an approach to waste management that is neither sustainable nor responsible - identifying new landfill sites, filling them with mixed waste and eventually moving on to new ones. ${ }^{50}$ This linear model, which has become a growing concern for many municipalities, is radically affecting the contexts in which they are sited, leaking hazardous runoff and leachate into the soil and groundwater of surrounding ecosystems. ${ }^{79}$

This project identifies conventional solid waste management strategies and argues that adopting an integrated systematic approach can help not only the processes that generate waste, but also enables cities officials to minimize waste accumulation. ${ }^{80}$ Using a community-based approach with the aid of local experts and agencies, this project integrates itself within the waste chain, aiming to re-route existing flows back into the economy. These ideals, which employ a circular economy model, can be further supported when all acting stakeholders of the waste chain understand its intentions. ${ }^{81}$

Throughout Brazil, and much of the developing world, solid waste management has become a high priority for policy makers and governments alike. In addition to the Formal Recycling Sector (FRS) there are a range of robust waste 'experts' or catadores in Brazil, that collect, transport, and recycle to make a living out of waste, albeit under the radar of the formal economy. ${ }^{82}$
79-'
Boyd, Toby. "The Informal Economy in Developing Nations: a Hidden Engine of Growth." The Informal Economy in Developing Nations: a Hidden Engine of Growth, World Intellectual Property Organization, 6AD
Hande, Siddharth. "The Informal Waste Sector: a Solution to the Recycling Problem in developing countries" Field Actions Science Reports. The Journal of Field Actions, Institut Veolia, 1 Mar. 2019. 29

Oteng-Ababio, M. Rethinking waste as a resource: insights from a low-income community in Accra, Ghana. City Territ Archit 1, 10 (2014). https:/l doi.org/10.1186/2195-2701-1-10

Miranda Ribeiro, Flávio de. "From Informal to Providers: A Sao Paulo State perspective for waste pickers at Brazilian Solid Waste Policy" "Waste Pickers At Solid Waste Policy. Oecd. Org, 2016. 5 . 
These informal pickers consist of not only grassroot level waste collectors but a series of middlemen who aggregate, sort and transport waste to the appropriate recycling facilities. Informal collection offers many advantages over the FRS as it effectively reduces the amount of waste ending up in local streets and landfills. Collectively operating in the hundreds of thousands, collectors and pickers often contribute to almost 90\% of their cities' recycling efforts, resulting in billions of dollars a year saved in waste processing fees. ${ }^{83}$

While these staggering numbers allude to the significance of the IRS, little attention is given from the formal economy. Seen as scavengers in the city, formal society often turns a blind eye to their efforts and instead sees them as a nuisance within the urban fabric. Informal collectors deal with a range of challenging and problematic day-to-day conditions, working in sometimes extremely poor conditions like open air landfills or contaminated collection areas. Recent attention from academic research, NGO's, and government funded cooperatives are beginning to recognise picking as a viable occupation within the city by providing new facilities with appropriate care and personal protective equipment. ${ }^{84}$

With added governmental and industrial support, informal waste collectors can spur grassroots investments to reduce poverty while providing additional benefits to the socioeconomic and environmental conditions of these regions. ${ }^{85}$ Thus, new solutions can be hypothesized to create guiding principles that could then be adapted and applied within the global North.
Miranda Ribeiro, Flávio de. "From Informal to Providers: A Sao Paulo State perspective for waste pickers at Brazilian Solid Waste Policy", Waste Pickers At Solid Waste Policy. Oecd. Org, 2016. 5 .

Marello, Marta, and Ann Helwege Solid Waste Management And Social Inclusion Of Waste Pickers: Opportunities And Challenges. 7th ed., Boston University, 2020, pp. 1-6, Accessed 21 Mar 2020.

Alter Chen, Martha, and Vic Van Vuuren. Cooperation amoung Workers In The Informal Economy: A Focus On Home-Based Workers And Waste Pickers. 3rd ed. International Labour Organization And Women In Informal Employment: Globalizing And Organizing, 2017, pp. 10-21, Accessed 21 Mar 2020. 


\subsection{CHALLENGES + OPPORTUNITIES OF SOCIAL INCLUSION}

Waste picking is an anonymous venture, often working alone, the field is primarily dominated by families and microenterprises of women, children and elderly relatives. ${ }^{86}$ In general, the appeal of waste picking comes from low barriers of entry and decent profit margins as waste is has value and a steady supply chain. However, waste picking is seen as a negative role in formal societies as it can be difficult for workers to obtain sufficient recognition and proper workers rights. ${ }^{87}$ Resulting in lower class societies turning to city streets to collect, sort, and sell secondhand material for a living. This negative outlook on city inhabitants has exponentially grown in recent years and further divided the cities economies.

Notwithstanding, the informality of this work allows waste pickers to bypass much of the formal responsibilities that the FRS is forced to comply with, further creating a disjunction between the informal and formal economies. ${ }^{88}$ While innovative waste management strategies are taking centre stage, research conducted in this thesis will generate new paradigms and conversations around waste recovery and take part in a conversation of social inclusion. Although equipment could significantly raise productivity, waste picker methods are labour intensive due to the scale of operation and a lack of available governmental funding. ${ }^{89}$
$86-$

Marello, Marta, and Ann Helwege Solid Waste Management and Social Inclusion of Waste Pickers: Opportunities and Challenges - Marta Marello, Ann Helwege, 2018." SAGE Journals, Marello and Helwege. 2016

lbid

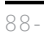

iBid. 5

Marello, Marta, and Ann Helwege Solid Waste Management And Social Inclusion Of Waste Pickers: Opportunities And Challenges. 7th ed., Boston University, 2020, P. 1-6, Accessed 21 Mar 2020 


\subsection{INCLUSION AS A SOLUTION \\ COOPERATIVES, TECHNOLOGY, AND POLICY}

Throughout much of Brazil, recycling cooperatives are becoming increasingly more sophisticated through municipal and state involvement to fund their working spaces, machines, and waste transport vehicles. Sao Paulo is home to between forty to eighty cooperatives, all acting at various levels of collection and sorting. ${ }^{90}$ Often under agreement with local municipalities, cooperatives are comprised of numerous waste collectors, sorters, and sellers who collect recyclables directly from households and shop owners. ${ }^{11}$

Through field work conducted in this thesis, it was observed that most cooperatives consist of large, open warehouses to conduct their operations. Split into varying zones, trucks first unload unsorted waste into large bins before it enters a conveyor belt system where workers sort waste by hand into their appropriate material streams. Materials with limited or no value, often small pieces of plastic, metal or paper, will remain unsorted and accumulates day-by-day in large containers at the back of the system. This conglomerate of materials, referred to as 'Rejecto' is a by-product of the recycling chain and often becomes the main supply for landfills and incinerators.

Subsequent zones in cooperatives include machine operated compactors, shredders, and forklifts to move bailed and compacted material. Warehouses have offices, kitchens, and lavatories as well as health and safety personal protective equipment.
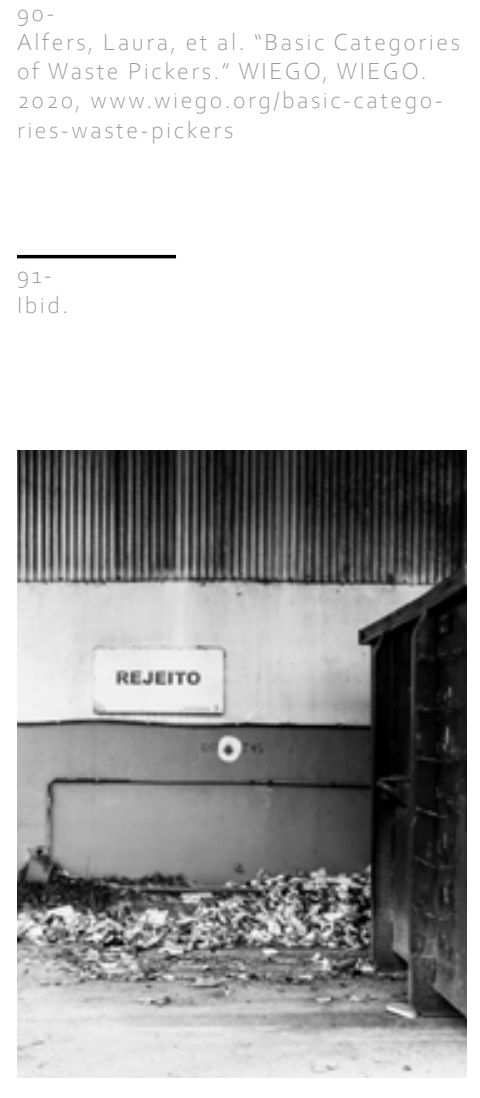

Fig. 039: 'Rejeito' The bi-product of informal recycling. 
Cooperatives' main objectives are to improve catadore livelihoods by defining strategies to increase the revenue from recyclables and by training catadores in sustainable business practices. ${ }^{92}$ Additional support will often come from the local development banks and NGOs. In contrast to the low standards of living among most Latin American waste pickers, some Brazilian cooperative members own cars and almost all own cell phones. They all wear uniforms and some use safety measures such as gloves and safety glasses while collecting. Nonetheless, they live well outside the mainstream of São Paulo's median standard of living and still face significant challenges for greater social inclusion. 93
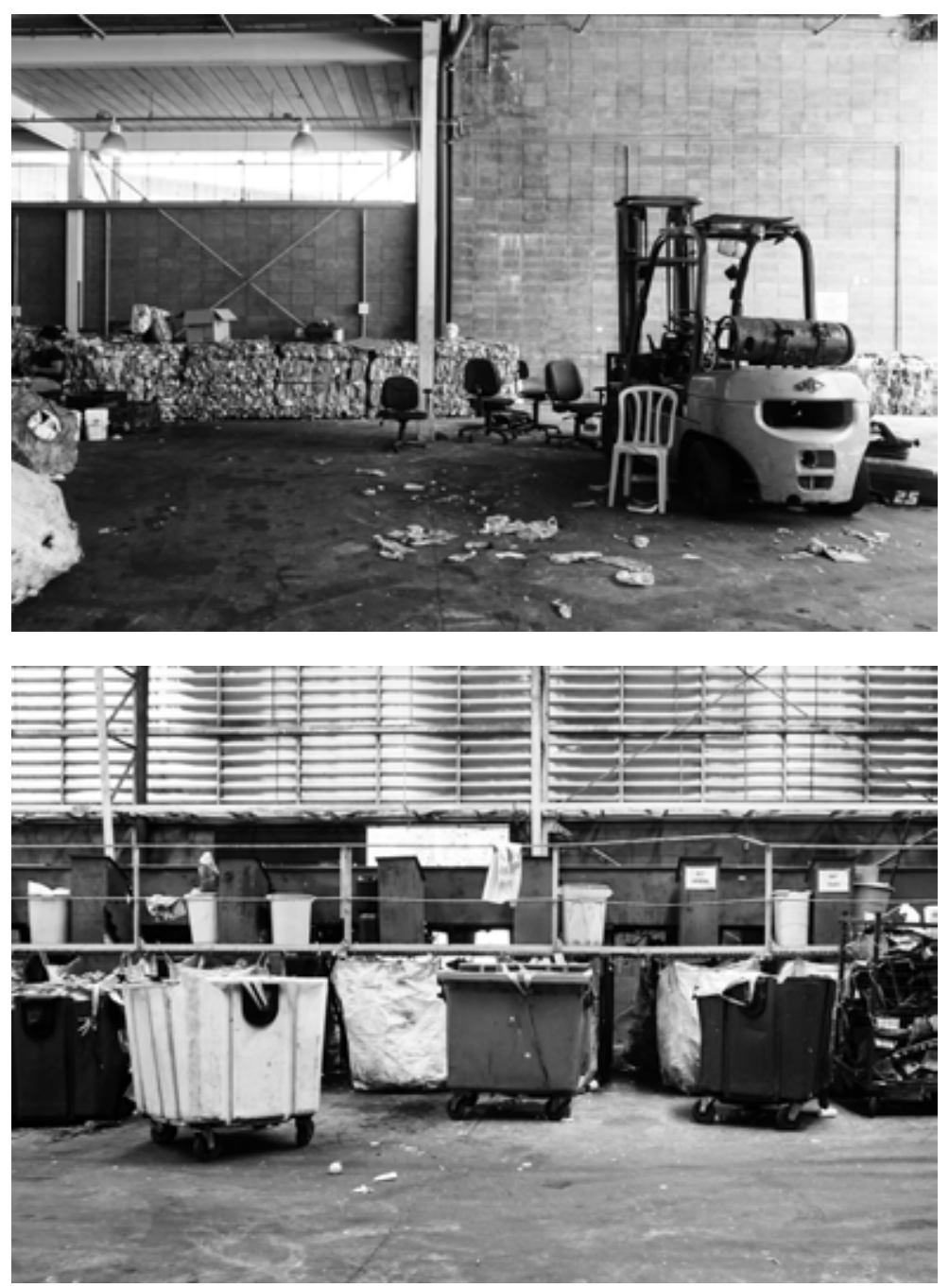

$\overline{92-}$ Ribeiro. "Selective waste collection in the São Paulo Metropolitan Region. impacts of the National Solid Waste Policy" Ambiente \& Sociedade, Health Sciences - University of Sao Paulo, Sept. 2017.

Ibid

Fig. 040: Image from Inside Cooperma Cooperative, Sao Paulo, Brazil
Fig. 041: Image 2 from Inside Coopermar Cooperative, Sao Paulo, Brazil 


\subsubsection{INCLUSION AS A SOLUTION COOPERATIVES, TECHNOLOGY, + POLICY}

As countries look for new methods of waste management, inclusion of the informal sector offers the hope of achieving higher recycling rates and greater economic cohesion. ${ }^{94}$ This chapter addresses the many complexities surrounding social inclusion and waste recovery techniques. Often referred to as an 'integrated solid waste management' strategy, organizations like The World Bank and InterAmerican Development Bank have both successfully funded waste picker integration through cooperatives, NGOs, and public private relationships. ${ }^{95}$ Advocacy organizations such as WIEGO ${ }^{68}$ have called for an intensification of such efforts through access to credit and technology, as well as through partnerships to collect recyclables in underserved communities. ${ }^{96}$ These measures have given many waste pickers higher standards of living, economic security and a sense of inclusion within society.

While collaboration between the formal and informal sector appears desirable, two trends can become apartment: the privatization and modernization of the waste sector. With each implying the other, both pose underlying threats to waste pickers, whether part of a cooperative or not. ${ }^{97}$ First, privatization would immediately add large competitors to the waste sector, but due to private corporations advnacing with technology-intensive systems, it would limit waste pickers access to material supply. ${ }^{8}$ On the other hand, this model holds a unique advantages where political involvement is leading the way for bridging these economies and their integration. It is common to see user-based data collection coming from many platforms around the city; notably through tech based programs like 'Cataki', a phone

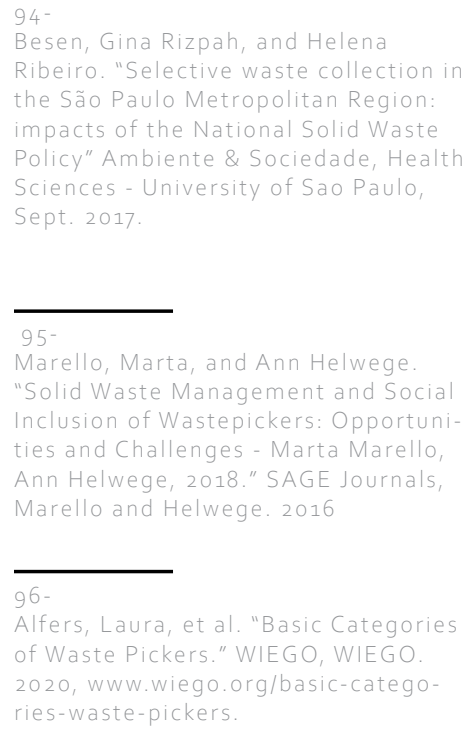

Marello, Marta, and Ann Helwege "Solid Waste Management and Social Inclusion of Wastepickers: Opportunities and Challenges - Marta Marello, Ann Helwege, 2018." SAGE Journals, Marello and Helwege. 2016

96

Alfers, Laura, et al. "Basic Categories of Waste Pickers." WIEGO, WIEGO. 2020, www.wiego.org/basic-categories-waste-pickers

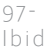

Ibid

lbid. 8 
based application designed in 2013 to aid in the efficiency and inclusion of the Informal Waste Sector. 99 'Cataki' is revolutionizing how waste pickers travel, collect and sort the waste from the city. Operating much like a dating site, pickers create online profiles with their collection vehicle and ideal waste streams. ${ }^{100}$ Allowing store owners or corporations to post pictures of their unwanted waste, which is geographically located within the app's mapping feature. With notifications, pictures, and descriptions forming the structure of the app, pickers can increase productivity, efficiency and contribute to alternative forms of waste management. ${ }^{101}$

Examples like these are increasingly present throughout Brazil and are creating precedents for other countries. These new options for waste pickers create deeper integration in society and helps promote the many benefits of integrated solid waste management. Frameworks provided in this thesis set out to understand not only current waste management practices of Sao Paulo, Brazil but aim to understand how the integration of new digital platforms can create alternative forms of recycling engagement within the city, concepts which will be described in subsequent chapters.

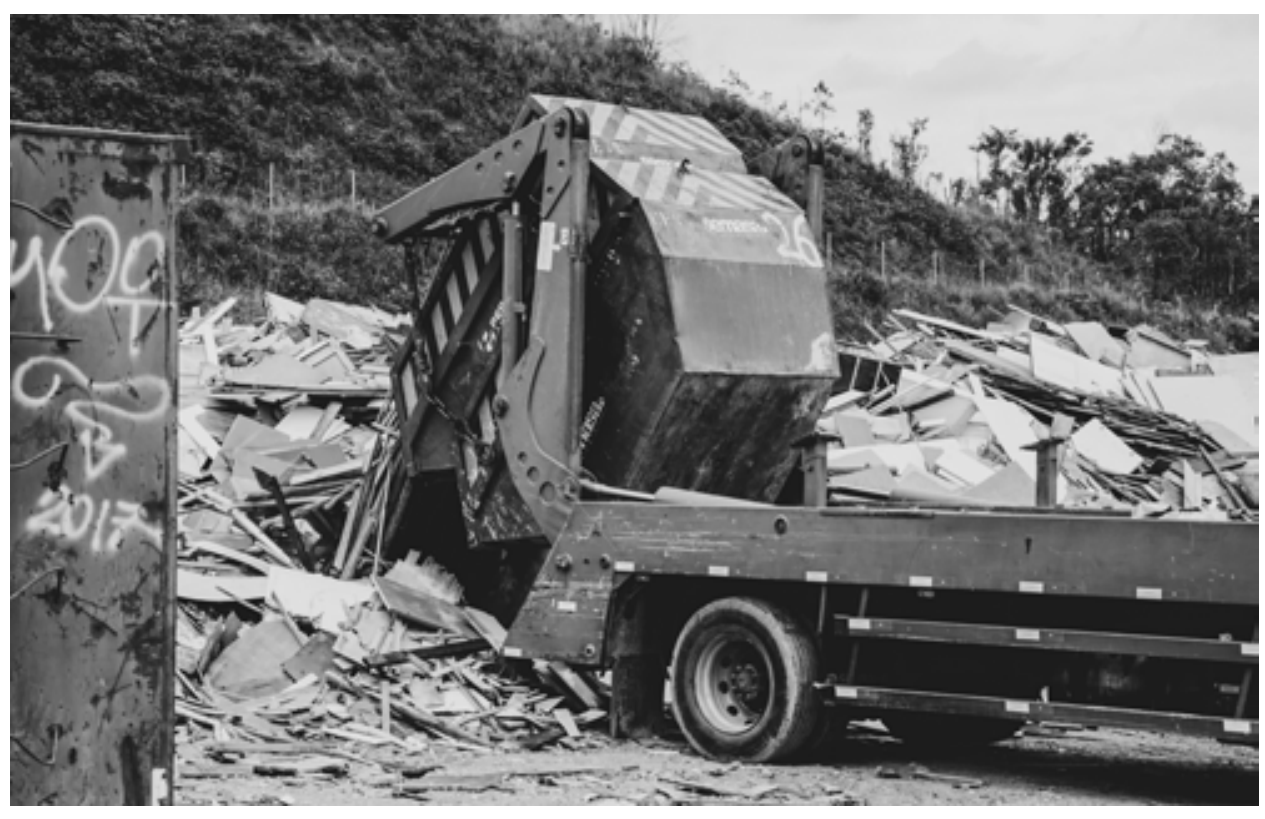




\subsection{SELECTIVE COLLECTION + FORMAL RECYCLING}

Waste collection is a public service in Brazil, following directives laid out by the Federal Constitution, recycling has become an integral part of the country's formal and informal economies. ${ }^{102}$ However, some municipalities have begun taking steps to introduce new partnerships within the informal and private sector. Their activities are interdependent but complementary, and make urban sustainability possible by advocating for more rational use of natural resources and inputs. Furthermore, it significantly reduces the final disposal of solid waste which generate greenhouse gases. ${ }^{103}$ In recent years, practices have been adopted by the formal economy that supports selective collection to enhance environmental and human health. These alternative models also embrace the concept of Walter R. Stahel's Performance Economy (PE). ${ }^{104}$ With a vision of an economy of loops, it aims to stimulate job creation, economic competitiveness, and waste prevention. Similar to a 'Cradle to Cradle' approach, the Performance Economy draws on several specific approaches that participate in a more Circular Economy (CE). With power in numbers, the PE is a labour force that is evidently present within the recycling industry.

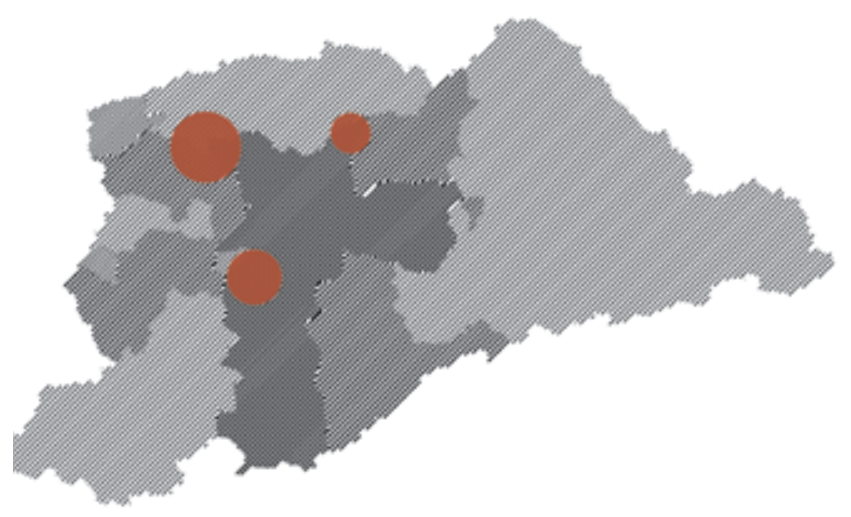

Carbonelli Campos, Juacyara, and Raquel Greice De Souza Marotta. Municipal Solid Waste in Brazil: A Review. 2nd ed., vol. 35, Federal University of Rio De Janeiro, 2017.

103

Alfers, Laura, et al. "Basic Categories of Waste Pickers." WIEGO, WIEGO. 2020, www.wiego.org/basic-catego ries-waste-pickers.

Stahel, Walter. "Circular Economy Schools Of Thought." Ellen MacArthur Foundation, Ellen MacArthur Foundation, 2016

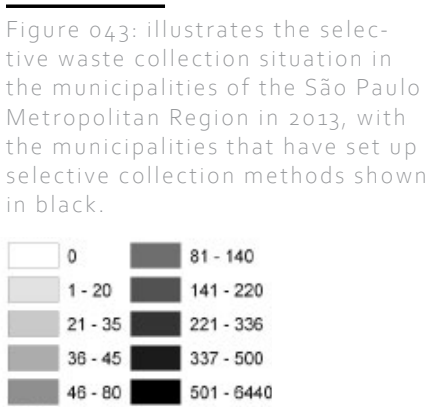


While many countries throughout the global South have identified the benefits of waste picker inclusion, many still lack the appropriate governmental action to do so. Additionally, research conducted by the Health Sciences department at the University of Sao Paulo illustrates how selective collection with the inclusion of waste pickers can increase volumes and efficiencies within the waste chain. ${ }^{105}$ Their research showcases the potential of inclusive waste management in semi-organized situations. This thesis builds upon this identified area of inclusive waste management to provide opportunity for the Level 2 Processor stage to take waste into a building product that can further assist in the inclusion of waste pickers as countries work to manage growing rates of solid waste.
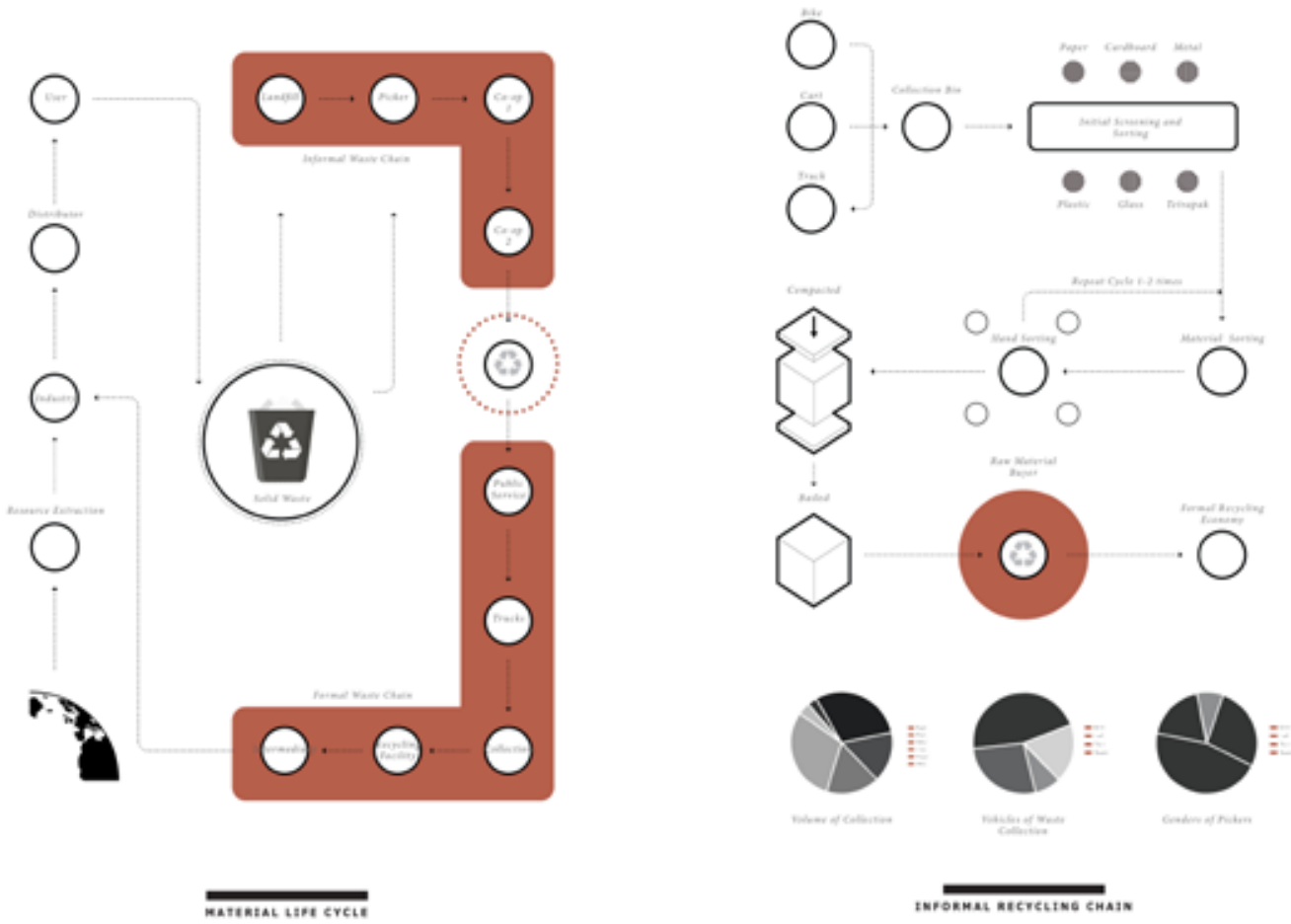

Fig. 044: Formal Waste Chain -These images depicts the Material Life-cycle and the Formal Recycling Chain in Sao Paulo, Brazil. 


\subsection{BUILDING FROM SECOND GENERATION MATERIALS}

Waste was once seen as a burden on our industries and communities; however, shifting attitudes and a better understanding of the depletion of natural resources has led to the identification of waste as a valuable resource that demands responsible solutions for collecting, separating, managing, and recovering. ${ }^{106}$ Over the last decade the holistic concept of a "zero waste" lifecycle has emerged as part of a cultural shift and a new way of thinking about materials after their product life span. ${ }^{107}$

Slums around the world have largely accepted recycling as a means of survival. In Sao Paulo, Brazil, the conglomerate organization of pickers has the potential to upgrade their living condition from objects discarded by the formal economy. ${ }^{108}$ By exploring recycled paper, bleached and unbleached pulps and various other cellulitic fibre types, this project aims to support a range of pickers who generally collect one main material, thus empowering an economy of paper collectors to provide additional inputs for the creation of new building components. First, it is important to understand some of the innovative products currently being made from waste in developing regions around the world.

\section{6}

Lehmann, Steffen. "Resource Recovery and Materials Flow in the City."

Sustainability Development Law and Policy, vol. 11, no. 1, 2011, pp. 28-29

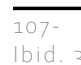

Ibid. 31

108

Dias, Sonia, and Lucia Fernandez. "Waste Pickers | WIEGO". Wiego.Org, 2020, 


\section{CASE STUDY 1: \\ PLASTIC LUMBER}

Plastic lumber has been developed and sold worldwide as a competitive alternative to traditional timber framed products. Produced by several manufacturers around the world, main uses have revolved around decking, roofing, and furniture. With increased global production and consumption of plastic, this material is well suited in its ability to turn old used plastic into structurally stable products that have the characteristics of extruded plastic. ${ }^{109}$ The use of plastic in place of lumber prevents deforestation and embraces circular economic principles in its ability to be recycled again into future plastic products. As the product is injectable, moulded or extruded, it has the ability to be blended with alternative agents to increase its fire-retardant and water-repellant qualities. However, the processes in which these products are made have extreme environmental consequences as they produce highly toxic off gasses. The advantages of up/recycling and less waste are commonly known, but also must be critically analysed alongside the disadvantages including the production of greenhouse gas, the negative carbon footprint and the offgassing side-effects of plastic lumber. ${ }^{110}$
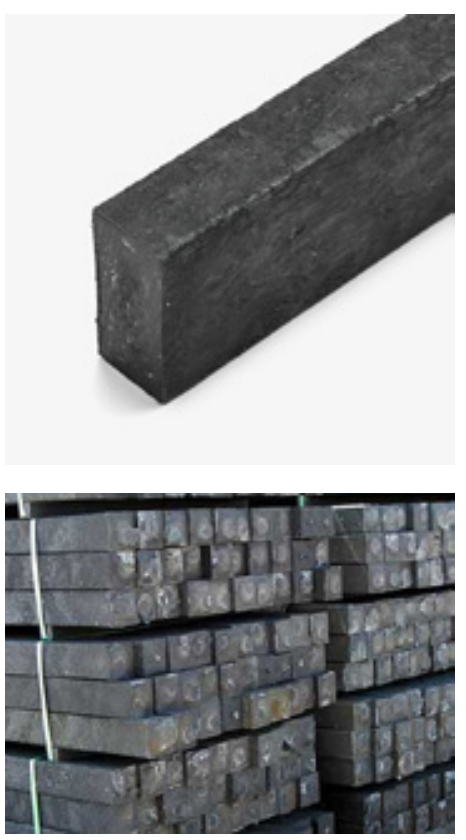

Fig. 045: Plastic Lumber Fig. 046: Plastic Lumber 2

109

A. dos Santos, Fernanda. "Processing And Properties Of Plastic Lumber" In Tech Open, Dec. 2018. Accessed 21 Mar 2020 


\section{CASE STUDY 2: \\ NEWSPAPER WOOD}

NewspaperWood is a relatively new innovative material that reverses the production process of making paper by making a wood-like material out of newspapers. NewspaperWood feedstocks include both pre- and post consumer recycled paper from printing presses in Eindhoven, Netherlands, where the material was developed and designed by Mieke Meijer with his company Vij5. ${ }^{111}$

The striking visual quality of NewspaperWood is its resemblance to natural wood. The manufacturer purposely cuts the many layers of glued newspaper that comprise the raw material to reveal dramatic curvilinear shapes resembling timber. Despite this close resemblance, it is evident upon close inspection that NewspaperWood is not a virgin lumber material. Nevertheless, it can be processed just like wood-including milling, cutting, and sanding. While this is a great example of ingenuity and design, it still lacks the ability to be recycled back into a form of production, due to the chemical nature of the binding agents and glues the material uses. ${ }^{112}$
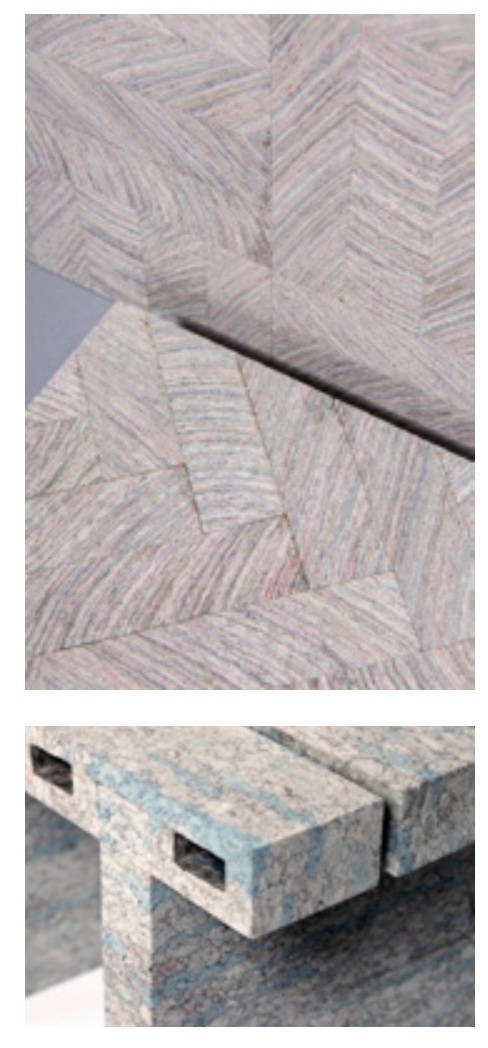

Fig. 047: Newspaper Wood 1 Fig. 048: Newspaper Wood 2

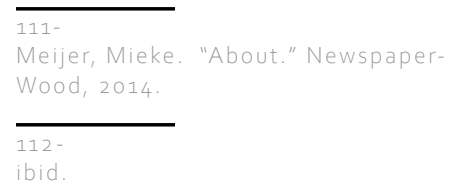




\section{CASE STUDY 3: MODROOF}

The modular roofing system named ModRoof is made from cardboard and agricultural waste. Founded by Hasit Ganatra, an engineering graduate from the University of Southern California who formed the company ReMaterials in India, it took 300 attempts in two years to develop the product. The cardboard is shredded and then blended into a pulp with the addition of water. Organic fibers such as cardboard, bamboo, and sugar-cane are added for reinforcement and the final mixture is poured into a mold with no harmful additives. It is cold pressed to extract the water in order to form the hardened panel. The panels are then heated and dried before a waterproofing paint is added. The modular panel can be interlocked with the surrounding panels, making it easy to install and maintain. ${ }^{113}$

ReMaterials is an exceptional example of a company that is striving to create alternative building components for the developing world. Furthermore, the material positions itself well within the global south for its easy material sourcing, production, installation and maintenance, which can mostly be done without specific sophisticated technologies. ${ }^{114}$

Understanding existing building techniques and material innovations within Sao Paulo is vital in understanding how and where new fibre based building components could fit within the economy. This chapter lists only a few of many innovative building materials being used throughout Brazil and other developing countries. Much like ModRoof, this thesis provides alternative material innovations that benefit from second generation feedstocks while preserving virgin resources and ex-
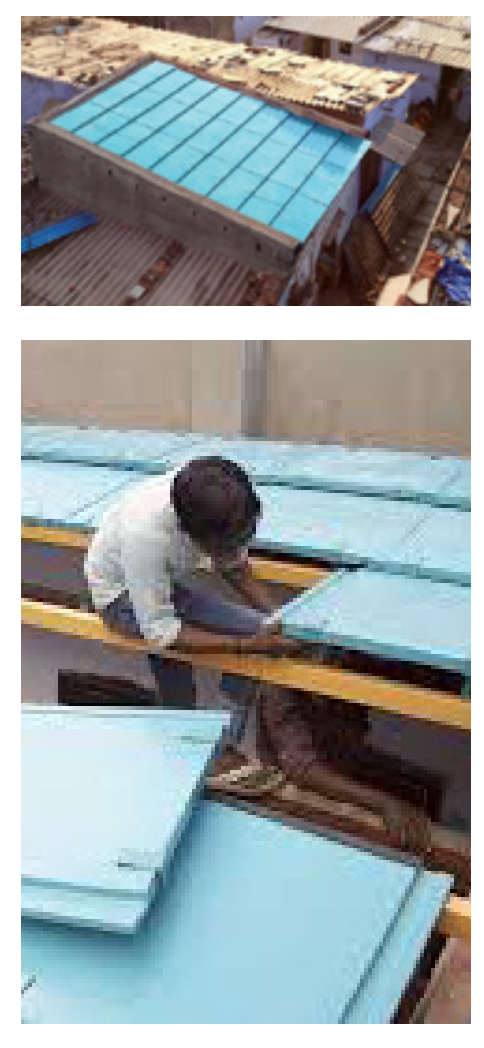

Fig. 049: Modroof 1 Fig. 050: Modroof 2

Ganatra, Hasit. "High Quality Affordable Roofing." Modroof. 2017 https://www. modroof. 
cluding the use of any toxic adhesives. The critical new element is a technique for processing paper waste called fibrulation.

Helping illustrate the growing potential of NMFC, a series of designs for architectural building components will be produced to demonstrate NMFC and its processes as a viable solution for self-sourced building components to be made available to waste pickers in Sao Paolo.

Using the natural high strength hydroxyl bonds of fibres in NMFC blend, this thesis reimagines recovered paper and cardboard and will create prototype building components that take place in a circular economy.

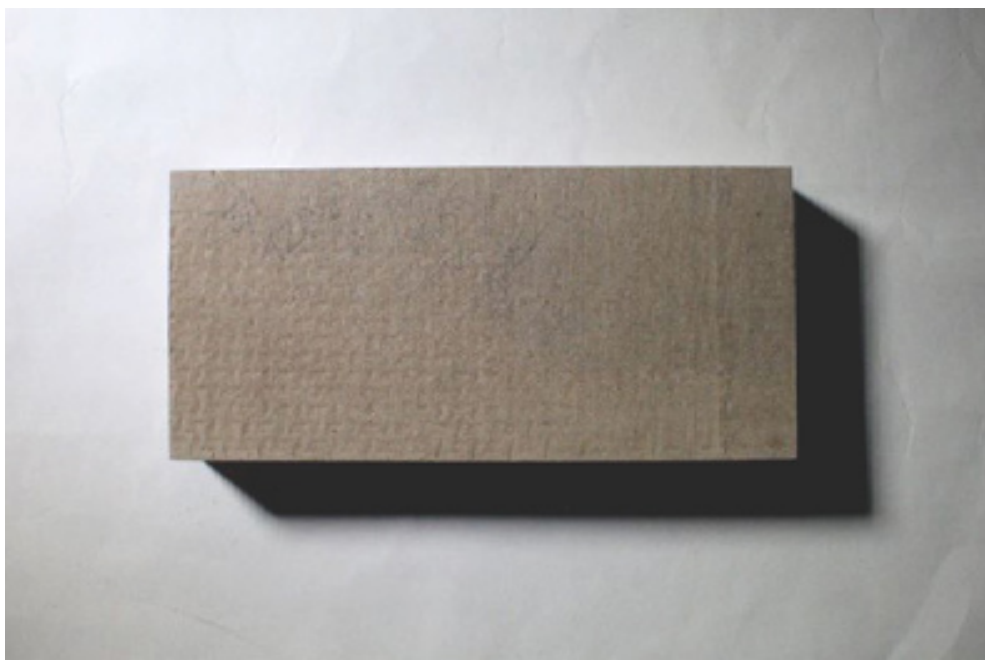

Fig. 051: Prototype NMFC building block 
F I ELD RESEARCH / 002 
SAO PAULO FIELD WORK RESEARCH JOURNAL

In early 2020, I had the priviliage to travel to Sao Paulo, Brazil to study ideas of waste management, the circular economy, and alternative cellulose recovery techniques.

- The following images are part of an anno- 


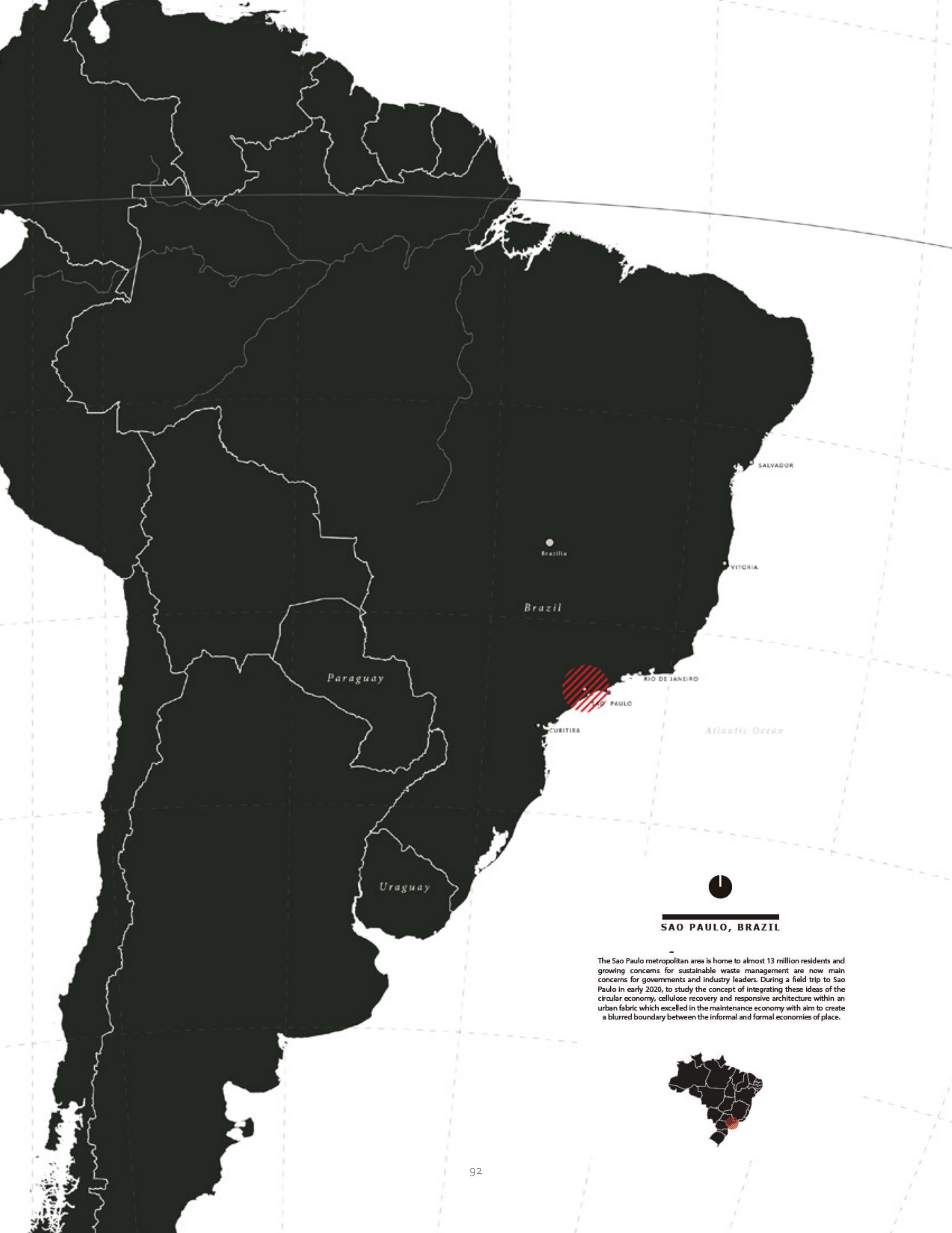




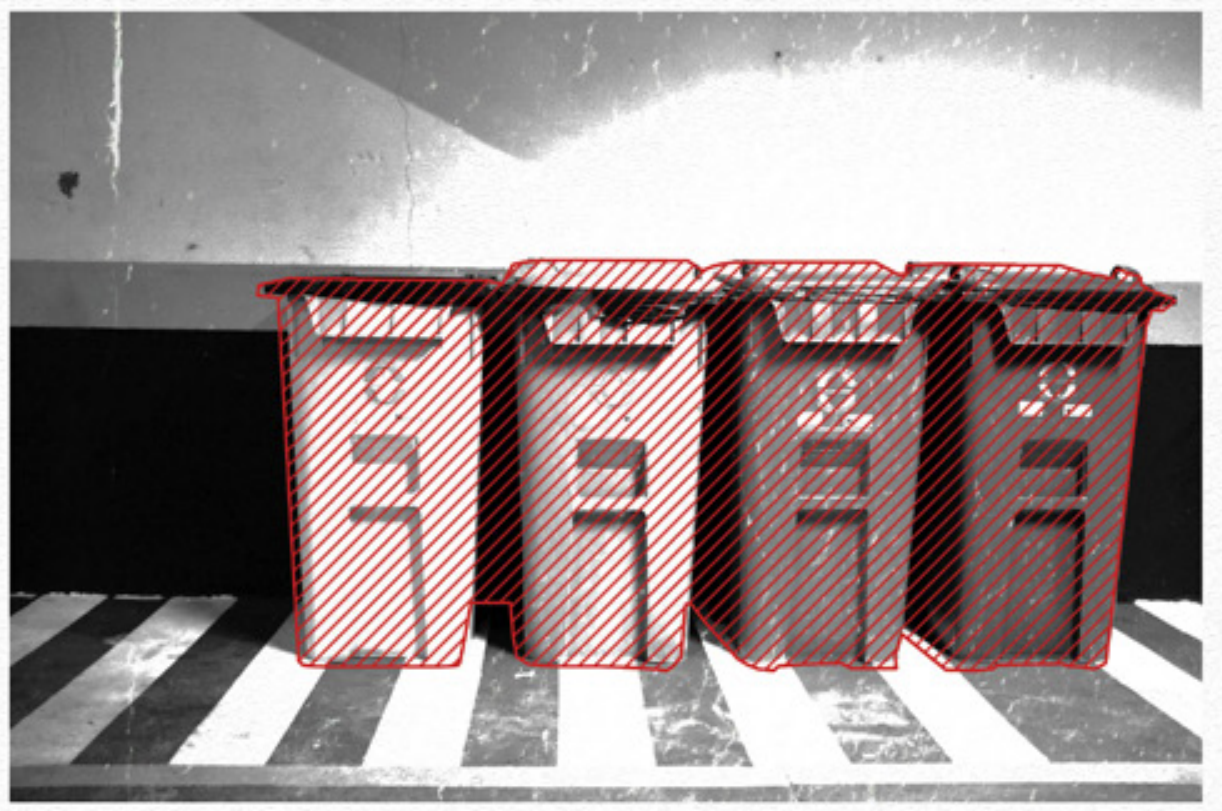

Collection Blas, Sao Paulo Subway Syster

Sorting bins are connonly found throughout the

entirety of the city. At the consuner level,

waste recycling avareness is effectively treated

before being picked through or taken avay by the

Formal Recycling Sector. 

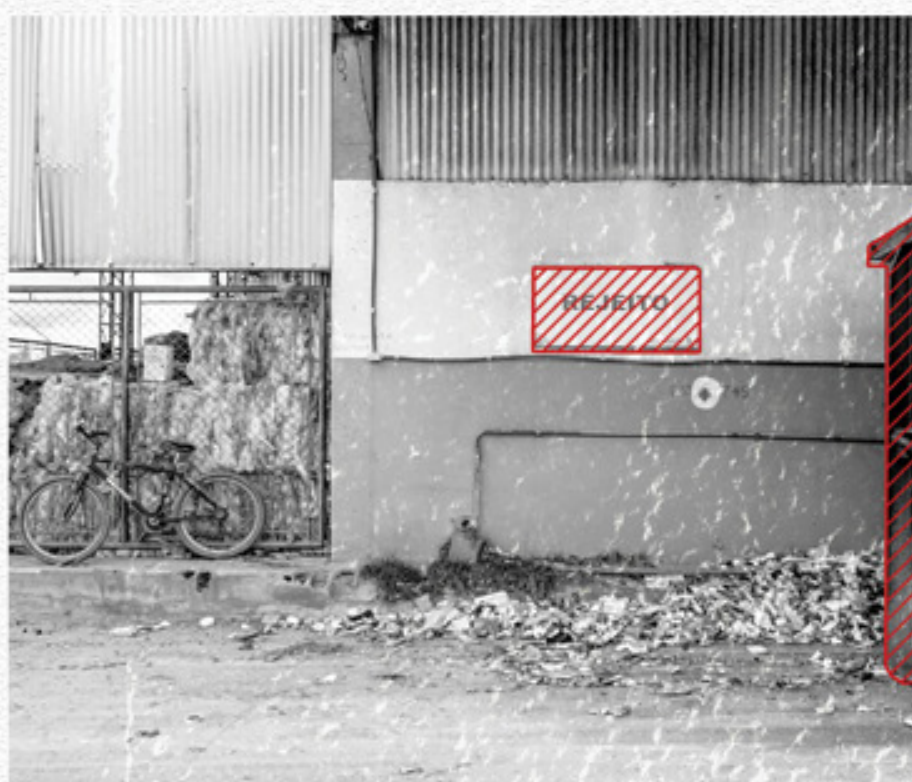

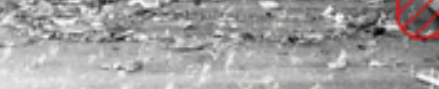
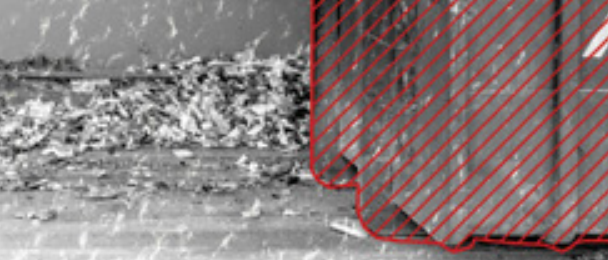

'Rojecto'

Cornonly knoun as 'reterial yith no ralue'.

Rejecto refers to the final stage of yaste dis

posal and the accumulation of naterial with no

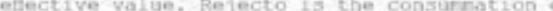

smail pieces of plastic, scrap wood, netal and

other sna11 elenents. With waste accumulation

contiauing to rise, so too does Rejecto, raising

serious conceraa for the future of lasdilla asd

vaste ranagonont around the globe. 


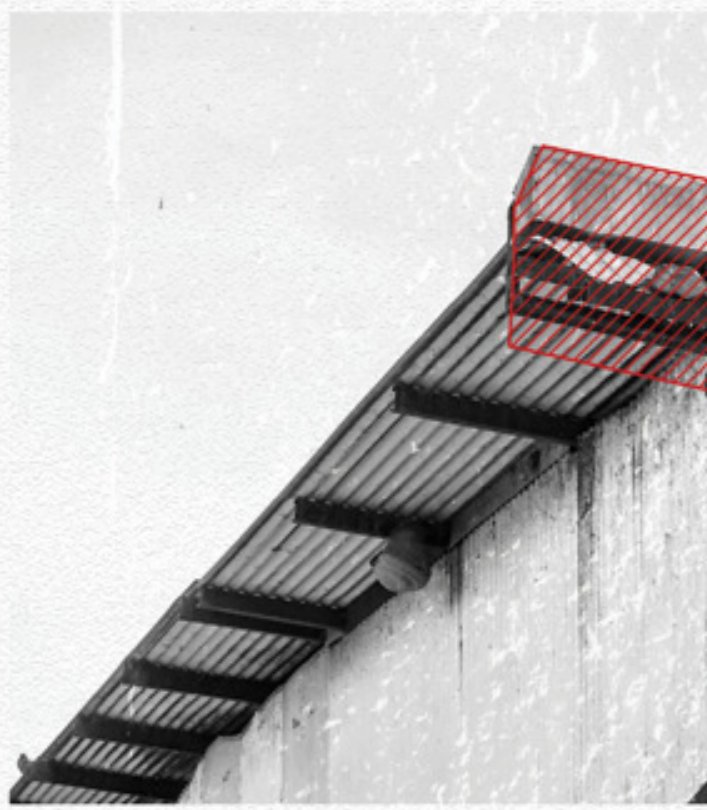

Recyclisg Cooperative, Sao Paulo Landfi:

Colloctives are an fintegral part of the sao

Pavio yaste sector. Working in both infornal and

formal districts, they perform daily tasks that

expose then to hazardous naterials and gases. 


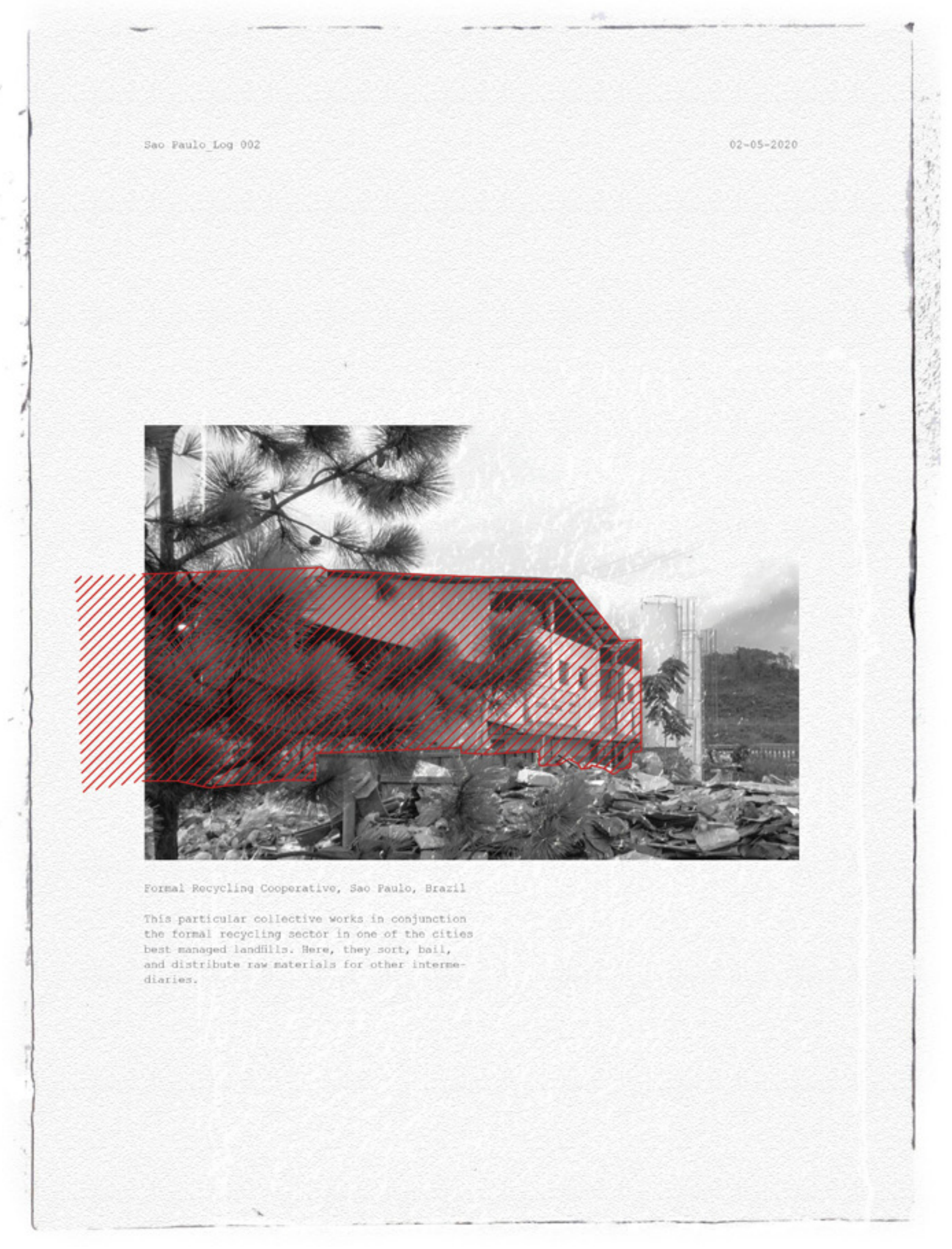




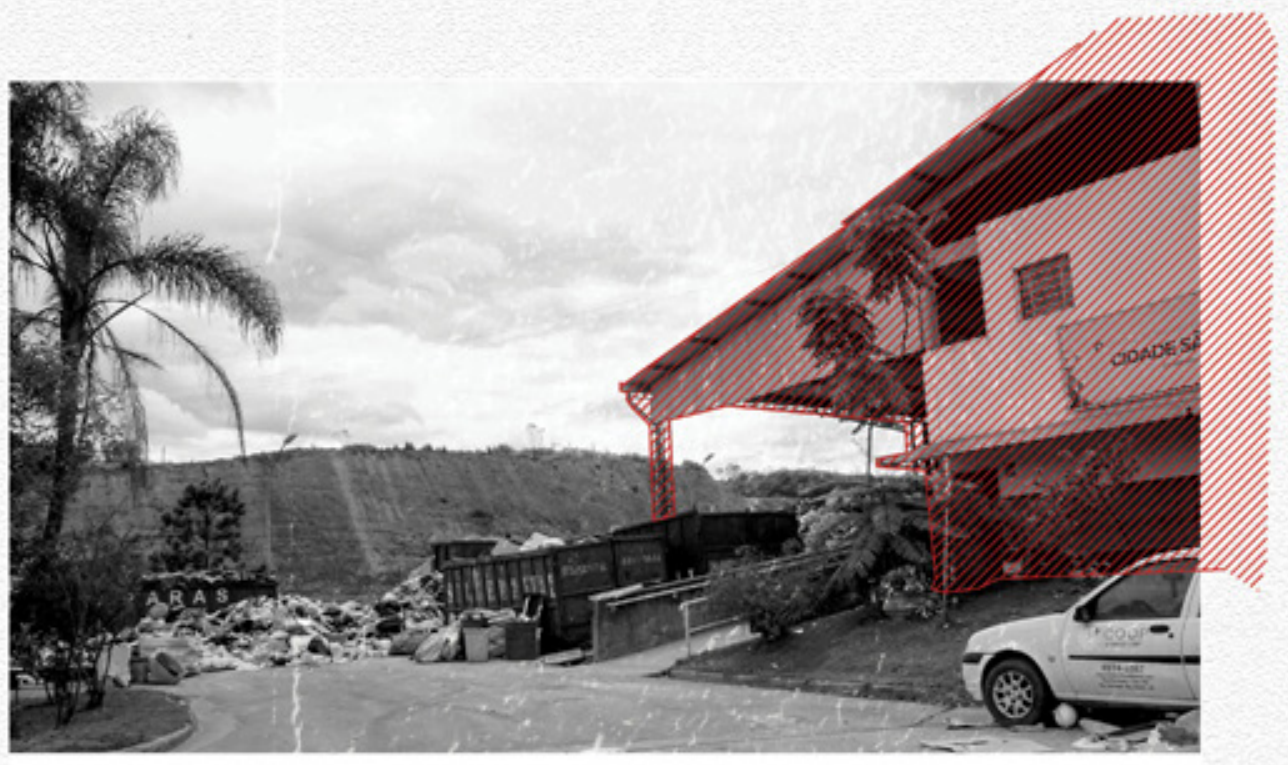

Foranl Landsil and Recycling Ceatre, Sao Paulo

Recycling cooperatives are often the engines

to effective vaste nanagenent in city landfills.

Cooperatives operate in conjunction with nunic

ipol and state waste managenent operations and

are often responsible for nuch of the industries

labour efforts. 


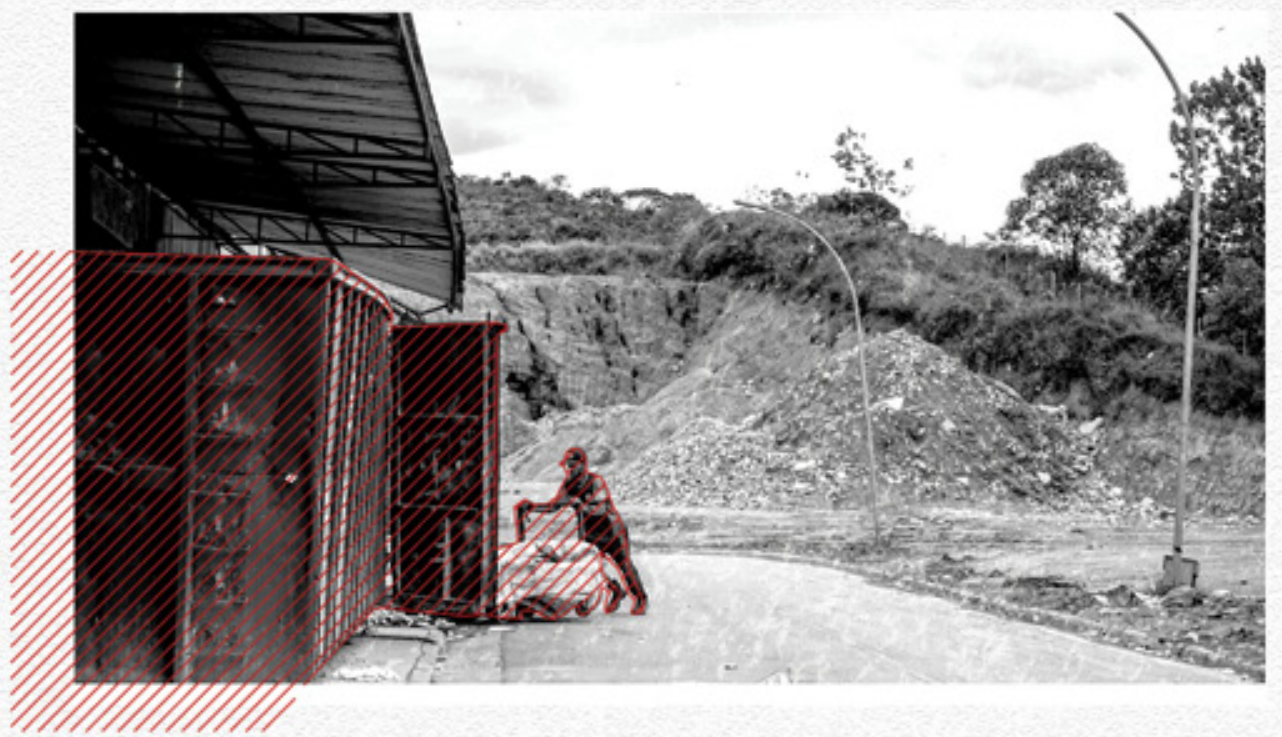

Foranl Landril and Recycling Ceatre, Sao Paulo

A waste sorter fs seen rowing Roincto naterial

into a large bin avaiting to be disposed of in a

landfill. This nethod is neither sustainable or

cespopstible and often ix the leading contributer

to hazardous runoff and leachate into ecosystenz

and uadergrouad aquifers. 


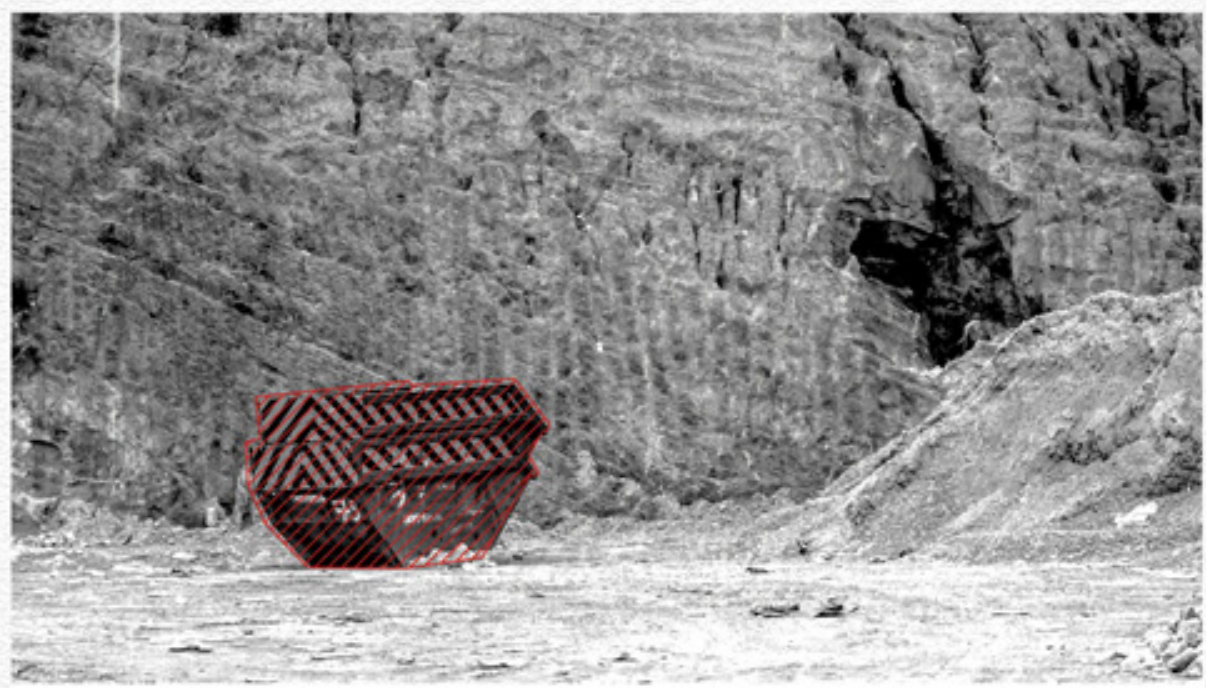

Foranl Landfill and Recycling Coatre, Sao Paulo

A single waste bin fs seen sitting before d

onall rock guarry in a local Soo Paulo landill. 


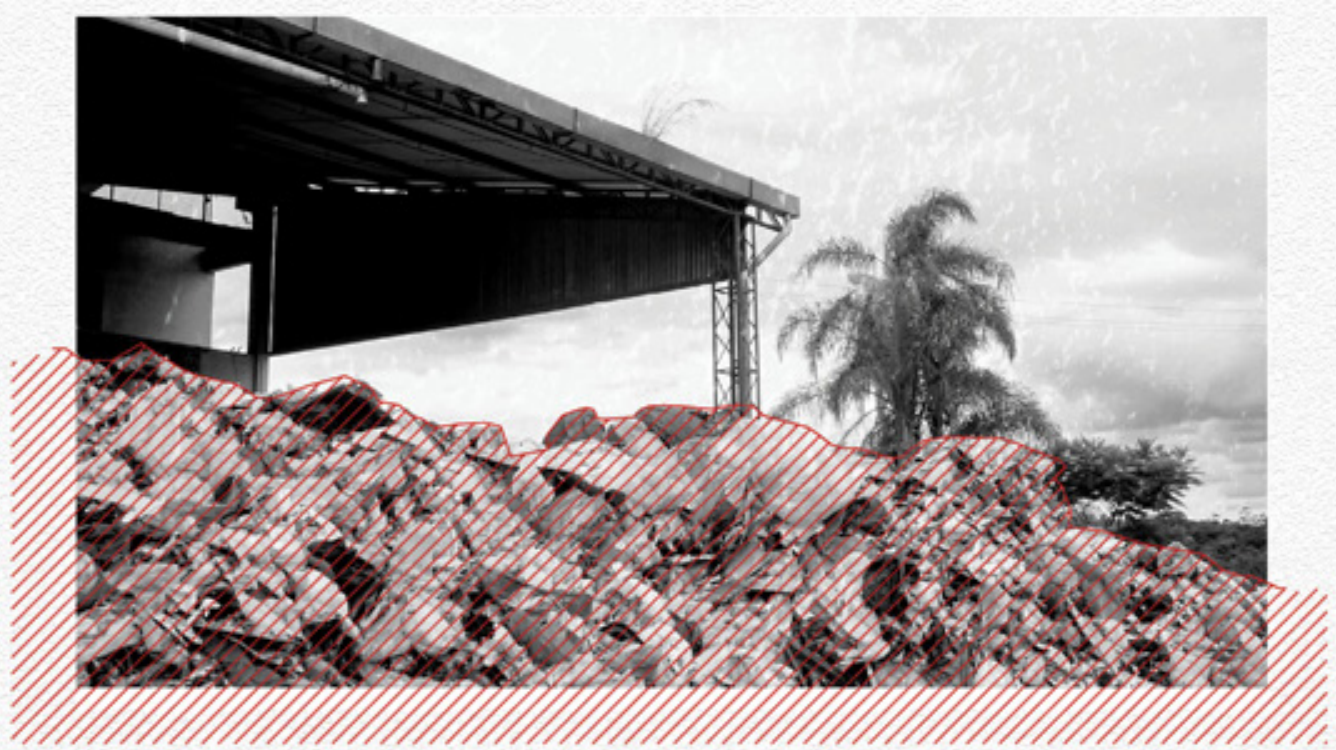

Foranl Landril and Recycling Coatre, Sao Paulo

Woste collection fa primarily a business - It

bolds Yalue, job security, and an ever groxing

supply of naterial, hovever as we continue to

exploit notural resources around the globe waste

accunulation is expected to grow beyond our

curreat processing netbods. By the year 2050,

we will accumulate ainost 3.4 billion tonges

of waste asnualiy, putting serbous pressure on

curreat waste nanagoneat practices that denand

altersative solut loas. 


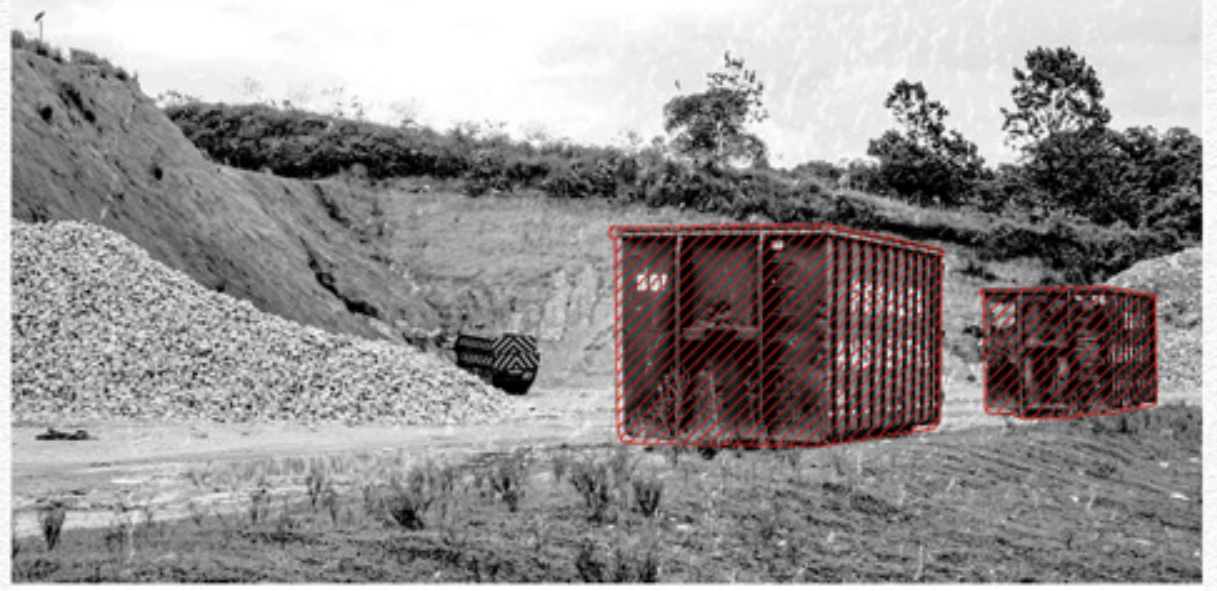

Foranl Landill and Recycling Coatro, Sao Paulo

Waste collection bins sit outside a Sao Paylo

recycling centre. A snall rock quarry is seen in

the background. 


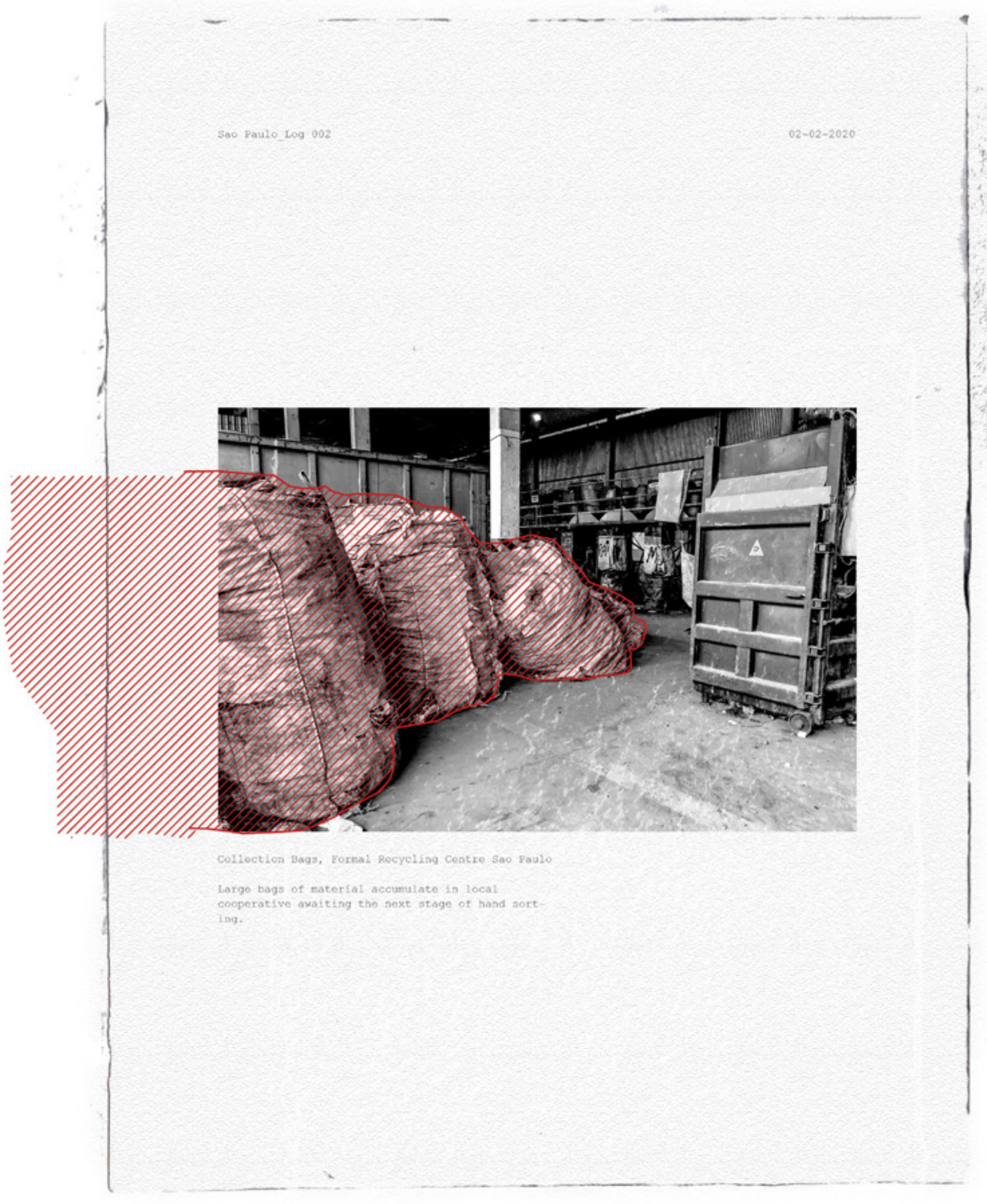




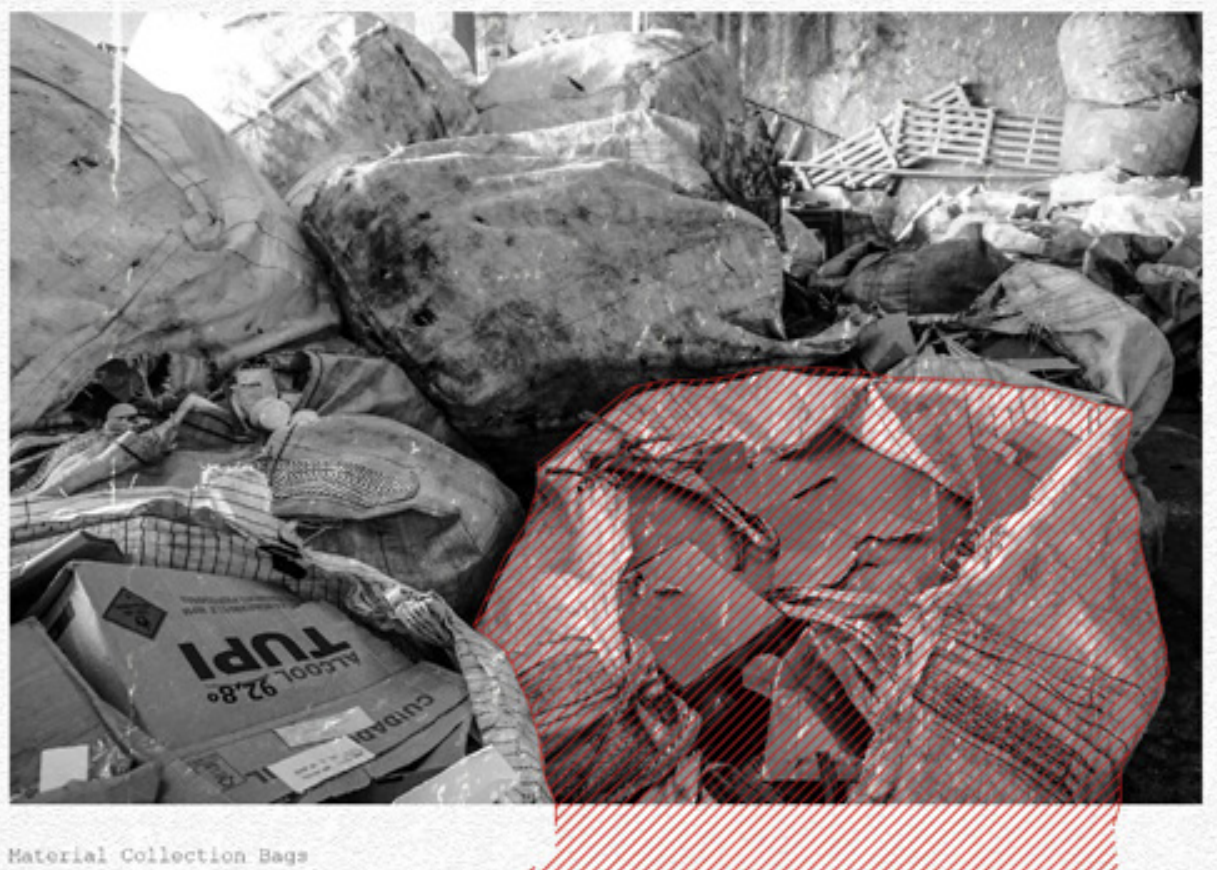

Bags of ray paper natorial ayoit to be sorted fo

Coppercaps recyeling centre. 


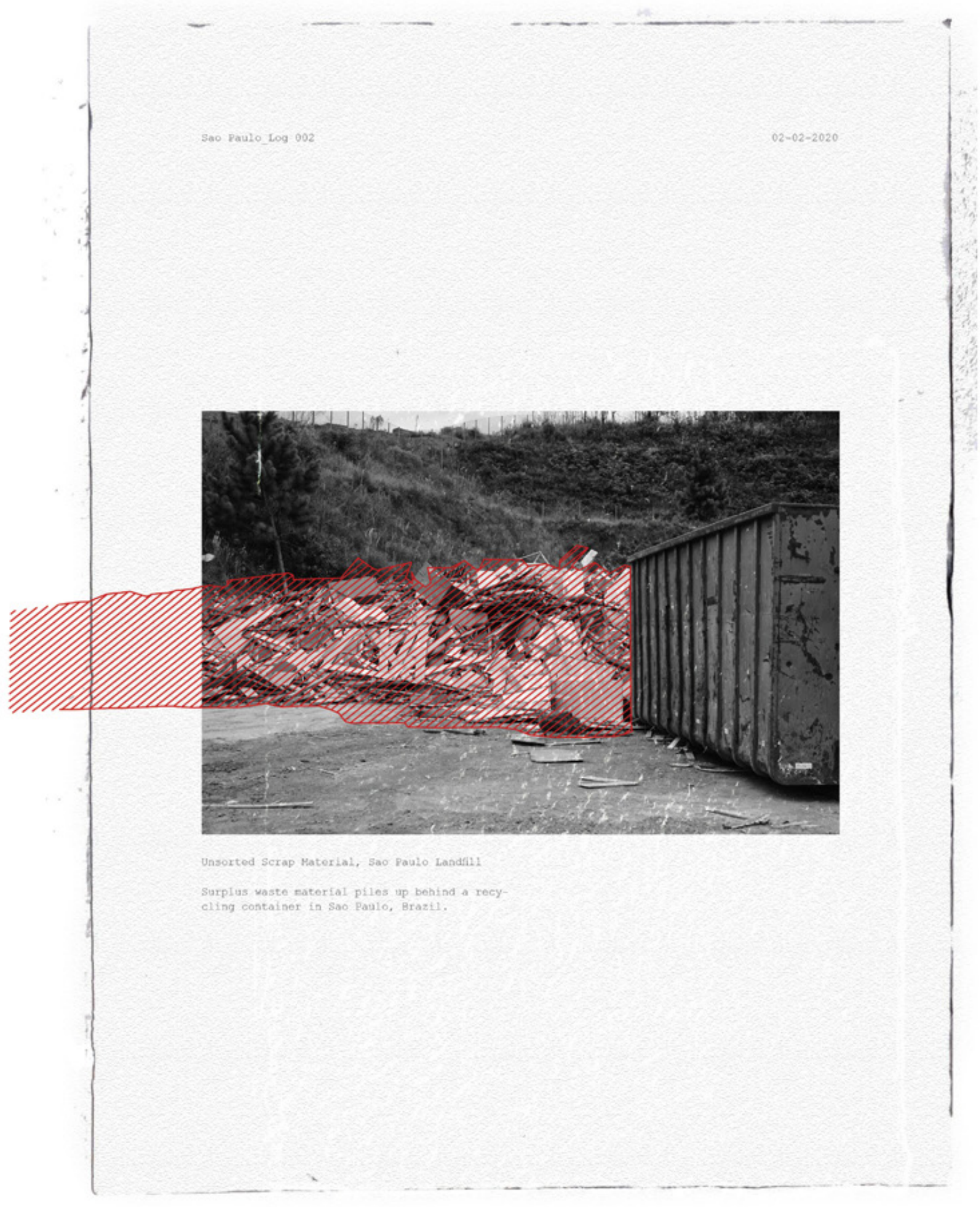




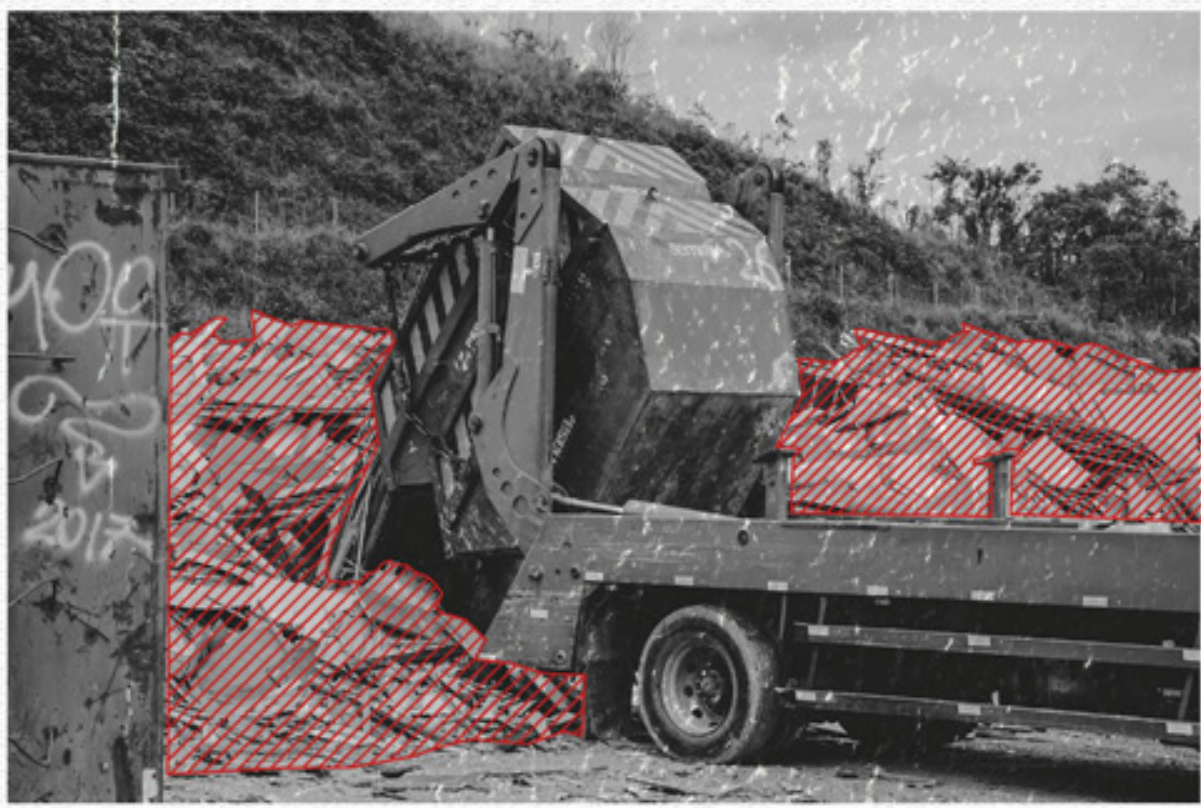

Recyclisg Coatre and Laadili, Sao Pauto

A formal waste collection truck seen durping

unsorted raw wood naterials into a landfil. This

naterial will then be sorted by nachine and cat-

egorized by hand. 

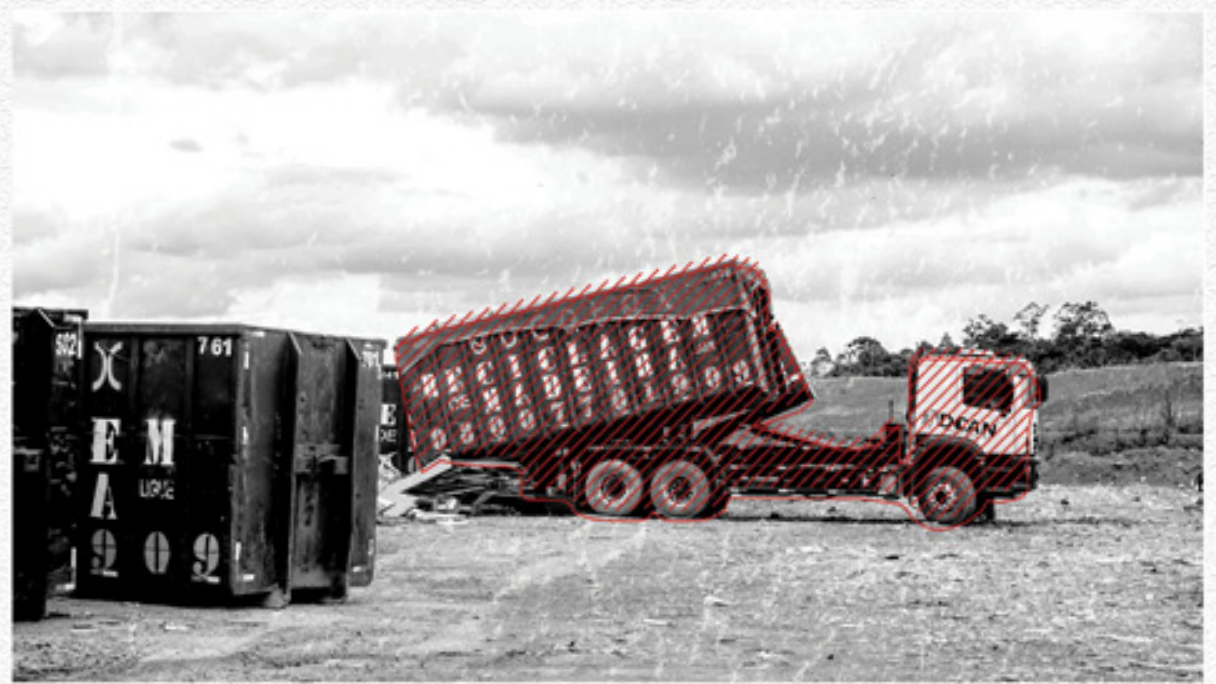

Foranl Landill and Recycling Ceatre, Sao Paulo

A formal waste collection truck is seen unlead

ing solid waste into large piles at a local

landfill in Sao Paulo, Brazil. 

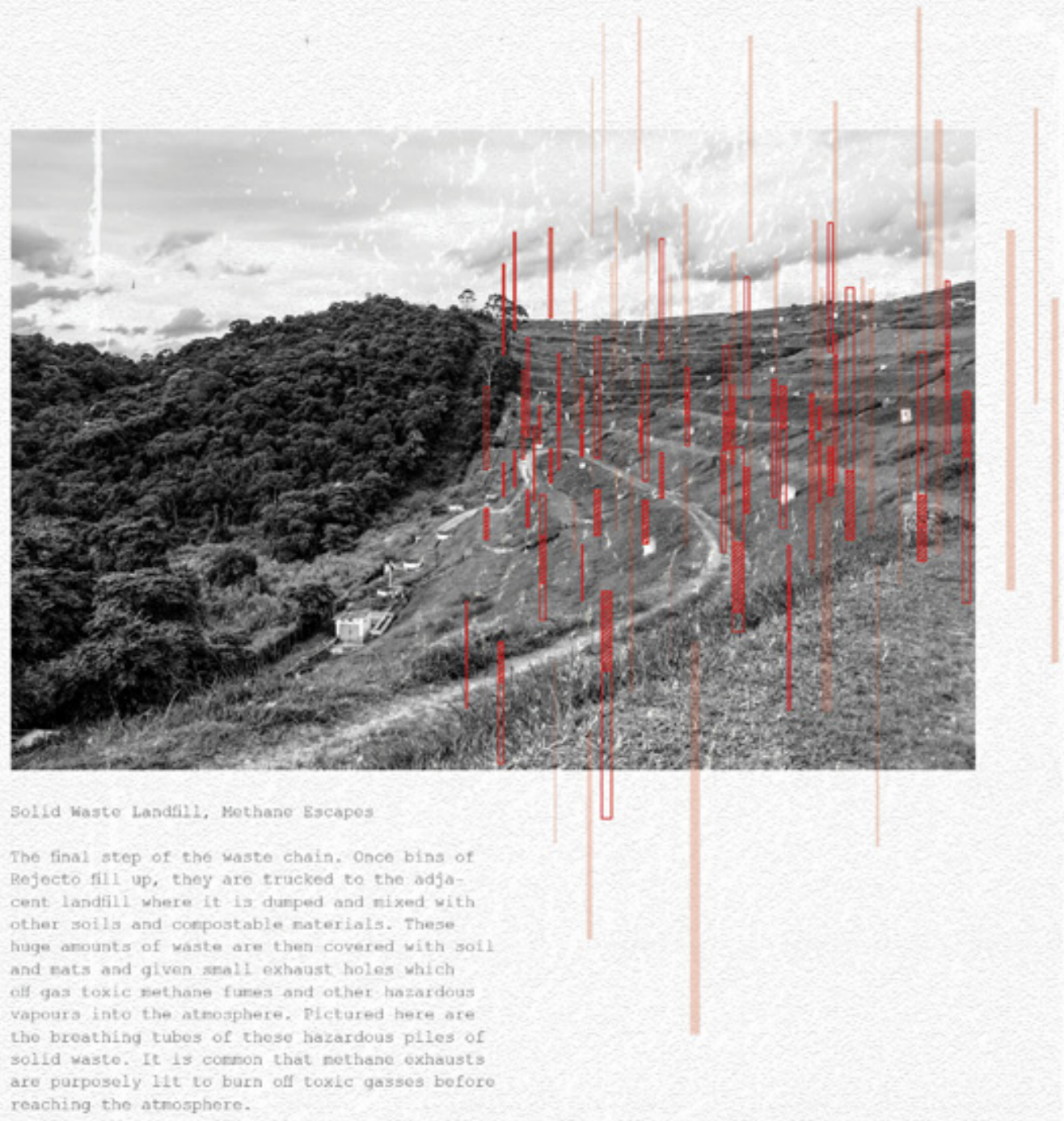


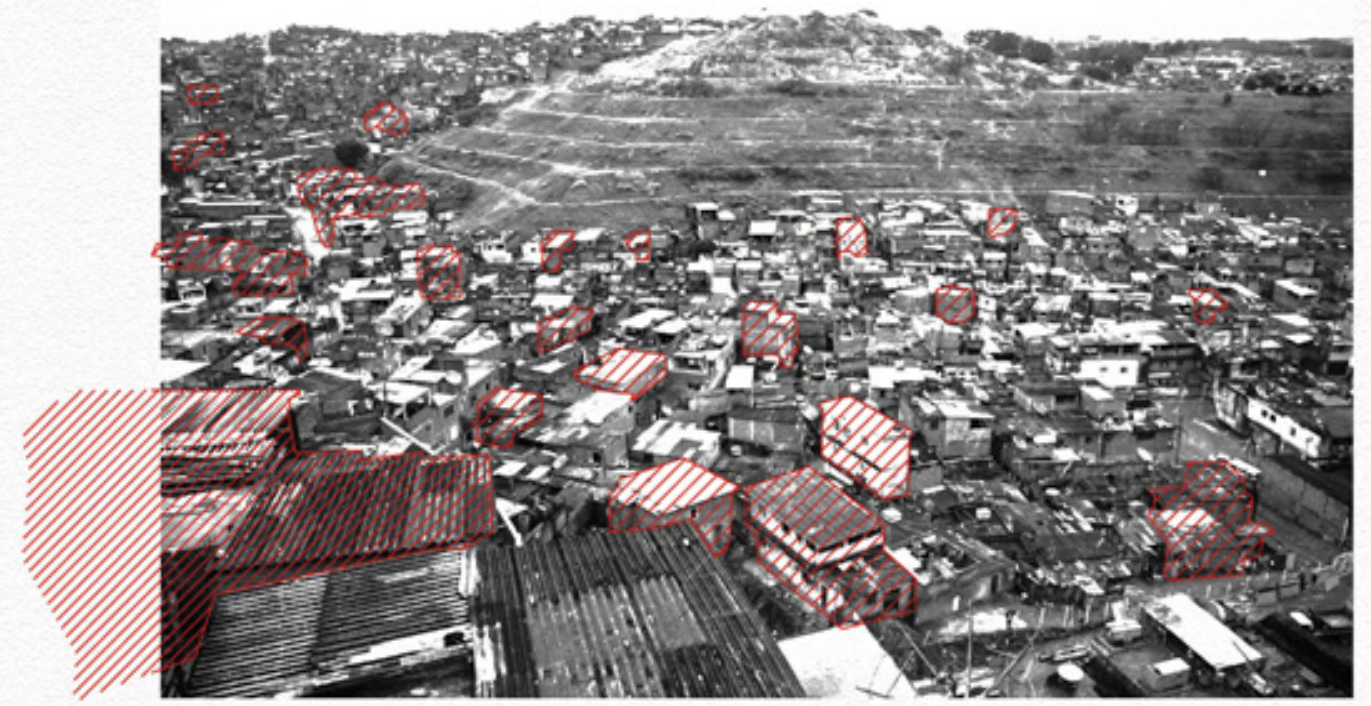

Paraisópolis Favela, Sao Paulo

An Aorial viex of Paraisónoliss, one of Sao

Paulos largest favelas. This inage depicts the

proposal of conponent by component. replacenent

in these regions. 


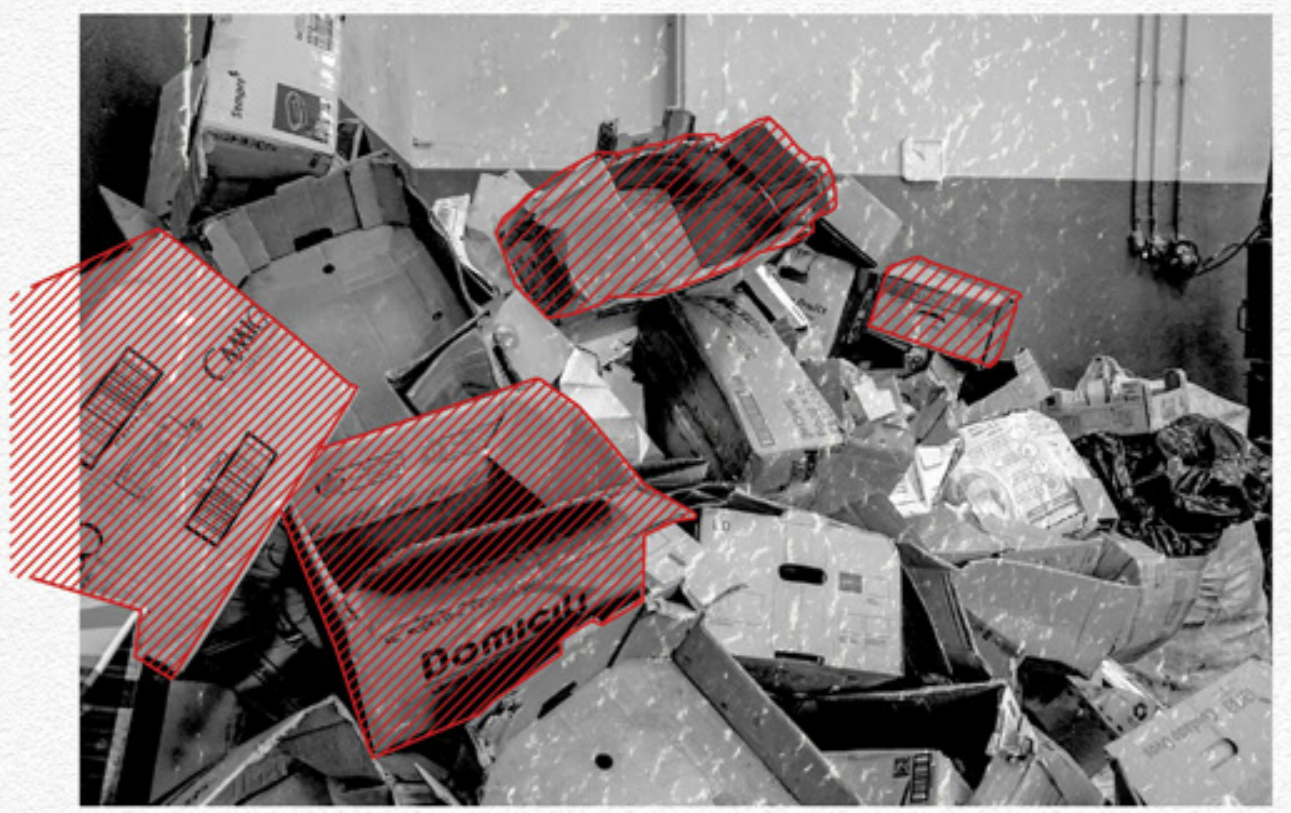

Recycled Cardboard Boxes

Boxes of Cardboard plle up in a local Informal

Recycling cestre. These will be broken down.

sorted, and conpacted into 1.2 tone bails. 


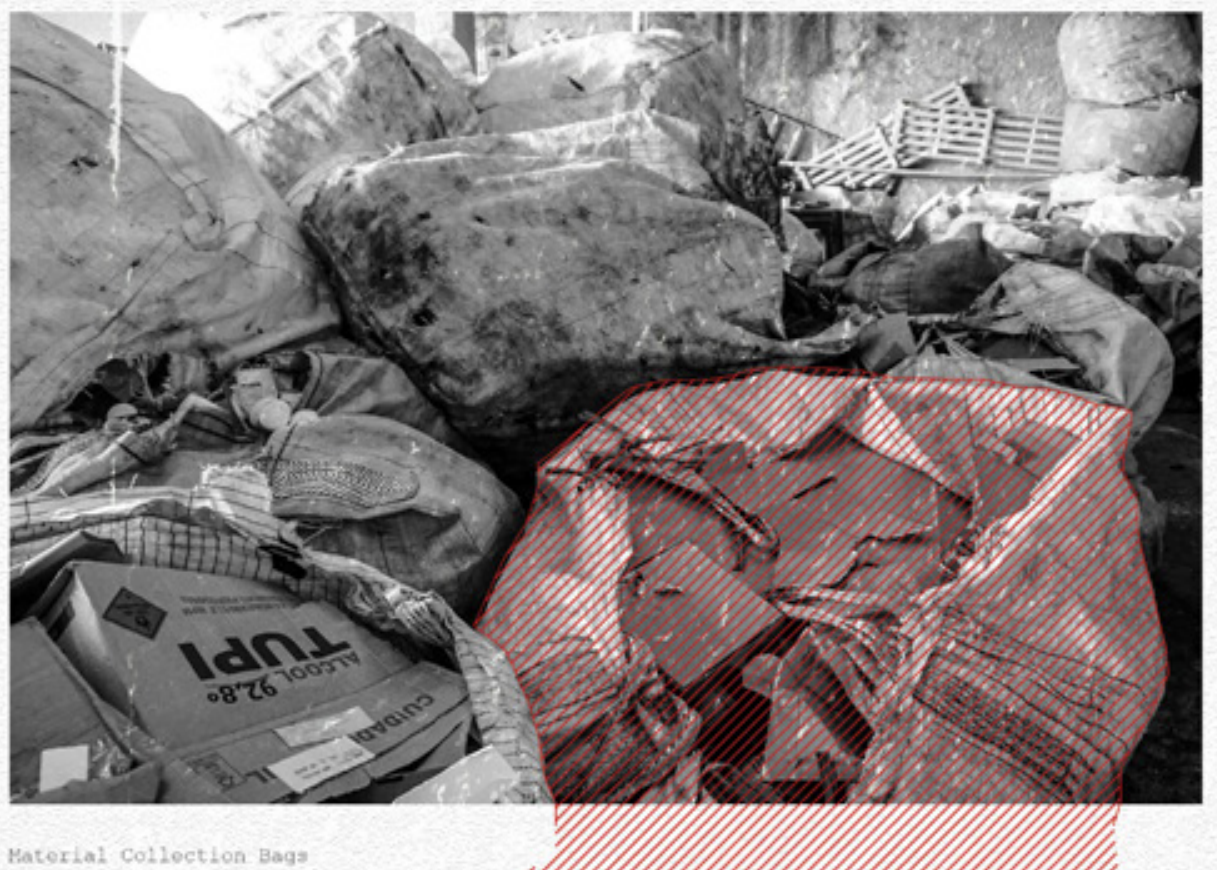

Bags of ray paper natorial ayoit to be sorted fo

Coppercaps recyeling centre. 


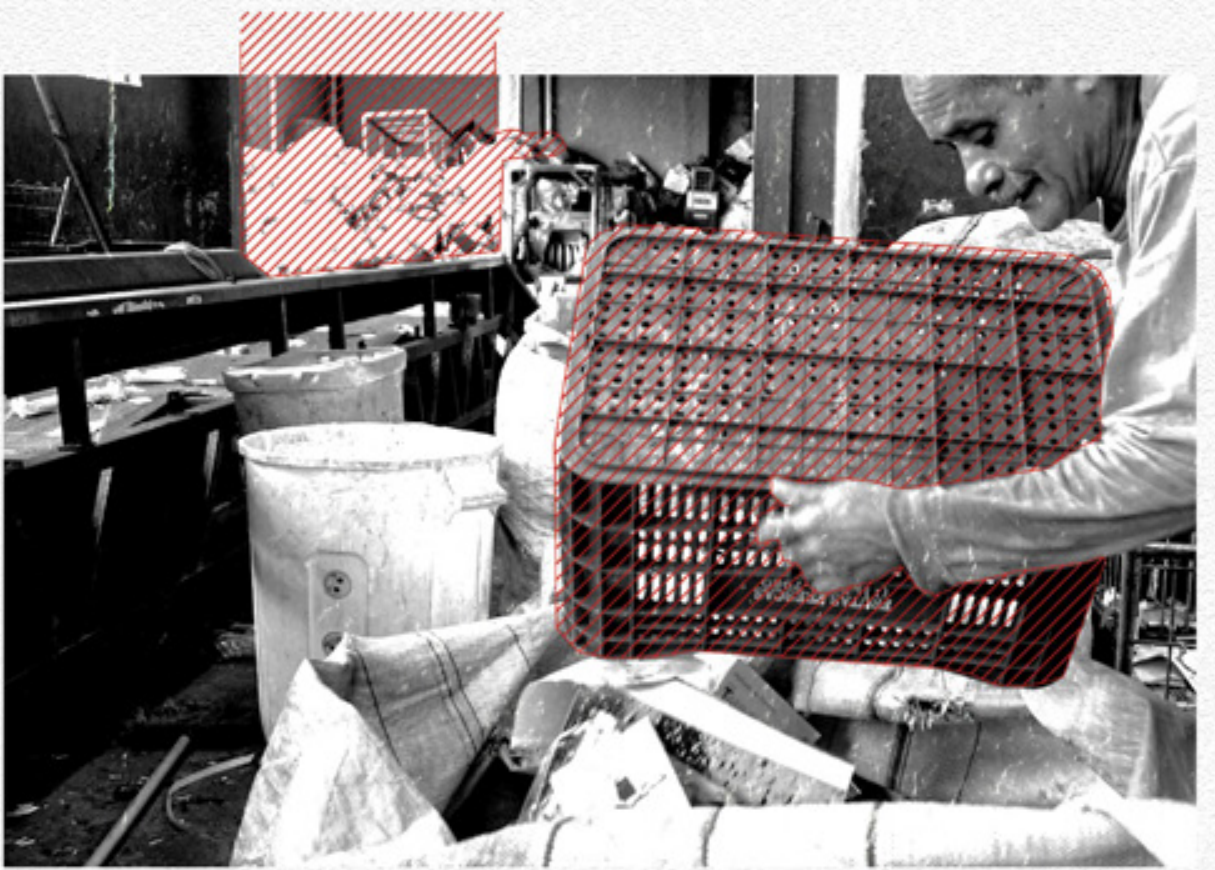

Material Collection Bag:

A- Iocal yaste sorter dixps other fibrous naterial

into bags that avait thoif next step in the re-

cycling chain. Once categorized to its appropri-

ate waste strean, it will go be sorted by hand

once nore before conpacting into solid h tonne

bails. 


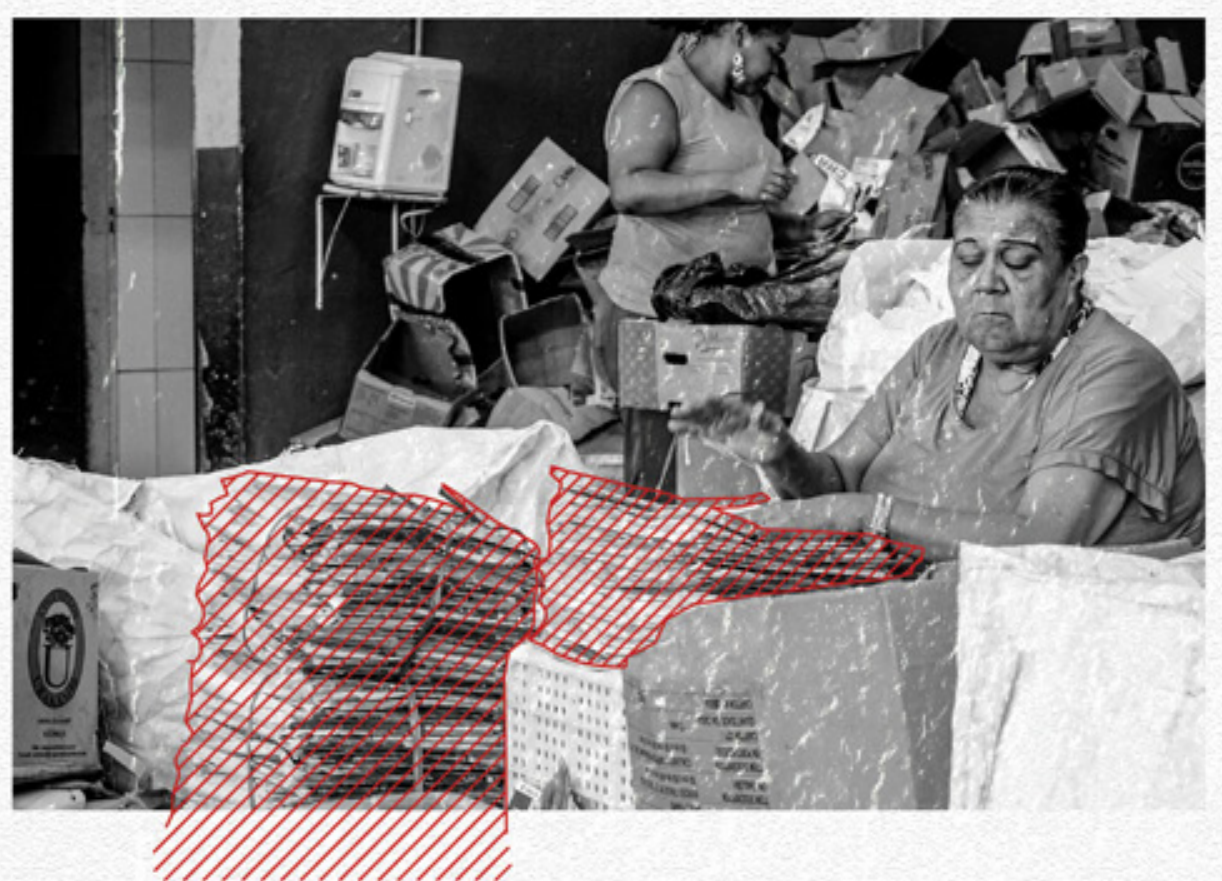

Kaste Sorter folding Newsprint

A Local worker sorts and folds newprint papers

that yill be recycied back into future nows-

priat, 


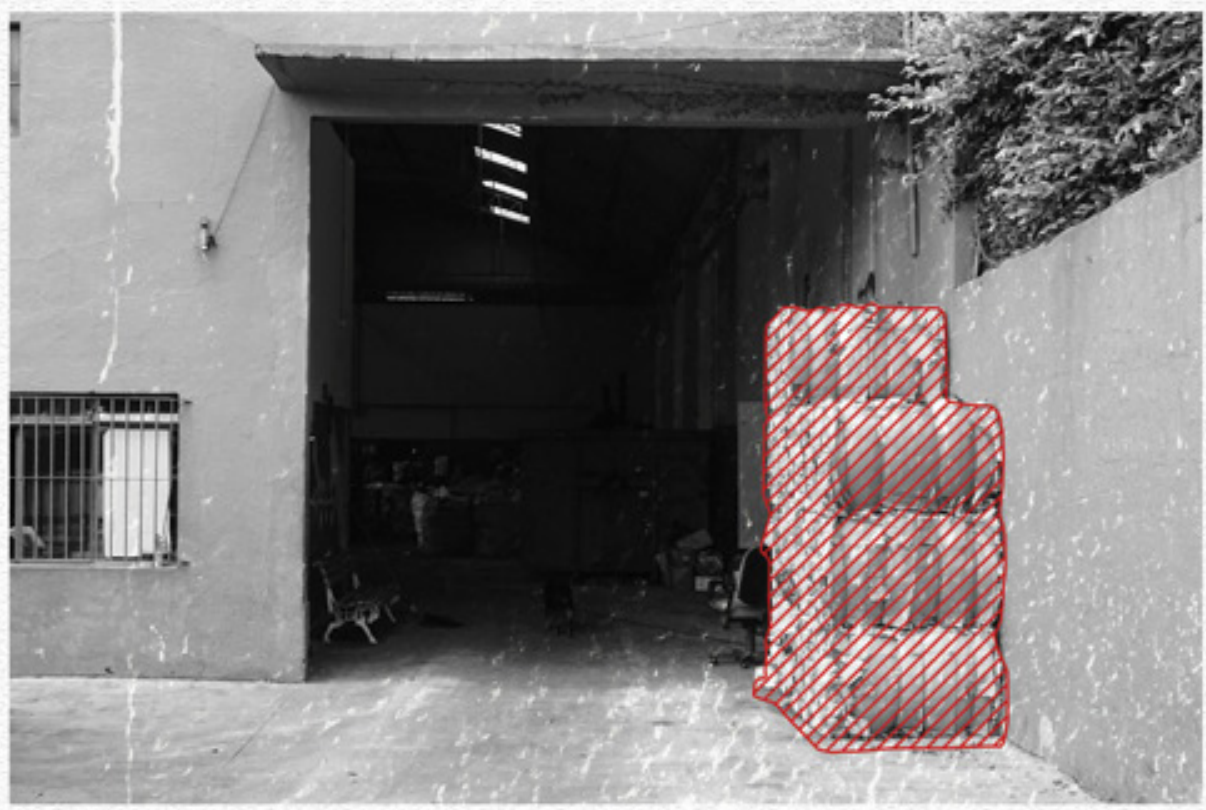

Coopercaps Recycling Cooperative, Sao Paulo

Bafls of compacted ray faterial avaft shipment

to local internediaries that will process and

transfore it into nen products. This is an ir

portant itage within thia project as it propomest

alternative destinates for rav naterial to be

transforned into nek building conponents. 


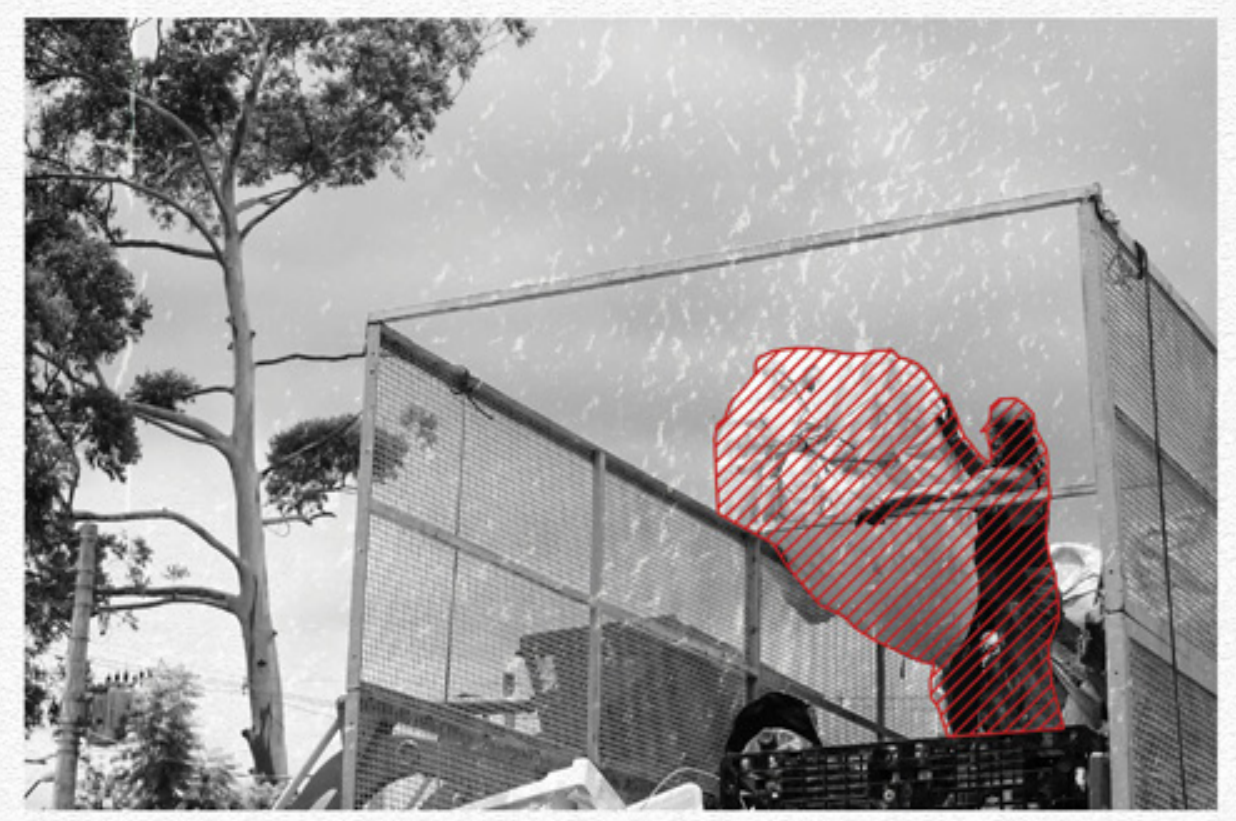

Coopercaps Recycling Cooperative

A worker is seen dropping off large quantities of

baggod naterial that will be hand sorted through

a conveyor belt systen before being conpacted

into the rau naterials of the bags contents. 

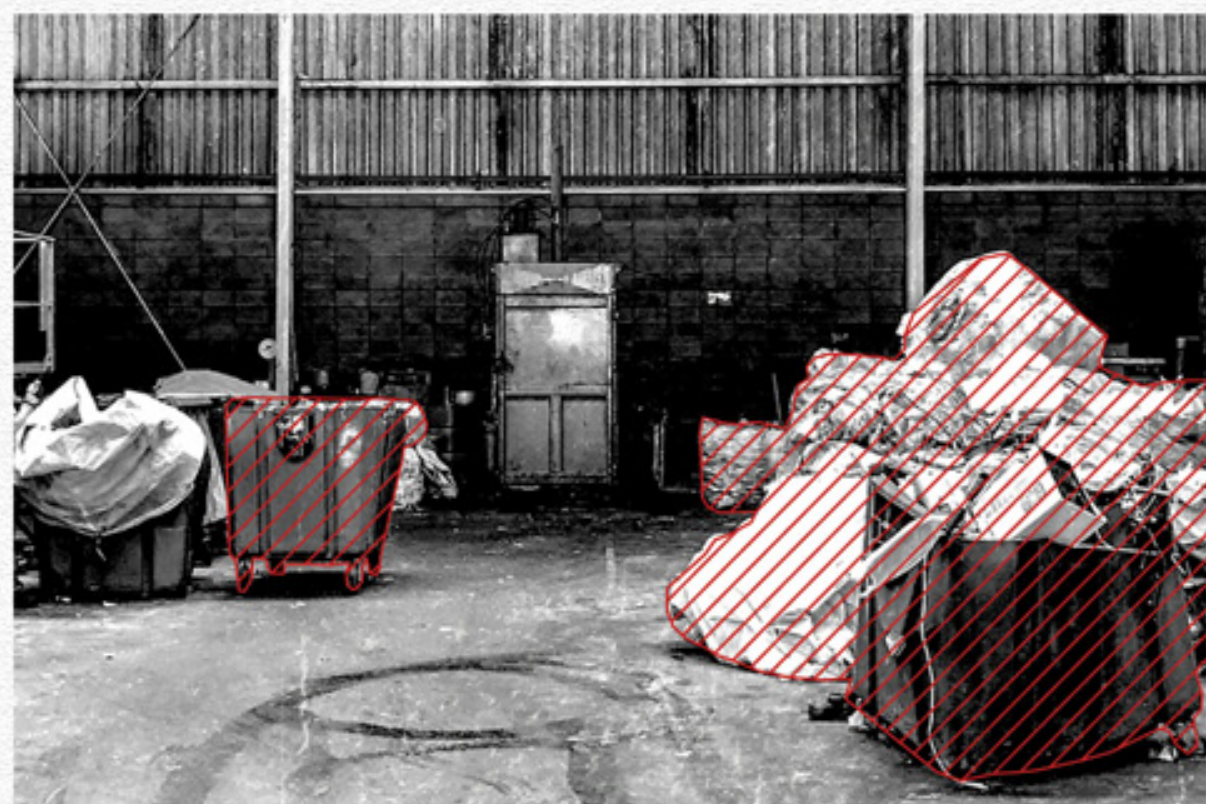

Coopercaps Recycling Cooperative

Haterifal sitts pat feotly in large bins and bags

avaiting the next stop in the waste chain. Next.

it will be sent to conpacters where it will be

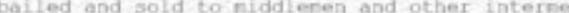

diaries. 


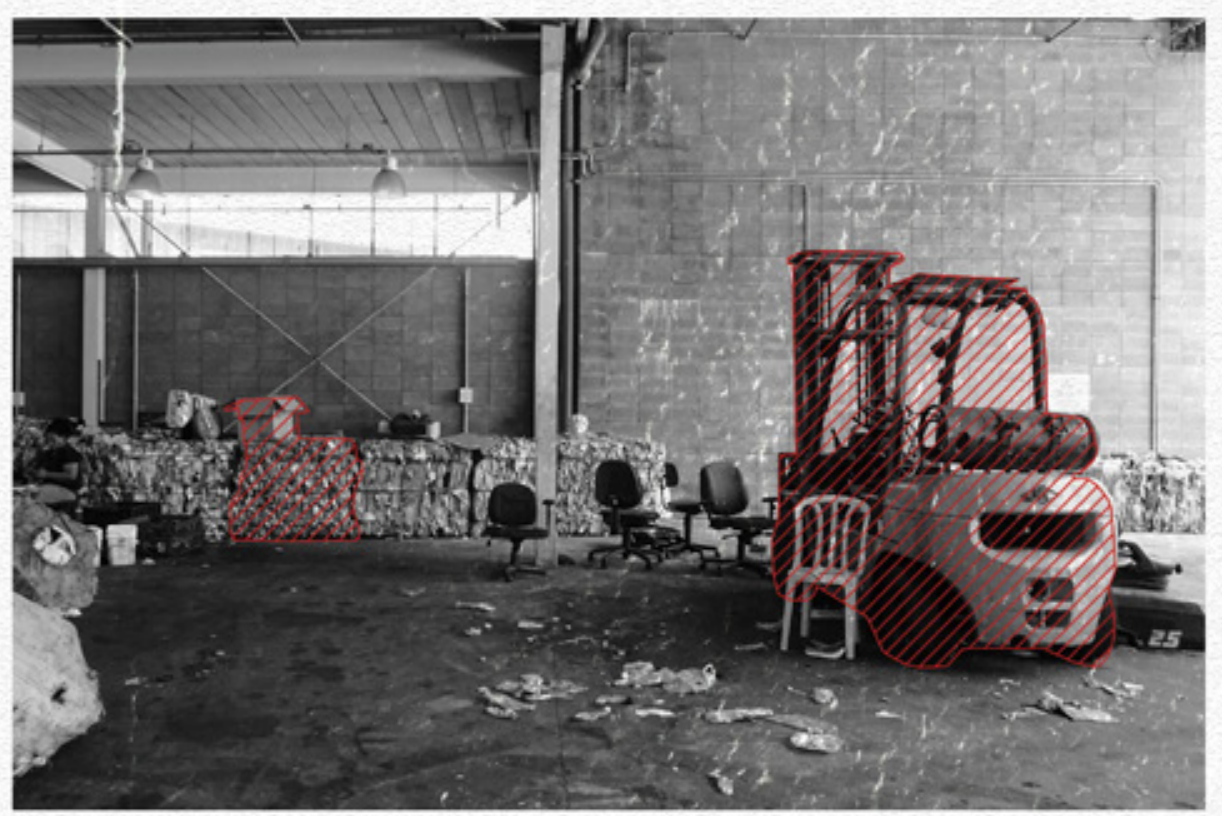

Coopercaps Sortiag Centre

Coopor caps is one of Sao Paulos leading re-

cyciling Cooperatives. They aro part of a self

sufficient collective of pickers, recyclers, sort-

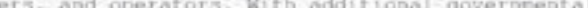

support, cooperatives are able to sort large

anounts of recyclable waste and provide greater

socio-ecoponic and exvirontestal besefits. 

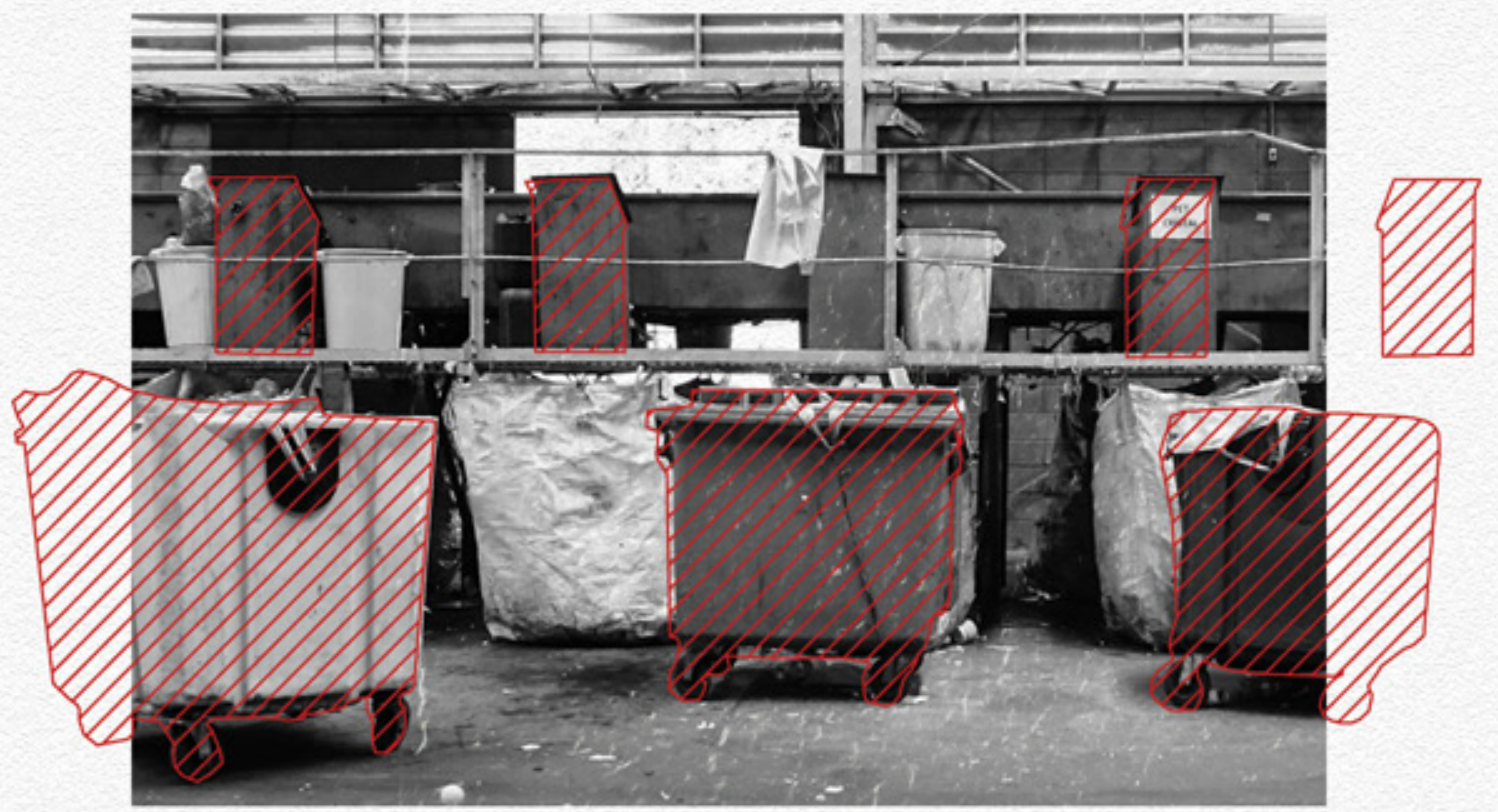

Coopercaps Recycling Cooperative

Colloctiwes are an integral part of the sao

Pavio yaste sector. Working in both infornal and

formal districts, they perforn daily tasks that

expose then to hazardous nateriols and gases. 


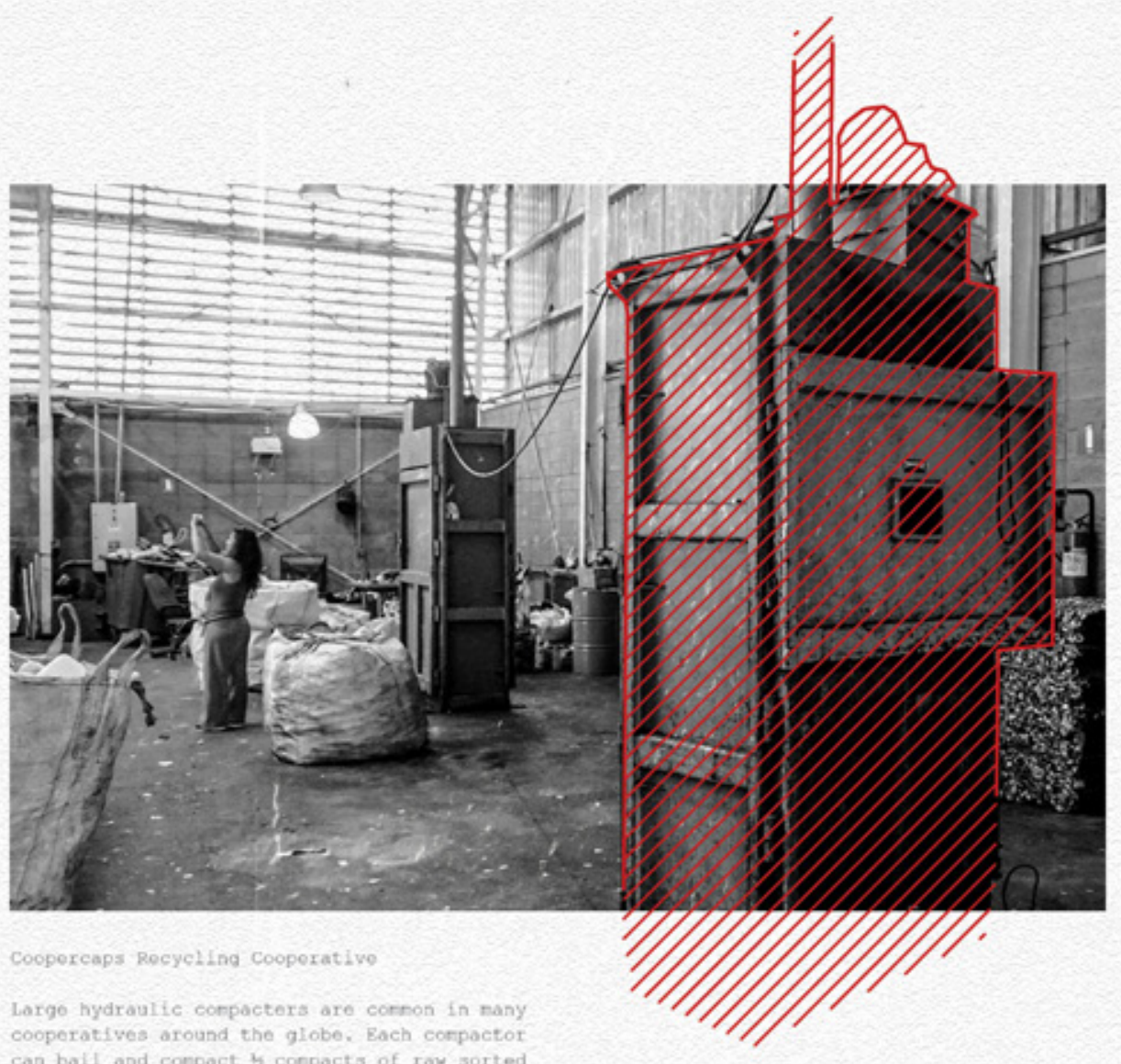

cooperatives around the globe. Each corpactor

naterial. 


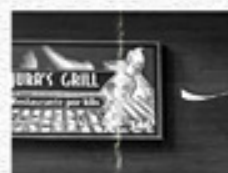

\section{AKKAR outlet}

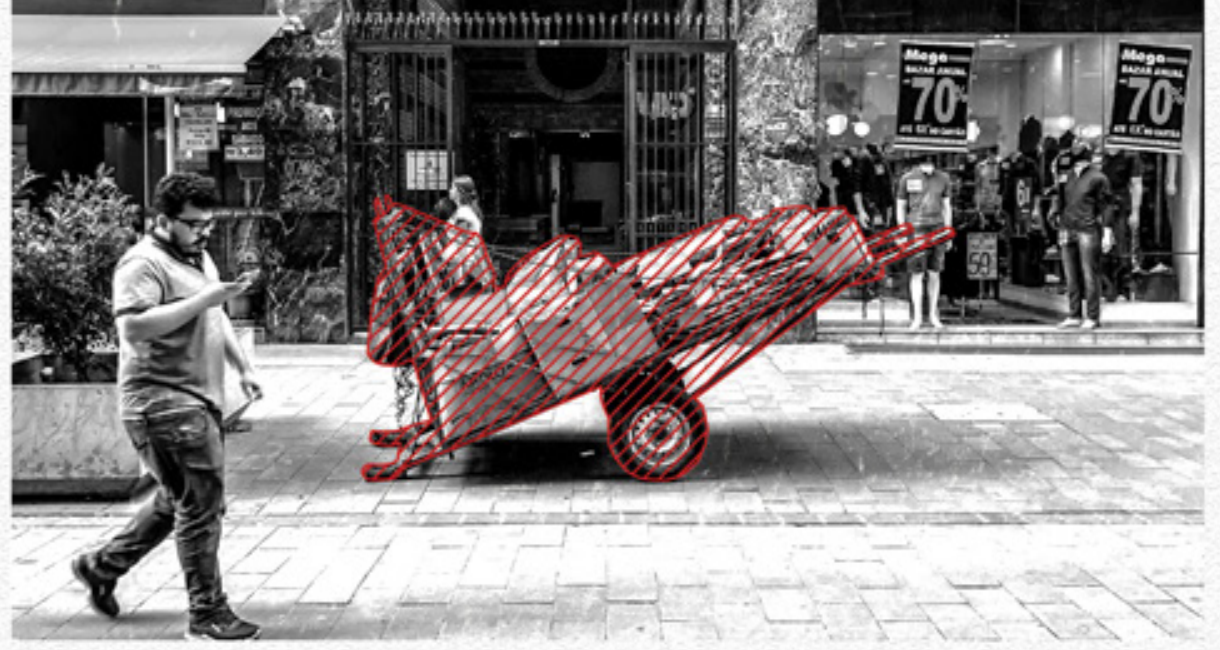

Waste Collectioa Car

City yaste collectors often noue through atreets

collecting froen storo owners, consuners, and

other collectors. Personal waste-carts can fill

up 4 tines through height in naterial per day. 


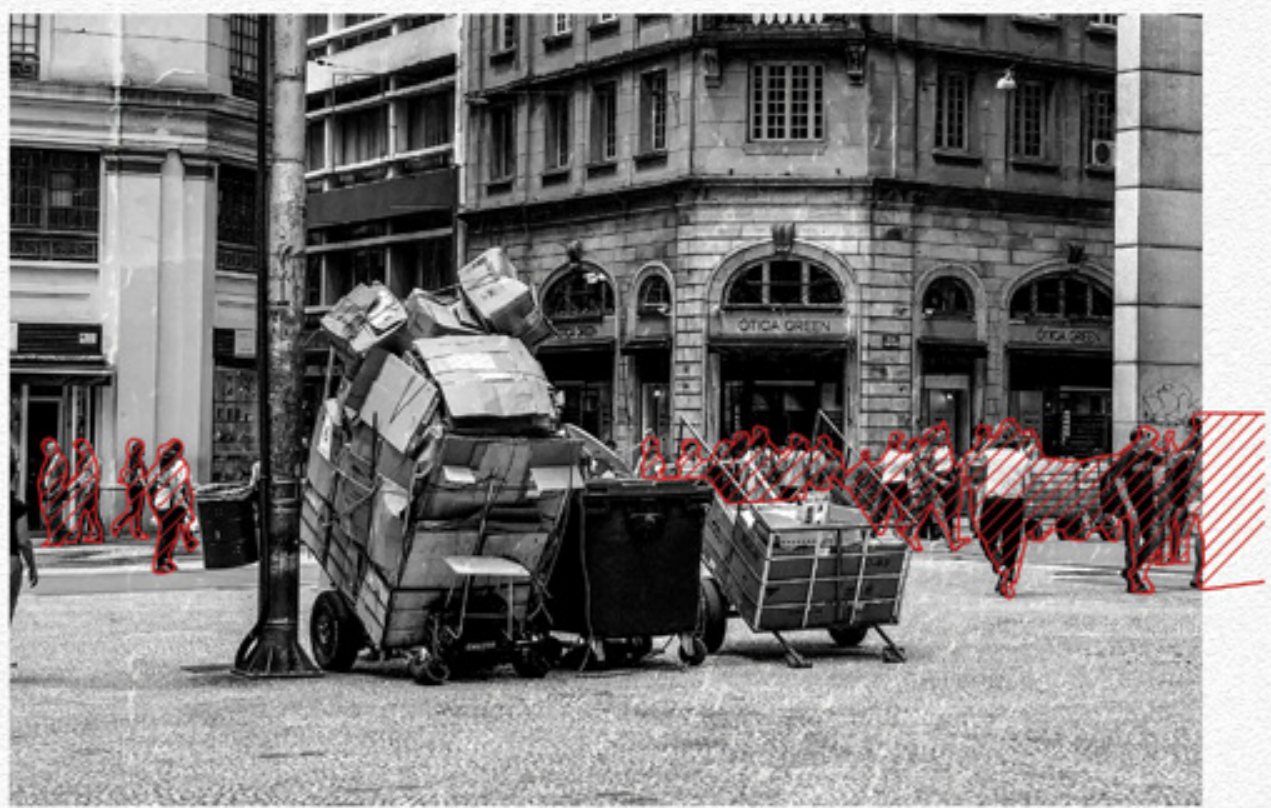

Cardboard Collection Carts, Sao Paulo

Inforral waste collection is an fntegral part of

the Sao paulo econony. Yet generations of societal

neglect has led to an integrated systen of col

ecting, picking, and repurposing. Here ve see how

the general public pays little attention to the

cleaners of the city. 


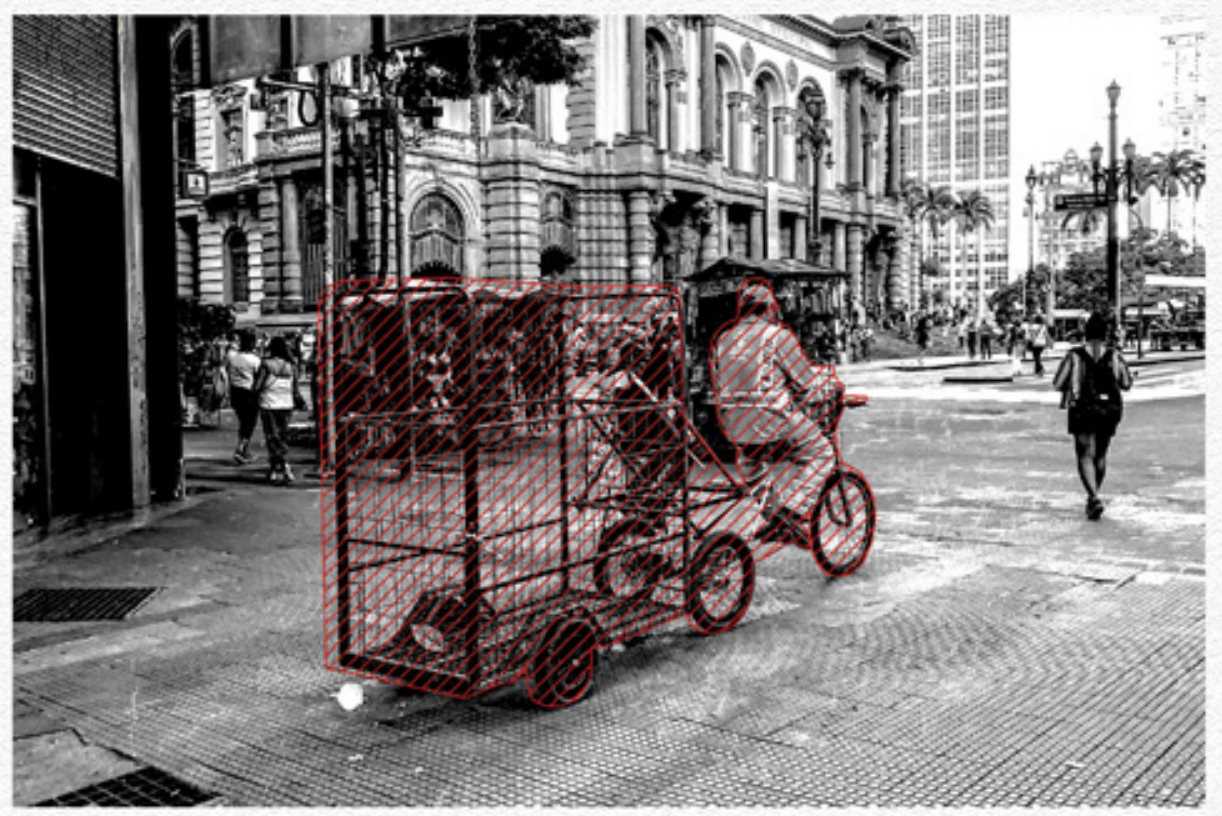

Foreal Recycling Sector, Cart net

Fornol recyeling takes place at aly-lewels, Bere

we see a local vaste collector in a unifort and

waste collection vehicle. 


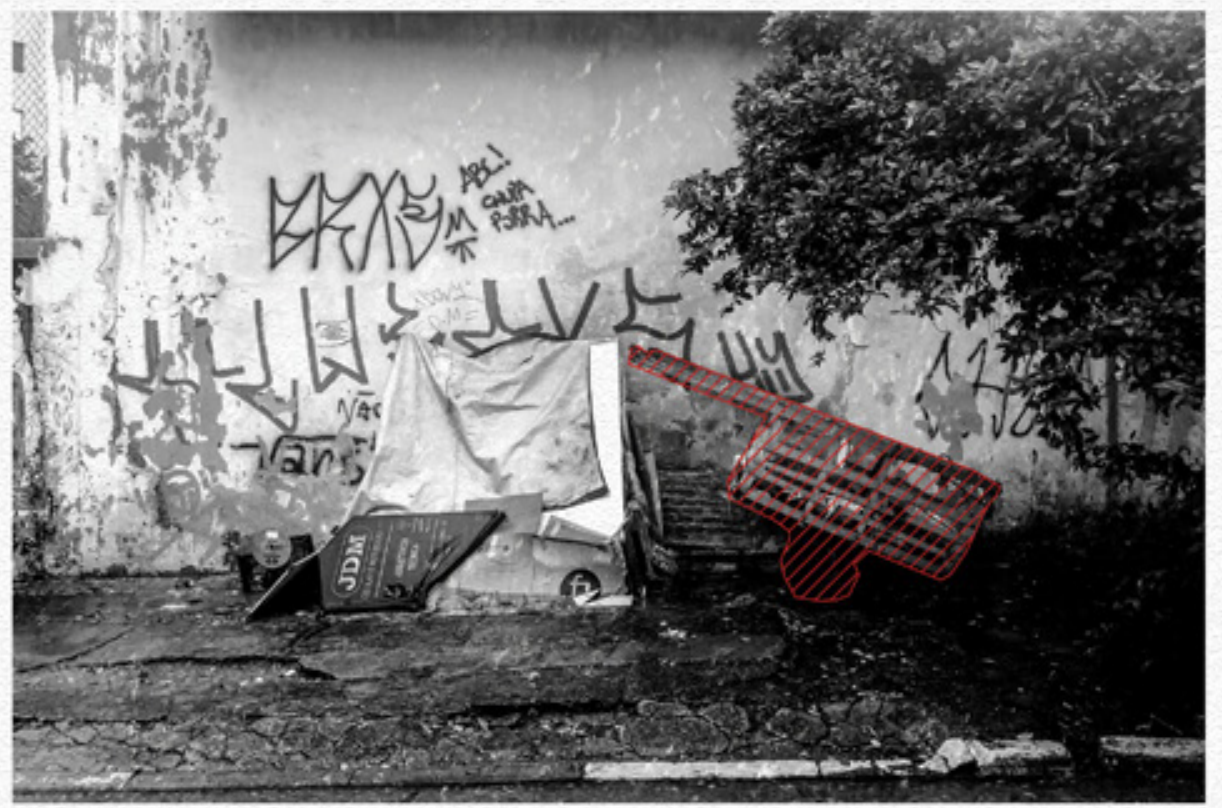

Waste Collection Cart

펴don in plain sfaht, waste collection wohicles

are found throughout the city fabric. 


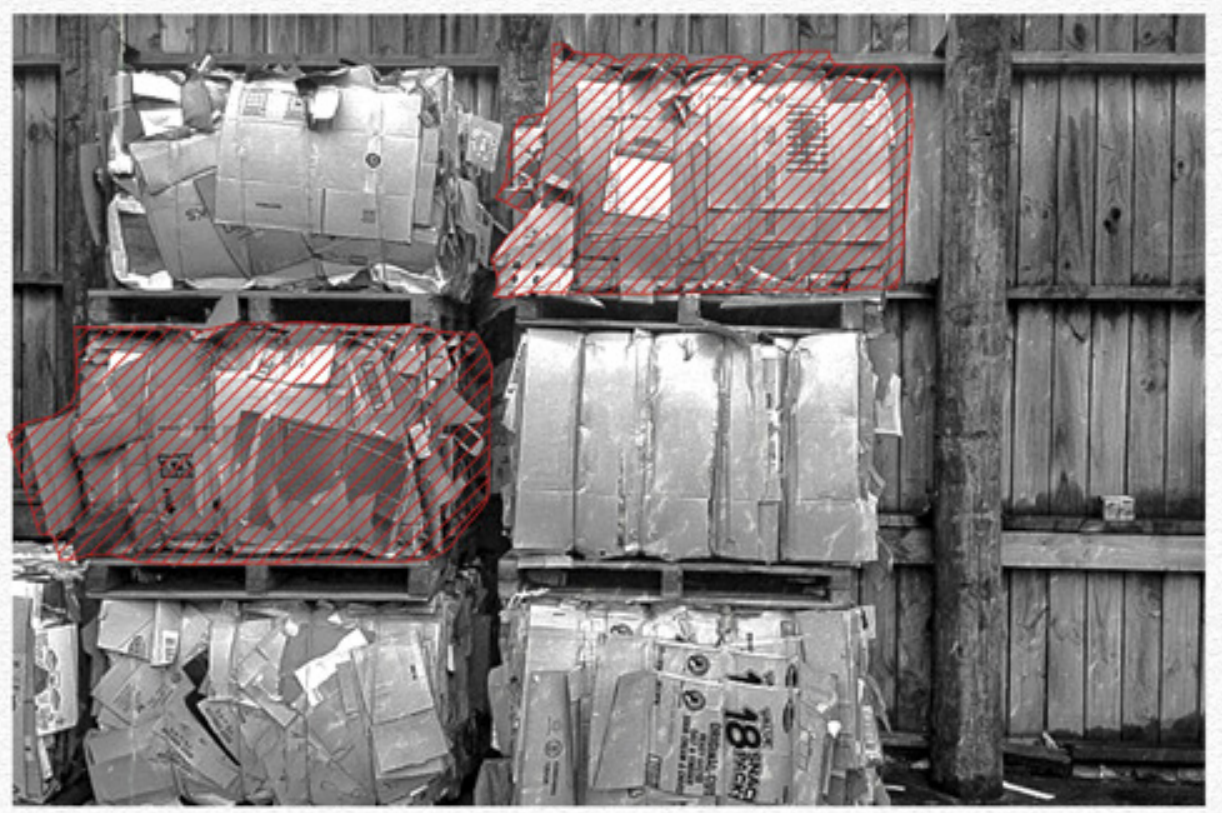

Sorted and Conpacted Cardboard Bails

Large bails of compacted cardboard await outside

a recycling centre to be transported to a local

internediary and industry who will recycling the

cardboard waste into new products. Using this

taw naterial, this thesis is able to reinagine

the current waste strean by providing nex desti-

natioas for Eaterial recovery and sasufacturisg. 


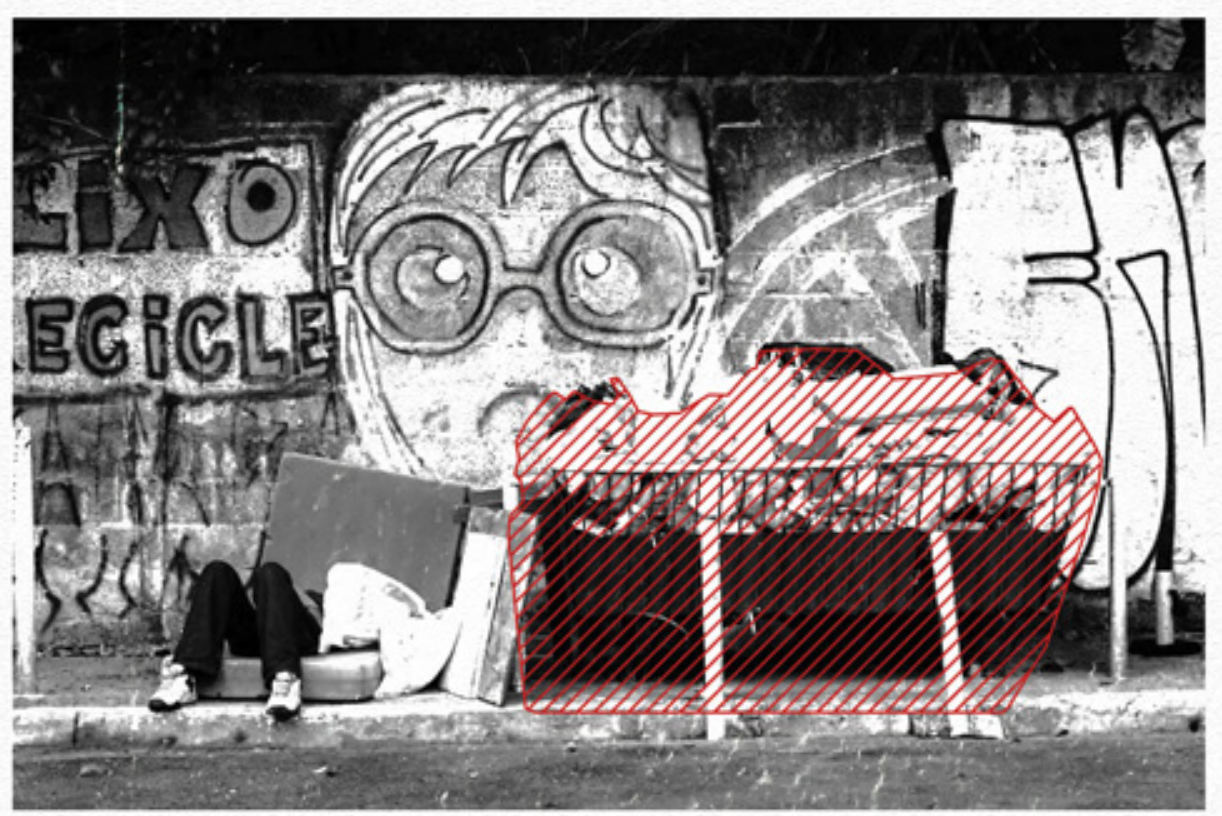

Foreal Waste Collection Bia

Waste accurulating in a city provided zaste bin .

Here we see a local waste collector keeping a

watchful eye on value naterials. 


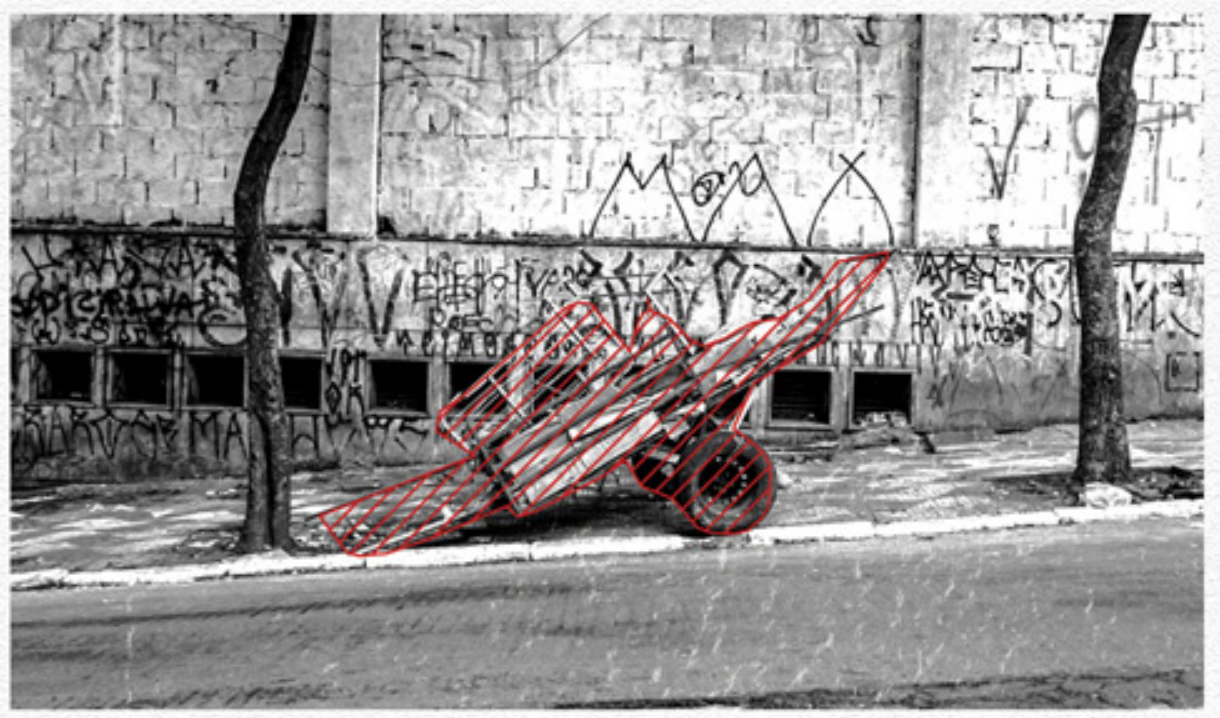

Waste Plicker Cart

A hand pade yaste cellectien cart its seen parked

on the side of the street. while its owner was

found collecting naterial around the corner. 


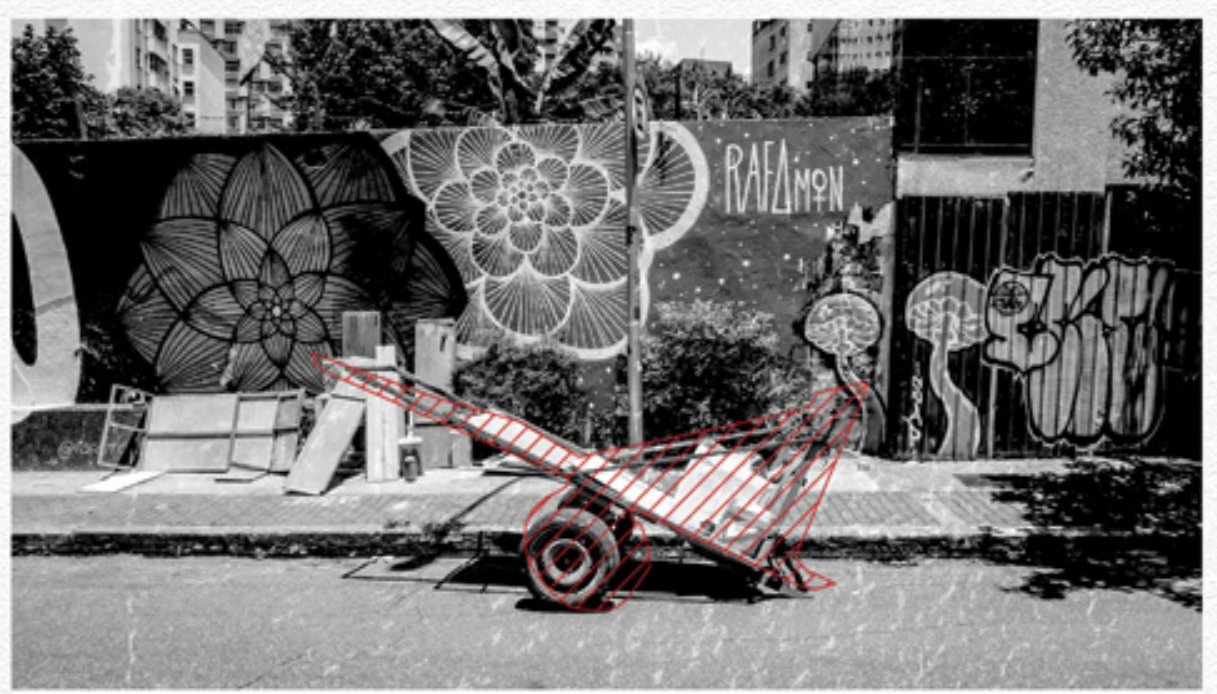

Waste Plcker Cart

Collectifues are an fntegral part of the sao

Pavio waste sector. Working in both infornd and

fornal districts, they perforn daily tasks that

expose then to hazardous naterials and gases. 


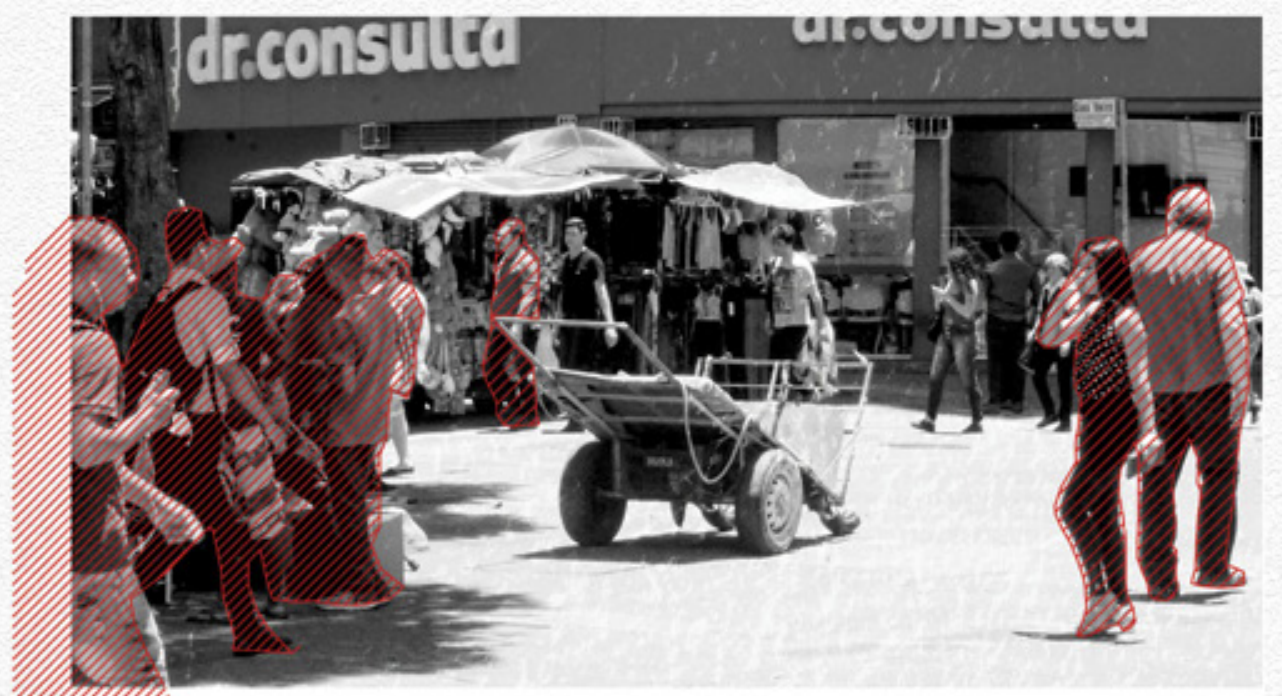

City Dvellers avold recogaitlon of Porsopal

Collection Cart in Sao Paulo Streot

Waste carts are seen throughout the city fabric

of Sao Paulo and are often ignored in public

settings. This blind acknowledgenent facilitates

their occupation as an invisible force within

the city, one that heavily underpins the cities

fortial econotiy. 


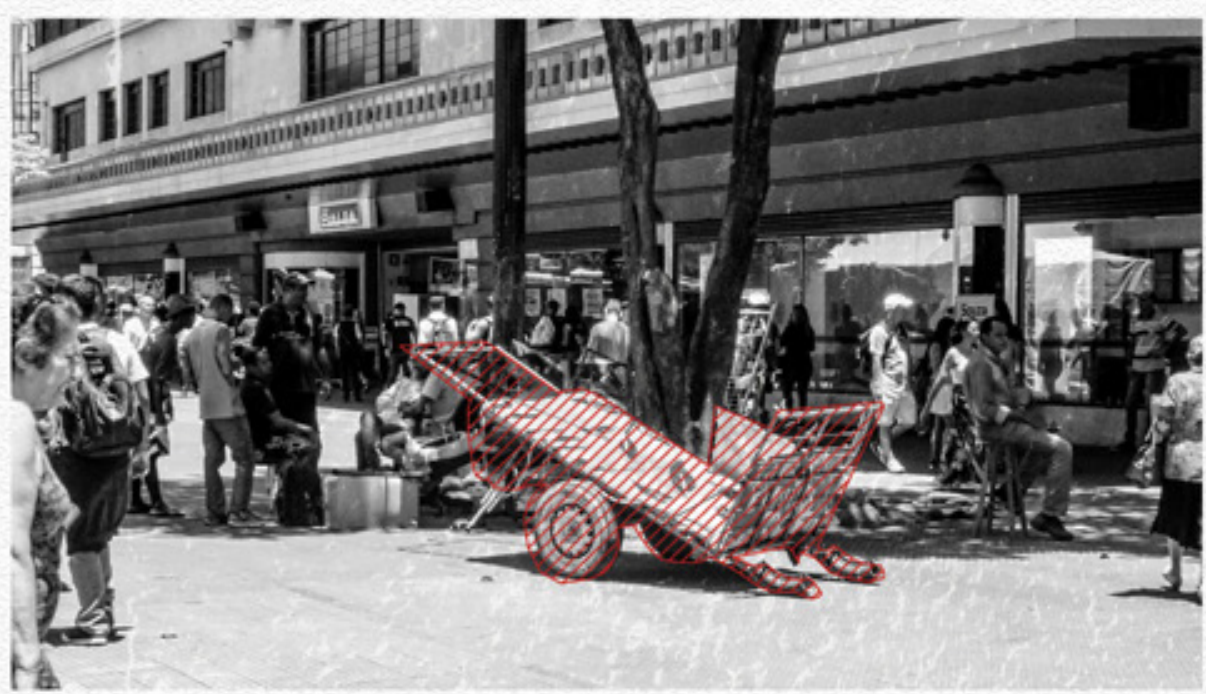

City Dwollers avold recogaitloa of Porsonal

Collection Cart in Sao Paulo Streo"

This sane cart is senp hern fron another ziex,

showing the integration of Waste picking within

the city fabric. 


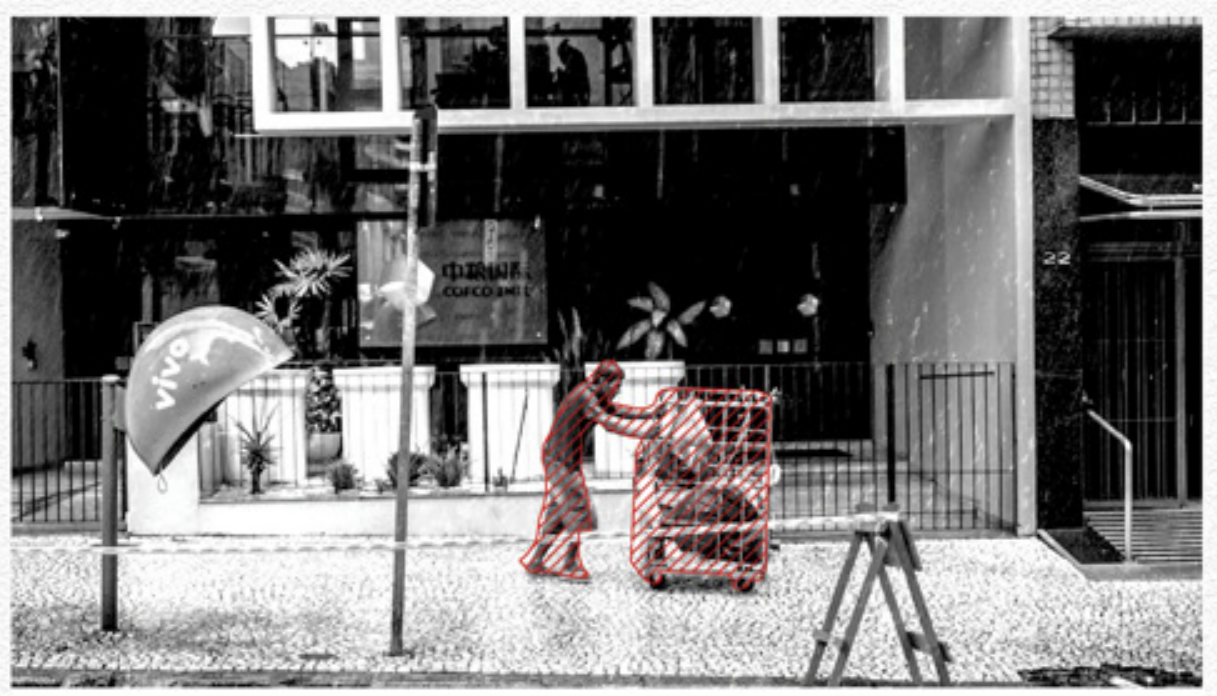

Waste Plcker Sao Paulo

Haste collectora are part of ap fotegrated waste

collection service. Working rain or shine,

pickers collect and forage through city street.

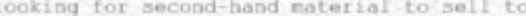

other waste processers in the recycling chain.

Collectors often vork alone doe to the competi-

Civer-antare of the busines.is 


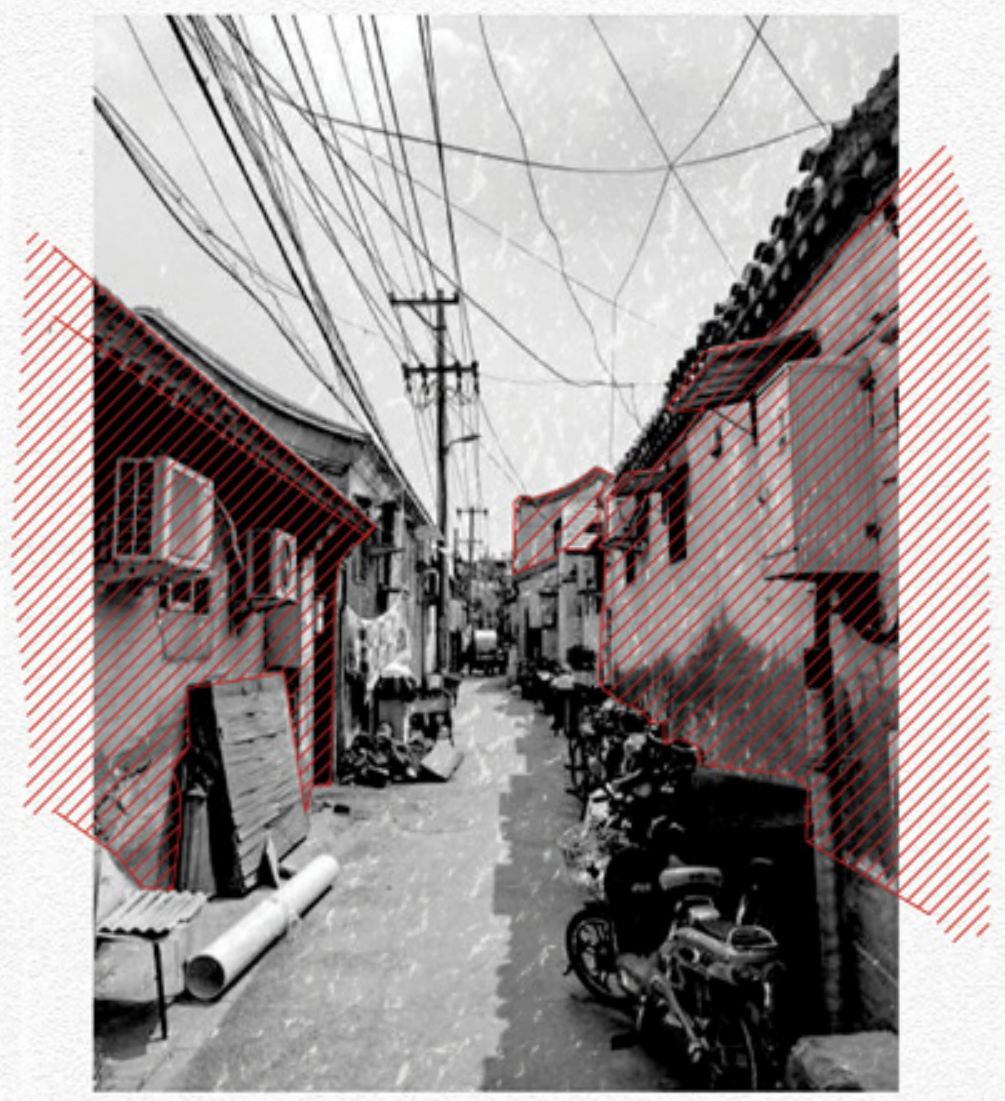

Stroot of Brazilian Favela

Favelas form in reglected zones of the city

fabeic, often holding little to no formal eity

infrastructure, these regions are host to a-ya

Fiety of social and environnontal hazards. Mhilo

these zones are often neglected trom the forms

society, they can be found to develop sophisti

catec focial-structuren that play an integra

part of the economies function. 


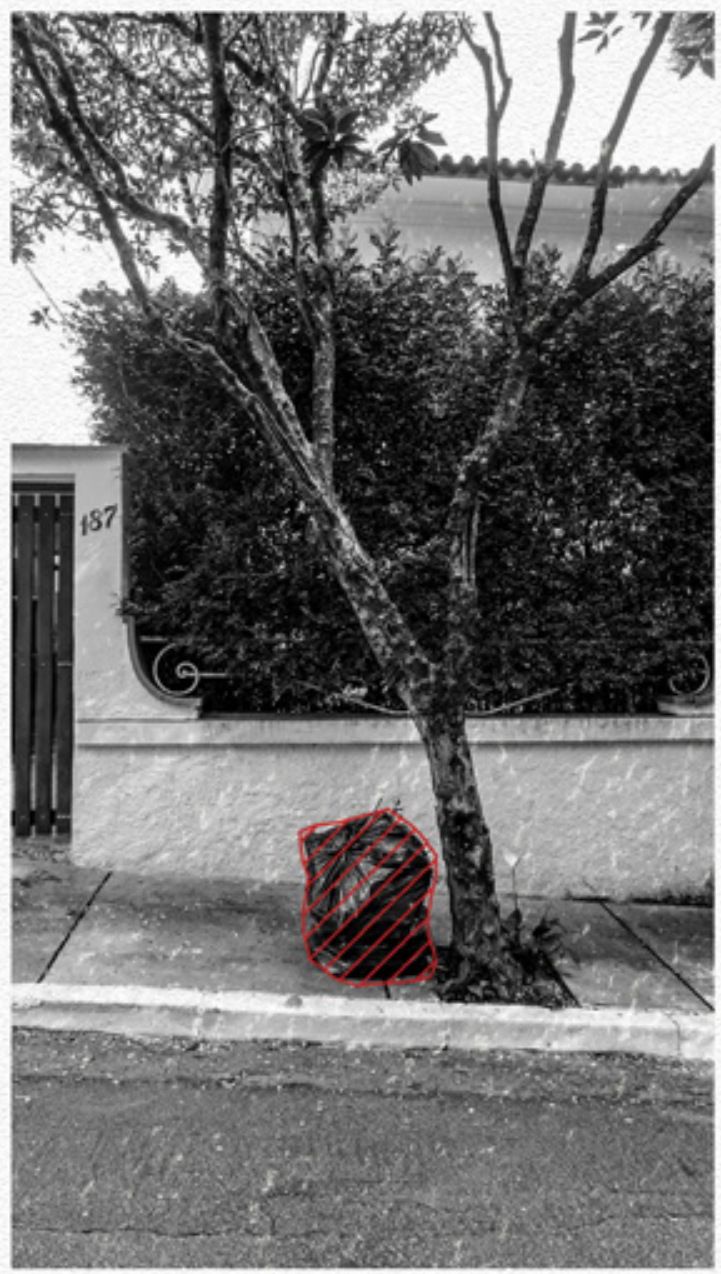

Curb Side Collection, Sao paulo

A single garbage bag sit.s patientiy on the nide of Sao Paulo sidewalk. 


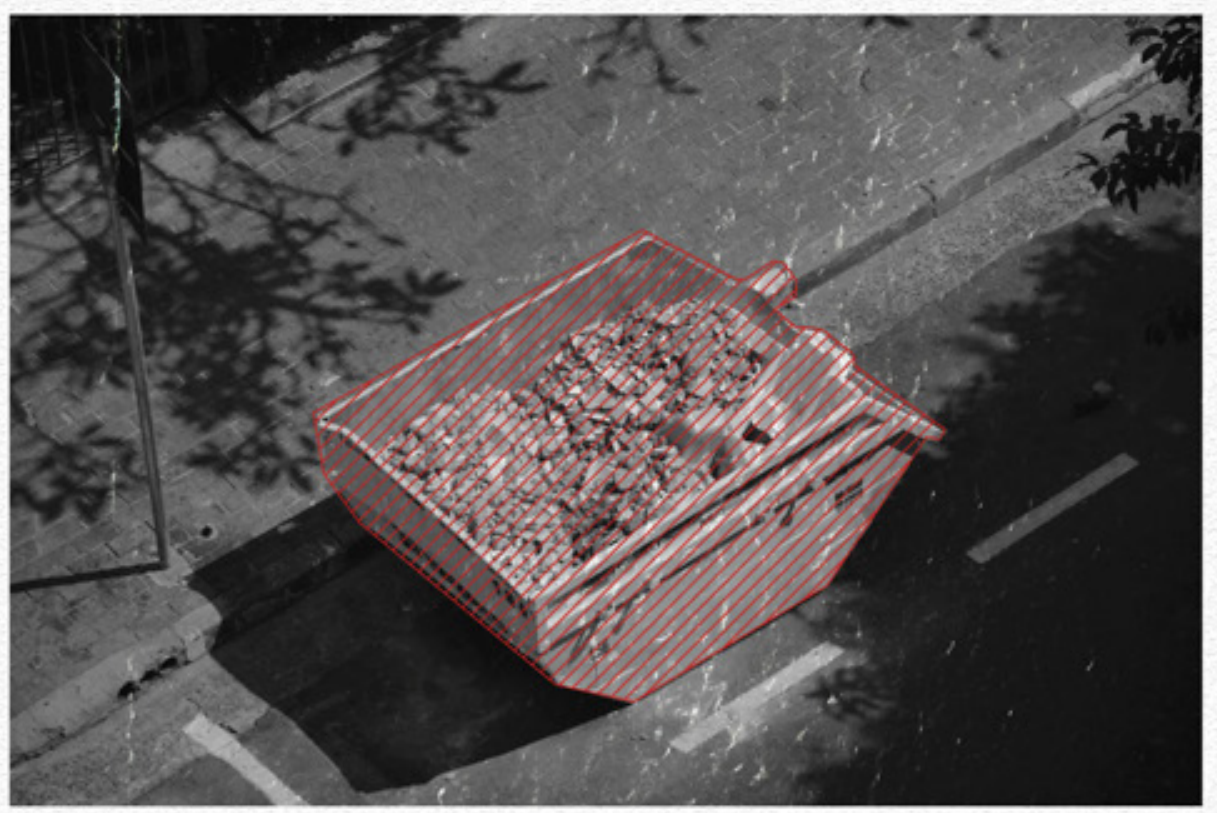

Curb side collection, Sao Paulo

Large steel contafners are found throughout Sas

pavio. Oxned by the fortal recycling sector,

they allow consuners and city dvellers easy ac-

cess to specific naterial vaste fireans. Further

facilitating the eficiency of the Sao Pailo waste

sector. 


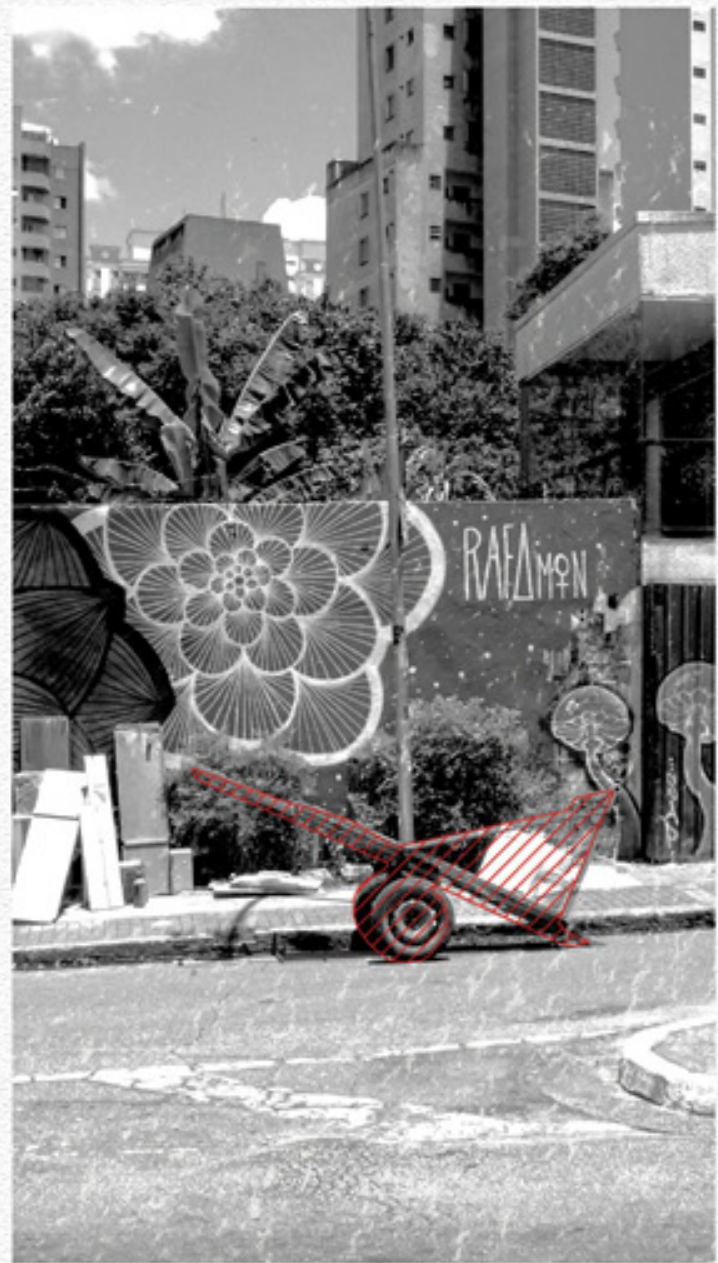

Waste pickor Cart, Sao paulo

A anonymoun wate cert is seen on a Sao- Pavlo

street. 


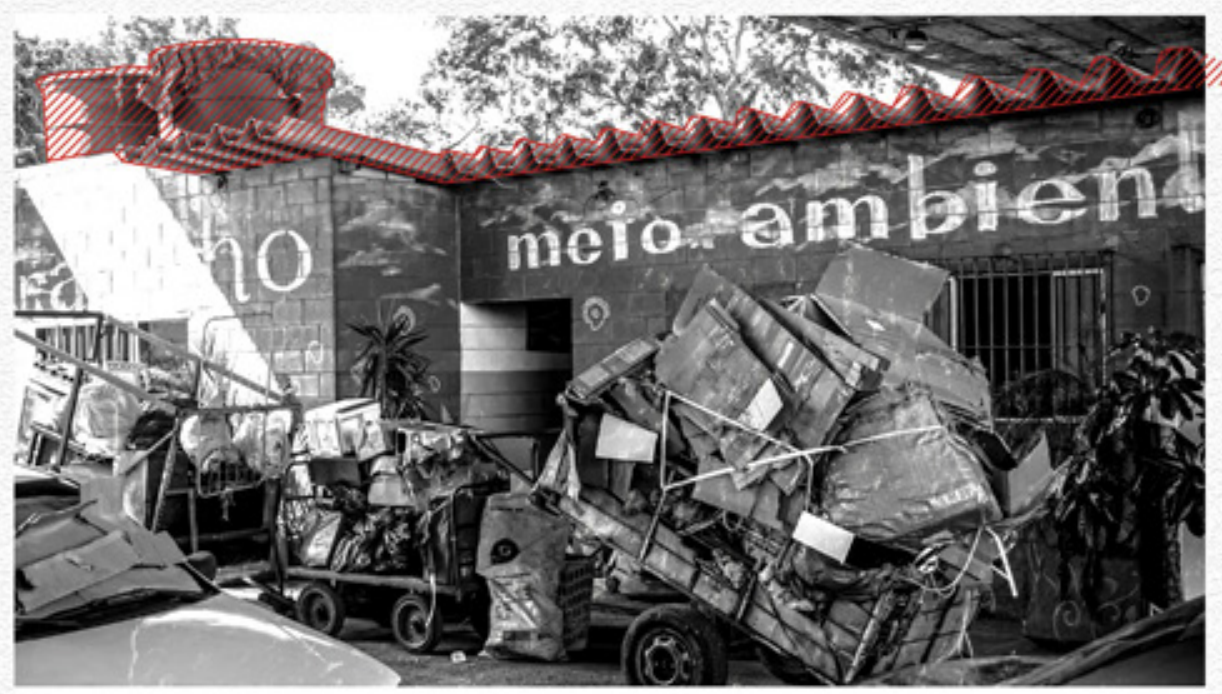

Alterative Roofing Materials

Inforral Recyeling cooperatives are founded by

individuals who ack external support and fund-

ing. Informal Cooperatives often use scrap or

found naterials to copstract their destroyrd

infrastructure. Here ve see sheet piles being

repurposed for a study and effective roofing na-

terint. 


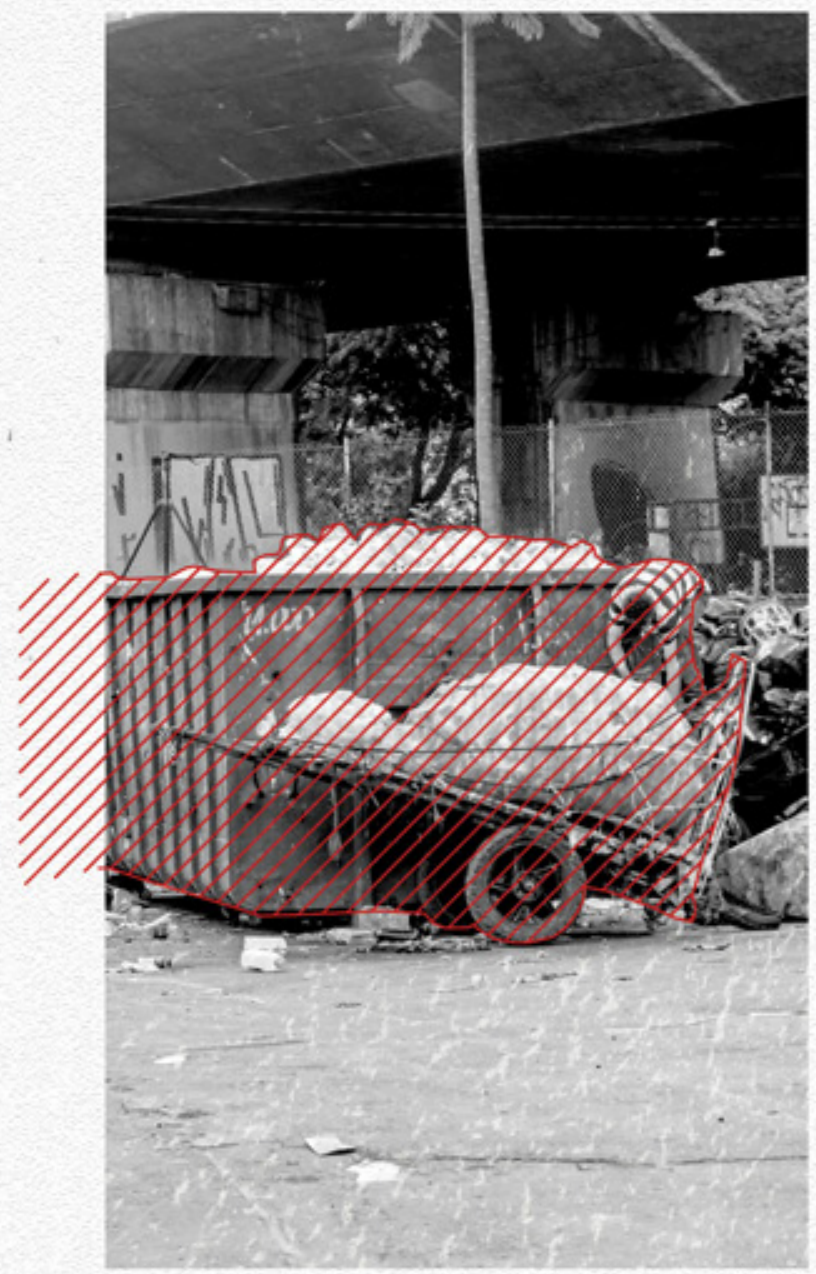

Infornal Recyeling centre, Sao favio

A waste collector is seen sorting his own col-

lections into their appropriate waste streams.

Workess will be paid for the total weight of re

eyclable material that is dropped of. Theit catt

ia weiqued or entry and exit. 


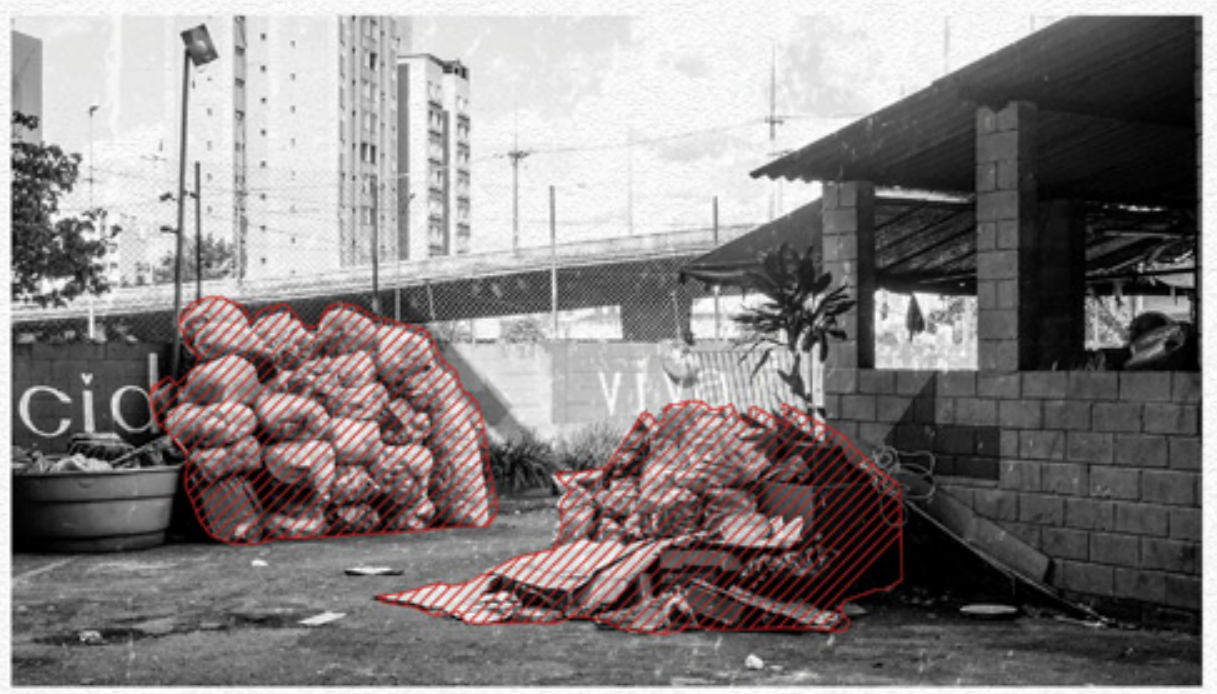

Eafornal Collection Ceatre, Sao Paulo

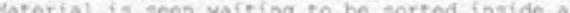
local informal recycling contre. 


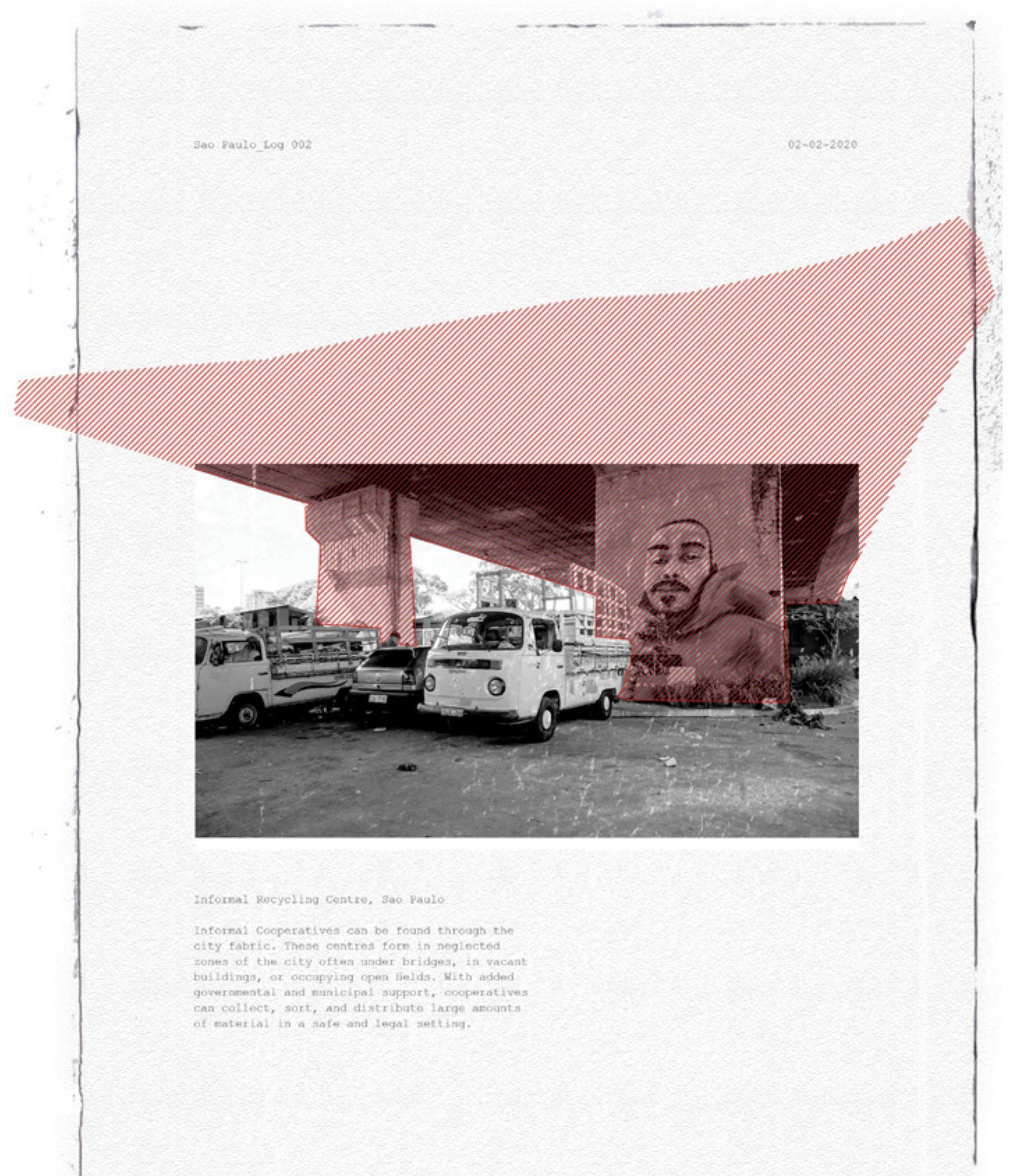




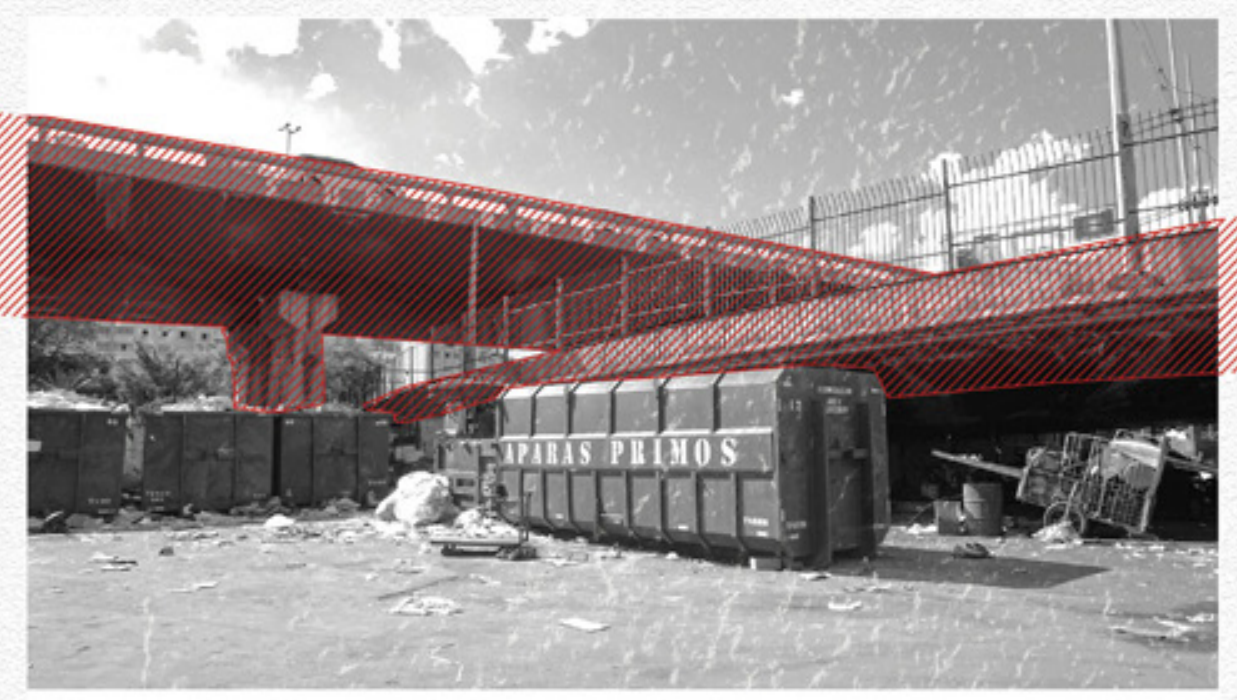

Informal Recycliag Centre in coraers of Clty

Intastructure

Highway interchanges becone the backdrop to o downtown collection centre in Sao Paulo, Brazil. 


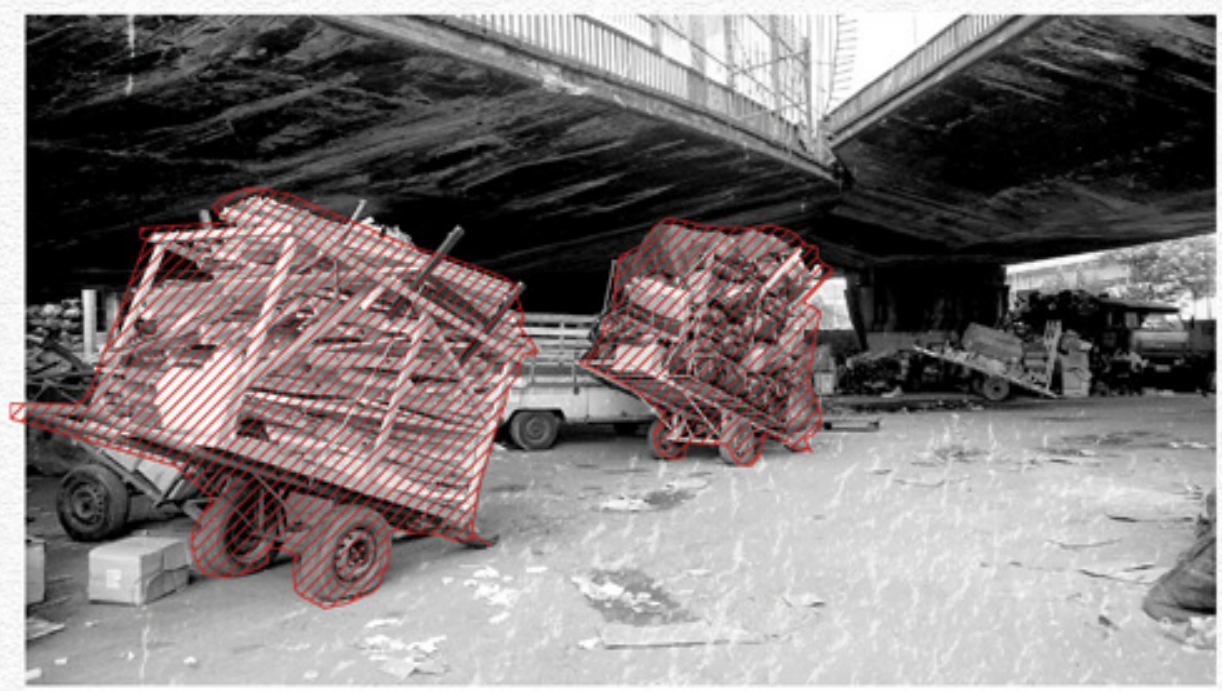

Infornal Recyellag Centre, Sao Paulo

City approved Cooporatives can support nasy

stakeholders within the waste strean. Together,

cooperatives can enploy thousands of pickers,

collectors, and sorters while providing greater

environmental and econonic benefits to the city

and its citizens. Shows here are two carts of

acrop netal that $x i h$ be enptied trito its appro

priate noterial atreans. 


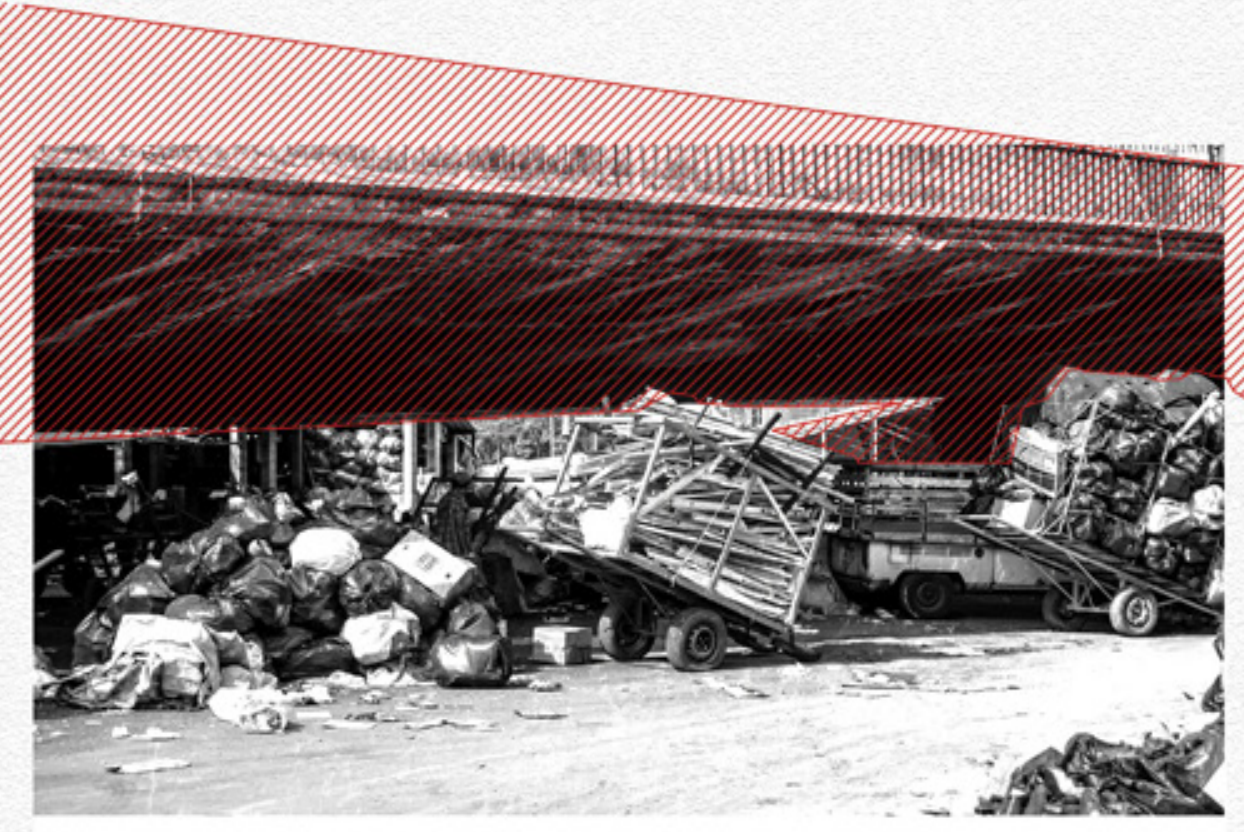

Infornal Recyellag Centre, Sao Paulo

A Sao Paulo interchange highuay is seen as the backdrop to an informal recycling centre. 

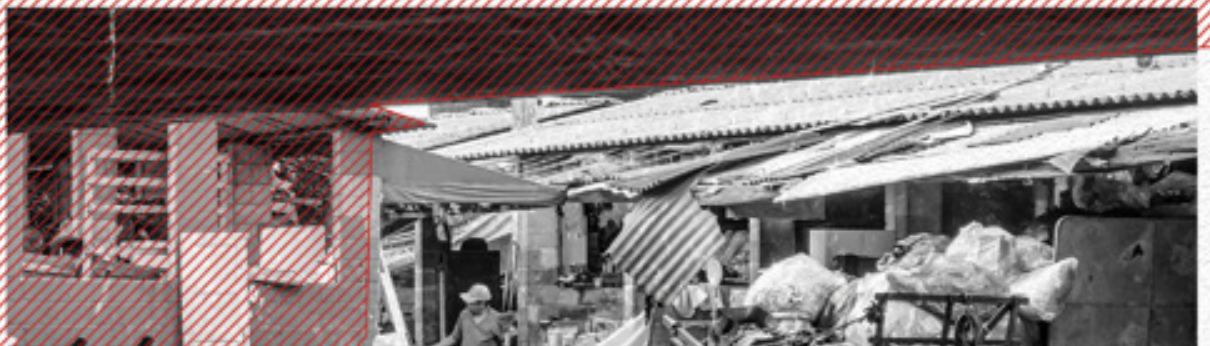

Pats 


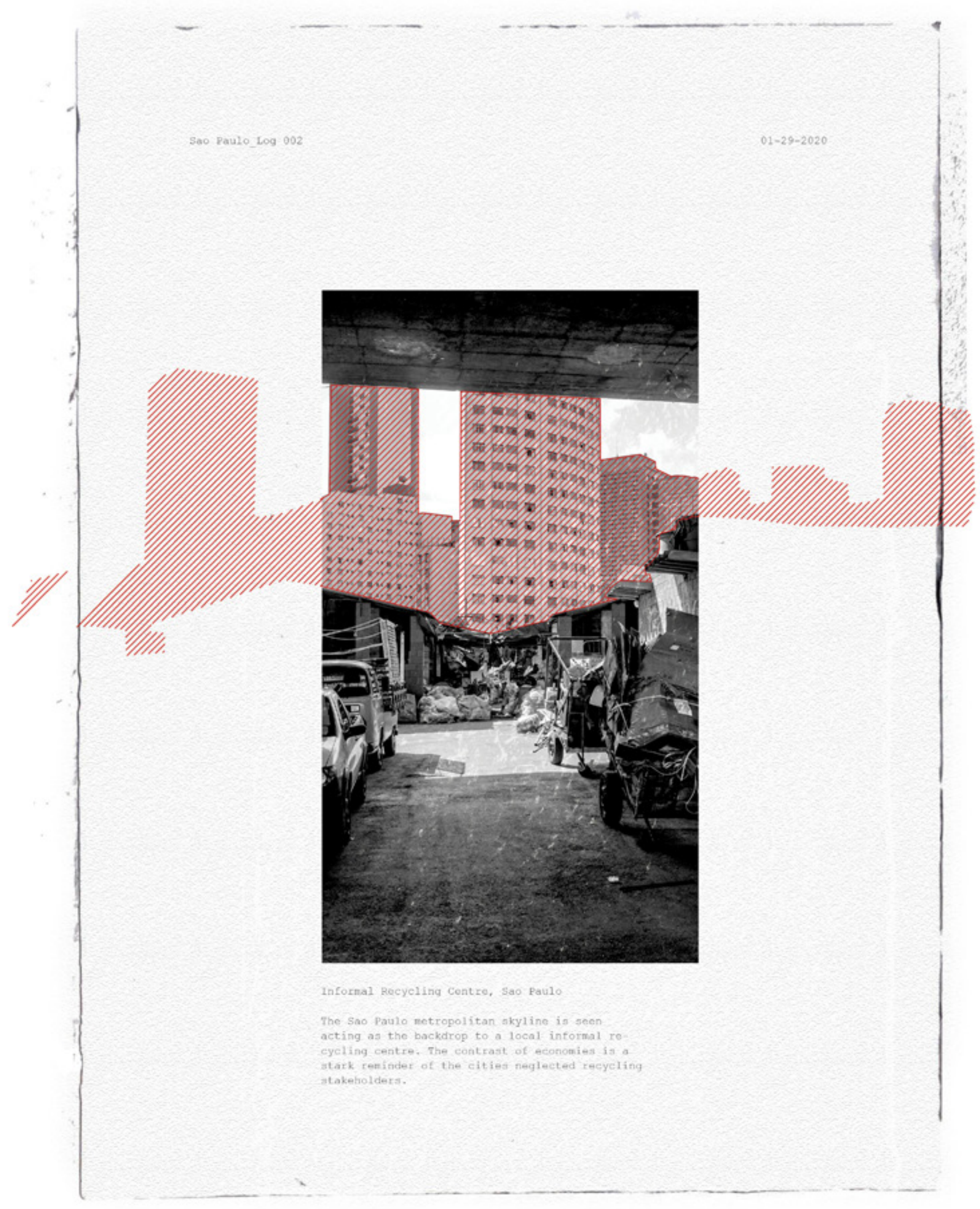



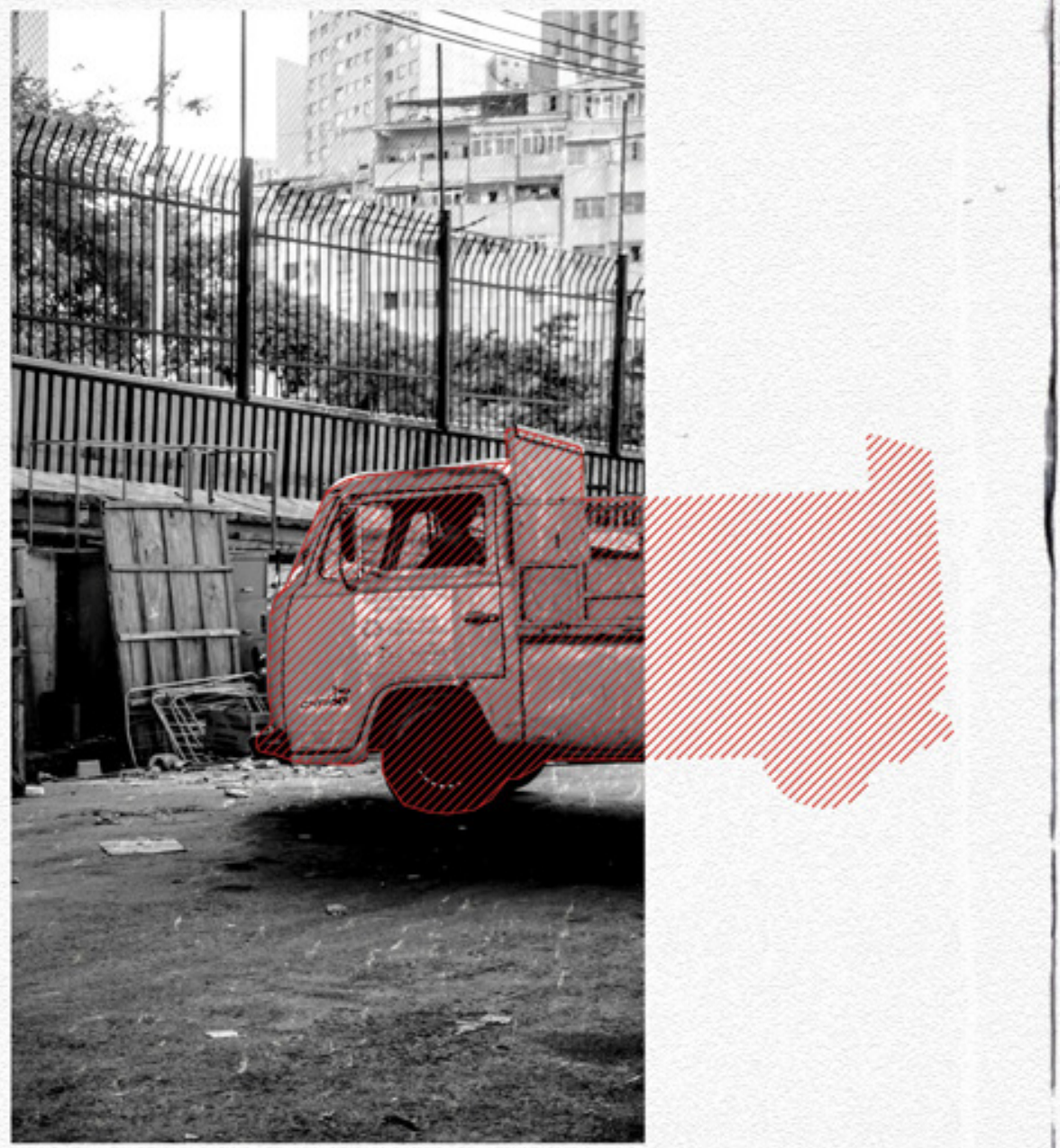

Informal Recyeling Centre, Sao pavio

An informal waste collector is seen picking up

bailed and sortod material bofore delivoring it

to other faternediaries. These middlemen are of

tea recogsized by varying copoeratives and othe:

later

larger assets 1 iko trucks, PFE, and contracts. 


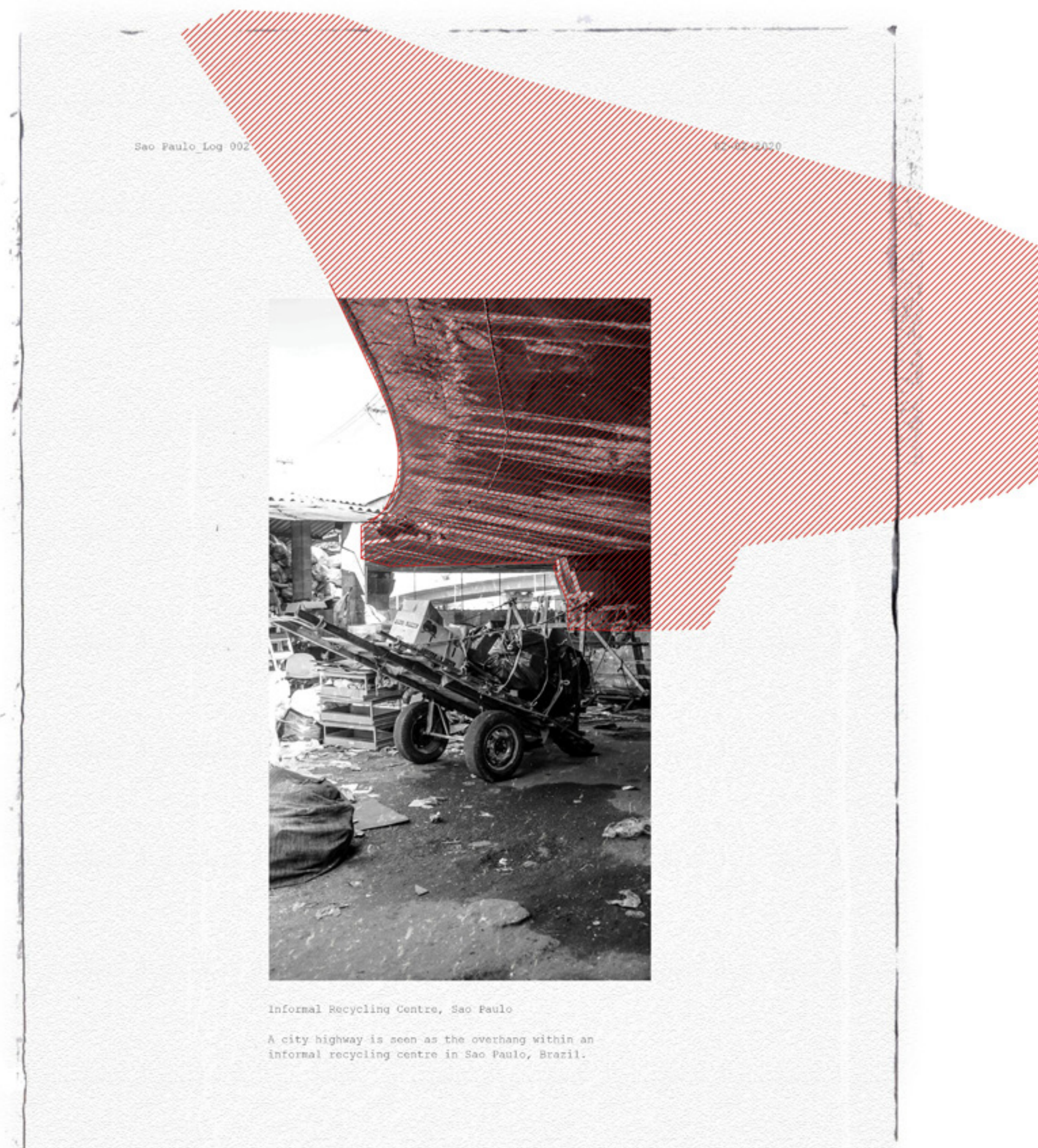



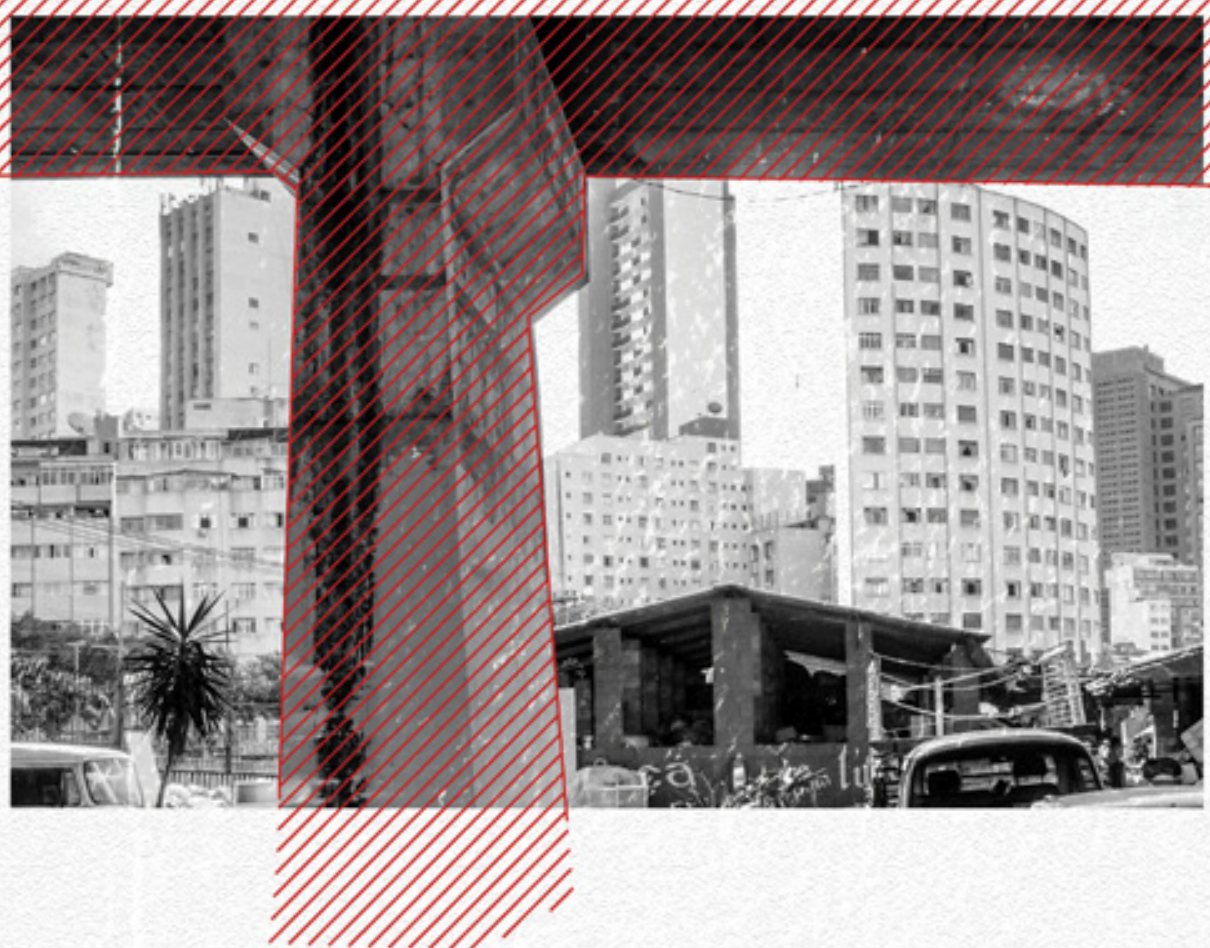

Enformal Collection Ceatre, Sao Paute

Neqlected zones of city fnfrastructure are ofter

adopted by laformal recycling centres and coop-

eratives due to their stable and central con

ditions. Seen here is one of many netropolitan

cooperatives that operate behind the public eye,

belping aliubinate-the contrast betwete infortal

asd formal econcmies of the city. 
PART IV MATERIAL EXPLORATIONS 
4.0 MATERIAL EXPLORATIONS

MATERIAL ARCHIVING

"As an architect, we design for the present, with an awareness of the past, for a future which is essentially unknown." 


\subsection{MATERIAL DEVELOPMENT NEXT STEPS}

Using resources within Carleton's engineering departments, a series of tests will be conducted to determine the products relevancy within the building industry. In order to understand the thermal properties of the material, I will use a vacuum autoclave to thermally modify the NMFC material and perform a series of standardized defined tests at varying temperatures for various lengths of time to create a matrix of samples. As thermal modification changes the properties of various species of wood differently, I must determine the internal changes for NMFC. To help with this, discussions with research partner Professor Owen Rowland and his biology lab at Carleton University will serve as the format for this objective. Research assistant, Quinn MacDonald (biology), who provided early guidance will assist in understanding how plant-based polymers and oils create unique agents to assist in the hydrophobic, and environmental qualities of the NMFC SIP.

During testing, the material will be observed on an hourly basis, with surface readings taken with our Infrared laser thermometer. Milling samples or 'paddles' for structural testing will help us achieve ASTM results regarding the materials tensile, compressive, and shear rate forces. To gain an understanding of the application of NMFC material for structural use, tests will be required at both a material level and structural component level. Through Professor Jeffrey Erochko, existing universal load frames in the structural laboratory at Carleton University will be used to 
load/test small-scale material samples and the full-thickness SIP samples that are fabricated of cellulosic material feedstocks, providing myself and our team with material structural data to inform design decisions about the future potential uses of these materials in architectural applications.

To conduct steady-state laboratory testing for insulative qualities, a guarded hot box constructed at Carleton University will be used. This apparatus allows for the steady-state testing of a $500 \mathrm{~mm}$ by $500 \mathrm{~mm}\left[1^{\prime}-6^{\prime \prime} \times 1^{\prime}-6^{\prime \prime}\right]$ wall specimen being installed between two chambers; the first representing outdoor conditions and kept constant at $-15^{\circ} \mathrm{C}$ and the second representing indoor conditions and held at $24^{\circ} \mathrm{C}$. This facility allows for the effective heat flux to be measured through the $500 \mathrm{~mm}$ by $500 \mathrm{~mm}\left[\mathrm{I}^{\prime}-\right.$ $\left.6^{\prime \prime} \times 1^{\prime}-6^{\prime \prime}\right]$ section, using heated plates and digital monitoring of the material inside and out. The computer software THERM will be used to predict the thermal performance of the wall, with experimental data being used to calibrate the models. THERM was developed by Lawrence Berkley National Laboratory, and uses a two-dimensional, steady-state, finite element method to determine heat flux and the temperature distribution within building envelope sections. Using these methods, the overall effective thermal resistance of the prefabricated building components will be determined.

These tests will be specifically designed to help illustrate the NMFC potential in the built environment. Providing vital material knowhow and scientific development in how second-generation materials may become the key to alternative material solutions around the globe. 


\subsection{ARTISAN SCALE MAKING}

To better understand the material at all scales, my investigations continued upon return to Carleton University supported by tools and equipment in the CSALT laboratory ${ }^{115}$ necessary to begin making small scale composite panels. I began forming questions that focused on artisan scale making to explore recovery techniques without the sophisticated machinery that Zeoform's technology requires.

I first began rummaging through the Architecture school to collect varying paper types to sort and refine with using a standardized Vitamix blender. These techniques that seemed quite quantitative, enaged me in a more qualitative world by performing waste picker techniques of selective collection. Over a matter of weeks of paper board making I began to notice recognizable differences in pulp colour, strength, and texture from various fibres collected and the type of paper that it subsequently produced, allowing me to formulate broader conversations around paper recovery and understand forms of knowledge that pickers would accumulate over a lifetime of picking.
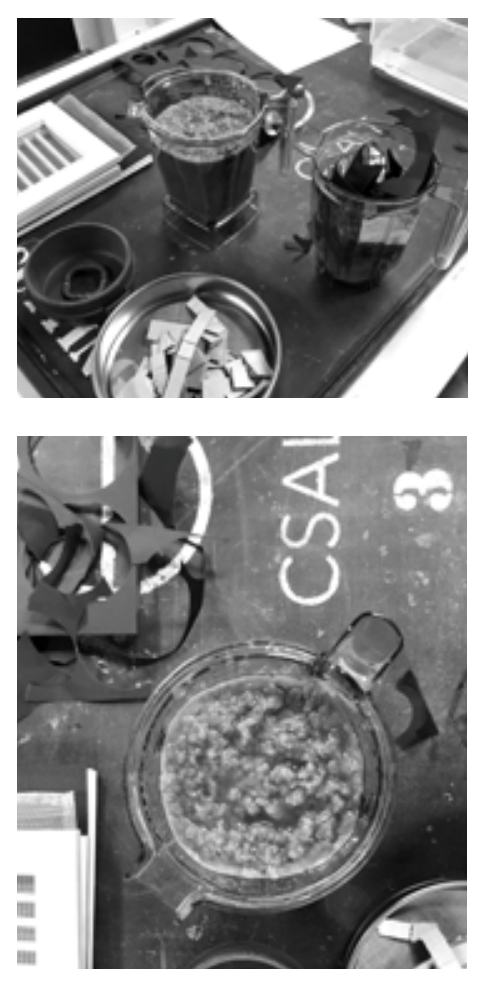

Fig. 052: Process photo of artisan scale making, Carleton University, 2019

Fig. 053: Process photo of artisan scale making, paper pulp. Carleton University, 2019 
Using only recovered paper and water, these analogous explorations created prototype building blocks in standard dimensions ( $\left.5^{\prime \prime} \times 5^{\prime \prime} \times 1^{\prime \prime}\right)$ which were in similar proportion to prototypes created in Australia. This artisan scale experimentation has helped me imagine what scales of operation could be deployed within the Sao Paulo context with relatively simple tools and infrastructure.
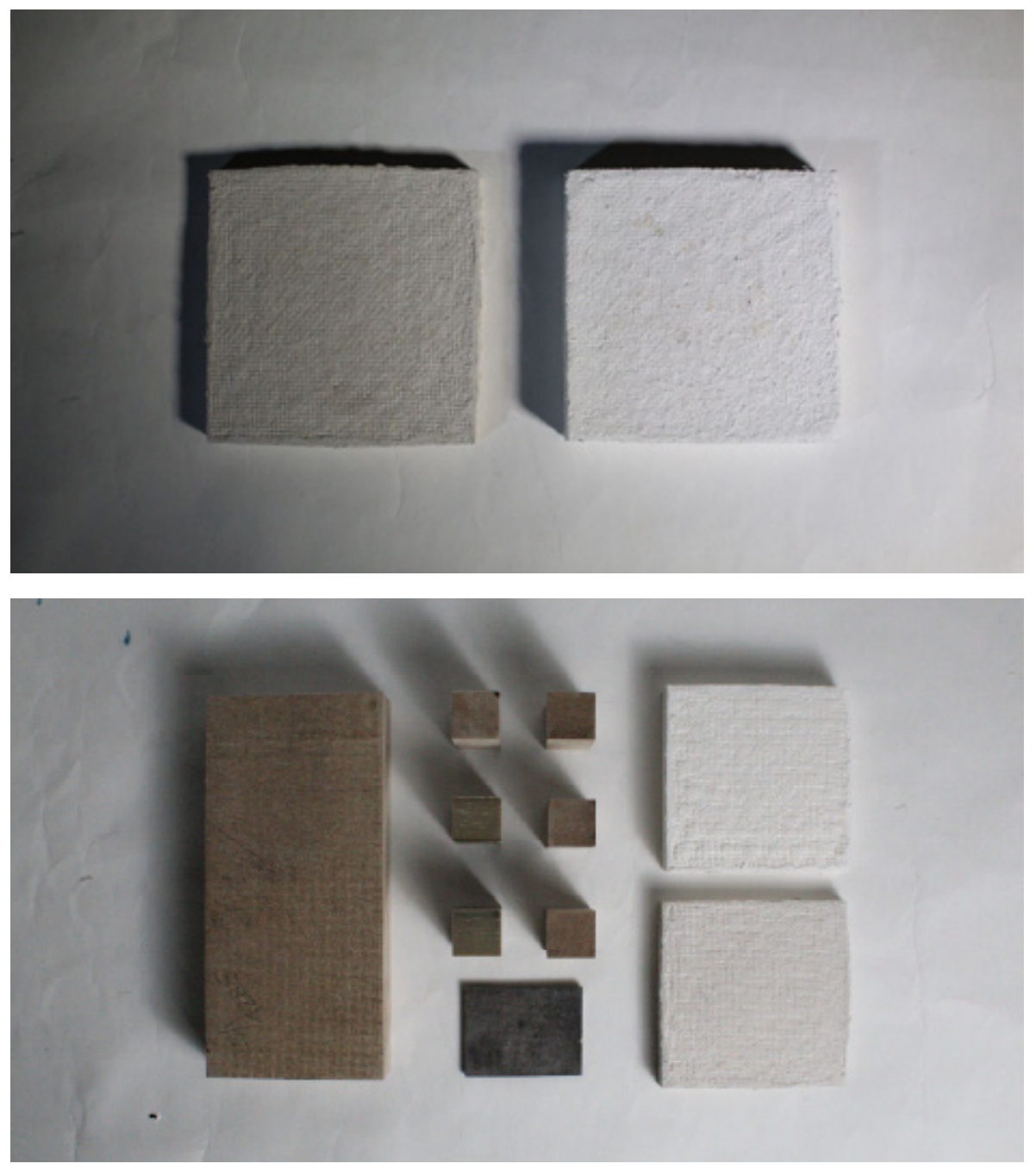

Fig. 054: Photo of paper pulp casted block 1, Carleton Universi-

ty, 2019

Fig. 055: Photo of paper pulp

casted block 2, Carleton Universi-

ty, 2019 


\subsection{PAPER MAKING}

After thorough research and analysis of traditional and modernized artisanal paper making processes, I began to design and fabricate my own set of handmade paper making tools. Similar to processes perfected in the 18th and 19th century, paper was first cut into inch sized pieces before a soaking period in water for up to twenty-four hours. Once fibres were fully saturated, I combined with more waste paper in a vitamix blender to create a porridge like consistency of shredded pulp. After multiple repetitions, I began to develop a tacit knowledge for the pulps consistency and appearance to achieve the best results. For example, if one is planning on making many sheets of the same colour paper, all pulp should be made prior to mat forming as introducing more mixed papers mid process will dramatically effect both the strength of paper as well as its overall appearance. Ideal fibres would be comprised of print making paper, watercolour paper and cotton type papers for their initial fibre strength and off-white appearance. Additionally, one could add a small amount of cardboard to the mix to create a slight tanned appearance after drying.

Next, pulp is thoroughly mixed together and placed in a separate container (\#1) with ratios of 10:1 water to pulp. Using a previously constructed mould + deckle $(M+D)$, I gently slid the $M+D$ inside container $\#_{1}$ from the longest edge and with a scooping motion to allow for pulp to fully disperse itself along the

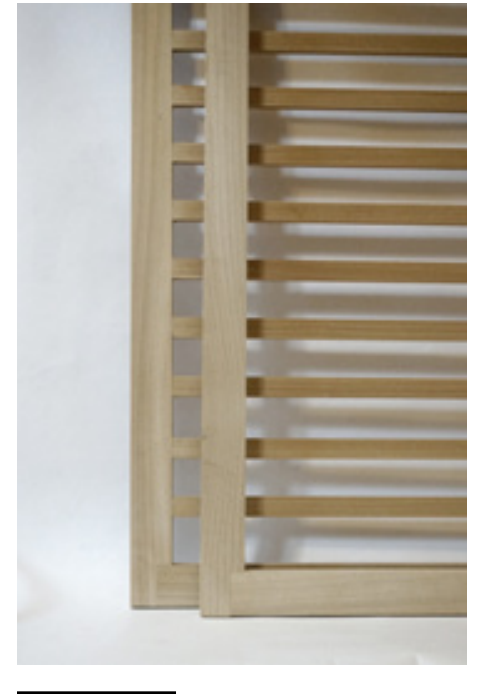

Fig. 056:18"x 24" Ash frame for paper making, 2019

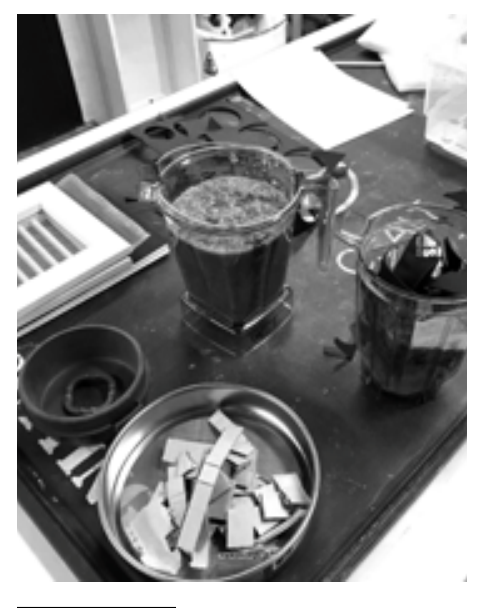

Fig. 057: Photo of paper pulp casted proces.

Carleton University, 2019 
metal screen of the deckle. Once fully dissolved and dispersed on top the deckle, I raised the M+D out of the pulpish water, while giving short back and forth motions in a perpendicular direction. This allowed fibres to equally settle as the water drained through the screen behind it. After letting the pulp rest for a few moments, I lifted the deckle off the mould to reveal about a $1 / 8$ " formed pulp mat. Next, using a large paint roller, I would slowly and consistently apply pressure to the top of the new pup mat. This process applies even pressure along the saturated mat and pushes water through the supporting screen behind. With a clean flat surface topped by absorbent towel adjacent to the container, I would flip my mould with the pulp mat, onto the dry absorbent towel. This uniform motion will ideally remove the pulp mat from the mould screen and leave a wet pressed paper mat on the absorbing towel. Following these steps, the mats are ready for the press, which Technical Instructors, Mark MacGuigan and Robert Wood were kind enough to provide an old book press, appropriate for rethinking paper. The paper mats would ideally sit for 2-3 days under consistent pressure to ensure a flat drying process.
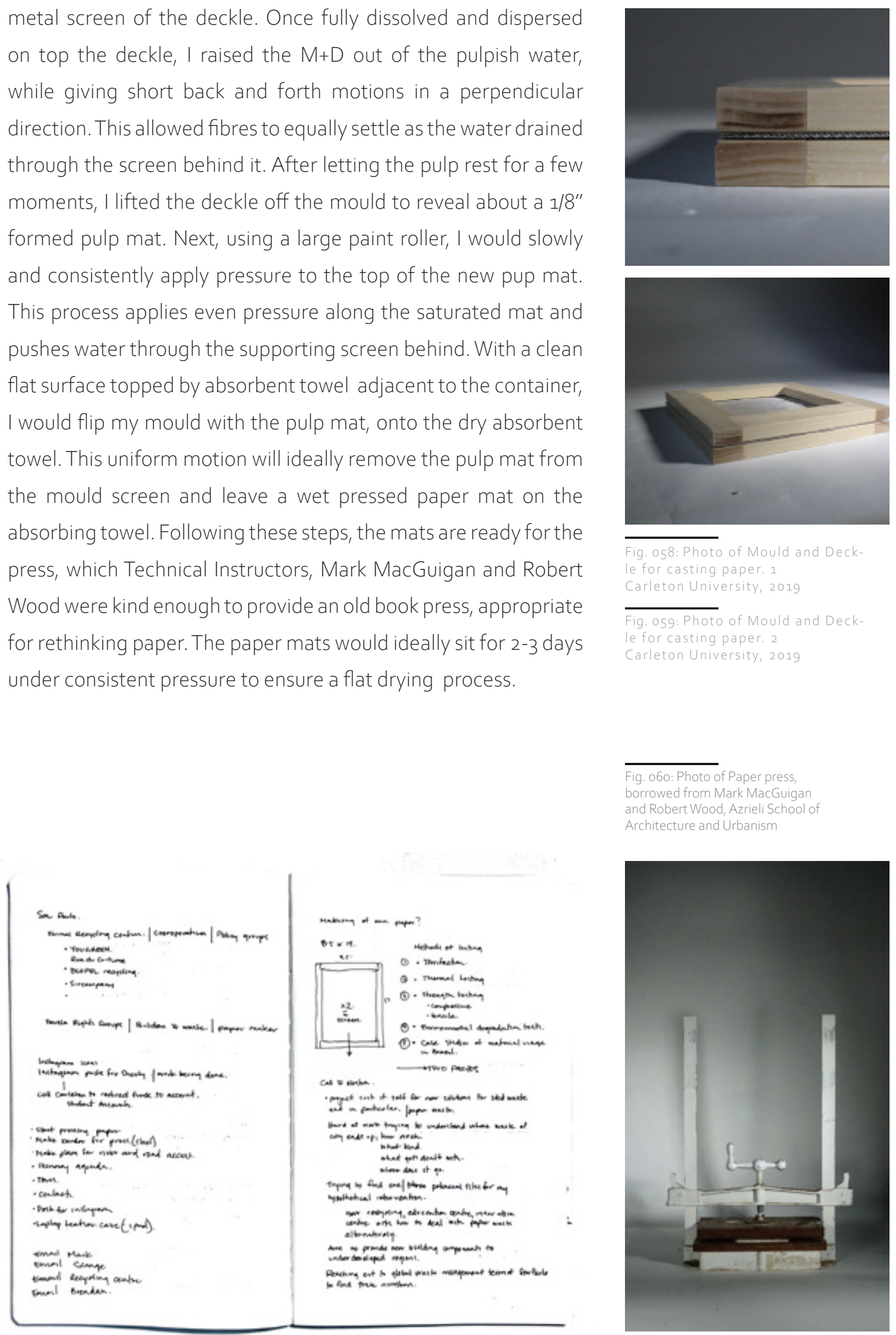

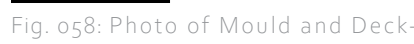
le for casting paper. 1 Carleton University, 2019

Fig. 059: Photo of Mould and Deckle for casting paper. 2 Carleton University, 2019

Fig. 060: Photo of Paper press, borrowed from Mark MacGuigan and Robert Wood, Azrieli School of Architecture and Urbanism

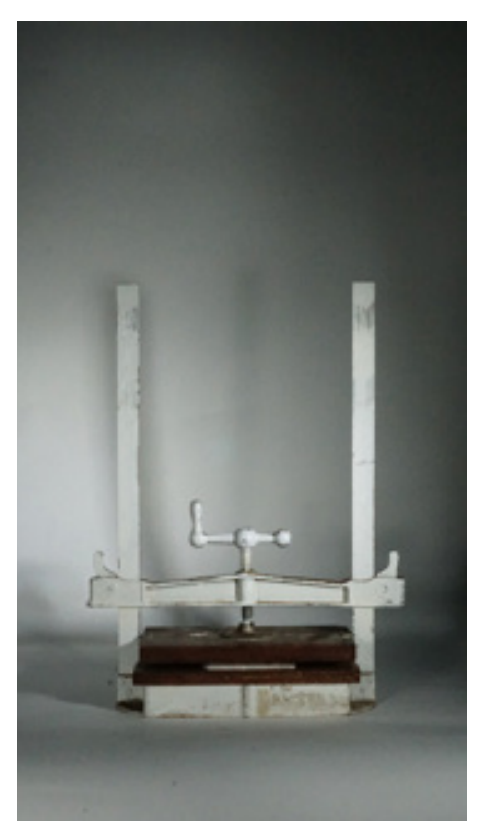




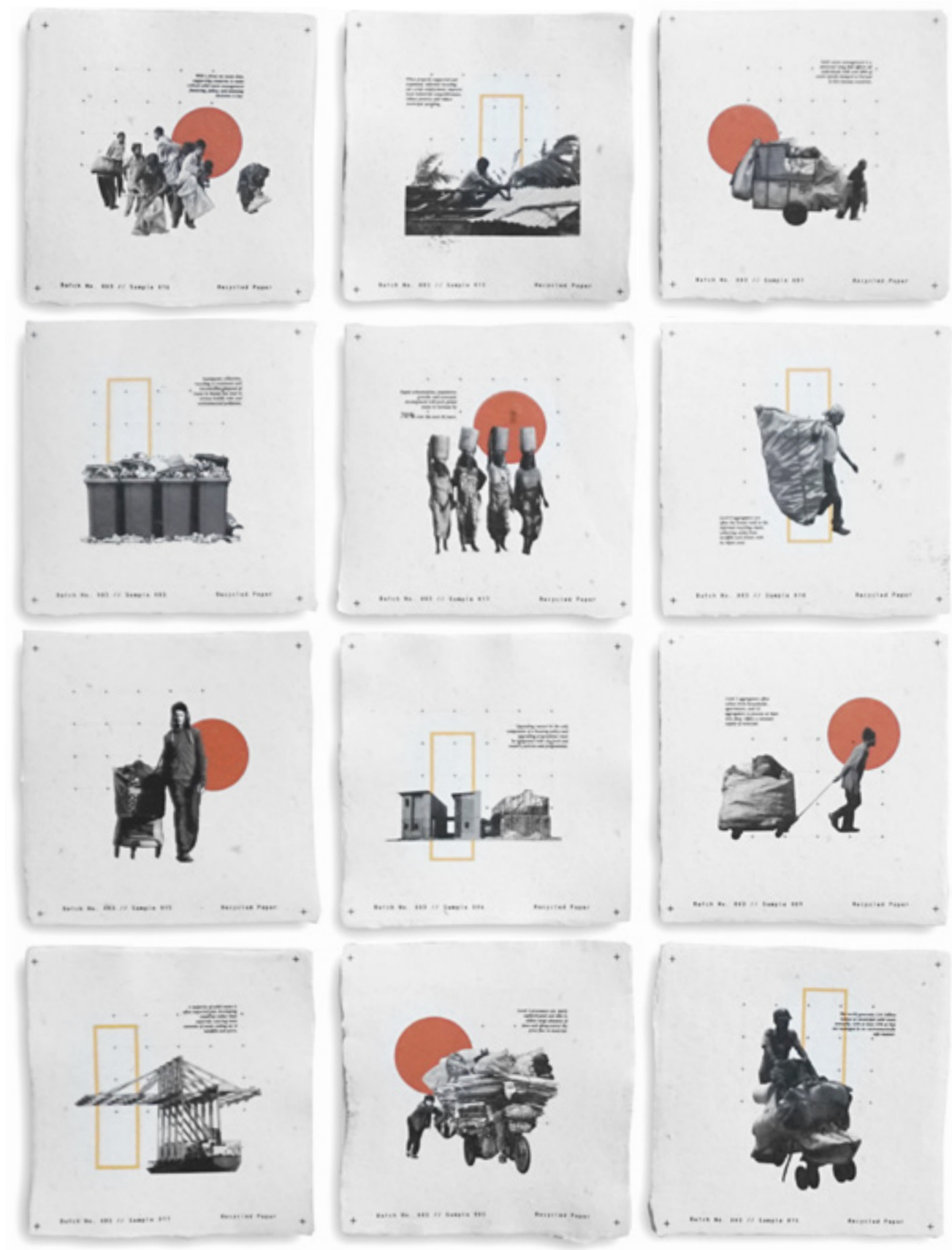

$\overline{\text { Fig. 061: Photo Montage of Informal }}$ Waste Pickers of the Global South. -Printed on hand-made paper for Colloquium 2. 2020. 
In the simplest form of paper recovery, this exploratory hands-on experiment started to identify and illustrate concepts and techniques that could be directly applied to the forming of NMFC in flat stock panels. The aim of this exploration was to familiarize myself with the tacit knowledge of making in similar fashion to what Martin Ernegg at Zeo has achieved over the years of his work, ultimately furthering my understanding of paper recovery techniques and reimagining how waste flows of paper could be rerouted back into new products.
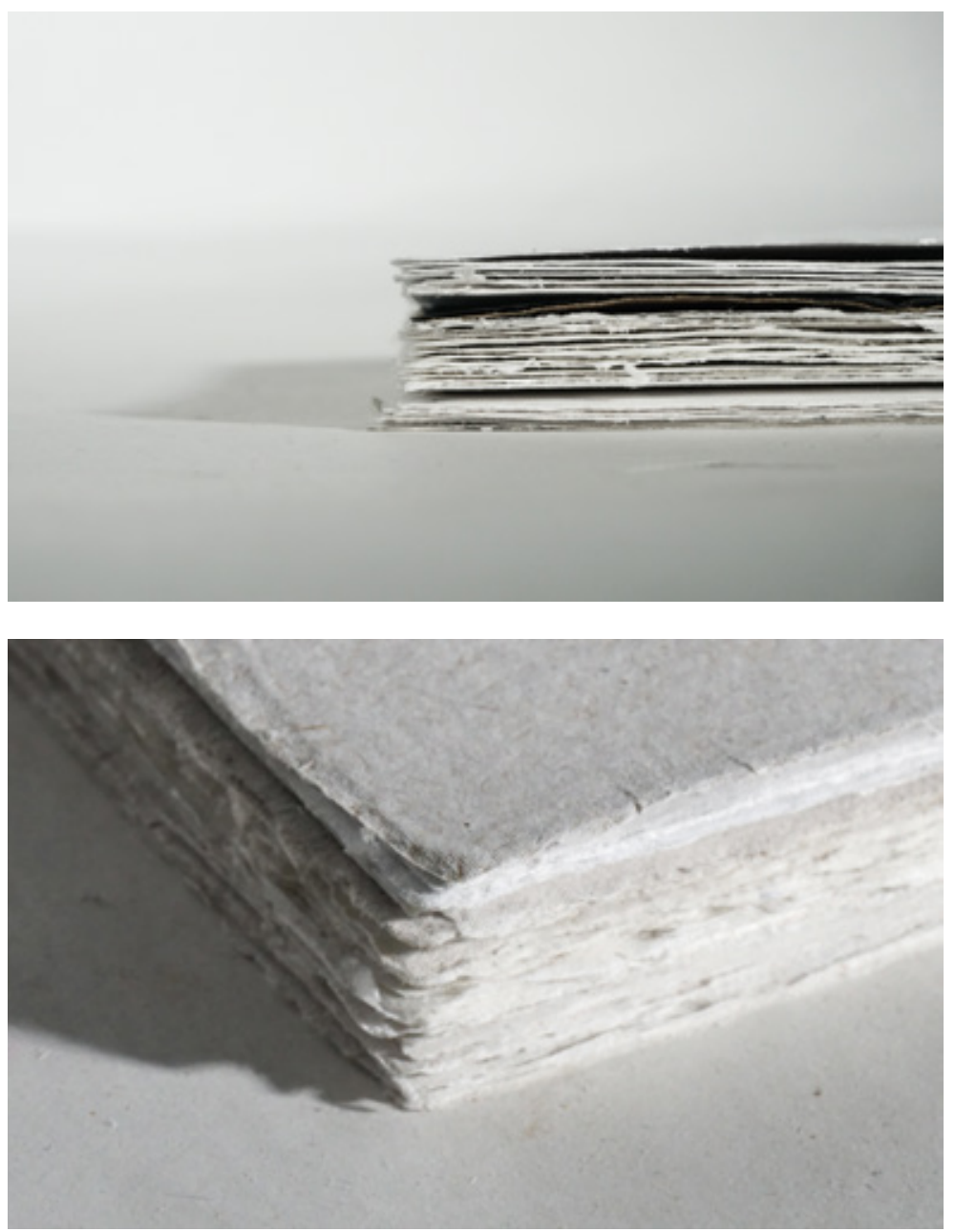

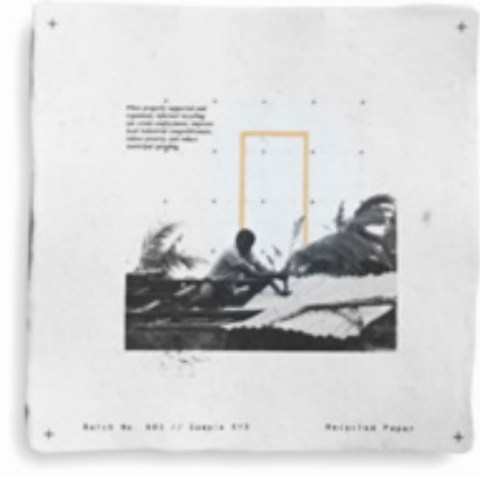

Fig. 062: Paper made by hand 1 Carleton University, 2019

Fig. 063: Paper made by hand 2 Carleton University, 2019 
PART V 
5.0 MATERIAL DEPLOYMENT GLOBAL SOUTH CONTEXT

"A slum is not a chaotic collection of structures; but a dynamic collection of individuals who have figured out how to survive in the most adverse of circumstances." 


\subsection{CONTEXTUALIZING ALTERNATIVE FRAMEWORKS}

Focusing on a global South context, this project aims to demonstrate new waste management frameworks while providing valuable information for waste recyclers to reimagine current paper waste flows within their immediate surroundings. It is estimated that more than a million tonnes of paper and cardboard waste end up unsorted and mixed with conventional solid waste in Sao Paulo landfills each year. ${ }^{116}$ However, with added funding and support from governments and industry leaders, waste pickers can dramatically increase their efficiency and productivity while improving the livelihoods of the pickers themselves. Investigations of the Philippines, India, and Latin American recycling sectors show universal dependence on the informal recycling sector in its ability to provide job security, sophisticated social structures, and greater economic and environmental benefits. ${ }^{117}$ In the current scenario, municipalities, multinational organizations and waste management companies have struggled to work with the informal stakeholders - despite evidence of the commercial, environmental and social benefits of forming partnerships.

"Participatory systems analyses are pretty unique. It's very difficult to understand a larger system if you don't even talk to the people who live within that system. They're the ones that need to decide what's the appropriate approach to dealing with the waste issue." 118

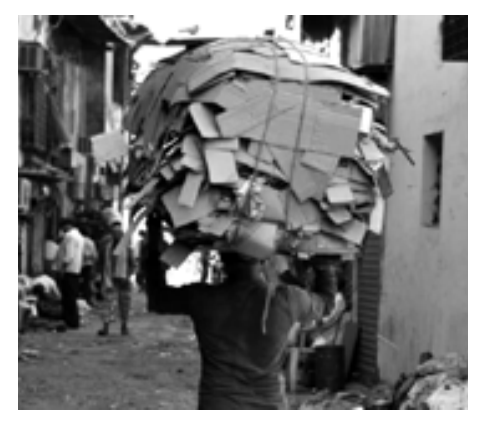

Fig. 064: Worker using wood products in construction. Brazil, 2016.

Ellen MacArthur Foundation. 2015 Building Blocks of a Circular Economy. Ellen MacArthur Foundation. Referenced 7 Decemeber 2019.

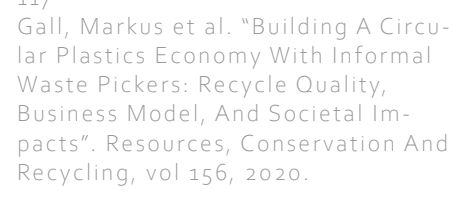

Marshall, Rachael. "Recycling Faces Challenges In Developing Countries". $U$ Of $G$ News, 2020 . 
By keeping materials inside the recycling chain for as log as possible, designing for disassembly, and understanding it's potential future uses, this project not only embraces circular economic principles, but is able to provide greater material value for pickers to upgrade their living conditions and communities by re-routing the waste stream back into their economy.

The concept of end-user engagement and participation is the core method and approach for this thesis and can be further exemplified when all stakeholders take action. If we look at the big picture, informal recycling is intrinsically linked and embedded within the urban fabric. The contrast of development, history, and people are vast, and traces of these changes are present within the depths and surfaces of these landscapes.
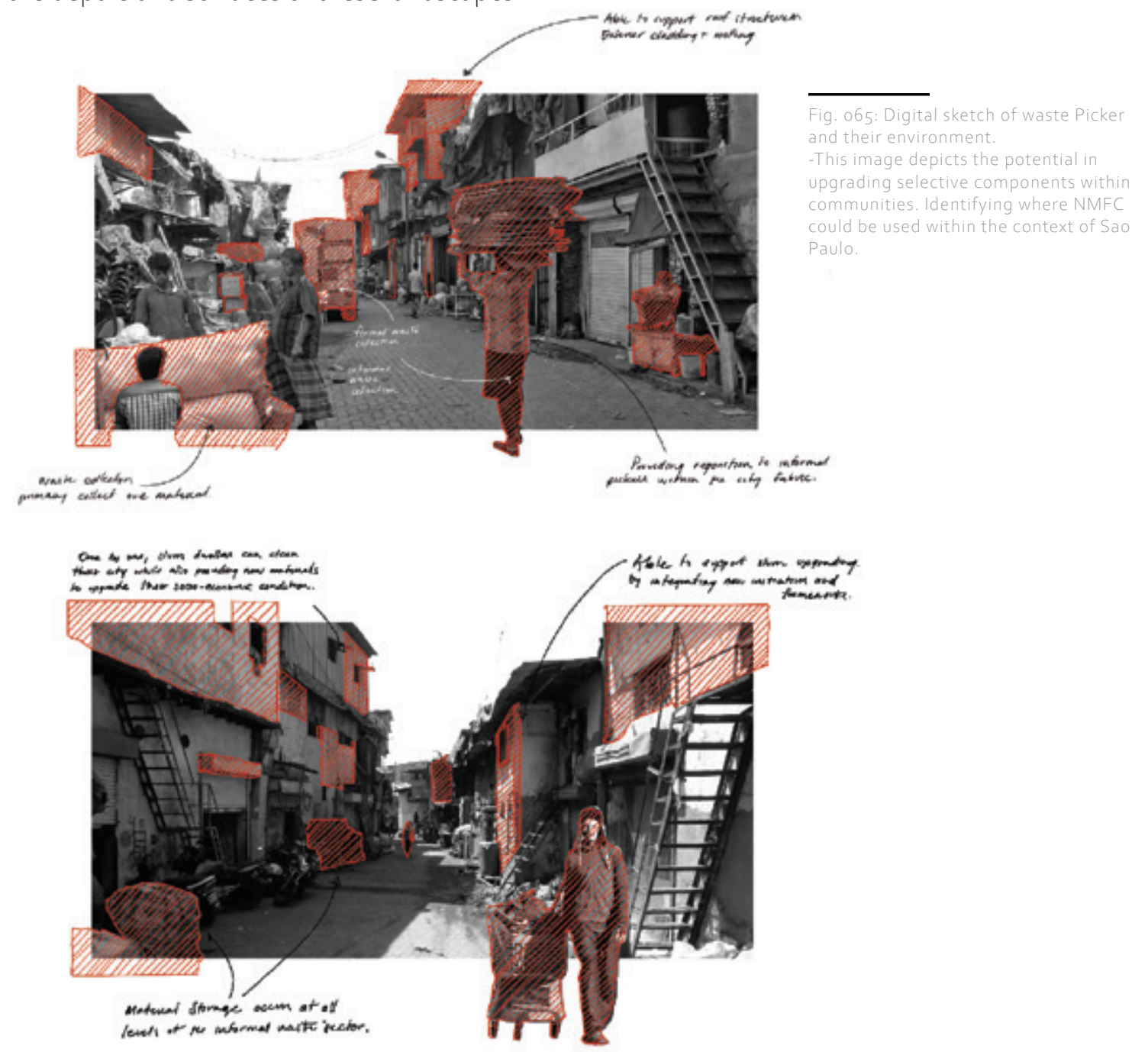


\subsection{ENGAGING IN THE CONVERSATION}

This project proposes alternative methods of public engagement, through a long-term architectural initiative that uses pamphlet style architectures to inform and educate the public on material recovery solutions and the benefits of waste picker inclusion.

Designed as a series of engaging mediums, the first is a 12 sided fold-out brochure that encases vital cellulose material know-how into a comprehensive infographic that can be distributed to industry leaders, public NGO's and recycling cooperatives. Both encouraging and educating the broader public on the potential of second-generation paper waste as a viable source for new building components. The information illustrated on this pamphlet will not only build a thriving, sustainable business model that uses renewable materials and innovative technology but also contribute to high-value eco-friendly products to create new market opportunity.

Illustrated on the reserve side of the pamphlet is a series of building component outputs that could be designed using material know-how demonstrated on the front. Effectively acting as a product demand checklist and material recovery solution methodolgy.
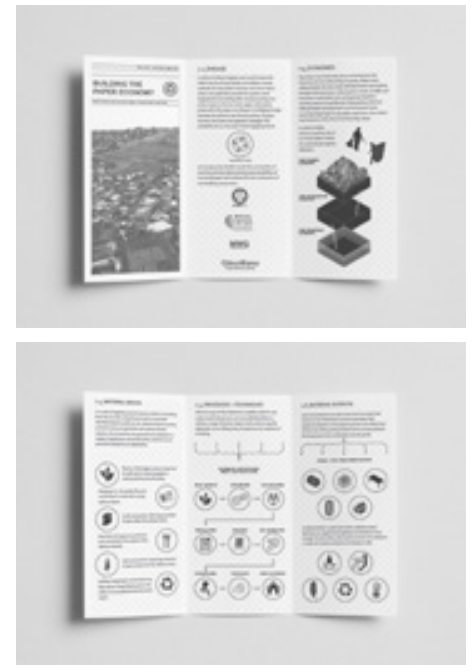

Fig. 066: Pamphlet Architectures 3 

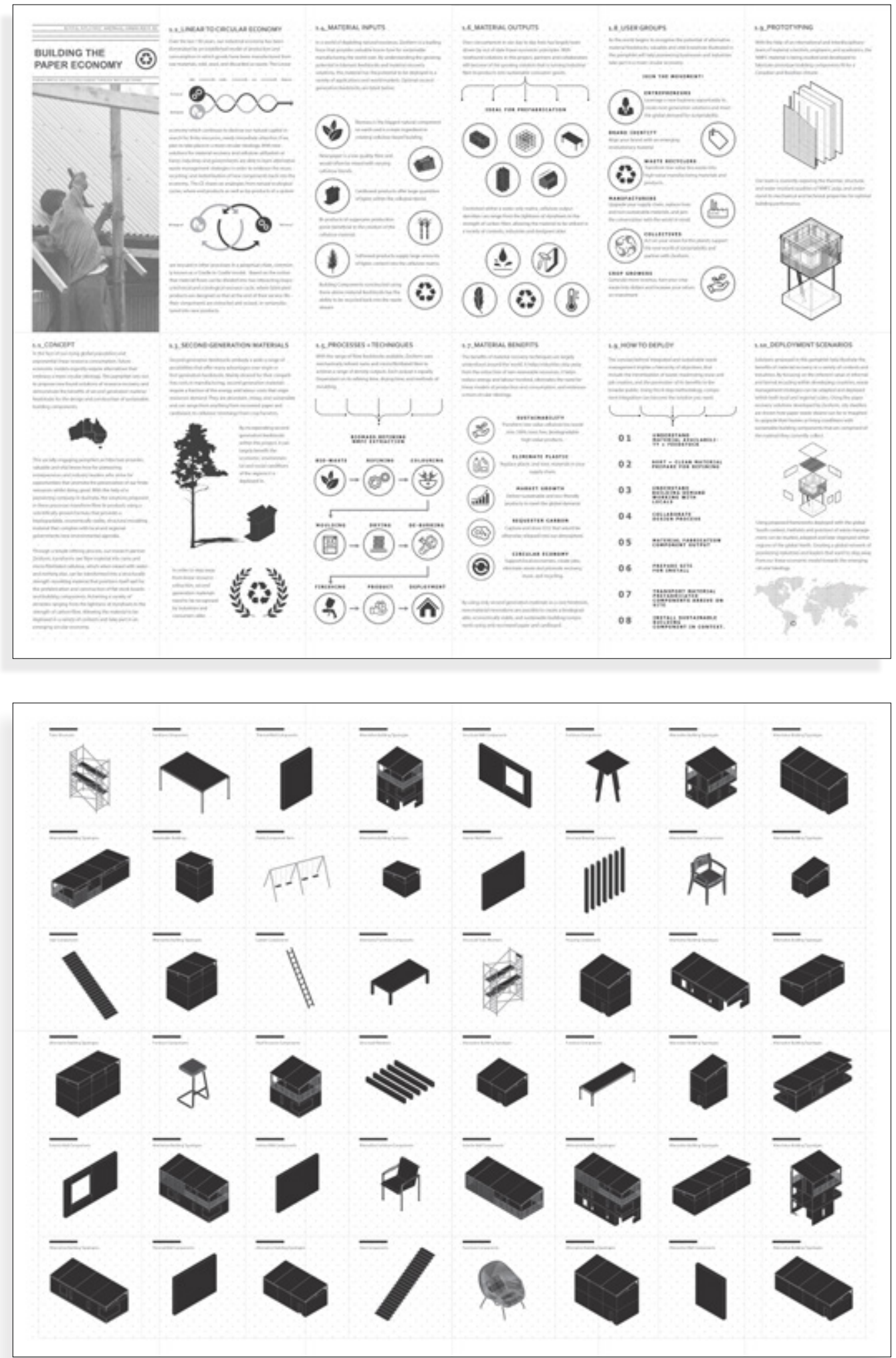


\section{Pamphlet 2}

The second pamphlet is aimed at illustrating the many complexities of the informal and formal recycling sectors of Sao Paulo. Focus is directed towards demographic analysis, urban material waste streams, and 5 proposed concepts of how to integrate economic and social change through informal inclusion. Together these pamphlets are designed to be integrated throughout the city fabric, engaging with all stakeholders of the recycling chain and broadening household collection techniques by illuminating the newfound solutions of paper waste products.

Illustrated on the back side of this pamphlet is both current and proposed recycling centres in the Sao Paulo Metropolitan Area. Helping both pickers and city dwellers identify selective collection regions of the city and where to bring paper waste products that be transformed into material products.

While the topic of waste management and informal picker inclusion holds complexity around the globe, concepts proposed through this thesis aim to learn from global South waste management strategies in order to be studied, analysed and later applied within the global North as we also begin the search for alternative material recovery solutions from the fall out of the National Sword Policy.

Together these documents will serve not only as a vital tool for understanding the complexities of the informal recycling sector, but also demonstrate how newly discovered material solutions can be integrated and adapted into the recycling industry. Through the formation of new talking points for professionals, academics and the general public, these pamphlets aim to raise awareness of the growing benefits, issues, and potential of waste picker inclusion.

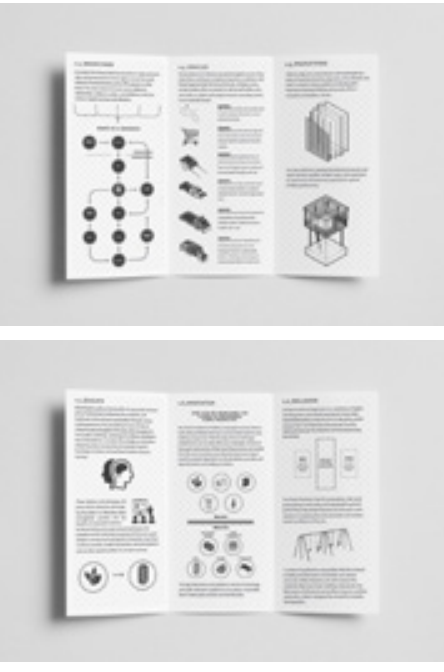

Fig. 068: Pamphlet Architectures 1 

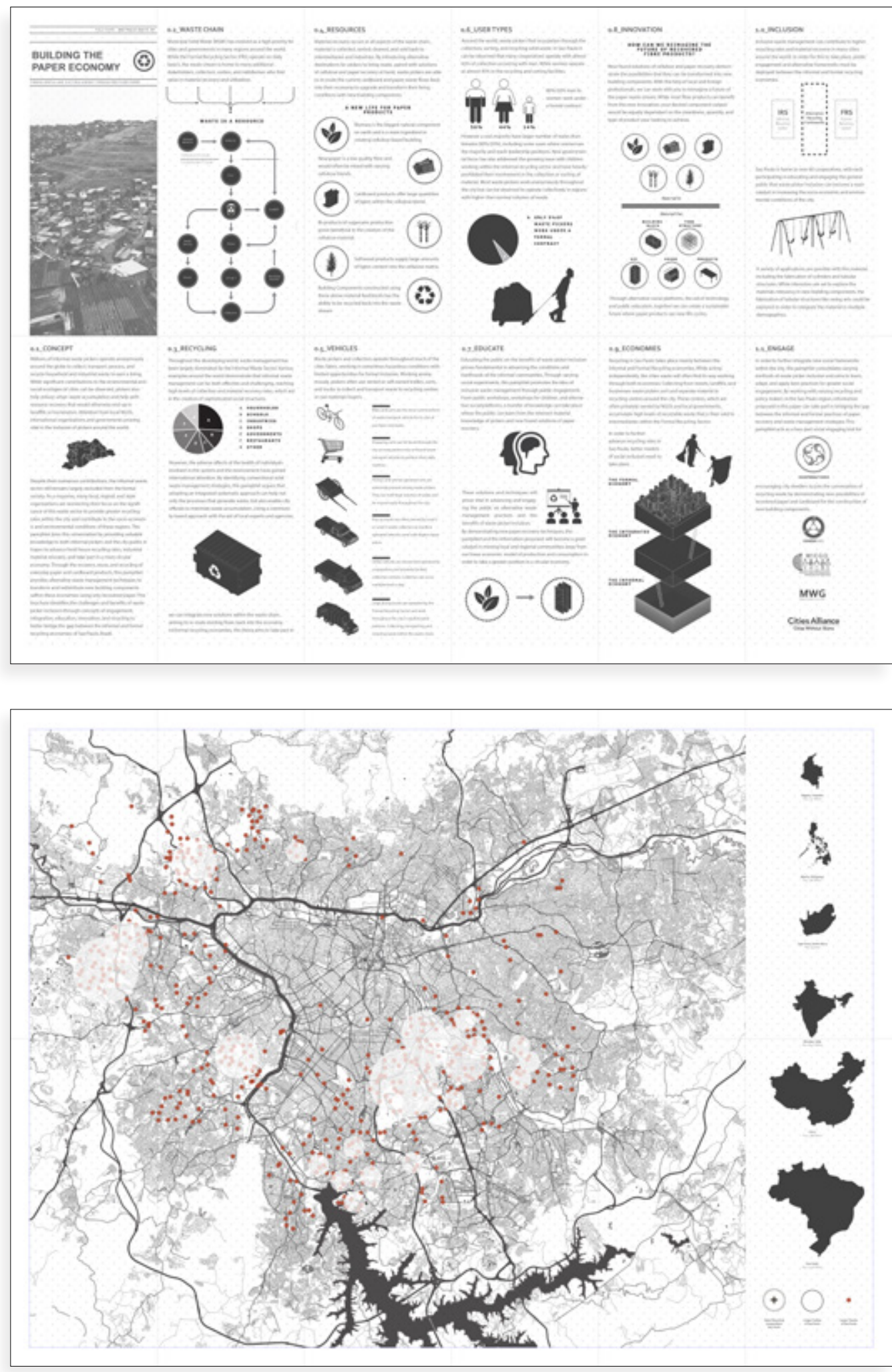

Fig 060 Building the Paper Economy Waste Picker Inclusion Pamphlet

This Pamphlet depicts the current and proposed methods of waste picker inclu-

sion in Sao Paulo, Brazil. 


\subsection{CONCEPTS OF DEPLOYMENT}

The concept behind integrated and sustainable waste management implies a hierarchy of objectives, that include the minimization of waste; maximizing reuse and job creation, and the promotion of its benefits to the broader public. ${ }^{119}$ In conjunction to the research conducted in this thesis, new academic and professional relationships have developed at the University of Victoria, BC, University of Sao Paulo, and Industry leaders in NSW, Australia. These relationships have proved vital to the development of these complex issues and show promise in providing alternative social platforms that engage in broader conversations of waste management and material recovery techniques. ${ }^{120}$

Over the last decade, academic research into Brazilian waste pickers has become increasing more evident. ${ }^{121}$ With power in numbers, this thesis joins the conversation of inclusive waste management while taking part in a formal transaction of local material knowledge and material recovery solutions that can be adapted, understood and be deployed in a variety of contexts.
Besen, Gina Rizpah, and Helena Ribeiro. "Selective waste collection in the São Paulo Metropolitan Region: impacts of the National Solid Waste Policy" Ambiente \& Sociedade, Health Sciences - University of Sao Paulo, Sept 2017.

Gutberlet, Jutta. "My Research." Jutta Gutberlet Inclusive Waste Management, Mapping Waste Governance, 2017

Carbonelli Campos, Juacyara, and Raquel Greice De Souza Marotta. Municipal Solid Waste in Brazil: A Review. 2nd ed., vol. 35, Federal University of Rio De Janeiro, 2017 


\section{NEW TYPOLOGIES}

\section{THE TYPICAL DWELLING REIMAGINED}

Slum upgrading is understood as a complex and unclear solution due to the many interrelated components (both physical and social) that must be addressed. In recent years, support structures have been made significant progress in areas like India and the Philippines. Where alternatively to slum upgrading, which often leads to the displacement of its occupants; these developments propose a concepts of 'slum transformation', which leads to a gradual transformation through a component-by-component methodology. Paired with the benefits of smart phone applications and cell phone ownership in Brazilian Favelas, slum dwellers can participate in both social and political platforms that increase the awareness of their situation. Furthermore, technology offers unique advantages to city planners and governments who can then prioritize infrastructural developments in areas that are require less authority based on data received from the slum dwellers. This thesis embraces this model by implementing frameworks that provide tools and knowledge for slum dwellers to recycle, re-use and transform their surrounding built environment. In order to bring this model to the physical realm, I chose to illustrate the concept of slum transformation through a component-by-component model that would be designed on the premise of open sourced collaboration.
Slum Upgrading:

Slum upgrading is a process through which informal areas are gradually improved, formalised and incorporated into the city itself, through extending land, services and citizenship to slum dwellers. It involves providing slum dwellers with the economic, social, institutional and community services available to other citizens.

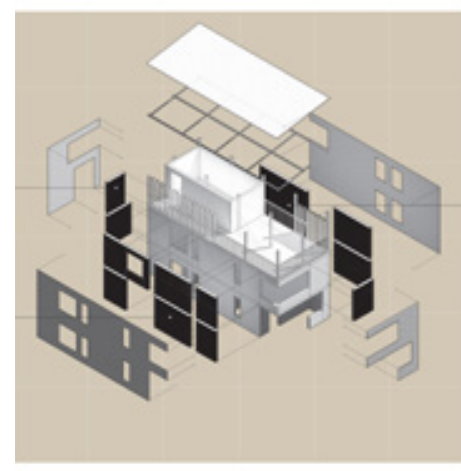

Fig. 070: Image depicting the upgrad. ing of select zones within a typical Saopaulo Paulo favela dwelling. 


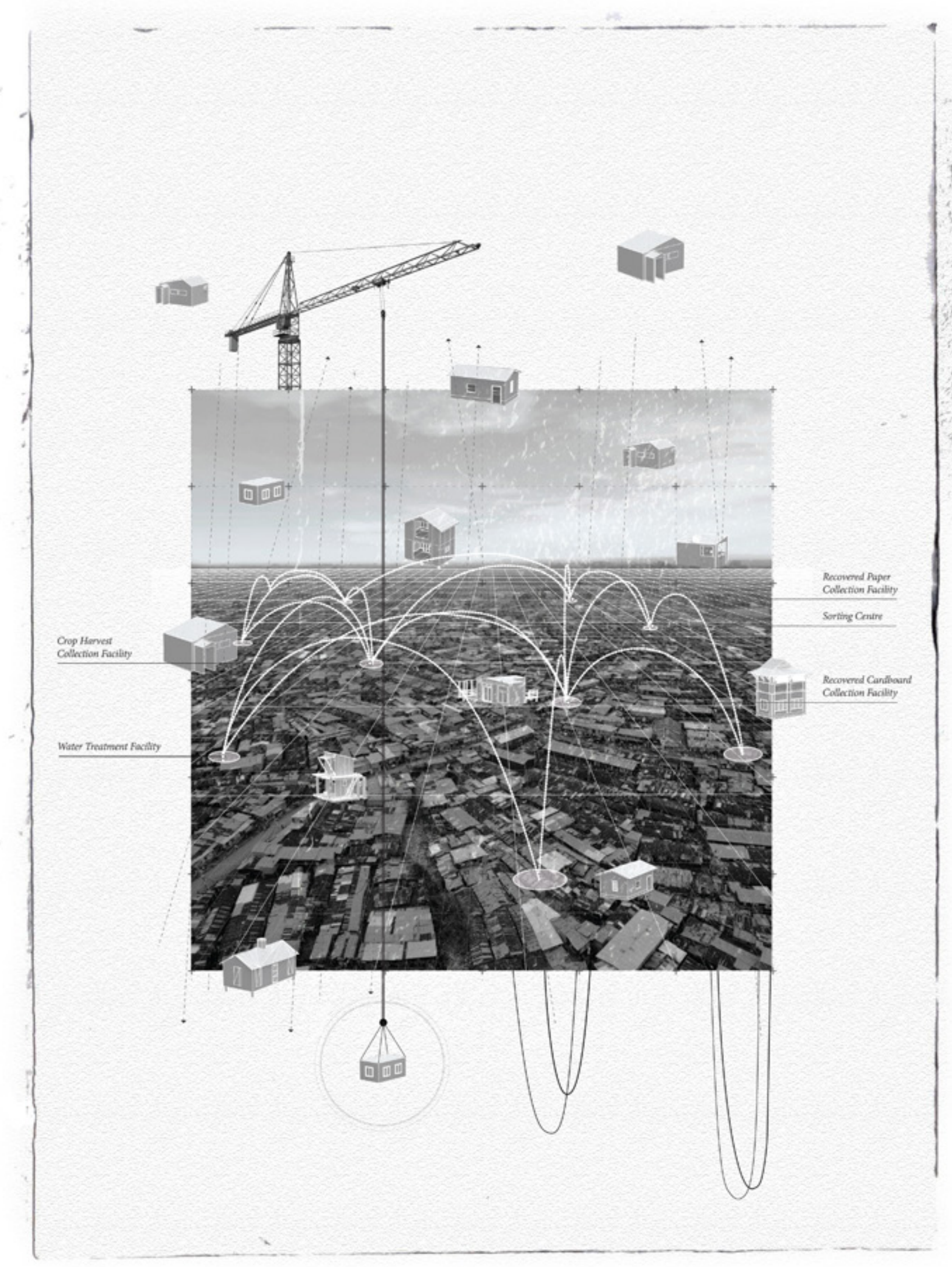



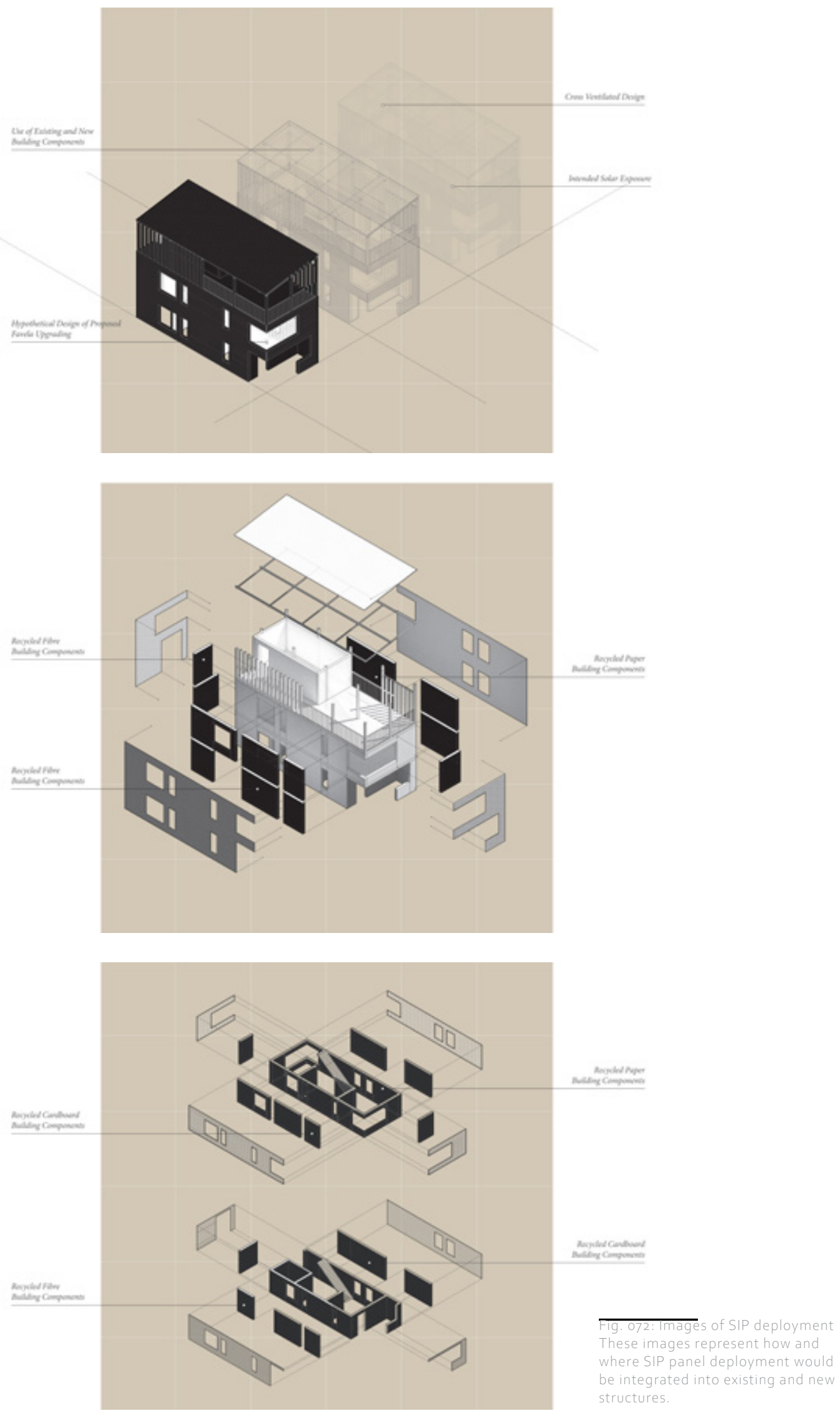


\subsection{CONCEPTS OF DEPLOYMENT POWER OF 3}

In a basic form, architecture is the result of justified collaboration between user and designer. Using this concept as a point of departure, the project proposes three scales of drawing that represent the projects interjection and proposal intervention. Using both ink and inkless drawing styles, a figurative line divides each drawing from the architects technical knowledge and the users involvement of function and program. Designed as a series of three architectural proposals; the dwelling, the factory, and community scales of this project, they stand together to represent the proposed frameworks being deployed in this thesis.

First the dwelling scale, aimed to represent the scale of a single family or home, where an architect's knowledge of structure, space, and design, act collaboratively between local knowledge and techniques. By using these concepts as a point of departure and recognizing the compleities of slum transofrmtion, this project does not propose a builidng butinstead a therotical framework built for collabaoation and its potential deployment.

This project recognises notable concepts adopted from Pritzker Prize winning Chilean architecture firm Elemental, in their half-ahouse redevelopment project. The half house concept struck me not only because of its physical nature but for its basic intensions.

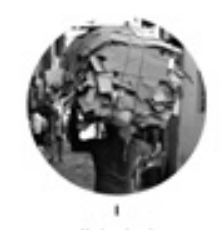

unsterstion Materid Avalably = Feedstiwk

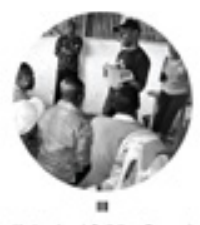
Understund sulsing Denent Werting wh teats

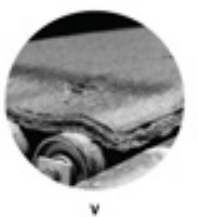
Mocerial Fobrication
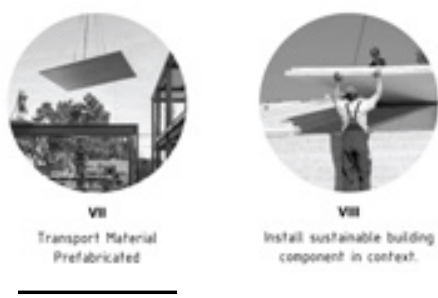
instal watrinwie buldim canowent in conters

Fig. 046: 10 Step Process for deploying alternative SIP components within Sao Paulo 


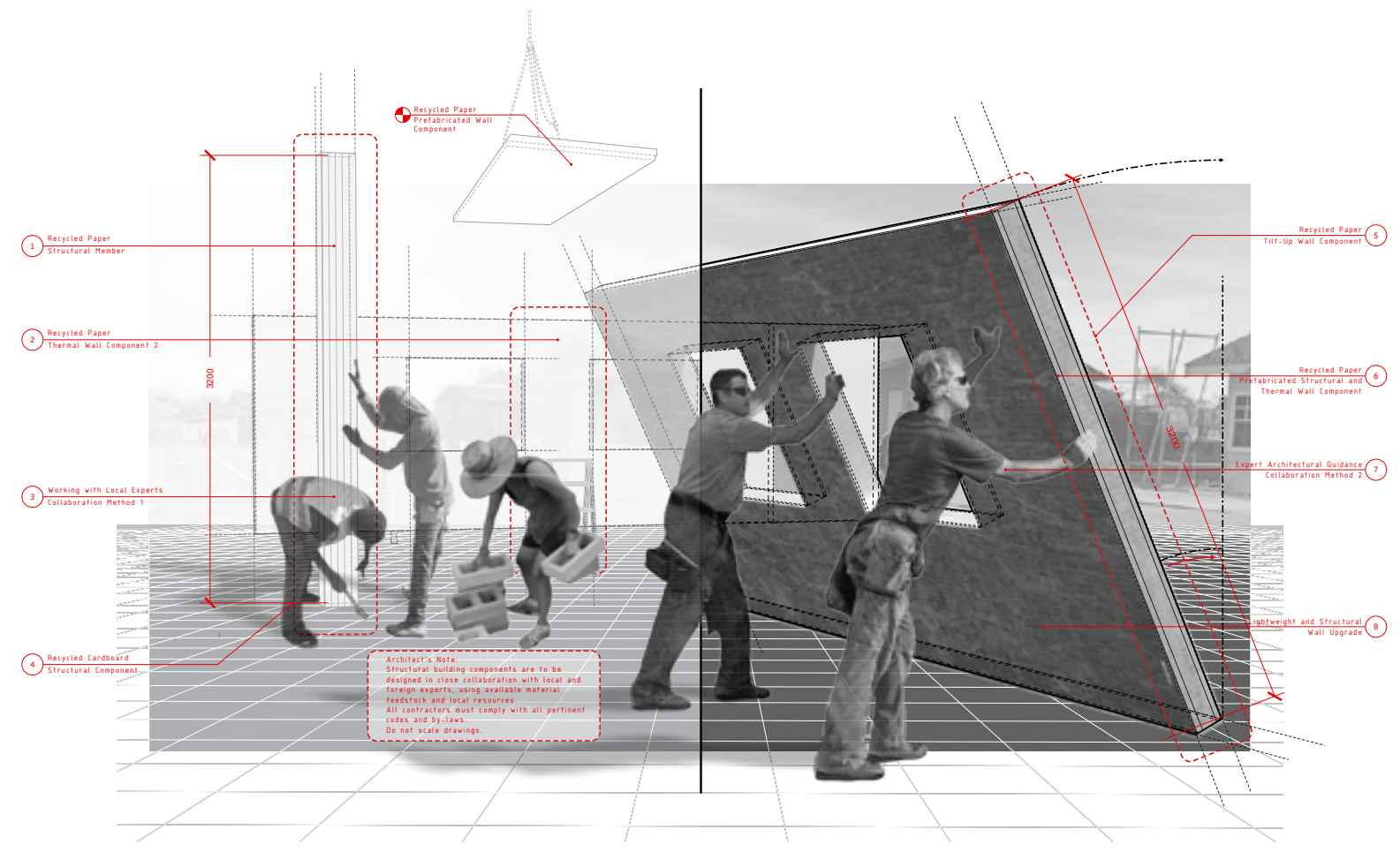

Fig. 073: The Dwelling Scale Operation and Collaboration

Hybrid drawing of proposed collaboration between waste pickers and formal

technical assistance. Image represents both informal and formal workers, working

together to construct single building components. 
Next, the Community Scale. This drawing represents the projects greater intensions by contributing to the transformation of community neighbours that currently live in substandard conditions. By merging and integrating the projects proposal within city dwellers, the project participates in a humble approach of transformation, limiting slum dweller displacement and giving opportunity back to the people who contributed to the components construction.

Fig. 074: The Community Scale Operation and Collaboration:

Hybrid drawing of proposed collaboration between informal dwellers and formal technical assistance. Image depicts how component by component replacement can achive greater transformation of slum dwellers housing conditions.

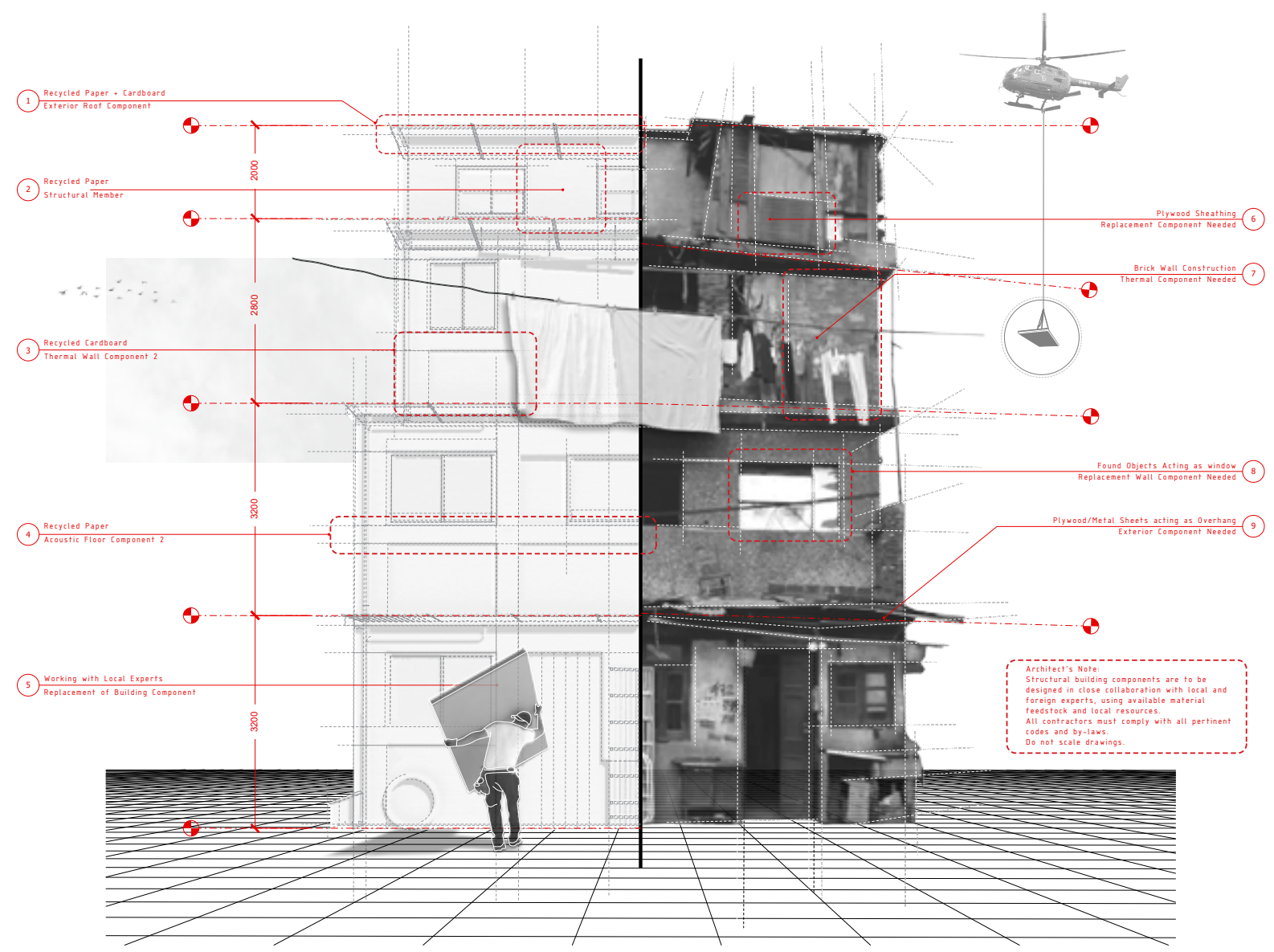


Finally, the Factory Scale. While this project does not propose a physical built form, it does propose new frameworks that address these issues by engaging in new methods of collaboration and the broader conversations of waste management solutions. Using the above concepts as a point of departure, three varying scales of interjection are then proposed. Without an assigned site, the project acts ambiguously and reactionary through the landscape, working with local site conditions, as well as local inherent knowledge of material recycling which is represented between the inkless and ink drawing styles. Using alternative methods of representation and new social platforms provided by the collaborative relationships developed in this thesis, the project illustrates its potential in a variety of scales and contexts.
Fig. 075: Factory Scale Operation and Collaboration: Hybrid drawing of proposed collaboration between informal and formal recyclers. Image depicts waste collecters brining waste paper material to be cleaned, sorted, and transformed into new building components.

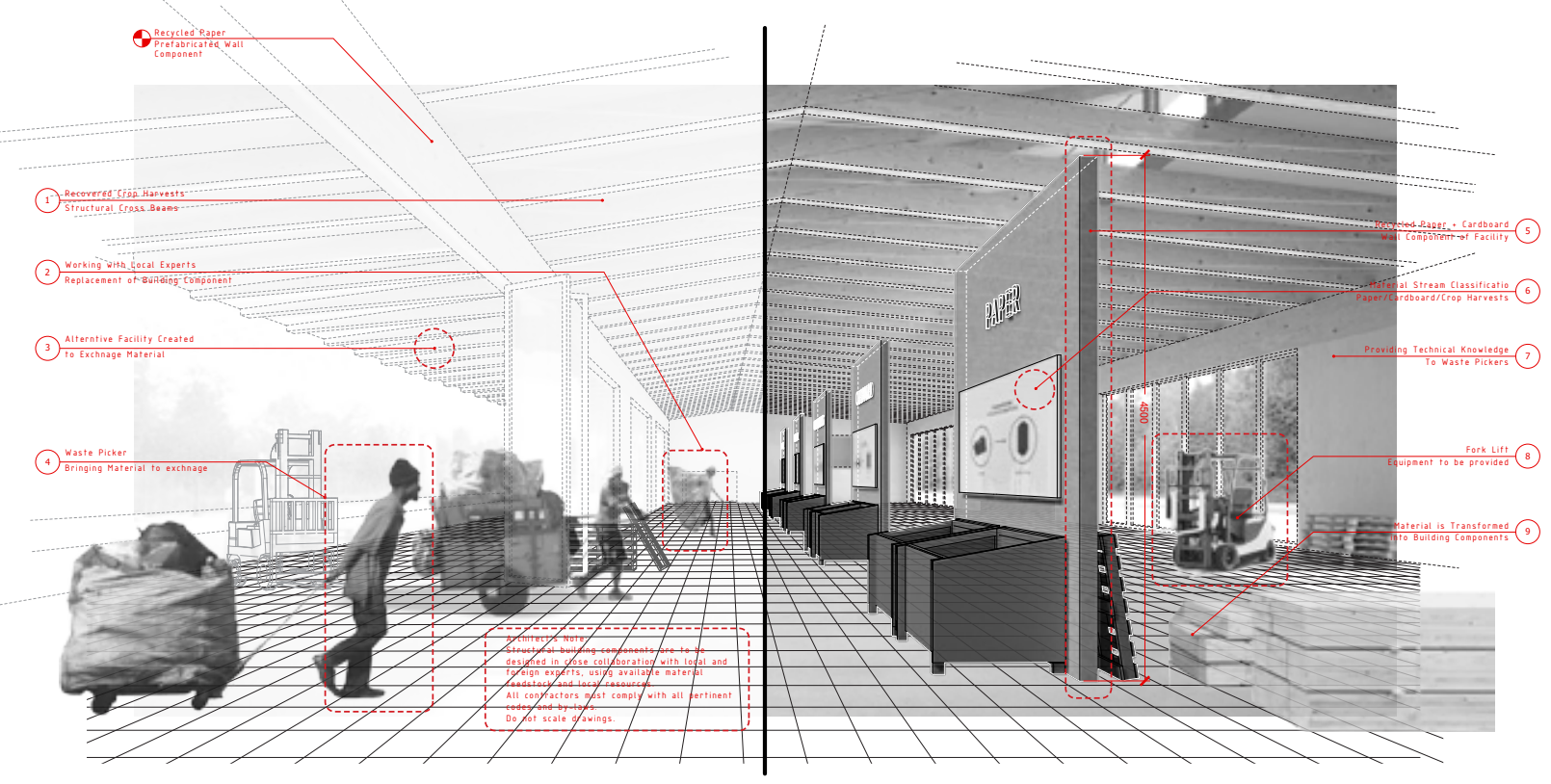




\subsection{CONCEPTS OF DEPLOYMENT POWER OF 5}

The concept behind integrated and sustainable waste management implies a hierarchy of objectives, that include the minimization of waste; maximizing reuse and job creation, and the promotion of its benefits to the broader public.

With power in numbers, this thesis joins the conversation of inclusive waste management that is able to take part in a formal transaction of local material knowledge and material recovery solutions that can be adapted, understood and be deployed in a variety of contexts.

Concepts of,

\section{Innovation}

Recycling

Inclusion

Engagement

\section{Education}

This project pairs the previously noted social engaging architectures to propose new thresholds between the informal and formal recycling economies. While the intensions of this project aim to create theoretical deployment scenarios in varying locations around the city, each site will be equally dependent upon its local context, knowledge of waste flows, and the demand for new products. By integrating these five values into the core of each future facility build, a series of drawings were produced to illustrate this integrated framework as an inclusive social experiment. 


\section{EDUCATION}

Intended to become a transaction of local material knowhow and new-found material recovery solutions this project embraces the concept of public education through a long term architectural initiative that uses social platforms of technology to inform and educate the broader public on alternative waste management practices.

In the deployment of each potential recycling centre, the project also proposes public workshops that engages all ages of city dwellers to inform the public on what can and cannot be achieved with recovered paper building components. Furthermore, from hands-on work conducted in the thesis, material experiments will be shared to encourage young adults and children to take part in the process of traditional hand-made paper making processes. Further encouraging younger generations to take part in the paper recycling chain by transforming the materials around them into new products for use in their everyday.

\section{INNOVATION}

The recycling industry is primarily founded on principles of innovation, while this still holds true within this project, each facility will be designed to showcase the varying possibilities of what recovered paper products could be transformed into. Using the pamphlet style architectures, the project illustrates new-found potentials in paper recovery and expands on waste recycling knowledge from city waste pickers. In addition to the innovative workshops proposed, professional collaboration from Zeoform and local organizations will help design, fabricate and distribute NMFC building components throughout the city. Much like the 'Cataki' app mentioned earlier in this thesis, this project embraces technological concepts in hopes to collaborate with varying social platforms to broaden the public awareness of environmentally responsible waste management strategies.

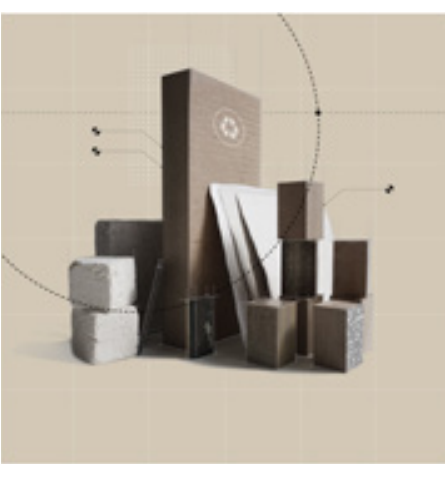

Fig. 077: Concept drawing of innovative building prototypes that are aimed at replacing exisiting building compoents in developing regions. 


\section{RECYCLING}

Foundational to this project, a recycling centre will become a main design component in all facilities. While most waste streams would be accepted, designated paper recovery infrastructure will become the primary elements to the product. This will ensure productive and efficient processes for material recovery systems and provide job security to acting waste pickers within the recycling sector.

\section{ENGAGING}

In order to further integrate itself within the informal and formal recycling economies, this thesis aims to take part in the emerging concepts of social inclusion, advancements in technology, and engage in public dialogue. Through a series of publicly accessible architecture and infographic pamphlets, broader conversations of material recovery and waste management solutions can be discussed. This drawing aims to represent the collaborative power of public conversation and shed light on the complexities of this topic.

\section{INCLUSION}

While waste pickers are given primary focus throughout this thesis, the frameworks being developed are designed to impact civilians within the formal economy. Through the collaboration of local agencies in Sao Paulo, and industry leaders in Australia, this project proposes alternative destinations and solutions for recyclers to transform their waste. With careful consideration into the livelihoods of pickers and the city as a whole, this project is supported by multiple engaging mediums that will inform, educate, and illustrate vital know-how of second generation material feedstocks. This drawing sets out to represent the integration of this project between the informal and formal recycling economies.

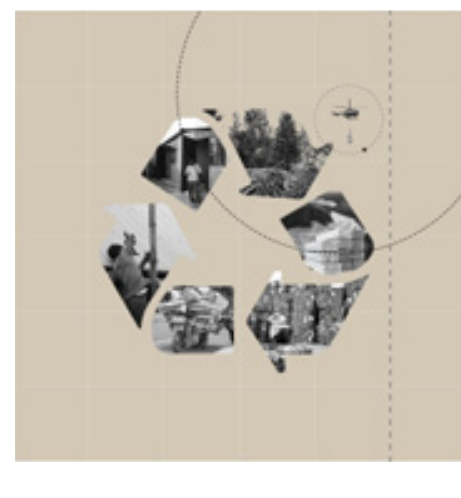

Fig. 078: Concept drawing of how recycling paper waste products can be reimagined to create new sustainable building components.

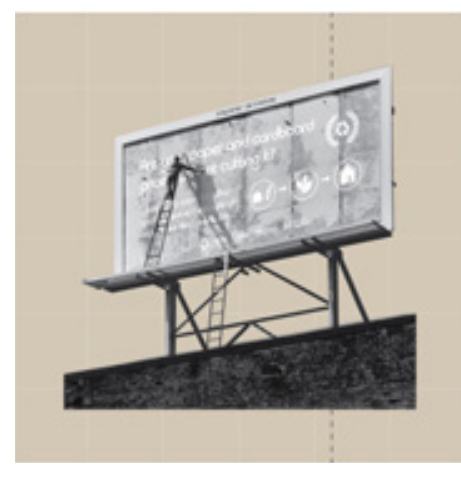

Fig. 079: Concept drawing of how public engagement will allow further integration of waste pickers within the recycling chain.

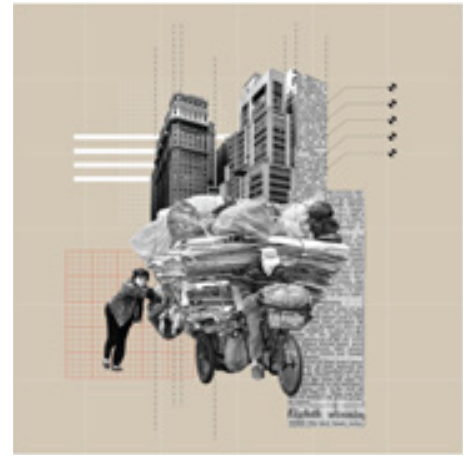

Fig. 080: Concept drawing of how waste pickers are the foundation to the formal economy and that further integration can advance the entirety of the economy. 


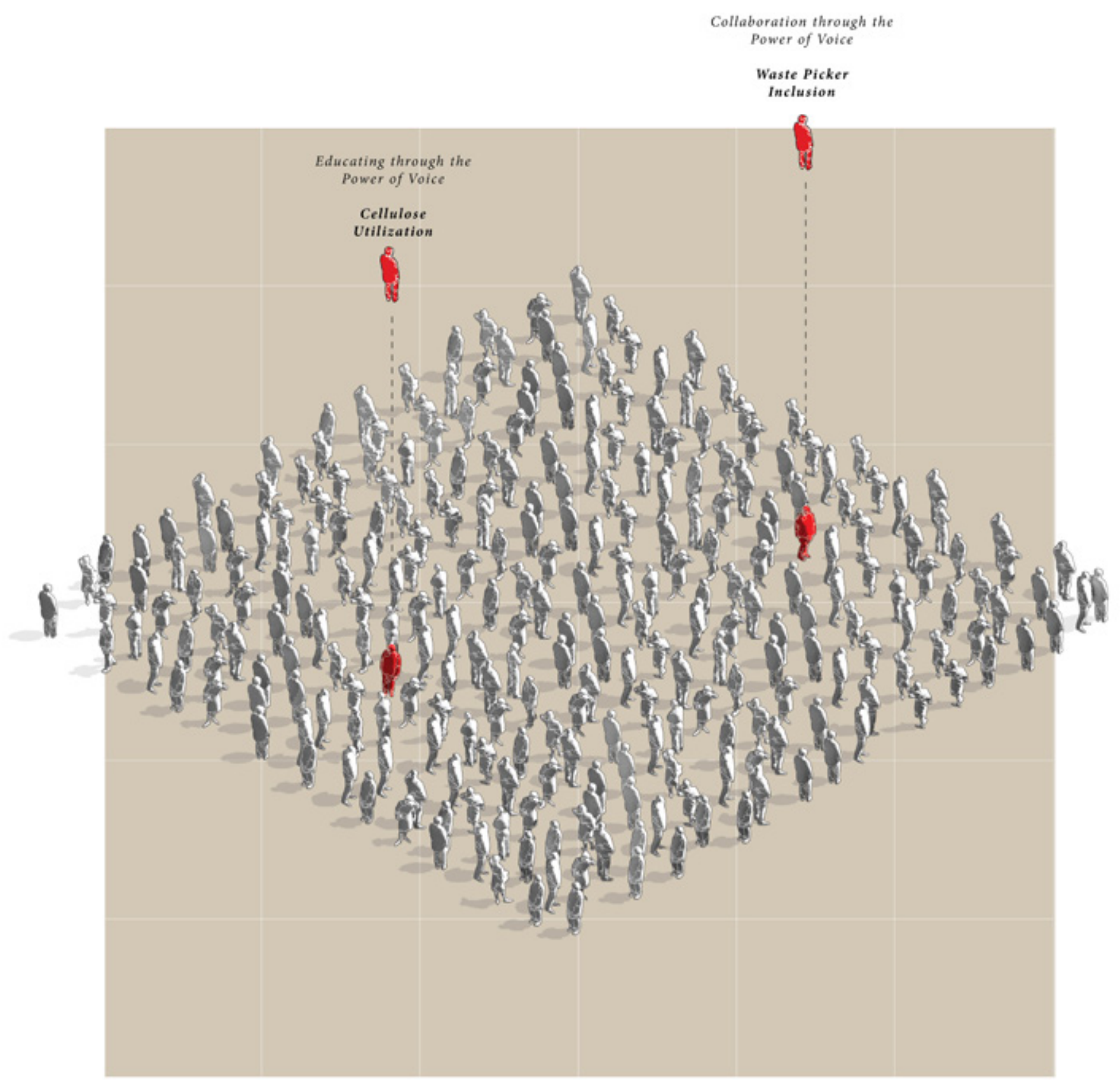

Fig. 076: Concept Drawing of how ed

ucatıng one person within the public

has the ability to engage with a range

of other citizens. 


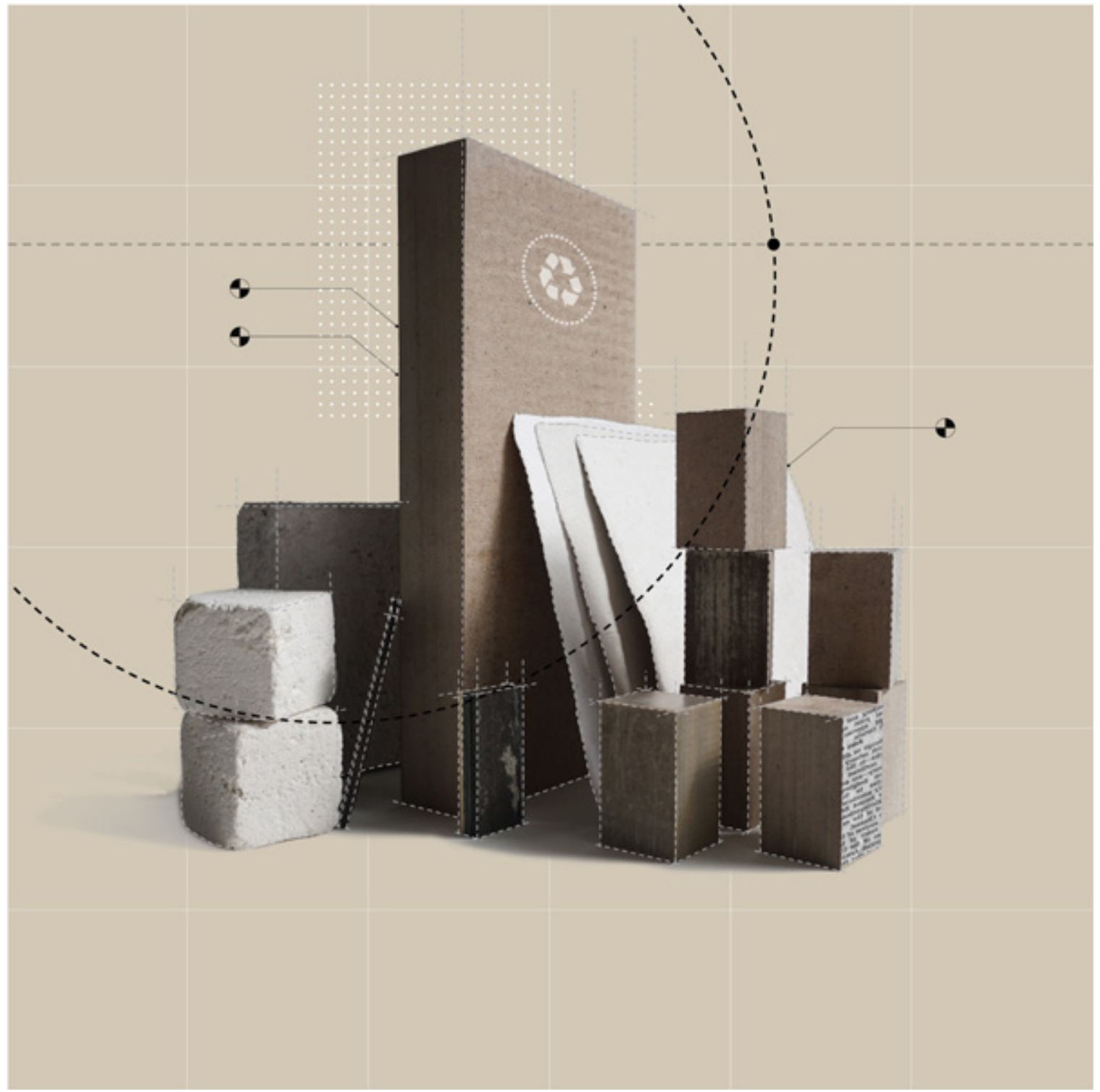

Fig. 077: Concept drawing of inno-

vative building prototypes that are

aimed at replacing exisiting building

compoents in developing regions. 


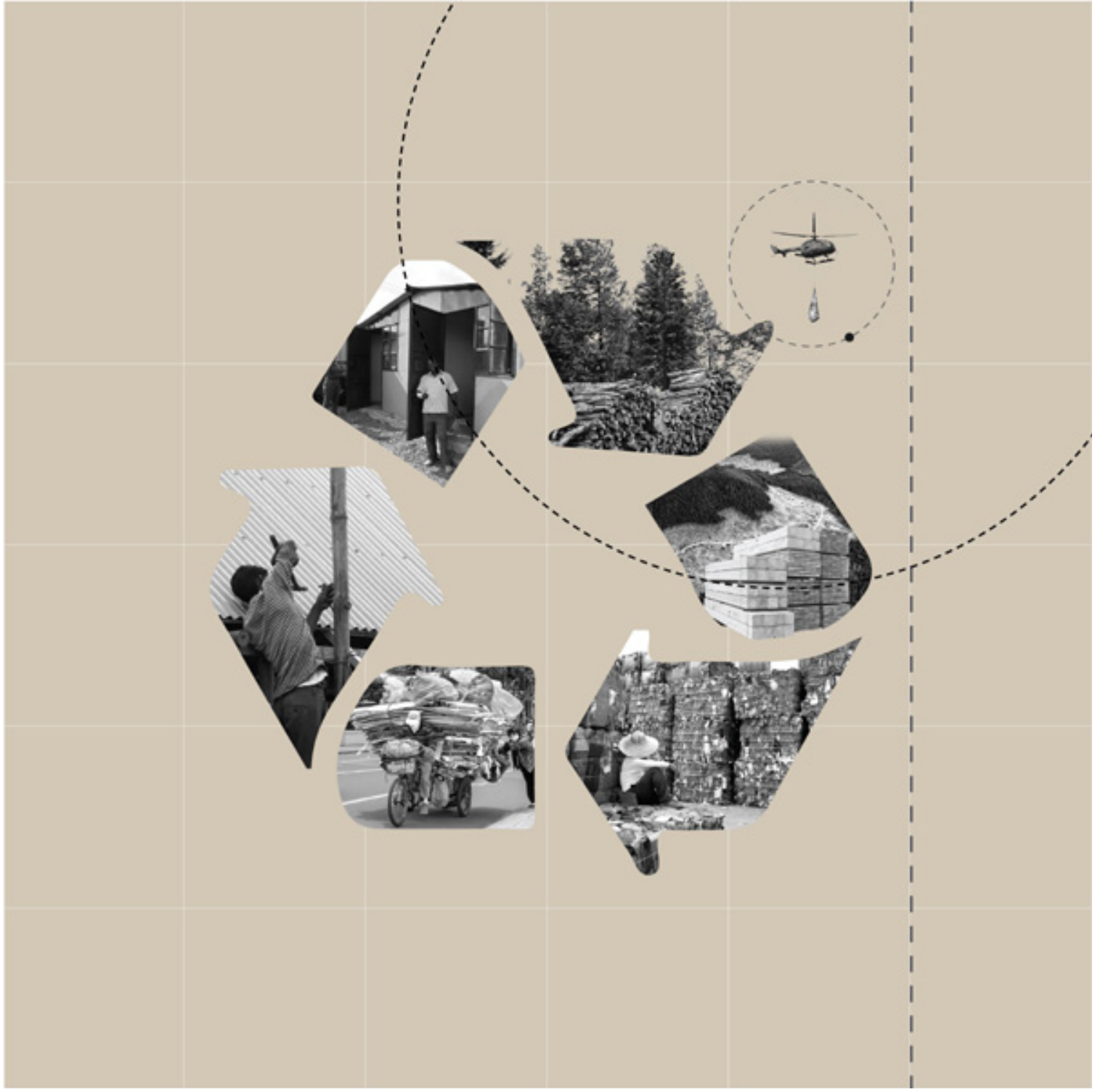

Fig. 078: Concept drawing of how re-

cycling paper waste products can be

reimagined to create new sustainable

building components. 


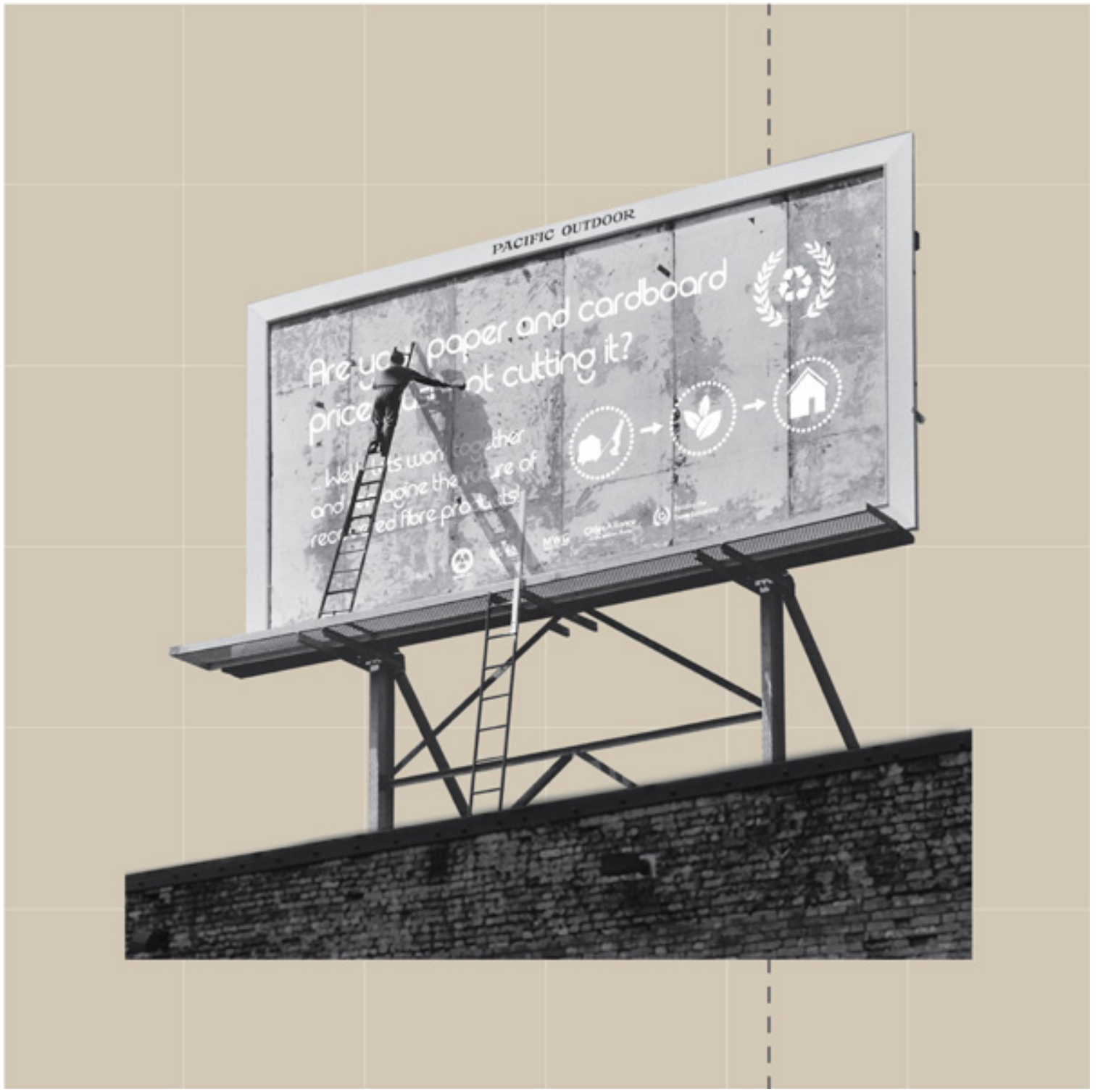

Fig. 079: Concept drawing of how

pub engagement will allow further

integration of waste pickers within

the recycling chain. 


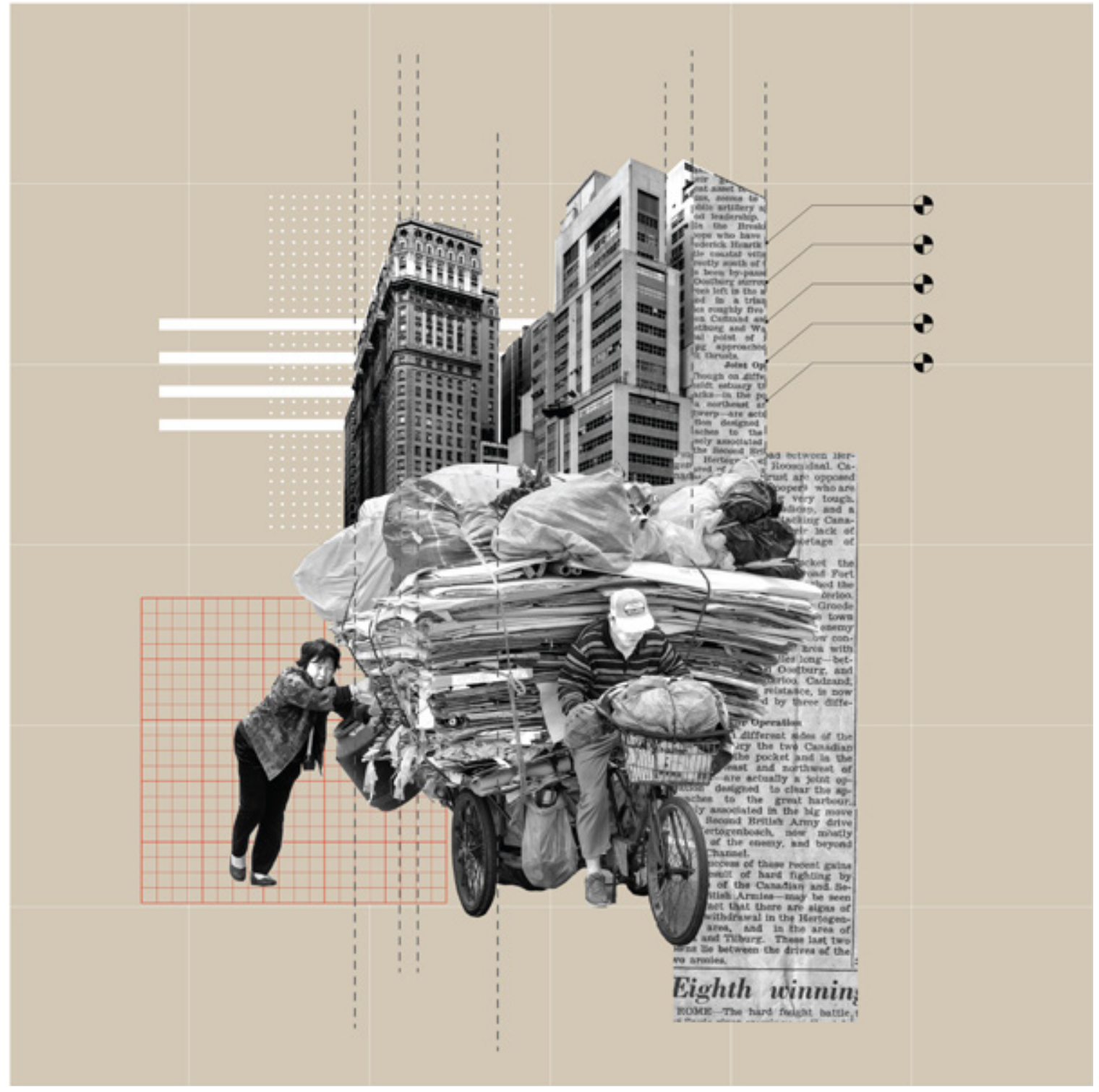

Fig. 080: Concept drawing of how waste pickers are the foundation to the formal economy and that further integration can advance the entirety of the economy. 
Together these concepts form a conversation of how alternative platforms for waste recovery can take place within Sao Paulo while providing new frameworks for waste picker inclusion. These new facilities will also for new methods for analysing the city to take place and radically remap the cities material resources. Supplementary analysis in areas like Latin America, India, and the Philippians has proven vital to the development of this project as it has generated broader perspectives and greater clarity of alternative solutions being explored throughout the global South. 
PART V I 
6.0 CONCLUSIONS + PROJECTIONS BUILDING THE PAPER ECONOMY

"Learning is creation, not consumption. Knowledge is not something a learner absorbs, but something a learner creates." 


\subsection{METHODS, TESTING, + PROTOTYPES NEXT STEPS}

Asking powerful questions is critical to developing and assessing new product ideas. Supplementary research supported by Mitacs Canada and industry partner Zeo IP Pty will continue in the subsequent months of this publication and become the primary investigation and scientific develoment of the the NMFC material.

With the help of Professor Jeffery Erochko, a civil engineer at Carleton University, we will follow the testing parameters for standard ASTM tests for wood-fibre boards and structurally insulated panels. His guidance and laboratory will prove crucial in determining the structurally rigidity and tensile properties of the material. Professor Cynthia Cruickshank, a mechanical engineer at Carleton will oversee the development of thermal resistance testing for the SIP panels using steady-state conditions in a guarded hot-box and THER software in her laboratory. Professor Owen Rowland, (biologist) and Quinn MacDonald (biology intern) will assist in understanding how plant-based polymers and oils can create unique agents that can assist in the hydrophobic, and environmental qualities of the NMFC SIP.

In addition to the talented team at Carleton University, continued collaboration between Zeoform and myself will inform strategic frameworks that enhance the materials relevancy for

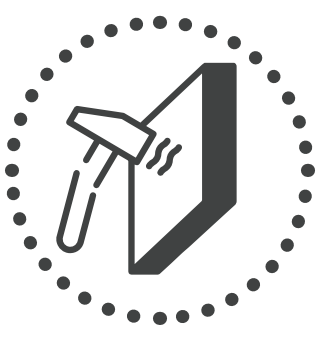

Structural Testing

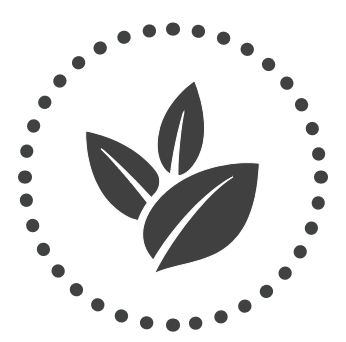

Biological Testing

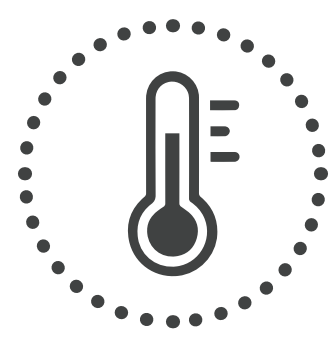

Thermal Testing applications in both the Canadian and Brazilian climates in a range of industries. Results from the above investigations will prove vital into how and where the recovered paper products can be reimagined for the design and fabrication of sustainable building components. 


\subsection{POST SCRIPT}

As the world begins to adapt to changing economic and environmental urgencies, recognition of second-generation waste may be the key to alternative material solutions. This thesis sets out to provide insight into the potential of cellulose recovery within the building industry while recognizing the importance of alternative waste management strategies. Building on work completed atZeo Ip Pty in the summer of 2019 with added support from local organizations and industries in Sao Paulo, Brazil and the University of Victoria, this thesis demonstrates newfound material recovery solutions that participate in a circular economy.

During this investigation research was able to open new conversations of social engaging architectures and demonstrate the complex challenges of waste management in many global South countries. Moreover, the humble approach to this thesis allows itself to work from a bottom-up approach, creating new opportunity for stakeholders at the lowest parts of the waste chain. By focusing on waste picker inclusion and alternative waste management techniques, frameworks presented in this document aim to serve both society and the environment.

The research presented in this project aims to become a case study into the potential of cellulose-based building components while addressing the global demand for alternative waste management strategies. The intention was to consider the past, present, and future of recovered fibre products and reimagine new frameworks that address the gap between informal and formal economies. While acknowledging the many complexities of this topic, this project embraces an avenue of 
thinking that will generate new conversations on alternative material recovery, thereby provoking consumers and industries alike to rethink what happens when we simply throw something away! 


\section{A P P E N DIX}

Hydroxyl groups are functional chemical compounds that are common within the natural environment. Sited as the first step in the 3 stages of materials entanglement, forming a natural bond between oxygen and hydrogen atoms. This chemical compound forms the foundational chemical bond within NMFC.

Rheology is a branch of physics that deals with the deformation and flow of matter. Specifically studying the flow of liquids and solids. NMFC has significant rheology applications with use in concrete as a high shear, high strength supporting agent.

Thermal Modification is a thermal process that converts biomass material into a coal-like material, which has better fuel characteristics than the original biomass. Often more brittle in character, NMFC will undergo a transformation that converts biomass material into a stable compound, leaving the material in a less permeable state and resembling a waterproof material.

NMFC Micro-Nano Fibrillated Cellulose is refined cellulose fibrils that react with water to form naturally occurring hydroxyl groups. Cellulose nano-particles display a high surface area which allows ample hydroxyl groups and form incredible amounts of fibre entanglement.

Decortication is a process that is often seen in medical procedures to remove the outer layers of a surface membrane. This plays particular significance when removing the outer layers of bark from plant stems to extract the naturally occurring bast fibres. 
Bast fibres are connected to the inner rings of plant fibres. These naturally occurring fibrils are often targeted for their superior strength when making textiles and have particular significance in the forming of Zeoform products.

Lignin is a class of complex organic polymers that form key structural materials in the support tissues of plants and algae. They are particularly important in the formation of cell walls of wood and barks. They are the key organic compound that is affected through the torrifaction process. 


\section{GLOSSARY OF TERMS}

\section{Cellulose}

Cellulose is the structural component of the primary cell wall of green plants, many forms of algae and oomycetes (species of mould). Cellulose is the most common organic compound on earth

\section{Nano- and Micro-Fibrulated Cellulose}

NMFC are micro refined cellulose fibrils that react with water to form naturally occurring hydroxyl groups. Cellulose nano-particles display a high surface area which allows ample hydroxyl groups and form incredible amounts of fibre entanglement.

\section{Bast Fibres}

Bast fibres are connected to the inner rings of plant fibres. These naturally occurring fibrils are often targeted for their superior strength when making textiles and have particular significance in the forming of Zeoform products.

\section{Lignin}

Lignin is a class of complex organic polymers that form key structural materials in the support tissues of plants and algae. They are particularly important in the formation of cell walls of wood and barks. They are the key organic compound that is affected through the torrifaction process.

\section{Circular Economy}

A circular economy is one that is restorative and regenerative by design and aims to keep products, components, and materials at their highest utility and value at all times, distinguishing between technical and biological cycles. Generally, by defining the Circular 
Economy we are referring to a closed-loop economy that does not generate excessive waste and whereby any waste becomes a resource (Wysokińska, 2016, p. 1)

\section{Linear Economy}

A linear economy traditionally follows the "take-make-dispose" step-by-step plan. A model adapted after the dawn of the Industrial Revolution that allowed raw materials to be harvested or extracted, transformed into products and consumed, and thus thrown away after serving a single purpose. Embraced for almost 150 years, this economic model holds limited value on recovered materials.

\section{Sharing Economy}

The Sharing Economy is an pre-modern economic system in which assets or services are shared between private individuals through a transaction or free. Typically, by means of data and technology, it is embraced by the modern consumer by handing down or sharing across platforms.

\section{Cradle to Cradle}

It is a holistic, economic, industrial and social framework that seeks to create systems that are not only efficient but are also essentially waste free. Deriving from the term Cradle to Grave, where a product is created and thrown away, Cradle to Cradle is the idea is that material goods can achieve a multi-generational value and never need to be thrown away. 


\section{B I B L I O G R A P H Y}

Alter Chen, Martha, and Vic Van Vuuren. Cooperation amoung Workers In The Informal Economy: A Focus On Home-Based Workers And Waste Pickers. 3rd ed., International Labour Organization And Women In Informal Employment: Globalizing And Organizing, 2017.

Alfers, Laura, et al. "Basic Categories of Waste Pickers." WIEGO, WIEGO. 2020

Balarman, Kavya. "Historical Perspectives on the Informal Waste Sector." Be Waste Wise, 2016, https://wastewise.be/2015/05/historical-perspectives-informal-waste-sector/\#.XoaSJYhKg1s

Besen, Gina Rizpah, and Helena Ribeiro. "Selective waste collection in the São Paulo Metropolitan Region: impacts of the National Solid Waste Policy" Ambiente \& Sociedade, Health Sciences - University of Sao Paulo, Sept. 2017.

Boyd, Toby. "The Informal Economy in Developing Nations: a Hidden Engine of Growth." The Informal Economy in Developing Nations: a Hidden Engine of Growth, World Intellectual Property Organization, 6AD

Brown, Jan. "Home." valubuild. VALUBUILD PANEL HOMES CORP, June 2, 2017. https://www.valubuild.com/the-history-ofsips.html Carbonelli Campos, Juacyara, and Raquel Greice De Souza Ma- 
rotta. Municipal Solid Waste in Brazil: A Review. 2nd ed., vol. 35, Federal University of Rio De Janeiro, 2017.

"The Circular Economy and the Built Environment." Global Foresight Research Innovation, Sept. 2016, pp. 5-12.

"The Concept of Circular Economy: Its Origins and Its Evolution." Research Gate, January 2018. https://doi.org/10.13140/ RG.2.2.17021.87523.

Dias, Sonia, and Lucia Fernandez. "Waste Pickers |WIEGO". Wiego.Org, 2020, https://www.wiego.org/informal-economy/ occupational-groups/waste-pickers.

"Disadvantages of Structural Insulated Panels." Bautex Systems. Bautex Systems. Accessed August 27, 2019. https://www. bautexsystems.com/blog/problems-with-structural-insulated-panels.

Duarte Pinheiro, Manuel. de Brito, Jorge. Dinis, Silvestre.

"Life-Cycle Impact 'Cradle to Cradle' of Building Assemblies."

Engineering Sustainability, 2014· 3-4.

Dufresne, Alain. (2012). Nanocellulose - From Nature to High Performance Tailored Materials. Berlin: De Gruyter, 2012.

Ellen MacArthur Foundation. 2015. Building Blocks of a Circular Economy. Ellen MacArthur Foundation. Referenced 7 December 2019.

Ernegg, Martin. "Field Research - Australia Log 17". New South Whales, Australia, 2019.

Fergutz, Oscar, et al. "Developing Urban Waste Management in Brazil with Waste Picker Organizations." Environment and Urbanization, vol. 23, no. 2, Oct. 2011, pp. 597-608. 
"The Future Of Modular Construction | Satellite Shelters". Satellite Shelters, Jan 4. 2019, https://www.satelliteco.com/blog/ the-future-of-modular-construction/. Accessed 11 Jan 2020.

Gall, Markus et al. "Building A Circular Plastics Economy With Informal Waste Pickers: Recycle Quality, Business Model, And Societal Impacts". Resources, Conservation And Recycling, vol $156,2020$.

"Global Industrial Revolution, Circular Economy \& Sustainable Development." Our Common Future, 2015.

"Growth Models: The Circular Economy Imperative - Leaders League". Www.Leadersleague.Com, 2020, https://www.leadersleague.com/en/news/growth-models-the-circular-economy-imperative. Accessed 19 Mar 2020.

Gutberlet, Jutta. "My Research." Jutta Gutberlet Inclusive Waste Management, Mapping Waste Governance, 2017.

Gutberlet, Jutta. "Sao Paulo Research Follow-Up". Skype, 2020.

Hande, Siddharth. "The Informal Waste Sector: a Solution to the Recycling Problem in developing countries" Field Actions Science Reports. The Journal of Field Actions, Institut Veolia, 1 Mar. 2019. 29

Hawken, Paul. Drawdown - the most comprehensive plan ever proposed to reverse global warming. New York: Penguin Books, 2018.

Helen Kopnina. Circular economy and Cradle to Cradle in educational practice, Journal of Integrative Environmental Sciences, $15: 1,123-138,2018$

Heshmati, Almas. "A Review of the Circular Economy and Its 
Implementation." International Journal of Green Economics, vol. 11, no. 3/4, Dec. 2015

laddic Shelters. "Global Mobile Factory: Construction: SIP Panels," 2005. http://iaddicshelters.net/mobile-factory/.

Illera, Danny, Jaime Mesa, Humberto Gomez and Heriberto Maury. "Cellulose Aerogels for Thermal Insulation in Buildings: Trends and Challenges" Coatings 2018.

Jenna Burrell, Invisible Users: Youth in the Internet Cafes of Urban Ghana (Cambridge: MIT Press, 2012), 14, 161, 180.

Jensen, Kasper. Building a Circular Future. 1st ed., vol. 3, 3XN/ GXN, 2016.

Jo Marchant, Justin Mott. "A Journey To The Oldest Cave Paintings In The World". Smithsonian Magazine, 2020.

Kaul, Inge. "The Rise of the Global South: Implications for the Provisioning of Global Public Goods." United Nations Development Programme: Human Development Report Office, vol. 2, 2013, pp. 2-18.

Kulb, Tania, and Carol Piccin. "Materialab Design". Materialab. Com.Br, 2017, http://materialab.com.br/.

Lawler, Adrienne, and Peter Desmond. "From the Linear Economy to the Circular Economy: A Basic Model." NYT Events. November 2018.

Lisa Parks, "Media Fixes: Thoughts on Repair Cultures," Flow, December 16, 2013.

Lehmann, Steffen. "Resource Recovery and Materials Flow in the City." Sustainability Development Law and Policy, vol. 11, no. 1, 
2011, pp. 28-29.

Loayza, Norman. "New Study Reveals the Complexity of the Informal Sector." World Bank. Sept 2018

Marello, Marta, and Ann Helwege. Solid Waste Management And Social Inclusion Of Waste Pickers: Opportunities And Challenges. 7th ed., Boston University, 2020, pp. 1-6, Accessed 21 Mar 2020.

Mattern, Shannon. "Maintenance And Care". Places, November 2018. Accessed 29 Mar 2020.

Marquis, Caitlin. "This is Advanced Energy": Second and Third Generation Biofuels." This is Advanced Energy": Second and Third Generation Biofuels, Advanced Energy Perspectives, 11 Dec. 2019

Marshall, Rachael. "Recycling Faces Challenges In Developing Countries". U Of G News, 2020, https://news.uoguelph. ca/2013/02/recycling-faces-challenges-in-developing-countries/. Accessed 13 Feb 2020.

Martin, Joshua, and Mandy Haggith. State OfThe Global Paper Industry 2018. 2nd ed., Environmental Paper Network, 2018, pp. 3-15, Accessed 19 Mar 2020.

Maynard, N. 2010. Structural insulated panels have many fans, so why don't more builders use them? Builder. August zoth, 2010. McDonough, William and Michael Braungart. Cradle to Cradle: remaking the way we make things. New York: North Point Press, 2002.

Meijer, Mieke. "About." NewspaperWood, 2014, http://www. newspaperwood.com/. 
Miranda Ribeiro, Flávio de. "From Informal to Providers: A Sao

Paulo State perspective for waste pickers at Brazilian Solid Waste

Policy", Waste Pickers At Solid Waste Policy. Oecd.Org, 2016.

Miranda Ribeiro, Flávio de. "Waste Pickers At Solid Waste Policy". Oecd.Org, 2016,

Moraes, Ricardo. "Destruction And Rebuilding In Vila Autodromo". The Wider Image, 2020

Moynihan, Alison E., "Evaluating the Benefits of and Barriers to Building with Structural Insulated Panels" (2014). Student Showcase. 5 .

Nathanson, Jerry. "Hazardous-Waste Management". Encyclopedia Britannica, 2nd ed., 2020.

Pacheco-Torgal, Fernando, and Luisa F. Cabeza. "Eco-Efficient Construction and Building Materials." ScienceDirect. Woodhead Publishing Limited, 2014.

Pimpadores movement. (2013. CatakiApp, Version 1.8.8. Cataki. org.

Pizzi, Antonio. Wood products and green chemistry. Annals of Forest Science, Springer Verlag/EDP Sciences, 2016, 73 (1), pp.185-203.

Pons, O. "Prefabricated Construction." Prefabricated Construction - an overview | ScienceDirect Topics. Barcelona Tech, February 14, 2014.

Reed, John, et al. "Why the World's Recycling System Stopped Working." Financial Times, FT Magazine Environment, 25 Oct. 2018 
Repo, Petteri, and Markku Anttonen. "Emerging Consumer Perspectives on Circular Economy." Consumer Society Research Centre, 2017, pp. 183-206., doi:10.1016/b978-0-08-1026304.00009-1.

Santos, Fernanda. "Processing And Properties Of Plastic Lumber". In Tech Open, Dec. 2018. Accessed 21 Mar 2020.

Siró, István and David Plackett. Microfibrillated cellulose and new nanocomposite materials: a review, Cellulose, Volume 17, Issue 2

Stahel, Walter. "Circular Economy Schools Of Thought." Ellen MacArthur Foundation, Ellen MacArthur Foundation, 2016.

Stahel, Walter R. "The Functional Economy: Cultural and Organizational Change." National Academy Press., 1997, pp. 14-39., doi:10.4324/9781315688404-2.

Subramanian, Arvind, and Martin Kessler. "The Hyper-Globalization of Trade and Its Future." Towards a Better Global Economy, Apr. 2014.

"The Paradigm Shift Needed in Technology: Sustainable Digital Design." Apply Digital Sustainability, 1 Oct. 2019. Upadhayay, Sugam, and Omaima Alqassimi. Ellenmacarthurfoundation.Org, 2020.

US Energy Information Association. Accessed: October 21st 2014 .

Wazeka, Robert. "Paper and Paperboard in Developing Countries: The Potential Is There." Unasylva - No. 144 - Pulp \& Paper in Developing Countries - Paper and Paperboard in Developing Countries: The Potential Is There, Forest Industry Division, 1984.

Wheeler, Alf. "Zeoform - Characteristics". Zeoform - Making 
Form Sustainable, 2011, https://www.zeoform.com/. Accessed 21

Mar 2020

World Agriculture: Towards 2015 - 2030. Towards Sustainability

Forestry. 1st ed., FAO, 2002.

Zilliacus, Ariana. "Half A House Builds A Whole Community: Elemental's Controversial Social Housing". Archdaily, Nov 2016. 
WILL YOU JOIN THE COVERSATION? 